UNIVERSIDADE DE SÃO PAULO

INSTITUTO DE GEOCIÊNCIAS

\title{
APLICAÇÃO E DESENVOLVIMENTO DOS MÉTODOS DE CARACTERIZAÇÃO DE AQUÍFEROS FRATURADOS UTILIZANDO POÇOS TUBULARES
}

MARCOS BOLOGNINI BARBOSA

Tese apresentada ao Programa de Geociências Recursos Minerais e Hidrogeologia para obtenção do título de Doutor em Ciências Área de concentração: Hidrogeologia

Orientador: Prof. Dr. Reginaldo Antônio Bertolo

SÃO PAULO 


\section{UNIVERSIDADE DE SÃO PAULO \\ INSTITUTO DE GEOCIÊNCIAS}

Aplicação e desenvolvimento dos métodos de caracterização de aquíferos fraturados utilizando poços tubulares

MARCOS BOLOGNINI BARBOSA

Orientador: Prof. Dr. Reginaldo Antonio Bertolo

Tese de Doutorado

$N^{\circ} 616$

COMISSÃO JULGADORA

Dr. Reginaldo Antonio Bertolo

Dr. Rodrigo César de Araújo Cunha

Dr. Paulo Henrique Ferreira Galvão

Dr. José Eloi Guimarães Campos

Dr. Ingo Daniel Wahnfried

Dr. Paulo Lojkasek Lima

SÃO PAULO

2020 
Ao meu pai Sergio Barbosa (In Memoriam), à minha mãe Marly Fre Bolognini e aos meus irmãos. 


\section{AGRADECIMENTOS}

Primeiramente, gostaria de agradecer o apoio das instituições cujo suporte foi fundamental para a realização desta pesquisa, através de financiamentos e bolsas de estudos: FINEP (processo 1824/2010), Ministério Público de São Paulo, CAPES (Bolsa Demanda Social), PDSE/CAPES (processo n. 88881.189743/2018-01), Programa de Aperfeiçoamento de Ensino (PAE) do IGc-USP.

Ao meu orientador, professor e amigo Dr. Reginaldo Bertolo, pela confiança e apoio nesses últimos sete anos de trabalho e convívio. Por sempre apoiar minhas iniciativas, e por ter me proporcionado a oportunidade de trabalhar junto com meu pai neste projeto, foram anos incríveis de aprendizado e amadurecimento.

Aos professores Ricardo Hirata, Amélia Fernandes, Veridiana Martins, Fernando Saraiva por todos os papos hidrogeológicos ao longo dos anos deste trabalho. Aos amigos e colegas do CEPAS/USP, pelo apoio e companheirismo - em especial ao Fabio Sartorio, companheiro de trabalho de campo e de tantos perrengues, e também a Paulo Lojkasek Lima, Ingo Wahnfried, Claudia Varnier, Sasha Hart, Daphne Pino, Silvia A. M. Ferreira, Paulo Lima, Elí Caçador, Gabriel Silva, Marcos Akira, Bruna Fiume, Rafael Terada, Caio Christofolletti, Elvio Savieto. Aos funcionários do Instituto de Geociências (IGc), sempre dispostos a ajudar.

Aos membros do grupo G360, da University of Guelph, em especial à Prof ${ }^{a}$. Dra. Beth Parker, Dr. Pat Quinn e Dr. Peeter Pehme pela oportunidade de trabalhar e aprender com eles em minha estadia no Canadá durante o mestrado, que foi de grande importância para o projeto de doutorado. Aos colegas do USGS, em especial John Lane, Fred Day Lewis, Carole Johnson, John Williams, Alton Anderson, Alison Waxman, Neil Terry and Martin Briggs. À Advanced Logic Technology (ALT), por fornecer licenças do software WellCAD e apoiar nosso grupo. Um agradecimento especial ao Claude Meunier da Terra Plus por auxiliar com as sondas geofísica e a amizade. À Mount Sopris Instruments pelo apoio e ajuda com os equipamentos em especial à Lia Martinez pela conversa e suporte. Ao Carlos Birelli do Instituto de Pesquisas Tecnológicas (IPT), pela parceria nos trabalhos de campo. Aos diretores e funcionários dos locais em que realizei atividades de campo, por nos permitirem acesso às propriedades e estarem sempre dispostos a ajudar.

À minha família, pelo apoio incondicional durante esta jornada de realizar uma pesquisa de Doutorado. Aos meus irmãos Rosana, Zeca e Danilo e sobrinha Mariana por serem as pessoas incríveis que são e estarem ao meu lado como família e amigos. À minha segunda 
família Luciano, Maici, Lola e Lucas. Aos meus amigos do Lindy Hop que tornaram meus dias mais alegres - em especial à Mariana Turco e Vivian Tsukamoto pela parceria e ajuda com a redação da tese. E ao grande amigo e professor Rodrigo Cunha, pelas conversas e apoio ao longo desta jornada. Aos meus pais Marly e Sergio, fonte de inspiração e amor, pessoas que sempre fizeram de tudo e mais um pouco para que eu me desenvolvesse como pessoa e profissional. Enfim, obrigado a todos que me ajudaram a chegar até aqui! 
“Antes havia tudo e nada ao mesmo tempo...

E esse tudo era a energia cósmica em repouso, em equilíbrio.

Nada não era sequer o vazio, era o estado não-manifesto, sem espaço nem tempo." - André Van Lysebeth 


\section{SUMÁRIO}

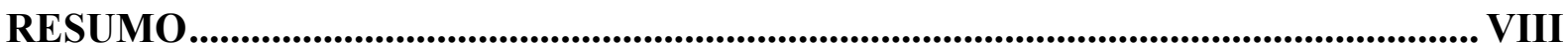

ABSTRACT ……................................................................................................................

LISTA DE FIGURAS.............................................................................................................XII

LISTA DE TABELAS ................................................................................................XVII

SIGLAS E ABREVIATURAS........................................................................................ XVIII

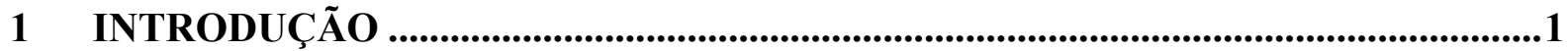

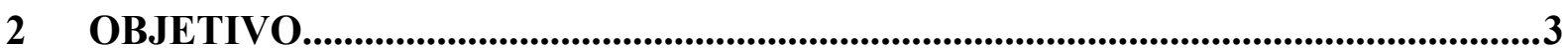

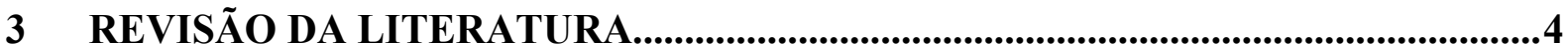

3.1 PROPRIEDADES FÍSICAS E HIDRÁULICAS DO MEIO FRATURADO..................4

3.1.1 Fluxo da água subterrânea em fraturas ................................................... 6

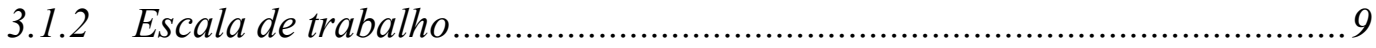

3.2 MÉTODOS DE INVESTIGAÇÃO DE MEIOS FRATURADOS..................................11

3.2.1 Discrete Fracture Network (DFN) ...................................................... 12

3.2.2 Fractured Bedrock Toolbox (FBT) ……………….............................. 13

3.2.3 Fractured Bedrock Field Methods and Analytical Tools ........................13

3.2.4 Guia para a caracterização regional do fluxo da água em aquiferos fraturados 14

3.3 TÉCNICAS GEOFÍSICAS DE POÇOS PARA A INVESTIGAÇÃO DE

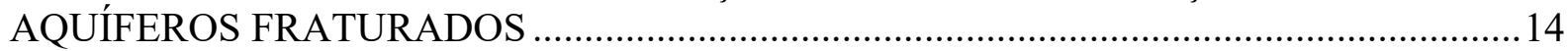

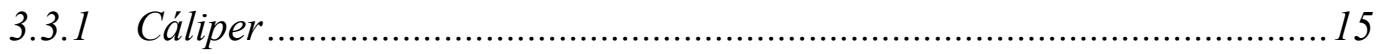

3.3.2 Gama natural.................................................................................. 16

3.3.3 Perfilagens de imageamento de poço (câmera de vídeo-inspeção, OTV e ATV) $\quad 17$

3.3.4 Resistividade de dupla indução …………………………………….....21

3.3.5 Perfil de temperatura e condutividade elétrica (FTCR) .........................22

3.3.6 Avaliação de fluxo com medidores tipo flowmeters .................................22

3.4 ENSAIOS HIDRÁULICOS COM OBTURADORES.................................................26

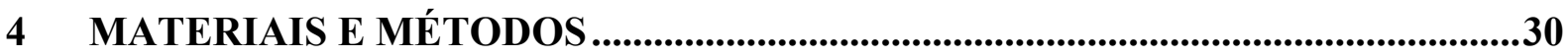

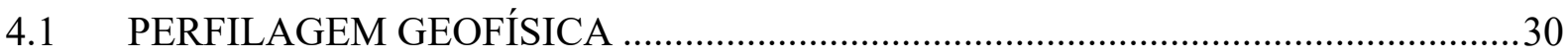

4.1.1 Filmagem com câmera ……............................................................... 31

4.1.2 Componentes e acessórios de superficie para a perfilagem geofísica ......33

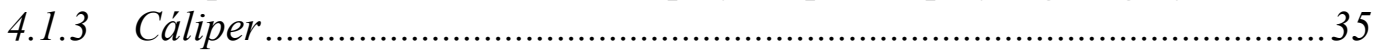

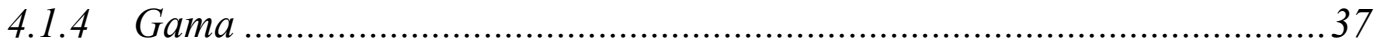

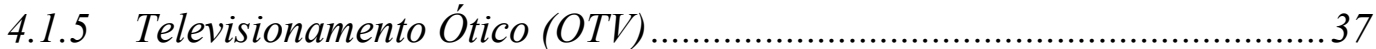

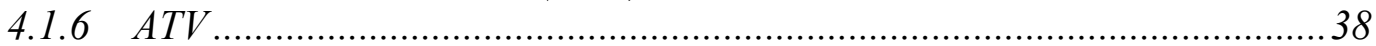

4.1.7 Resistividade de dupla indução (curta e longa) .......................................39

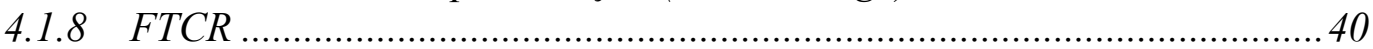

4.1.9 Flowmeters ........................................................................................ 41

4.1.10 Processamento e integração de dados geofísicos .....................................46

4.2 ENSAIOS HIDRÁULICOS E AMOSTRAGEM COM OBTURADORES ..................51 
4.2.1 Considerações sobre o uso de obturadores para obtenção de parâmetros

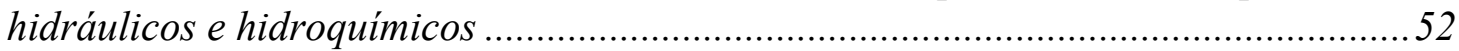

4.2.2 Materiais adquiridos e desenvolvidos para o uso de obturadores............55

4.2.3 Método para a realização de ensaios hidráulicos e amostragem ............ 67

4.3 CONSTRUÇÃO DA UNIDADE MÓVEL DE ENSAIOS HIDRÁULICOS E

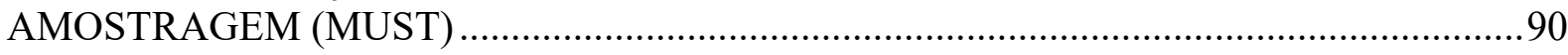

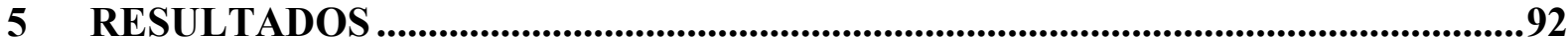

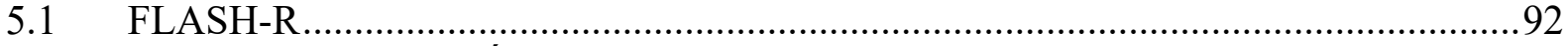

5.2 APLICAÇÃO DO MÉTODO DE INVESTIGAÇÃO.............................................92

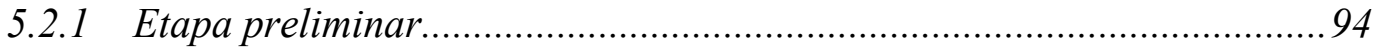

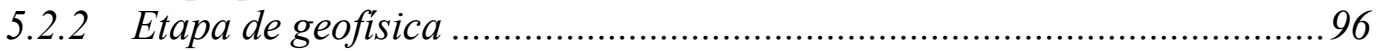

5.2.3 Unidade móvel de ensaios hidráulicos e amostragem MUST ................ 106

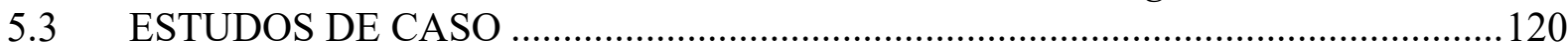

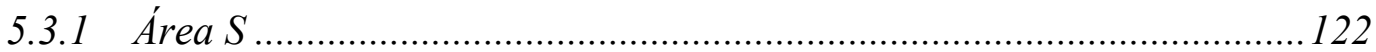

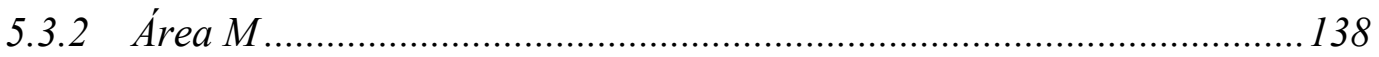

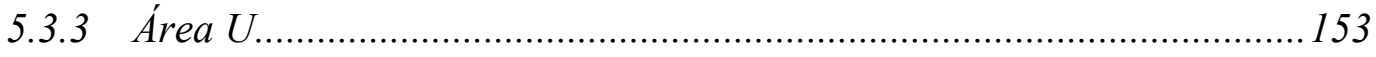

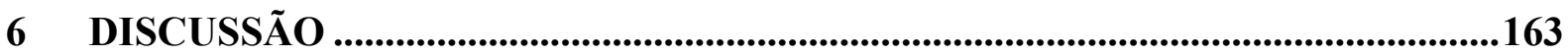

7 CONCLUSÕES............................................................................................................ 176

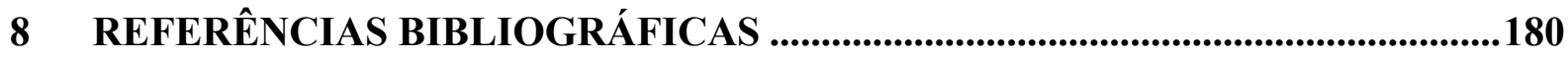

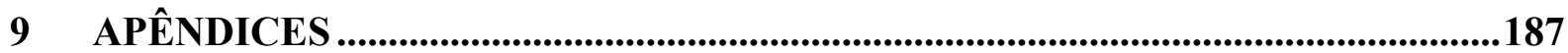

APÊNDICE I: UMA NOVA VERSÃO DO PROGRAMA FLASH EM R PARA A ANÁLISE DE ENSAIOS EM UM ÚNICO FURO (ARTIGO) …...................................... 188 APÊNDICE II: PERFIL GEOFÍSICO EM DETALHE DO POÇO 1204.............................195 APÊNDICE III: EXEMPLO DE DADOS BRUTOS E PROCESSADOS DOS ENSAIOS

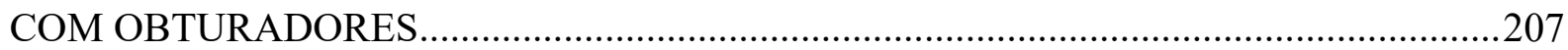




\section{RESUMO}

BARBOSA, M. B. (2020). Aplicação e desenvolvimento dos métodos de caracterização de aquíferos fraturados utilizando poços tubulares. Tese de Doutorado. São Paulo, Instituto de Geociências, Universidade de São Paulo. 210p.

Os aquíferos fraturados são reservatórios de água doce importantes no Brasil (recobrem cerca de $36 \%$ do território), e entender os mecanismos que controlam a sua dinâmica hidráulica e hidroquímica tem grande valor científico e prático relevante para a sociedade. Ainda assim, este tipo de aquífero é pouco estudado se comparado aos meios porosos. Esta disparidade ocorre devido às características intrínsecas desse tipo de aquífero, que lhes conferem elevado grau de complexidade, pela sua heterogeneidade e anisotropia, e inacessibilidade. Tendo em vista a dificuldade de acesso aos aquíferos fraturados, é importante que se faça uso racional e eficiente dos poços tubulares, utilizados para abastecimento e, portanto, presentes em grande parte do território. Seu uso apresenta desafios para estudos de hidrogeologia e ambientais. Visando contribuir para o avanço dessa área do conhecimento, esta tese se propõe a aplicar e desenvolver os métodos de trabalho para a caracterização de aquíferos fraturados e incorporar técnicas amplamente utilizadas internacionalmente ao cenário brasileiro. Para tanto, são abordados, em detalhe, aspectos desde o planejamento até a interpretação integrada dos resultados. As técnicas utilizadas deram ênfase aos aspectos construtivos do poço, às características físicas e estruturais da rocha e às propriedades hidráulicas e hidroquímicas do poço e do aquífero. Para isso, foram utilizados equipamentos de geofísica de poços e obturadores para ensaios hidráulicos e amostragem de água. A aplicação de métodos de caracterização de fluxo em furo aberto compreendeu o aprimoramento da técnica de processamento e análise de dados para obtenção de parâmetros hidrogeológicos, resultando em uma nova versão do software FLASH. Quanto ao uso de obturadores, foi desenvolvida uma unidade móvel para ensaios hidráulicos e amostragem de água subterrânea em trechos discretos. O método foi aplicado em 29 poços tubulares e aprimorado a partir da experiência adquirida. $\mathrm{O}$ enfoque dado nesta pesquisa tem viés metodológico e propõe contribuir com o planejamento e execução de trabalhos em aquíferos fraturados. O método estabelece a forma de utilização de técnicas geofísicas e hidráulicas, em furos abertos e porções discretas com uso de obturadores. Ele tem uma progressão em três etapas: preliminar; geofísica; e ensaios hidráulicos e amostragem com obturadores. A etapa de geofísica faz uso de oito sondas de forma sequencial: câmera, cáliper, 
gama, ótico, acústico, resistividade, temperatura e condutividade ou resistividade do fluido, flowmeter. Os principais aspectos que influenciam a qualidade dos trabalhos realizados em poços são o método utilizado na perfuração do poço; a condição em que o poço se encontra; a preparação adequada da etapa de campo; a sequência de execução das técnicas de caracterização; os procedimentos de coleta de dados; e os procedimentos de processamento e análise dos dados.

PALAVRAS-CHAVE: aquifero fraturado, geofisica de poço, obturadores 


\section{ABSTRACT}

BARBOSA, M. B. (2020). Development and application of methods for characterization of fractured aquifers using water wells. PhD. Thesis. São Paulo, Institute of Geosciences, University of São Paulo. 210p.

Fractured aquifers are an important freshwater reservoir in Brazil (they cover approximately $36 \%$ of the territory) and understanding the mechanisms that control its hydraulic and hydrochemistry dynamics has relevant scientific and practical value to society. Yet they still barely studied in comparison with porous media. This discrepancy occurs due to the intrinsic characteristics of this type of aquifer, attributable to an elevated grade of complexity, as a result of its heterogeneity and anisotropy, and inaccessibility. Bearing in mind the difficulty of accessibility to fractured aquifers, it is important to make a rational and efficient use of wells drilled for water supply and therefore present in large parts of the areas. However, its use presents challenges for hydrogeological and environmental studies. Envisaging the contribution for the advancement of this area of knowledge, this thesis proposes the application and development of procedures for the characterization of fractured aquifers and to incorporate widely used techniques abroad to the Brazilian scenario. Therefore, aspects from planning to integrated interpretation of results are covered in detail. The techniques utilized emphasized the well construction aspects, the physical and structural characteristics of the rock as well as the hydraulic and hydrochemistry properties of the well and aquifer. To accomplish that, it was used borehole geophysics tools and straddle packers for hydraulic testing and groundwater sampling. The application of open hole characterization methods included the improvement of a computer program for flow-log analysis of single holes and data analysis to obtain hydrogeological parameters. As for the use of packers, a mobile unity was developed for hydraulic testing and sampling of water in discreet intervals. This method was applied in 29 water wells and improved according to the experience gained. This research focuses on methodological aspects and therefore intends to contribute with the planning and execution of fieldwork in fractured aquifers studies. The method establishes the use of geophysical and hydraulic techniques in open holes and discrete portions with packers. It has a progression in three stages: preliminary; borehole geophysics; and hydraulic testing and sampling with packers. It was used a sequence of eight borehole geophysics as camera, caliper, gamma, optical, acoustic, resistivity, fluid temperature and conductivity or resistivity and flowmeter. The main aspects that influence the quality of the work are the drilling method; the well 
condition; proper preparation of the fieldwork; the sequence of the characterization techniques; the data collection procedures; and data processing and analysis procedures.

KEYWORDS: fractured aquifer, borehole geophysics, packer 


\section{LISTA DE FIGURAS}

Figura 3.1. (1) Representação do fluxo de uma fratura natural com irregularidade e rugosidade na parede da rocha; e (2) representação de uma fratura por uma abertura (2b) entre dois planos paralelos (GALE, 1982)......

Figura 3.2. Limite superior da lei de Darcy e a transição do fluxo laminar para o turbulento com relação ao número

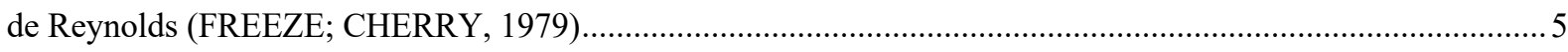

Figura 3.3. Curva estatística da frequência da abertura da fratura (VAN GOLF-RACHT, 1982 apud DOMENICO; SCHWARTZ, 1990)

Figura 3.4. Diagrama ilustrando o Volume elementar representativo (adaptado de HUBBERT, 1957 apud DOMENICO; SCHWARTZ, 1990)..... 10

Figura 3.5. Efeito da escala na obtenção dos parâmetros hidráulicos em campo.

Figura 3.6. Ilustração esquemática de uma fratura que intercepta um furo cilíndrico, indicando como a direção e o mergulho são interpretados a partir das imagens geradas por uma sonda ótica ou acústica (PAILLET; OLLILA, 1994).

Figura 3.7. Componentes da sonda ATV, à esquerda, e princípio de funcionamento do pulso ultrassônico ........2 21

Figura 3.8. Princípio de funcionamento da sonda HPF (adaptado de HESS, 1986 apud KEYS, 1990) ...............23

Figura 3.9. Princípio de funcionamento da sonda EMF (YOUNG \& PEARSON, 1995).................................24

Figura 3.10. Princípio de funcionamento da sonda SF (YOUNG \& PEARSON, 1995) ...................................25

Figura 3.11. Ensaios hidráulicos realizados com obturadores (QUINN; CHERRY; PARKER, 2012) ...............28

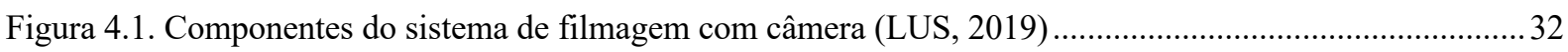

Figura 4.2. Desenho esquemático dos componentes de superfície para operação das sondas da MSI ................. 34

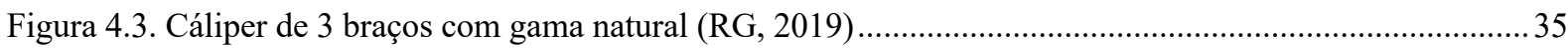

Figura 4.4. Aferição e calibração do cáliper da MSI.................................................................................. 36

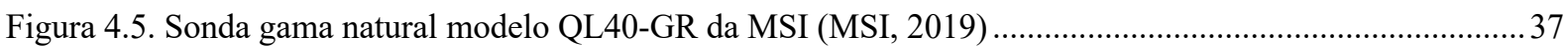

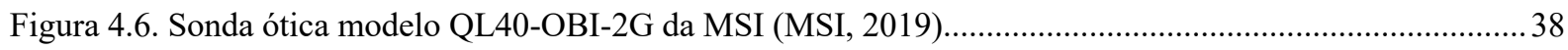

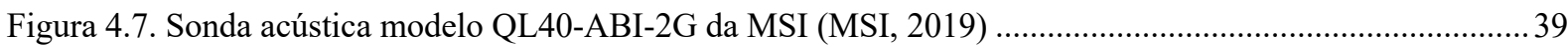

Figura 4.8. Sonda de resistividade de dupla indução modelo QL40-IND da MSI (MSI, 2019) ...........................39

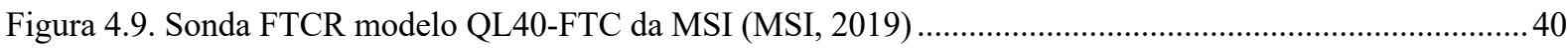

Figura 4.10. Sonda HPF modelo HFP-2293 da MSI (Modificado de MSI, 2019)..........................................42

Figura 4.11. Sonda EMF modelo 9722E-M Flowmeter da CG (CG, 2019) ...............................................42 
Figura 4.12. (1) aferição e calibração de flowmeters para medidas estáticas; (2) foto da calibração realizada em laboratório com HPF

Figura 4.13. Sonda SF modelo QL40-SFM da MSI (MSI, 2019)

Figura 4.14. Ensaio com fluxo induzido (bombeamento) no poço 255 com o HFP-2293 da MSI 44

Figura 4.15. Ficha de campo para ensaio com flowmeter .46

Figura 4.16. Vazamento entre os intervalos obturados pela parede do furo e pela rede de fraturas 53

Figura 4.17. Equipamentos para a realização de ensaios hidráulicos e amostragem com obturadores. 56

Figura 4.18. Componentes que são inseridos no poço com obturadores 57

Figura 4.19. Modelos de obturadores utilizados, (1) N Packer; (2) P Packer; e (3) P5-9 Packer 57

Figura 4.20. Tubo desenvolvido para o fácil acoplamento com vedação de $O$ 'ring entre a cabeça (tubo branco sch 40) e a luva (tubo cinza sch 80). Quando inflados os obturadores, o tubo funciona como poço temporário e permite a comunicação da superfície com o intervalo. 59

Figura 4.21. Válvula de acionamento pneumático SS8BK-1C da Swagelok (Swagelok, 2019)

Figura 4.22. (1) cabeça da composição para o conjunto de obturadores P Packer; (2) cabeça da composição para o conjunto de obturadores P5-9 Packer; e (3) prensa cabo para isolamento do intervalo inferior com uma proteção para o transdutor.

Figura 4.23. Componentes do sistema de elevação (1) Guincho de corrente; (2) talha de corrente; (3) mini-guincho; (4) estrutura de aço para utilização do guincho; e (5) tripé em alumínio para utilização da talha elétrica.

Figura 4.24. Componentes hidráulicos: (1) tanque pulmão para regularização da pressão de entrada na bomba (2) bomba centrifuga de pressurização da linha de injeção; (3) inversor de frequência utilizado para controlar a bomba centrífuga; (4 e 5) medidor de vazão ultrassônico; (6 e 7) manômetro e registro da linha de injeção de água; (8) bomba de pressão e vácuo utilizada no ensaio de pulso pneumático; (9 e 10) bomba Grundfos MP1 e inversor de frequência para controlar a vazão.

Figura 4.25. Curvas características da MP1 (Grundfos, 2019)

Figura 4.26. Componentes pneumáticos: (1) cilindros de nitrogênio de 50 1; e (2) registros e manômetros utilizados para inflar os obturadores, fazer amostragem e abrir as válvulas pneumáticas.....

Figura 4.27. Sistema de amostragem de baixa vazão com válvulas de retenção e controladora de pressão alimentada com gás nitrogênio.

Figura 4.28. Sistema de comunicação e processamento de dados composto pelo CR1000, conversor de sinal digital, computador e software.....

Figura 4.29. Entradas, saídas e conexões do CR1000 (Campbell, 2019) 66

Figura 4.30. Interface do software LoggerNet

Figura 4.31. Características do barômetro 61302 da Young ..... 
Figura 4.32. Processo de isolamento de um intervalo e estabilização da carga hidráulica . 70

Figura 4.33. Ensaio de estanqueidade em um intervalo que não apresentou fluxo. Foram aguardados 6 min e nenhuma alteração da pressão no intervalo intermediário foi observada

Figura 4.34. Dois ensaios de pulso com injeção de água em um intervalo. Não foram observados vazamentos para os níveis adjacentes

Figura 4.35. Processo de isolamento de um intervalo e ensaio de estanqueidade com vazamento para o nível superior. Após constatado vazamento a pressão no obturador foi aumentada e um novo ensaio foi realizado, que mesmo assim apresentou vazamento

Figura 4.36. Processo de isolamento de um intervalo e ensaio de estanqueidade com vazamento para o nível inferior

Figura 4.37. Modelo de ficha de campo para o ensaio de estanqueidade de intervalos isolados 73

Figura 4.38. Referência para o cálculo da carga hidráulica a partir das medidas de pressão e nível d'água 74

Figura 4.39. Etapas do ensaio de pulso com aplicação de vácuo no intervalo isolado 75

Figura 4.40. Equipamento utilizado para o ensaio de pulso pneumático; (1) operação durante um ensaio; e (2) detalhe dos componentes. 77

Figura 4.41. Ficha de campo para registro do ensaio de pulso 78

Figura 4.42. Ensaio de pulso pneumático em um intervalo do poço 255 sem vazamento para os níveis adjacentes. Ensaio de elevação das 14:00 às 14:38 e ensaio de rebaixamento das 14:38 às 15:12 .78

Figura 4.43. Resultados e interpretação para o ensaio de pulso com rebaixamento por Hvorslev: 1) variação da vazão em função do tempo calculada a partir de $\mathrm{dH}$, início do ensaio na vazão máxima; 2) variação da carga no tempo, dados do ensaio utilizados na interpretação; 3) dados do ensaio com maior representatividade para determinação da inclinação da reta.

Figura 4.44. Resultado de um ensaio de carga constante no poço P1 com seis vazões de injeção

Figura 4.45. Ficha de campo para registro dos dados de ensaio de carga constante 84

Figura 4.46. Exemplo de resultados para ensaio de carga constante. Acima, resultados obtidos para todas as vazões utilizadas no ensaio e linhas de tendência linear e polinomial e abaixo apenas resultados dentro do regime laminar que pode ser representado por uma expressão linear .84

Figura 4.47. Ficha de campo para registro dos dados de ensaio de bombeamento ..... 86

Figura 4.48. Ficha para registro dos dados de amostragem de água subterrânea 89

Figura 4.49. Construção da unidade móvel de ensaios hidráulicos e amostragem denominada Mobile Unit for Sampling and Testing (MUST). Projeto da MUST (acima) e ensaio no poço do Instituto de Geociências (abaixo) 
Figura 5.1. Método de trabalho adequado para a investigação de aquíferos fraturados utilizando poços tubulares

Figura 5.2. Exemplo das condições de conservação e proteção de alguns dos poços em que foram realizados os trabalhos. (1) poço localizado ao lado do depósito de lixo, sem proteção sanitária recebendo toda a água que escorria pelo pátio da empresa; (2) poço sem tampa (coberto com uma lata) recebendo toda a sujeira carregada pela água da chuva que acumulava ; (3) poço construído dentro dos padrões exigidos por norma; (4) poço abaixo do piso com água vertendo para seu interior e carregando toda a sujeira acumulada no pátio.

Figura 5.3. Exemplo de imagens captada pela câmera com (1) materiais em suspensão e (2) turbidez elevada...97 Figura 5.4. Exemplo de combinação dos dados da sonda acústica (tempo de trânsito e amplitude do sinal acústico), cáliper e imagens da câmera.

Figura 5.5. Exemplo de imagem gerada com o OTV. À direita a imagem foi ampliada 15 vezes para visualização das características da rocha.

Figura 5.6. Exemplos das diferenças entre as sondas de televisionamento ótico, acústico e cáliper

Figura 5.7. Exemplo de feições de fluxo identificadas com o OTV (1) e a câmera (2 a 5). As imagens 1 a 3 são da mesma feição de fluxo observada no poço 1204 da Área S .

Figura 5.8. Análise comparativa entre dados gerados pela sonda FTCR em condições de fluxo ambiente (azul) e induzido (vermelho). Foram identificadas três zonas hidraulicamente ativas no poço B3

Figura 5.9. Perfil de fluxo gerado com dados dos flowmeters para o poço B3. Neste perfil pode ser observada a diferença de resposta que cada sonda apresenta para um mesmo poço. A vazão utilizada para o ensaio com fluxo induzido foi diferente para cada sonda.....

Figura 5.10. Sistemas de movimentação da composição que foram utilizados

Figura 5.11. Sistemas de movimentação da composição de obturadores: (1) guincho de corrente localizado dentro do trailer e estrutura de aço fixada na cabeça do poço, tripé utilizado apenas para montagem da composição; (2) talha elétrica fixada no topo do tripé; (3) guincho de corrente localizado dentro do trailer e tripé .................... 108

Figura 5.12. Configuração A da MUST 110

Figura 5.13. Características de operação da configuração A da MUST.

Figura 5.14. Configuração B da MUST

Figura 5.15. Detalhes da montagem e operação da configuração B. (1) detalhe da montagem das mangueiras e cabos que comunicam com o intervalo e conectam na bomba; (2) sistema de ensaio de pulso com ar acoplado à mangueira de PE de 20 mm; (3) monitoramento da carga hidráulica com transdutores e medidor de nível....... 116 Figura 5.16. Características de operação da configuração B da MUST.

Figura 5.17. (1) zona de deformação do furo decorrente do esforço principal no maciço (breakout); (2) trecho em que a câmera entra em uma cavidade do furo e não avança mais no poço 255 
Figura 5.18. Perfil integrado do poço 255 da Área S (ATV, gama, HPF, FLASH e obturador) 131

Figura 5.19. Imagens obtidas a partir da câmera para o poço 1204. (1 e 2) marcas de água escorrida na parede do furo; (3) oxidação da parede do furo, cor avermelhada, a partir dos 123,5 m; e (4) incrustação observada em 164 $\mathrm{m}$.

Figura 5.20. Perfil integrado do poço 1204 da Área S (ATV, gama, HPF, FLASH e obturador) 134

Figura 5.21. Resultado da modelagem de fluxo do HPF no programa FLASH-R para o poço 1204. 136

Figura 5.22. Imagens geradas com a câmera no poço P2 da área M. (1) indício de escorrimento de água na parede do furo; (2) imagem da rocha do Grupo Itararé, siltito com seixo pingado; (3) imagem da rocha do Grupo Itararé, intercalação arenito-argila; (4) contato entre a rocha do Grupo Itararé e do Complexo Amparo; (5) imagem da rocha do Complexo Amparo.

Figura 5.23. Resultado da modelagem de fluxo do HPF no programa FLASH-R para o poço P2 145

Figura 5.24. Perfil integrado do poço P2 da Área M (ATV, gama, HPF, FLASH e obturador)..... 146

Figura 5.25. Imagens geradas com a câmera no poço P4 da área M. (1) fratura na rocha sedimentar vertendo água para o poço; (2) imagem da rocha do Grupo Itararé (diamictito); (3) contato entre a rocha do Grupo Itararé e do Complexo Amparo; (4) imagem da rocha do Complexo Amparo 148

Figura 5.26. Resultado da modelagem de fluxo do HPF no programa FLASH-R para o poço P4 da Área M.... 151

Figura 5.27. Perfil integrado do poço P4 da Área M (ATV, gama, HPF, FLASH e obturador)..... 152

Figura 5.28. Perfil integrado do poço B3 da Área U. 158

Figura 5.29. Resultado dos ensaios com flowmeters (HPF, EMF e SF) para o poço B3 160

Figura 5.30. Resultado da modelagem de fluxo do HPF no programa FLASH-R para o poço B3 161

Figura 5.31. Resultado da modelagem de fluxo do EMF no programa FLASH-R para o poço B3. 162

Figura 6.1. (1) obturador com a borracha esmagada pela pressão da coluna de água sendo retirado do poço 1204; (2) detalhe da borracha esmagada e o início da formação de um sulco longitudinal, que pode afetar o isolamento de intervalos durante a realização de ensaios 165

Figura 6.2. Trabalho em que o obturador ficou travado no poço e foi necessário o uso de caminhão munck para retira-lo do poço. 166

Figura 6.3. Coleta de amostra de branco de equipamento para controle de qualidade da amostragem e avaliação de contaminação cruzada pelos equipamentos

Figura 6.4. Resultados das perfilagens cáliper, ATV e OTV para o poço 255. As manchas azuis escuras no perfil do ATV são resultado da descentralização da sonda no furo 


\section{LISTA DE TABELAS}

Tabela 4.1. Técnicas geofísicas e fornecedores utilizados

Tabela 4.2 Características dos transdutores utilizados com os obturadores

Tabela 5.1 Comparação entre sistemas de movimentação da composição no poço.

Tabela 5.2. Aspectos positivos e negativos das duas opções de posicionamento dos transdutores 116

Tabela 5.3. Principais características e resultados dos três estudos de caso apresentados

Tabela 5.4. Resumo dos dados dos poços 255, 256 e 1204 da Área S obtidos no cadastro de poços.

Tabela 5.5. Atividades realizadas e principais resultados para o poço 255 da Área S 126

Tabela 5.6. Resultados dos ensaios hidráulicos com obturadores no poço 255 129

Tabela 5.7. Atividades realizadas e principais resultados para o poço 1204 da Área S..... 132

Tabela 5.8. Resultados da modelagem de fluxo com o FLASH-R para o poço 1204. 135

Tabela 5.9. Resultados dos ensaios hidráulicos com obturadores no poço 1204 137

Tabela 5.10. Resumo dos dados dos poços P2 e P4 da Área M obtidos no Sistema de Informação De Águas Subterrâneas (SIDAS) do Departamento de Águas e Energia Elétrica do Estado de são Paulo. 140

Tabela 5.11. Atividades realizadas e principais resultados do poço P2 da Área M 142

Tabela 5.12. Resultados da modelagem com o FLASH-R para o poço P2 144

Tabela 5.13. Resultados dos ensaios hidráulicos com obturadores no poço P2 144

Tabela 5.14. Atividades realizadas e principais resultados do poço P4 da Área M 148

Tabela 5.15. Resultados da modelagem de fluxo com o FLASH-R para o poço P4 150

Tabela 5.16. Resultados dos ensaios hidráulicos com obturadores no poço P4 153

Tabela 5.17. Resumo dos dados construtivos dos poços da Área U 154

Tabela 5.18. Atividades realizadas e principais resultados do poço B3 da Área U 156

Tabela 5.19. Resultados da modelagem de fluxo com o FLASH-R para o poço B3 159

Tabela 6.1. Comparação entre os diferentes equipamentos para ensaio hidráulico e amostragem com obturadores, modelos norte americanos e a MUST. 164

Tabela 6.2. Análise comparativa das técnicas utilizadas no método de caracterização de aquíferos fraturados por meio de poços tubulares 


\section{SIGLAS E ABREVIATURAS}

ABNT: Associação Brasileira de Normas Técnicas

ALT: Advanced Logic Technology

ATV: televisionamento acústico

cáliper: cáliper mecânico de três braços

CEPAS: Centro de Pesquisa de águas Subterrâneas

CETESB: Companhia Ambiental do Estado de São Paulo

CG: Century Geophysical

DAEE: Departamento de Águas e Energia Elétrica do Estado de São Paulo

DCE: Dicloroeteno

DFN: Discrete Fracture Network

EMF flowmeter eletromagnético

EQM: Erro Quadrático Médio

FA: fluxo ambiente

FBT: Fractured Bedrock Toolbox

FI: fluxo induzido por bombeamento ou injeção

FLASH-R: Flow-Log Analysis of Single Holes em R

FLASH: Flow-Log Analysis of Single Holes

FTCR: sonda de temperatura e condutividade elétrica ou resistividade

gama: gama natural

HPF: flowmeter de pulso de calor

IPT: Instituto de Pesquisas Tecnológicas

LUS: Laval Underground Surveys

mca metro de coluna de água

MSI: Mount Sopris Instruments

MUST: Mobile Unit for Sampling and Testing

$\mathrm{N}$ : número de fraturas por unidade de distância transversal à face da rocha

NA: nível d’água

NB: Norma Brasileira

OTV: televisionamento ótico

RG: Robertson Geologging 
rw: raio do poço/furo (L)

SF: flowmeter de hélice

SIDAS: Sistema de Informação de Águas Subterrâneas do DAEE

TCE: Tricloroeteno

USGS: United States Geological Survey

VER: Volume Elementar Representativo 


\section{INTRODUÇÃO}

Os aquíferos fraturados recobrem cerca de 36\% do território nacional (LIMA, 1996), e os serviços ambientais prestados por estas unidades geológicas tem impacto social, econômico e ambiental. Um grande número de usuários e empresas tem seu abastecimento de água garantido por meio da explotação destes aquíferos, assim como muitos ecossistemas são dependentes de sua dinâmica de fluxo natural.

Os aquíferos fraturados constituem um reservatório de água doce de importância significativa, sendo um recurso estratégico fundamental em tempos de mudanças climáticas, e de aumento na demanda por água nas cidades e zonas de produção agrícola. Seja no tocante à quantidade (e.g. esgotamento) e à qualidade (e.g. poluição) da água, entender os mecanismos que controlam sua dinâmica hidráulica e hidroquímica tem valor científico e prático relevante para a sociedade.

Apesar de sua importância, o conhecimento sobre aquíferos fraturados é ainda incipiente no Brasil, e de maneira geral no mundo. Isso se deve tanto à sua complexidade geológica, como aos custos elevados para sua caracterização. Tais estudos demandam a execução de perfurações em material duro com equipamentos caros para que observações diretas possam ser realizadas. Por outro lado, o uso de perfurações existentes permite um acesso direto aos aquíferos fraturados a custo mais baixo. No entanto, o uso de poços perfurados para fins de abastecimento apresenta desafios quando utilizados em estudos hidrogeológicos e ambientais. Portanto é necessária a adoção de procedimentos e técnicas com vistas à obtenção de dados representativos.

Os desafios para o estabelecimento do método de estudo dos aquíferos são de ordens variadas. Por vezes, pequenos obstáculos não previstos acarretam perdas materiais e descontinuidade dos trabalhos. Erros na ordem de aplicação de uma técnica ou na execução de procedimentos podem resultar em desperdício de recursos e retrabalho. Portanto, o objetivo deste estudo é justamente contribuir para a obtenção do melhor resultado através do estabelecimento de um método eficiente, de fácil entendimento e aplicação.

Existem métodos de caracterização de aquíferos fraturados que são discutidos por muitos autores (FIACCO; DALY; DROBINSKI, 2004; GOLDER, 2010; PARKER; CHERRY; CHAPMAN, 2012), sendo que a maioria deles trata dos procedimentos e técnicas que são aplicados em perfurações na rocha. Toda perfuração em rocha causa um distúrbio no aquífero, que gera um viés de coleta de dados. No entanto, o uso de poços tubulares apresenta 
particularidades que justificam uma análise mais detalhada para superar os desafios que estas obras impõem.

O principal desafio no uso dos poços está relacionado às suas características construtivas e a grande variabilidade que estes podem apresentar no Brasil. Apesar de existirem normas para a perfuração de poços (ABNT NB588 e NB1290), muitos são construídos fora do padrão. Segundo um levantamento realizado pela FUSP (2002), mais de $70 \%$ dos poços perfurados para abastecimento no Estado de São Paulo são clandestinos, e encontram-se em condições desconhecidas sem a aprovação do órgão regulador. $\mathrm{O}$ desenvolvimento de um método específico para utilizar poços tubulares no contexto brasileiro possibilita incorporar as técnicas consagradas internacionalmente e superar desafios que fazem parte da realidade local.

O método de trabalho proposto foi demonstrado por meio de estudos de caso, e as técnicas utilizadas são de dois tipos: aquelas que fazem uso de equipamentos de geofísica; e as que fazem uso de obturadores de pressão para ensaios hidráulicos e amostragens discretas. As técnicas geofísicas utilizadas neste trabalho são as adequadas ao estudo de aquíferos fraturados em rocha cristalina, quais sejam: câmera de vídeo-inspeção, cáliper mecânico (3 braços), gama natural, resistividade da rocha (curta e longa), imageamento ótico e acústico, temperatura e condutividade elétrica, ou resistividade, do fluido e ensaio de fluxo com flowmeter.

A sequência de 13 atividades proposta neste trabalho otimiza os recursos disponíveis para a caracterização de aquíferos fraturados por meio de poços tubulares, tanto para rochas sedimentares quanto ígneas e metamórficas. Dadas as características dos aquíferos fraturados, estudos mais abrangentes podem contemplar outras técnicas de aquisição de dados, na medida em que a complexidade aumenta. Destacam-se os levantamentos estruturais em imagens aéreas e afloramentos, métodos geofísicos de superfície, perfurações com recuperação de testemunho e sistemas multiníveis. 


\section{OBJETIVO}

O objetivo desta tese é a aplicação e o desenvolvimento de métodos de trabalho para a caracterização de aquíferos fraturados utilizando poços tubulares no contexto brasileiro. $\mathrm{O}$ termo aquífero fraturado adotado, se refere a unidades hidrogeológicas em que a porosidade primária (matriz da rocha) é desprezível, e o armazenamento e o fluxo de água se dá pelas descontinuidades da rocha (fraturas). O trabalho contemplou duas linhas de pesquisa distintas, uma de desenvolvimento, e outra de aplicação prática das técnicas existentes e desenvolvidas.

Os objetivos específicos são:

1. Desenvolvimento de equipamentos e técnicas

a. Desenvolvimento de uma unidade móvel para ensaios hidráulicos e amostragem de água subterrânea em trechos discretos (Mobile Unit for Sampling and Testing - MUST), que faz uso de obturadores de pressão para o isolamento de seções do poço/furo; e

b. Aprimoramento da técnica de modelagem de fluxo em furos abertos para ensaios com flowmeter.

2. Proposição do método de trabalho a partir de estudos de caso

a. Utilizar equipamentos de caracterização de aquíferos fraturados em poços tubulares para avaliar seu desempenho e comparar diferentes técnicas e fabricantes;

b. Aplicar diferentes sequências de trabalho para a proposição de um método de caracterização hidráulica e hidroquímica; e

c. Avaliar o uso de poços tubulares para fazer a caracterização de aquíferos fraturados (propriedade físicas e hidráulicas). 


\section{REVISÃO DA LITERATURA}

Neste item são apresentados os estudos e a base teórica que foram consultados para o desenvolvimento desta pesquisa na seguinte sequência: propriedades físicas e hidráulicas dos aquíferos fraturados; abordagens consagradas para sua investigação; técnicas de geofísica de poços; e ensaios hidráulicos com obturadores.

\subsection{Propriedades físicas e hidráulicas do meio fraturado}

O estudo mais aprofundado do fluxo em aquíferos fraturados teve início na década de 1950, quando foram realizados experimentos em laboratório simulando o fluxo em uma única fratura (GALE, 1982). Esse foi o marco para o desenvolvimento de equações básicas para descrever o movimento da água nesse meio. Para tanto, considerou-se que o fluxo é governado pela lei de Darcy e a permeabilidade da fratura, ou transmissividade, é simplificada para a abertura entre dois planos paralelos (Figura 3.1). Tais estudos identificaram alguns aspectos importantes para o fluxo em ensaios com placas de vidro e de concreto, como: efeito de pequenas rugosidades; efeito da variação da abertura em larga escala; e não linearidade do fluxo com número de Reynolds $\left(\mathrm{R}_{\mathrm{e}}\right)$ elevado.

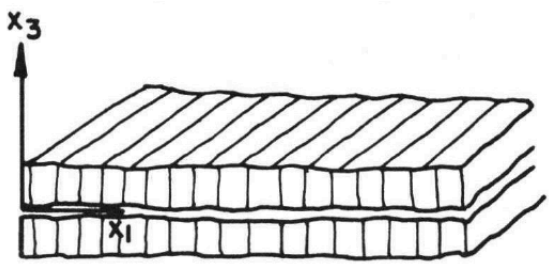

1 Fratura natural

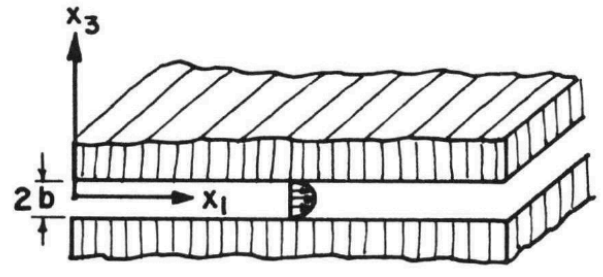

2 Abertura entre planos paralelos

Figura 3.1. (1) Representação do fluxo de uma fratura natural com irregularidade e rugosidade na parede da rocha; e (2) representação de uma fratura por uma abertura (2b) entre dois planos paralelos (GALE, 1982)

Conforme demonstrado por Hubbert (1957), a lei de Darcy apresenta um limite superior e um inferior. O limite inferior tem pouca aplicação prática, uma vez que está relacionado a velocidades de fluxo muito baixas. Já o limite superior é, na verdade, uma faixa de transição onde as forças inerciais passam a ser significativas para o fluxo. Para determinar esta transição, utiliza-se o número de Reynolds (HUBBERT, 1957), que é um número adimensional e representa a relação entre forças viscosas e inerciais (Equação 3.1). Quando há predomínio das forças inerciais sobre as viscosas, o fluxo se torna turbulento. Essa relação não linear entre vazão específica e gradiente hidráulico associada ao $R_{\mathrm{e}}$ é ilustrada na Figura 3.2. 


$$
R_{e}=\frac{\rho q D}{\mu}
$$

Equação 3.1

Em que:

q - descarga específica $(\mathrm{L} / \mathrm{T})$

D - comprimento característico com base na geometria do meio (L)

$\mu$ - viscosidade dinâmica $\left(\mathrm{L}^{2} / \mathrm{T}\right)$

$\rho$ - densidade do fluido $\left(\mathrm{M} / \mathrm{L}^{3}\right)$

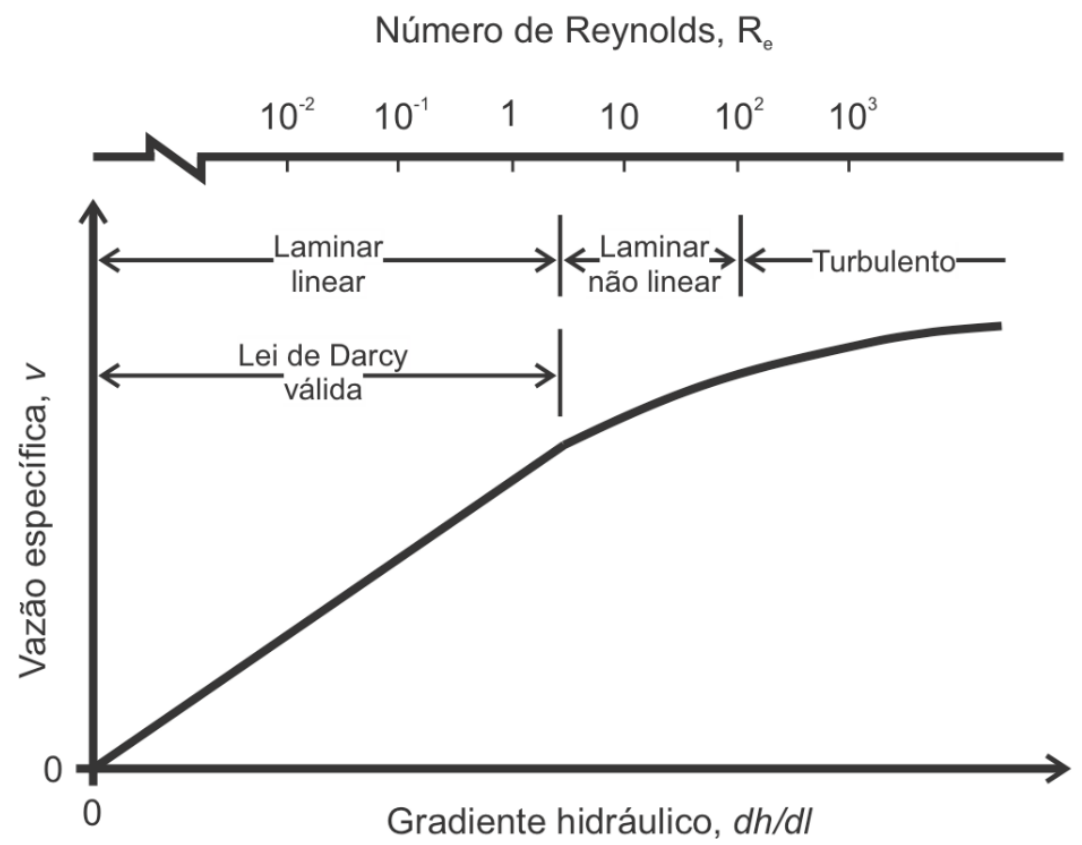

Figura 3.2. Limite superior da lei de Darcy e a transição do fluxo laminar para o turbulento com relação ao número de Reynolds (FREEZE; CHERRY, 1979)

Não há, atualmente, consenso sobre qual o melhor valor para o comprimento característico (D). Conforme discutido em Quinn et al. (2011), alguns autores sugerem a abertura hidráulica média (e.g. ELSWORTH; DOE, 1986; KONZUK; KUEPER, 2004; WITHERSPONN et al., 1980), enquanto outros, inclusive o autor, adotam a própria abertura hidráulica (e.g. NICHOLL et al., 1999; ZIMMERMAN et al., 2004). O instante em que o fluxo começa a deixar de ser linear é representado pelo número de Reynolds crítico $\left(\mathrm{R}_{\mathrm{ec}}\right)$ e pode variar de valores menores que um até cinco (KONZUK; KUEPER, 2004; NICHOLL et al., 1999; QUINN; CHERRY; PARKER, 2011; ZIMMERMAN et al., 2004). Quinn et al. (2011) apresentam uma revisão da literatura para valores de abertura das fraturas, medidas em laboratório por diferentes técnicas e que pode ser utilizado para o cálculo do $\mathrm{R}_{\mathrm{ec}}$. 


\subsubsection{Fluxo da água subterrânea em fraturas}

Snow (1965) foi um dos primeiros a desenvolver uma equação que descrevesse o fluxo da água em uma única fratura, por meio da derivação da equação de Navier-Stokes para fluxo não turbulento de um fluido viscoso e incompressível. Antes dele, alguns autores já haviam desenvolvido trabalhos nesse sentido, conforme apresentado por Gale (1982). Aplicando a equação de Darcy para determinar a condutividade hidráulica de uma única fratura, tem-se:

$$
K_{f}=\frac{\rho g}{12 \mu}(2 b)^{2}
$$

Equação 3.2

Para um regime estacionário e isotérmico, a equação pode ser reescrita para o fluxo por unidade de carga hidráulica da seguinte forma:

$$
Q=-2 b w \frac{\rho g 2 b^{2}}{12 \mu} \frac{d h}{d l}
$$

\section{Equação 3.3}

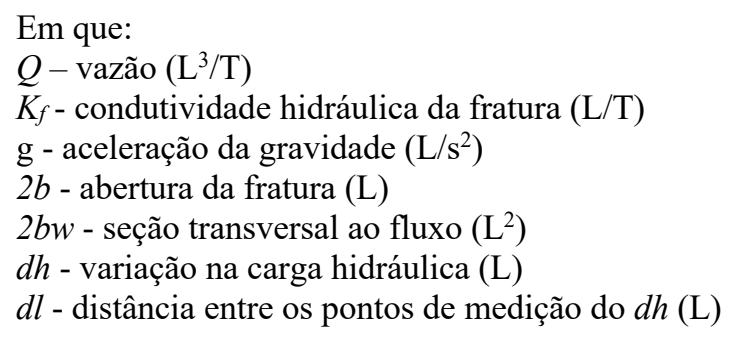

Com base na lei cúbica, Snow (1969) correlacionou a densidade e abertura de fraturas com a condutividade hidráulica por meio da Equação 3.3.

Considera-se que as fraturas interceptadas em um determinado intervalo são paralelas, planares e apresentam mesma abertura. A partir desta premissa, é calculada a abertura, permeabilidade e condutividade hidráulica equivalentes para um volume de rocha (Equação 3.4 e Equação 3.5). É importante observar que, pelo fato de a abertura da fratura estar elevada à terceira potência, pequenas variações neste parâmetro têm grande influência na condutividade hidráulica (DOMENICO; SCHWARTZ, 1990). Apesar das fraturas no intervalo terem o mesmo peso na premissa do cálculo da condutividade hidráulica, é possível fazer o cálculo reverso, atribuindo-se pesos para cada fratura, isoladamente. 


$$
K_{r}=\left(\frac{\rho g}{\mu}\right)\left(\frac{N b^{3}}{12}\right)
$$

Equação 3.4

$$
k=\frac{N b^{3}}{12}
$$

Equação 3.5

\footnotetext{
Em que:

$N$ - número de fraturas por unidade de distância

$K_{r}$ - condutividade hidráulica da rocha $(\mathrm{L} / \mathrm{T})$

$k$ - permeabilidade
}

Conforme discutido por Witherspoon (1980) e outros (BERKOWITZ, 2002; KONZUK; KUEPER, 2004; NICHOLL et al., 1999; RENSHAW, 1995; ZIMMERMAN; BODVARSSON, 1994), não é possível fazer uma medição direta e precisa da abertura real da fratura. Na prática, primeiro é obtida a condutividade hidráulica da rocha em campo para, posteriormente, ser calculada a condutividade hidráulica da fratura e sua abertura (Equação 3.4 e Equação 3.2). Uma fonte de erro que deve ser considerada para esse cálculo é o número de fraturas em um determinado intervalo de ensaio. Isto tem um impacto relevante na interpretação da velocidade de fluxo da água, cujo cálculo para as fraturas é feito com a Equação 3.6. Para sua aplicação, é necessário calcular a porosidade da rocha pela soma das aberturas das fraturas no trecho ensaiado (Equação 3.7).

$$
\begin{gathered}
v=-\frac{K_{r}}{\emptyset_{r}} \cdot \frac{d h}{d l} \\
\text { Equação } 3.6 \\
\emptyset_{r}=\frac{N 2 b}{B}
\end{gathered}
$$

Equação 3.7

Em que:

$\emptyset_{r}$ - porosidade da rocha

$B$ - intervalo do ensaio (L)

Obs: para o caso de uma única fratura temos $\emptyset_{r}=1$ e o $\mathrm{K}_{\mathrm{r}}=\mathrm{K}_{\mathrm{f}}$

As aberturas das fraturas em um aquífero apresentam uma distribuição do tipo log normal, com aquelas de maior abertura ocorrendo em pequenas quantidades (RENSHAW, 
1995). O gráfico da Figura 3.3 ilustra essa relação entre frequência e abertura. Alguns estudos confirmam essa tendência de existirem relativamente poucas fraturas com maiores aberturas e mais raras são as responsáveis pelo fluxo (BERKOWITZ, 2002; LONG et al., 1982; PAILLET, 1993; PAILLET; OLLILA, 1994). Um estudo em rochas graníticas realizado por Long e Billaux (1987) concluiu que apenas $0,1 \%$ das fraturas mapeadas contribuem para o fluxo em larga escala, tendo sido observada uma variação na transmissividade de quatro ordens de grandeza, dentre as fraturas transmissivas. Paillet (1993) observou que mesmo em condições de proximidade entre vários poços (distancias de 10 a $50 \mathrm{~m}$ entre si), são poucas as fraturas que apresentam continuidade lateral, indicando que a conectividade entre fraturas tem um papel tão importante quanto a abertura das fraturas. Embora esta ideia seja aceita pela maior parte dos autores, Pehme et al. $(2010,2013,2014)$ verificaram em estudos com uma sonda de temperatura de alta resolução que em rochas sedimentares muitas fraturas que participam do fluxo não são identificadas em ensaios convencionais em furos abertos.

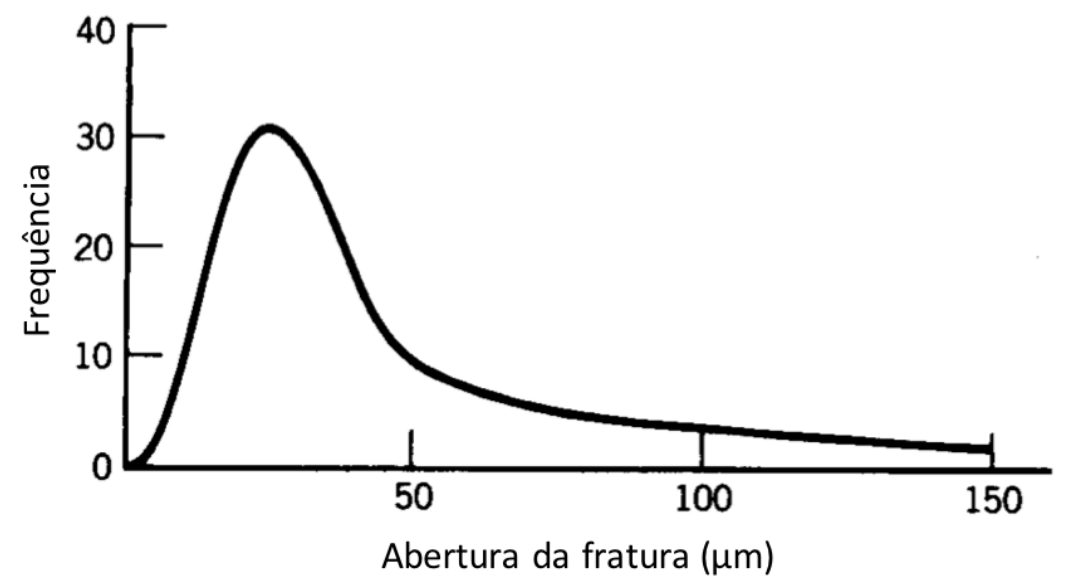

Figura 3.3. Curva estatística da frequência da abertura da fratura (VAN GOLF-RACHT, 1982 apud DOMENICO; SCHWARTZ, 1990)

Quando se realiza uma perfuração em um aquífero fraturado, são interceptadas fraturas com aberturas, direções, mergulhos, geometrias e extensões variadas. Este furo atua como um canal que conecta todas essas fraturas, sem o qual não seria possível comunicação direta, ocasionando um distúrbio no meio. Com o tempo, um novo estado de equilíbrio é estabelecido, como resultado de uma média ponderada entre carga hidráulica e transmissividade das fraturas interceptadas, aqui denominada como carga hidráulica média do poço. A relação entre essas duas propriedades gera um fluxo de água entre diferentes zonas, sendo que aquelas que têm carga superior à média fornecerão água para o poço, e aquelas com menor carga receberão essa 
água. Este fenômeno é descrito pela Equação 3.8 e Equação 3.9, modificadas de Sokol (1963) e discutido por Quinn et al. (2016).

$$
\begin{gathered}
C H_{m p}=\frac{\sum C_{i} T_{i} h_{i}}{\sum C_{i} T_{i}} \\
\text { Equação } 3.8 \\
C_{i}=\left(\frac{2 \pi}{\ln \left[\frac{r_{0}}{r_{w}}\right]_{i}}\right)
\end{gathered}
$$

Equação 3.9

$$
\begin{aligned}
& \text { Em que: } \\
& C H_{m p} \text { - Carga Hidráulica média do Poço }(\mathrm{L}) \\
& C_{i} \text { - grupo das variáveis exceto } \mathrm{T} \text { e } \mathrm{h}(\text { adimensional }) \\
& T_{i} \text { - transmissividade da fratura ou trecho } \mathrm{n}\left(\mathrm{L}^{2} / \mathrm{T}\right) \\
& h_{i} \text { - carga hidráulica da fratura ou trecho } \mathrm{n}(\mathrm{L}) \\
& r_{0} \text { - raio de influência da fratura, que é função da } \mathrm{T}(\mathrm{L}) \\
& r_{w} \text { - raio do poço/furo }(\mathrm{L})
\end{aligned}
$$

O raio de influência $\left(\mathrm{r}_{0}\right)$ é um parâmetro que dificilmente pode ser medido. Seu valor pode variar entre cada fratura ou intervalo ensaiado, já que depende da transmissividade e da conectividade. Na prática, a maior parte dos trabalhos encontrados na literatura sobre meios fraturados optaram por valores na faixa de 0,6 m a 60 m (QUINN; CHERRY; PARKER, 2011). Muitos adotaram um valor médio de 30 m (DAY-LEWIS et al., 2011; HAIMSON; DOE, 1983; QUINN; CHERRY; PARKER, 2012, 2011; SHAPIRO; HSIEH, 1998), uma vez que o $\mathrm{r}_{0} / \mathrm{r}_{\mathrm{w}}$ está em uma função logarítmica e a variação de uma ordem de grandeza em seu valor tem impacto de fator 2 na transmissividade. Quinn et al. (2016) sugerem a adoção de dois $\mathrm{r}_{0}, 3 \mathrm{~m}$ para transmissividades mais baixas $\left(\mathrm{T}<10^{-5} \mathrm{~m}^{2} / \mathrm{s}\right)$ e $30 \mathrm{~m}$ para mais elevadas $\left(\mathrm{T} \geq 10^{-5} \mathrm{~m}^{2} / \mathrm{s}\right)$.

\subsubsection{Escala de trabalho}

Determinar a escala de trabalho é fundamental para o planejamento de um projeto de caracterização de aquífero fraturado, uma vez que as técnicas de coleta de dados em campo são representativas de diferentes escalas (BERKOWITZ, 2002; CLAUSER, 1992; SAUTER, 1991). Esse efeito da escala é ilustrado na Figura 3.4., onde a porosidade varia muito no regime microscópico, podendo ser um ou zero, caso caia no domínio do vazio ou da rocha. Quando se chega ao regime macroscópico (V3), praticamente não há variação, o que, segundo Bear (1972), 
é o Volume Elementar Representativo (VER) e não há mais variação estatisticamente significativa. Contudo, como pode ser observado nessa mesma figura, em cenários reais conforme se aumenta a escala de análise, a porosidade pode ser afetada pela heterogeneidade do meio, especialmente quando ocorrem variações estratigráficas conforme apontado por Domenico e Scwhartz (1990). Segundo o autor, esse limite superior pode ser definido como regime megascópico.

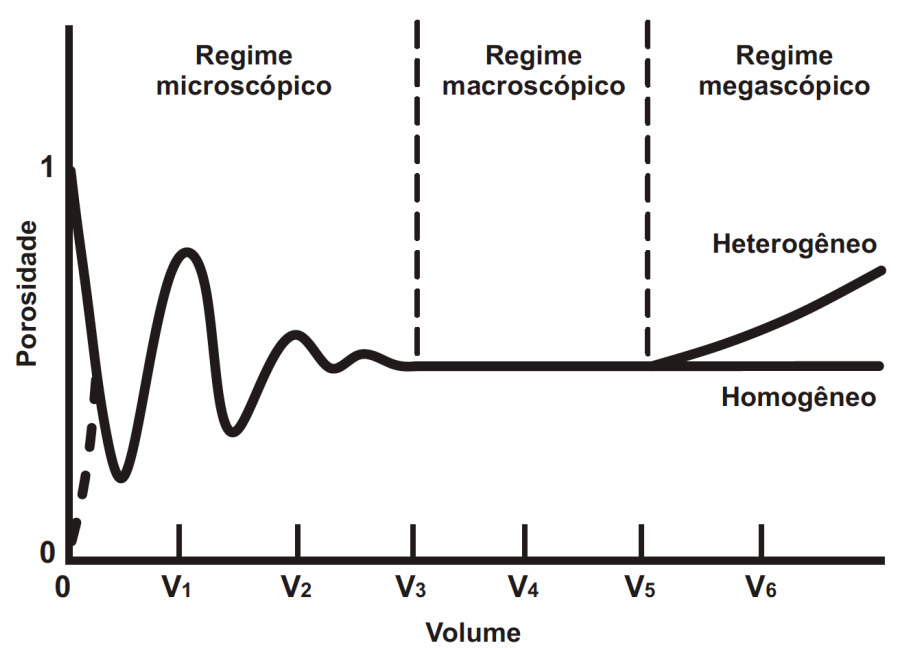

Figura 3.4. Diagrama ilustrando o Volume elementar representativo (adaptado de HUBBERT, 1957 apud DOMENICO; SCHWARTZ, 1990)

Estudos que se encontram no regime megascópico necessitam de dados representativos dessa escala. Conforme sugerido por Domenico e Schwartz (1990), uma solução prática é realizar ensaios para caracterizar o maior volume possível do aquífero. Contudo, isso nem sempre garante que o ensaio se aproxime de um VER em meios muito heterogêneos e complexos. Segundo o autor, para certos tipos de rocha é questionável se existe um volume elementar representativo. Fazendo um adendo a essa questão, Berkowitz (2002) conclui que não apenas a conectividade geométrica da rede de fraturas tem um papel importante no controle de fluxo, mas também a distribuição de condutividades em uma fratura em razão da rugosidade, o que gera uma heterogeneidade nas próprias fraturas.

Um estudo publicado por Sauter (1991) demonstra o efeito da escala nos diferentes valores obtidos para parâmetros hidráulicos de um aquífero cárstico (Figura 3.5). O autor observou uma variabilidade de até seis ordens de magnitude no valor da condutividade hidráulica. Em geral, quanto maior o volume de aquífero ensaiado, maior o valor da transmissividade, embora em alguns casos uma barreira hidráulica ou zona impermeável possa ser encontrada. Esse fenômeno de escala faz com que ensaios de bombeamento produzam 
valores de maior magnitude quando comparados com ensaios tipo pulso. Por isso, definir a escala de trabalho de acordo com os objetivos do projeto é essencial. Domenico e Schwartz (1990) fazem considerações em seu livro sobre a escolha da escala de trabalho e seu impacto nos métodos de caracterização.

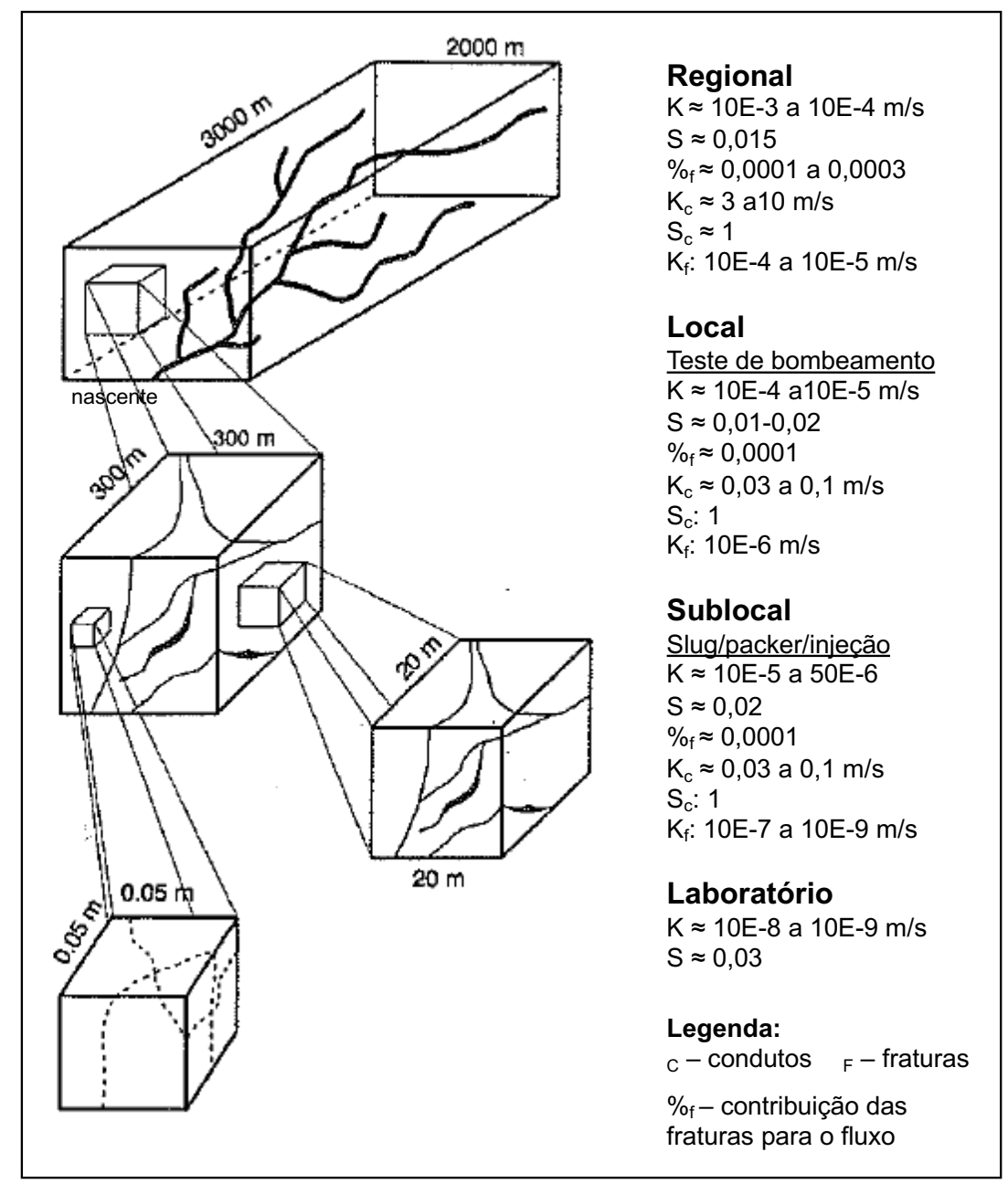

Figura 3.5. Efeito da escala na obtenção dos parâmetros hidráulicos em campo

\subsection{Métodos de investigação de meios fraturados}

Atualmente muitos autores discutem abordagens e técnicas para o estudo de aquíferos fraturados. A maior parte dos trabalhos encontrados foram motivados por estudos de casos de contaminação da água subterrânea. Neste item, serão apresentados os principais aspectos das abordagens identificadas na literatura que focam na caracterização de aquíferos fraturados e serviram de referencia para este trabalho, organizadas por ordem de importância.

Foram selecionadas quatro metodologias, três desenvolvidas para o estudo da contaminação em aquíferos fraturados (FIACCO; DALY; DROBINSKI, 2004; GOLDER, 
2010; PARKER; CHERRY; CHAPMAN, 2012) e apenas uma conta com um viés mais hidrogeológico (COOK, 2003). O principal tipo de contaminação pesquisada por estes autores são os solventes clorados, por estarem presentes em muitos casos de contaminação, serem mais densos do que a água e apresentarem elevada toxicidade. A seguir são apresentadas, de maneira sucinta, cada uma delas.

As quatro abordagens se assemelham em muitos aspectos, embora algumas características sejam incisivas em algumas delas. A título de ilustração, é possível citar o enfoque no uso de dados químicos de testemunho e a escala de trabalho em alta resolução por Parker et al. (2012); abordagem mais regional para entender a relação hidráulica entre água superficial e o aquífero em Cook (2003), e o planejamento mais compartimentado em etapas de Fiacco et al. (2004) e Golder (2010), se aproximando mais das práticas do serviço de consultoria. Uma característica marcante a todas, exceto em Fiacco et al. (2004), é o planejamento de toda a investigação para alimentar modelos matemáticos.

\subsubsection{Discrete Fracture Network (DFN)}

A metodologia denominada Discrete Fracture Network (DFN) foi apresentada por Parker et al. (2012) e tem como principal característica e que a difere das outras abordagens, a recuperação e amostragem de testemunhos para quantificação da contaminação, além de uma escala de trabalho de detalhe em alta resolução. Apesar de ter sido desenvolvida para aplicação em rochas sedimentares (porosidade da matriz de 2-20\%), pode ser aplicada a qualquer tipo de rocha. A DFN combina técnicas geofísicas, ensaios hidráulicos discretos e instalação de poços multiníveis para a calibração de modelos numéricos (e.g. SUDICKY; MCLAREN, 1992; THERRIEN; SUDICKY, 1996). Esses modelos são utilizados como ferramenta para a elaboração do modelo conceitual, que por sua vez serve de base para a tomada de decisão no processo de gerenciamento da área contaminada. Dois tipos de modelagens são realizados: estática e dinâmica; a primeira, para representar a geologia e auxiliar na delineação de unidades hidrogeológicas; a segunda, para simular o fluxo da água e transporte de contaminantes. A modelagem é pensada logo no início do projeto, para "organizar o pensamento" e "orientar a coleta de dados" (BREDEHOEFT, 2010). 


\subsubsection{Fractured Bedrock Toolbox (FBT)}

A abordagem denominada Fractured Bedrock Toolbox (FBT) tem como principal característica sua versatilidade, por contar com uma equipe multidisciplinar para a aplicação de inúmeras técnicas e ferramentas sequenciais aplicadas ao estudo de contaminação (FIACCO; DALY; DROBINSKI, 2004). Sua abordagem é dividida em duas etapas. A primeira compreende as atividades não intrusivas, como levantamento de dados em bibliografia, inspeções na área (inclusive mapeamento de fraturas em aforamentos) e investigações geofísicas de superfície. Já a segunda trata das atividades intrusivas que tem como finalidade comprovar o modelo conceitual preliminar do site, estabelecido na etapa anterior. Ademais, nesta segunda etapa, são realizadas as perfurações, perfilagens geofísicas de poço, ensaios hidráulicos, monitoramento de cargas hidráulicas e amostragem de água.

\subsubsection{Fractured Bedrock Field Methods and Analytical Tools}

O Fractured Bedrock Field Methods and Analytical Tools é uma abordagem iterativa, por conta da própria dinâmica de construção, validação e reformulação do modelo conceitual, pela combinação das diversas técnicas de geologia, hidrologia, geofísica e geoquímica para dar suporte à caracterização da área de estudo (GOLDER, 2010). Se assemelha bastante à FBT, embora seja organizada em quatro etapas: etapa de escritório, caracterização de superfície, caracterização em poço único e caracterização em poços múltiplos.

A etapa de escritório compreende o levantamento de dados existentes para planejar a etapa de estudos de superfície que, por sua vez, compreende o mapeamento de feições estruturais em afloramentos, imagens aéreas e mapeamento geofísico de superfície. A etapa intrusiva é feita sempre perfurando-se um poço na rocha e realizando, preferencialmente, perfilagens, ensaios hidráulicos e amostragem de água. A cada novo poço instalado é operada a quarta etapa deste método, que consiste na realização de campanhas de monitoramento e ensaios hidráulicos entre poços. Ao final de cada atividade, o modelo conceitual é atualizado e planejada a próxima etapa. 


\subsubsection{Guia para a caracterização regional do fluxo da água em aquíferos fraturados}

Em seu guia para a caracterização regional do fluxo da água em aquíferos fraturados, Cook (2003) organiza esta tarefa em quatro grandes grupos sequenciais: caracterização geológica; caracterização hidráulica; fluxo da água (recarga e descarga do aquífero), e modelagem matemática.

A primeira etapa consiste basicamente no levantamento de dados estruturais em imagens aéreas, afloramentos e perfurações. A segunda compreende ensaios hidráulicos variados (e.g. bombeamento com e sem obturadores, medidores de vazão e ensaios com traçadores). A terceira foca em técnicas de datação, assinatura hidroquímica e estudo de balanço hídrico. Por fim, a quarta etapa consolida todos os dados gerados em um modelo matemático.

\subsection{Técnicas geofísicas de poços para a investigação de aquíferos fraturados}

Neste trabalho são consideradas técnicas geofísicas de poços todas aquelas que fazem uso do sistema de aquisição de dados próprios para esta finalidade (data logger, cabo e guincho para geofísica), que para KEYS (1990) é a ciência de registrar e analisar medições contínuas ou pontuais de propriedades físicas em poços ou furos. A câmera de filmagem também foi incluída nesta classe embora tenha um sistema próprio.

As ferramentas geofísicas para poços são elementos fundamentais na investigação de aquíferos fraturados, uma vez que podem fornecer informações detalhadas da rocha, do poço, das fraturas e da dinâmica hidráulica, com elevado custo benefício e de forma rápida e prática (MALIVA, 2016). Sua aplicação se dá, em geral, em poços abertos, eis que muitas sondas não funcionam em trechos revestidos (COLLIER, 1993). Dentre as características que tornam as perfilagens geofísicas ferramentas indispensáveis para estudos em subsuperfície destacam-se a agilidade na coleta de dados e visualização dos dados em tempo real. Além de permitir a tomada de decisão em campo sobre o andamento de outros trabalhos que dependem dos dados gerados, eventuais problemas com a perfilagem podem ser identificados instantaneamente e o trabalho refeito na mesma mobilização.

Para garantir a qualidade dos dados gerados por equipamentos de geofísica de poço é importante verificar a precisão e acurácia do registro de profundidade, as condições do poço e a velocidade da perfilagem (MALIVA, 2016). Sempre que possível, é interessante comparar e calibrar os dados obtidos pelas sondas com medições diretas em campo (e.g. características 
construtivas do poço, dados de ensaios hidráulicos com obturadores ou ensaios nos testemunhos).

\subsubsection{Cáliper}

O cáliper é composto de braços mecânicos conectados a um potenciômetro, em que a resistência é proporcional à abertura dos braços. Ao ser posicionada no fundo do poço ou profundidade desejada, os braços são abertos por um comando eletrônico e encostam na parede do poço. Conforme a sonda é puxada para cima, a variação no diâmetro é registrada em função da variação na abertura dos braços mecânicos (STERRETT, 2007). Essa variação na resistência é convertida para variação de voltagem, e enviada para o data logger, o qual converte o sinal em unidades de engenharia (MALIVA, 2016).

A perfilagem com o cáliper mecânico (cáliper) permite registrar: a variação no diâmetro do furo/poço; a ocorrência de colapsos ou obstruções; identificar quebras, fissuras, cavidades e fraturas; aspectos construtivos (posição do tubo de revestimento, tubo filtro, profundidade do furo); e correção de outros logs que sejam afetados pela variação no diâmetro. A partir desses dados também é possível tomar decisões como evitar trechos que possam oferecer risco a ferramentas de maior valor ou até a suspensão de outras atividades para o poço, especialmente quando não se dispõe da câmera para uma primeira avaliação do furo.

A versão mais comum dessa sonda, a mesma utilizada neste trabalho, é a de três braços, que mede o diâmetro médio do poço. Existem também cálipers de quatro braços, mais sofisticados, que podem gerar medidas em dois planos e dispor até de magnetômetro para orientação da variação do diâmetro. Todavia, tratam-se de ferramentas que apresentam um custo mais elevado e podem ser substituídas pelo cáliper acústico da sonda acústica (Item 3.3.3).

De acordo com Sterrett (2007), a velocidade de perfilagem com a sonda cáliper pode variar de 3 a $6 \mathrm{~m} / \mathrm{min}$ dependendo da resolução desejada. Esta é uma das sondas com maior probabilidade de ficar presa no furo por ter "braços" que podem travar em cavidades do furo e, portanto, o autor recomenda que seja verificada a condição do poço antes de realizar este tipo de trabalho. Os principais dados que podem ser obtidos com o cáliper de três braços, bem como a resposta no sinal que pode observada, são indicados a seguir:

1. Profundidade do poço: profundidade que a sonda alcança no poço e medida pelo contador acoplado ao guincho. Às vezes, essa sonda pode ficar presa em algum trecho e não chegar até o fundo; 
2. variação média do diâmetro: a variação média no diâmetro ao longo do poço é medida pela abertura dos braços e pode ser resultado da característica da rocha, método de perfuração e diâmetro da broca;

3. presença de feições estruturais (e.g. fraturas e quebras) - quando o cáliper passa por uma fratura, é observada uma resposta de alargamento no diâmetro do poço localizada, que pode ser diferenciada de quebra mecânica cuja resposta consiste em grandes vazios ou diâmetros maiores que a perfuração;

4. posicionamento de tubo de revestimento e filtro: a resposta dos braços às ranhuras do filtro é simétrica a onda de alta frequência e, no tubo de revestimento, a abertura dos braços é constante, gerando uma linha bem suavizada, ambas bem diferentes da resposta na porção de rocha;

5. volume do poço: o perfil de variação do diâmetro pode ser integrado matematicamente para gerar o volume do poço ou trechos do mesmo. Este tipo de informação é muito utilizado para calcular o volume de cimentação em obras de engenharia ou mesmo para o seu tamponamento; e

6. suporte para outras perfilagens: outras ferramentas de perfilagem dependem do diâmetro do poço para calibrar e interpretar suas medidas (e.g. interpretação estrutural com a perfilagem ótica). Nesses casos, o cáliper pode ser de grande utilidade.

\subsubsection{Gama natural}

A sonda de raios gama natural (gama) é a ferramenta de perfilagem de radiação nuclear de maior utilização em estudos de hidrogeologia (KEYS, 1990). Sua aplicação mais comum é a identificação litológica e correlação estratigráfica, principalmente em depósitos sedimentares (MALIVA, 2016; STERRETT, 2007). As radiações gama são emitidas, predominantemente, pelo ${ }^{40} \mathrm{~K},{ }^{238} \mathrm{U}$ e ${ }^{232} \mathrm{Th}$ (isótopos de potássio, tório, urânio e seus subprodutos), bem como seus produtos de decaimento (LANE et al., 2002). A detecção da radiação gama é feita em um cristal cintilante de iodeto de sódio (NaLTI) que emite fótons ao ser atingido pela radiação natural. Os fótons são amplificados e convertidos em pulsos elétricos, que são contados e transmitidos para o data logger. A velocidade recomendada para perfilagem com a sonda gama varia de 3 a 6 
$\mathrm{m} / \mathrm{min}$ e o intervalo de registro dos dados, em geral, é feito entre 15 e $30 \mathrm{~cm}$ (STERRETT, 2007).

Segundo Keys (1990), a intensidade da radiação nas rochas ígneas é maior em rochas silícicas (e.g. granito) do que em rochas básicas (basalto). Dois minerais que emitem bastante radiação nestas rochas são a ortoclase e biotita. Singhal e Gupta (2010) relatam pouca consistência na resposta gama de rochas ígneas e metamórficas, com variações associadas à heterogeneidade mineral e não tanto ao grau de metamorfismo, dificultando a interpretação dos dados. Por outro lado, em depósitos sedimentares os elementos radioativos tendem a acumular em materiais mais finos (e.g. micas, feldspatos e argilominerais) e, portanto, podem ser utilizados para avaliar a estratigrafia desses depósitos com maior precisão (KEYS, 1990; SINGHAL; GUPTA, 2010). Portanto, esta sonda tem aplicação na caracterização estratigráfica de aquíferos fraturados, especialmente se analisada em conjunto com outras técnicas (e.g. condutividade/resistividade, susceptibilidade magnética ou amplitude de sinal acústico).

Para a interpretação dos dados obtidos com a sonda gama natural, três aspectos que podem afetar as leituras devem ser considerados (KEYS, 1990). O primeiro é a redução do sinal causado pelo revestimento do poço. O segundo está relacionado ao material utilizado para a cimentação do revestimento, que pode ter um efeito de diminuir ou aumentar a resposta não associada à matriz. E o terceiro, embora não muito significativo, resulta de grandes variações no diâmetro do furo e na centralização da ferramenta, que podem causar um desvio do sinal, uma vez que a leitura da radiação é inversamente proporcional à distância (MALIVA, 2016).

\subsubsection{Perfilagens de imageamento de poço (câmera de vídeo-inspeção, OTV e ATV)}

As perfilagens de imageamento de poço são amplamente utilizadas em estudos de hidrogeologia e podem fornecer informações úteis a respeito dos dados construtivos do poço e da rocha. Conforme descrito por Maliva (2016), a principal delas é a identificação de estruturas rúpteis, principalmente aquelas que desempenham papel no fluxo de água. Os resultados desse tipo de equipamento são essenciais para o planejamento de outras atividades de investigação e para avaliar se o poço está em condições favoráveis para a realização de outras atividades (e.g. ensaios com obturadores).

As ferramentas utilizadas para imageamento do poço são de dois tipos, aquelas que fazem uso de imagens óticas, câmera de vídeo inspeção e ótica, e de imagens acústicas, que 
fazem uso de pulso ultrassônico para mapear a parede do furo. As características de cada uma destas sondas são apresentadas nos subitens a seguir.

\section{Câmera de vídeo inspeção (câmera)}

A câmera é um equipamento versátil e útil na investigação de aquíferos fraturados, embora tenha uma utilização limitada para a caracterização da rocha. Por não conter sensores de orientação, esta câmera não permite uma interpretação estrutural das feições observadas, no entanto seu custo-benefício é muito atrativo. Os dados gerados são exportados no formato de vídeo com imagem colorida e podem ser convertidos em imagens que ilustram feições que sejam importantes. Em geral, esses equipamentos são compostos por duas câmeras, lateral (com rotação de $360^{\circ}$ ) e frontal, permitindo alternância entre uma e outra. Os dados são gerados em tempo real e sua operação é realizada por um controlador em superfície. De acordo com Maliva (2016), este é o equipamento mais utilizado para o imageamento de poços, devido ao custo baixo e sua versatilidade para o mercado de poços tubulares.

Para que a filmagem obtenha boas imagens, é necessário o uso de centralizador e que a água do poço esteja limpa (NRC, 1996). É importante que os poços sejam desenvolvidos para remover resíduos oriundos da perfuração ou incrustações que possam ter se desenvolvido ao longo do tempo. Os principais aspectos que podem ser observados com a câmera são:

1. dados construtivos do poço: profundidade, extensão e integridade dos tubos de revestimento e filtro; profundidade atual do poço; trechos com maior irregularidade na parede do poço; trechos com risco de queda de rocha;

2. características hidráulicas: profundidade do nível d'água; presença de contaminantes em fase livre ou residual; turbidez da água e presença de sujeira; entradas e saídas de água (percolação na parede acima do NA ou trechos com grande movimentação de água);

3. características da rocha: identificação do tipo de rocha e contato litológico; mineralogia; cor da rocha; intemperismo ou oxidação de trechos do poço; ocorrência de fraturas e quebras mecânicas; bandamentos e xistosidade da rocha; e

4. outros: auxílio para o resgate de equipamentos; comparação e balizamento de outras perfilagens. 


\section{Perfilagem ótica (OTV)}

A perfilagem ótica (Optical Televiewer - OTV) gera imagens coloridas contínuas e em alta resolução da parede do poço, permitindo a caracterização de estruturas planares (e.g. foliações, bandamentos e fraturas) que interceptam o poço, quanto à espessura, mergulho e direção (WILLIAMS; JOHNSON, 2004). Na imagem gerada, as feições que interceptam o poço são visualizadas como sinusóides orientadas no plano 2D. O exemplo da Figura 3.6 demonstra como é feita a interpretação de direção e mergulho das estruturas e feições observadas. A sonda dispõe de três acelerômetros, que permitem quantificar a inclinação do furo (desvio do poço e correção da profundidade), além de um magnetômetro triaxial para orientar a imagem com o norte magnético ou para o lado mais alto, em furos direcionais.

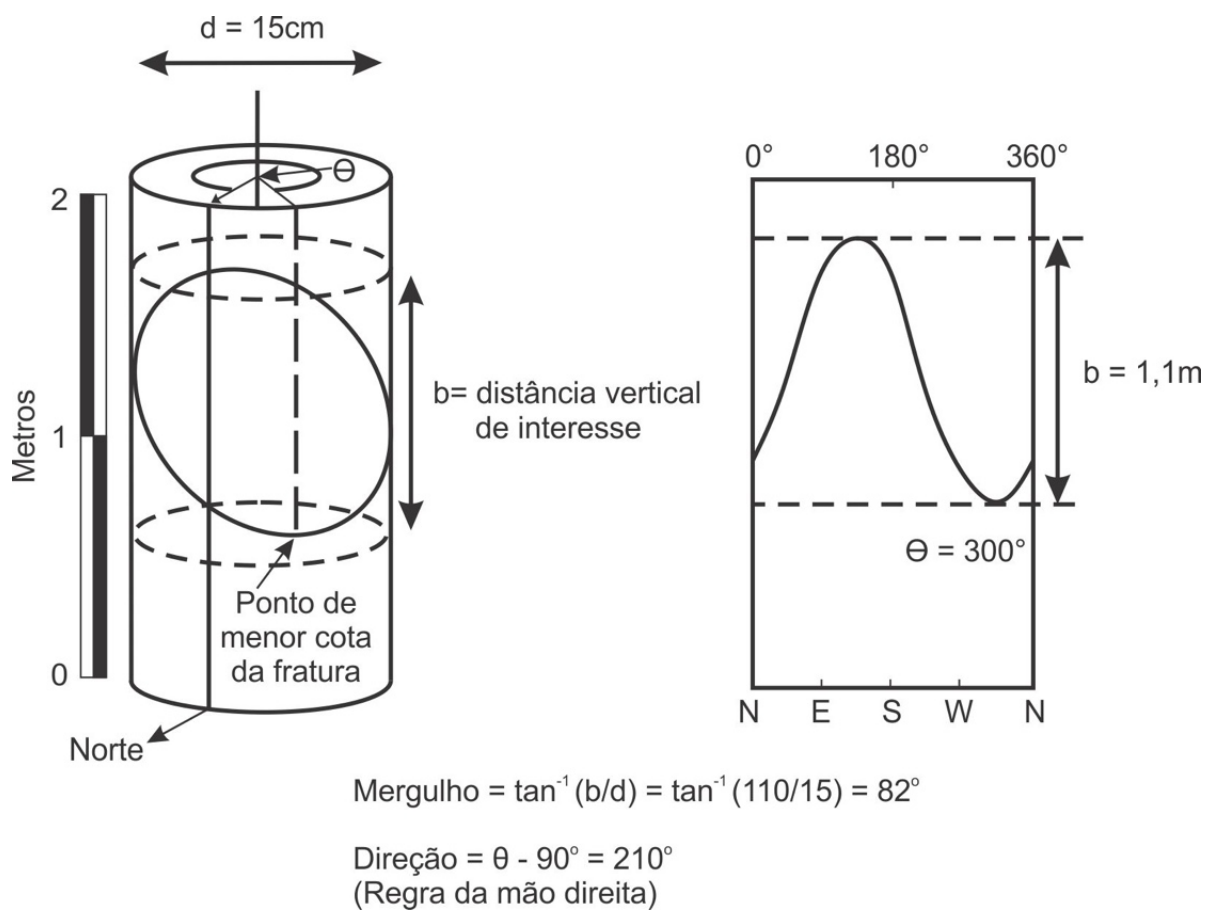

Figura 3.6. Ilustração esquemática de uma fratura que intercepta um furo cilíndrico, indicando como a direção e o mergulho são interpretados a partir das imagens geradas por uma sonda ótica ou acústica (PAILLET; OLLILA, 1994)

O OTV é composto por um anel de LED para iluminar o furo, um refletor hiperbólico e uma câmera registra as imagens. A perfilagem pode ser realizada dentro e fora da água, sendo que a qualidade da imagem depende da turbidez da água, da centralização da ferramenta no furo e incrustação na parede do furo. Os principais resultados que podem ser obtidos com o OTV são os mesmos que a câmera pode fornecer além de imagens contínuas em alta resolução e orientadas, que podem ser utilizadas para caracterizar: 
1. dados construtivos do poço: extensão e integridade dos tubos de revestimento e filtro; trechos com maior irregularidade na parede do poço;

2. características hidráulicas: presença de contaminantes em fase livre ou residual; indícios de percolação de água na parede do furo acima do nível d'água; e

3. características da rocha: identificação do tipo de rocha e contato litológico; mineralogia; cor da rocha; intemperismo ou oxidação de trechos do poço; ocorrência de fraturas, foliação, bandamentos, xistosidade e análise estrutural (abertura aparente, direção e mergulho); e quebras mecânicas.

\section{Perfilagem Acústica (ATV)}

As perfilagens acústicas (acoustic televiewer - ATV) produzem imagens contínuas em alta resolução da parede do poço, por meio da emissão de ondas ultrassônicas de alta frequência e registro do sinal de retorno, amplitude e tempo de trânsito (KEYS, 1990). O pulso ultrassônico é emitido por um transdutor e refletido num ângulo de $90^{\circ}$ por um espelho, que gira em alta velocidade no interior da sonda, de modo a gerar uma imagem contínua em $360^{\circ}$ (SINGHAL; GUPTA, 2010). Assim como no OTV, as feições que interceptam o poço são visualizadas como sinusóides orientadas no plano 2D (Figura 3.6).

O princípio de funcionamento da sonda é ilustrado na Figura 3.7. A sonda dispõe de três acelerômetros, que permitem quantificar a inclinação do furo (desvio do poço e correção da profundidade), além de um magnetômetro triaxial para orientar a imagem para o norte magnético ou para o lado mais alto, em furos direcionais. A sonda precisa estar imersa em fluido para realizar a perfilagem (e.g. água ou lama de perfuração) e pode obter bons resultados em rochas de cor escura, água turva e paredes de poços com revestimento não metálico (WILLIAMS; JOHNSON, 2004). 


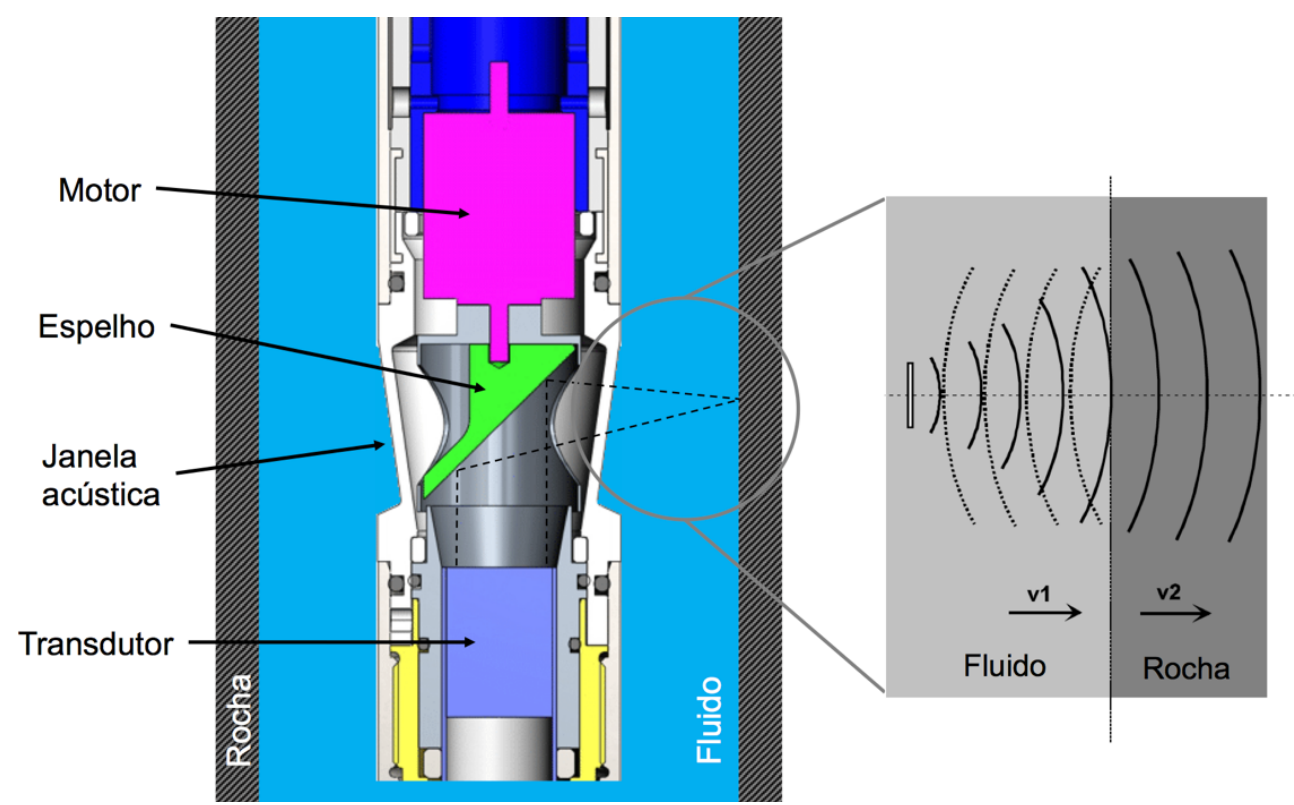

Figura 3.7. Componentes da sonda ATV, à esquerda, e princípio de funcionamento do pulso ultrassônico

A qualidade dos dados gerados pelo ATV é altamente dependente da centralização da ferramenta no furo, da irregularidade da parede, velocidade de perfilagem, velocidade de rotação do espelho, comprimento e frequência da onda ultrassônica (MALIVA, 2016). O tempo de trânsito do sinal é uma função do diâmetro do furo e da densidade do fluido. Portanto, se a densidade é conhecida, é possível obter um cáliper acústico e contínuo do poço. A amplitude do sinal é função da impedância acústica da formação (varia de acordo com a densidade da rocha) e pode dar indícios da porosidade do material. Os principais resultados que podem ser obtidos com a perfilagem acústica são:

1. dados construtivos do poço: inspeção da integridade do revestimento metálico; extensão e integridade dos tubos de revestimento e filtro não metálicos; variação do diâmetro de perfuração; desvio do poço; volume do poço; cáliper 3D; e

2. características da rocha: mudança litológica com base na variação da porosidade; ocorrência de fraturas e análise estrutural (abertura aparente, direção e mergulho); e quebras mecânicas e quebras no plano de menor esforço (breakout).

\subsubsection{Resistividade de dupla indução}

A resistividade é utilizada para a caracterização do meio rochoso, medindo a resistividade elétrica da rocha. A medição curta e longa é realizada gerando dois campos magnéticos de diferentes raios de atuação, penetrando horizontalmente na parede do poço e atingindo duas distâncias diferentes (KEYS, 1990). Essa medição com diferentes alcances é 
importante para identificar alteração das condições originais da rocha gerada pela perfuração. $\mathrm{Na}$ medida de menor alcance pode ser visualizado o efeito de preenchimento de poros por lama de perfuração. A segunda medida, com um maior raio de penetração, serve para confirmar o valor da primeira medida ou indicar que há alteração do meio rochoso. Alterações causadas pela perfuração podem afetar o comportamento hidráulico do poço e mascarar características do aquífero.

Esta sonda pode ser utilizada fora e dentro da água, e em poços sem e com revestimento (metálico ou de PVC) sem o uso de centralizador. Em ambientes de resistividade elevada, essa sonda pode ser substituída pela sonda de indução eletromagnética.

\subsubsection{Perfil de temperatura e condutividade elétrica (FTCR)}

A sonda de perfilagem de temperatura e condutividade elétrica ou resistividade (Fluid Temperature and Conductivity or resistivity - FTCR) é uma sonda que gera um perfil contínuo desses parâmetros. Os dados obtidos com esta ferramenta são representativos da interação das zonas hidraulicamente ativas que são comunicadas por meio do furo aberto. A movimentação da sonda no furo pode causar distúrbio na coluna de água, sendo que quanto maior o diâmetro da sonda e a velocidade de descida, maior o distúrbio. Em condições de ausência de fluxo, a resposta do perfil de temperatura tem progressão gradativa de aproximadamente $0,2{ }^{\circ} \mathrm{C}$ a cada $10 \mathrm{~m}$ devido ao gradiente geotérmico (KEYS, 1990).

Geralmente são realizados ensaios com fluxo ambiente e induzido (injeção ou bombeamento), a comparação desses resultados pode ser utilizada para inferir as principais entradas de água no furo (KEYS, 1990). Mudanças abruptas na temperatura e/ou condutividade são indicativos de zonas de fluxo. Em alguns casos, pode ser utilizado um traçador (e.g. sal ou água destilada) para avaliar a dinâmica hidráulica.

Avanços recentes na sensibilidade de sensores de temperatura permitiram $o$ desenvolvimento de técnicas de perfilagem de alta resolução em poços revestidos, por tecidos impermeáveis, para avaliar a ocorrência de fraturas hidraulicamente ativas (PEHME et al., 2014, 2010, 2013). Esses estudos indicam que a detecção das fraturas hidraulicamente ativas é subestimada em poços abertos. Entretanto, essa técnica ainda está em processo de desenvolvimento e não se encontra disponível comercialmente. 


\subsubsection{Avaliação de fluxo com medidores tipo flowmeters}

A utilização de sondas de caracterização de fluxo em poços (flowmeters) é uma forma relativamente rápida e barata para obter parâmetros hidráulicos de campo (Hess, 1986; Molz et al., 1994). A partir de ensaios em condições de fluxo ambiente e induzido, pode-se identificar as zonas mais transmissivas, a direção de fluxo no furo aberto e a distribuição de cargas hidráulicas das principais zonas identificadas. Os três tipos de flowmeters utilizados nesse trabalho são: de pulso de calor (heat pulse flowmeter - HPF), eletromagnético (electromagnetic flowmeter - EMF), e de hélice (spin flowmeter - SF). Todos são aplicados no mapeamento de zonas de fluxo axiais com relação ao furo.

O HPF utiliza um pulso de calor, gerado em uma resistência, como traçador para determinar o fluxo em um intervalo (HESS, 1986). A sonda é composta por um par de termistores localizados equidistantes, acima e abaixo, da resistência (Figura 3.8). Quando o pulso é detectado no termistor superior, o fluxo é ascendente; e descendente caso contrário. $\mathrm{O}$ HPF trabalha em uma faixa de vazão de 0,2 a 8 1/min (HESS; PAILLET, 1990) e pode ser utilizado para mapear condições de fluxo natural ou induzido (bombeamento). Existem muitos estudos documentando o uso do HPF para a caracterização hidráulica de aquíferos fraturados (e.g. BUSSE et al., 2016; JOHNSON et al., 2016; PAILLET, 2001; PAILLET; CROWDER, 1996; PAILLET; OLLILA, 1994; ROBINSON et al., 2016; WILSON et al., 2001).

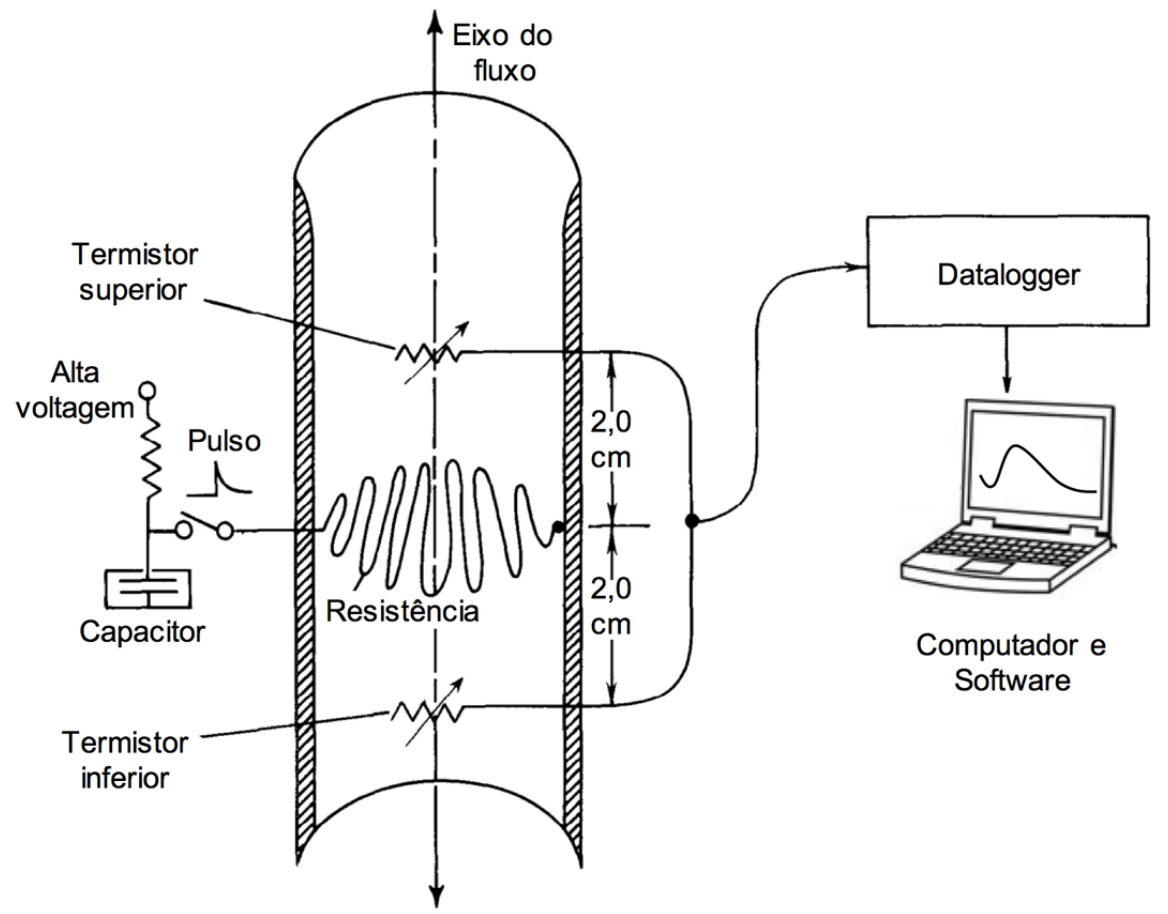

Figura 3.8. Princípio de funcionamento da sonda HPF (adaptado de HESS, 1986 apud KEYS, 1990) 
A resposta do HPF é obtida em velocidade e convertida em vazão. O cálculo da vazão resulta da multiplicação da seção interna da sonda pela velocidade de deslocamento do pulso. Para que os dados sejam representativos do fluxo real que atravessa a seção do furo, é importante que a sonda esteja centralizada no furo e todo o fluxo seja direcionado para sua seção interna. Para isto, devem ser utilizados centralizadores e diverters ou obturadores acoplados à sonda (BUSSE et al., 2016; PAILLET, 2004; PAILLET; OLLILA, 1994), ou ajustado um fator de correção para a vazão que passa por fora da sonda, quando não utilizado um acessório que direcione todo o fluxo para a parte a sua parte interna. Paillet (2004) descreve algumas medidas, preventivas e corretivas, para garantir a qualidade dos dados obtidos em poços com muita irregularidade e diâmetros grandes.

O EMF foi desenvolvido por Tennessee Valley Authority em 1989 (YOUNG AND PERSON, 1995), e mede a velocidade da água com base no princípio da Lei de Indução de Faraday. Esse tipo de sonda pode realizar a coleta de dados pontuais (medidas estacionárias) e dinâmicas (com a sonda em velocidade constante), numa faixa de $0,1 \mathrm{~m} / \mathrm{min}$ a $82 \mathrm{~m} / \mathrm{min}$ (NEWHOUSE, IZBICKI \& SMITH, 2004).

O EMF possui um eletroímã e dois eletrodos localizados a $180^{\circ}$ entre si, formando um campo magnético perpendicular $\left(90^{\circ}\right)$ dentro de um cilindro oco, por onde a água passa (Figura 3.9). Segundo a Lei de Indução de Faraday, a tensão induzida gerada por um condutor (água do poço) que se move em ângulos retos através do campo magnético é diretamente proporcional à velocidade desse condutor (velocidade da água que atravessa o campo). A utilização de um diverter faz com que, idealmente, toda a água passe através do cilindro oco que integra a ferramenta, e, conhecido o diâmetro desse cilindro, é possível calcular a vazão do fluxo de água (PAILLET; REESE, 2000).

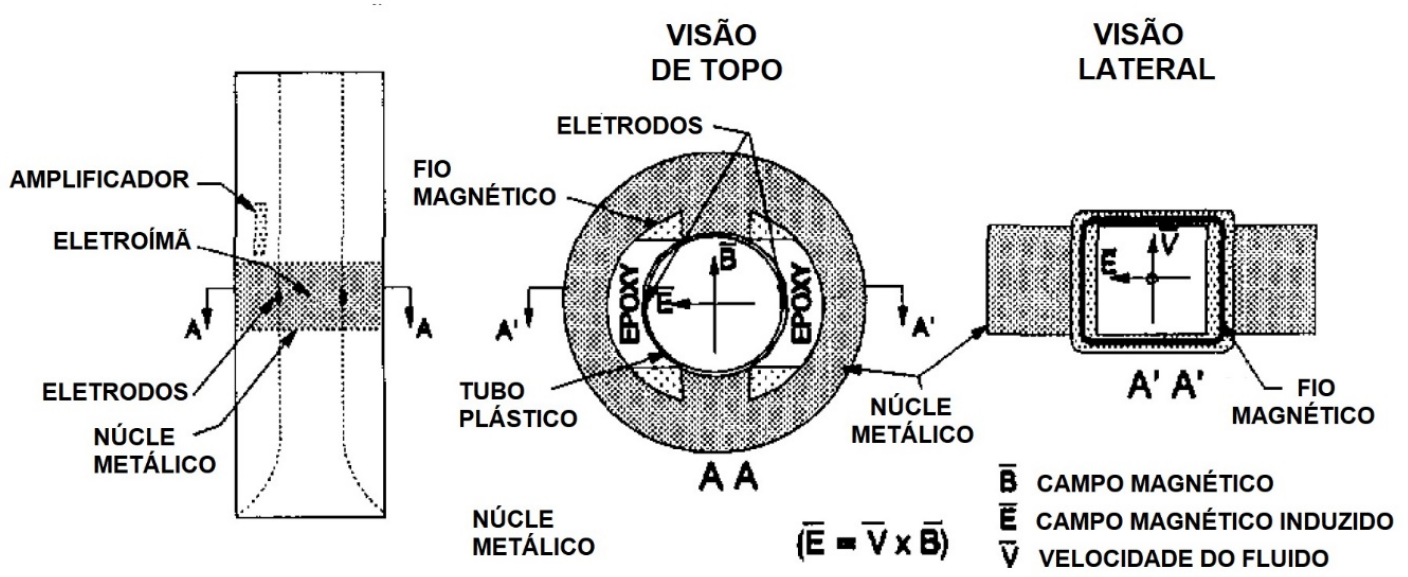

Figura 3.9. Princípio de funcionamento da sonda EMF (YOUNG \& PEARSON, 1995) 
O SF (Figura 3.10) foi desenvolvido pela indústria do petróleo, na qual fluxos altos (>100 1/min) são comuns. Essa sonda mede a velocidade da água por meio da rotação de uma hélice ou rotor. Este tipo de sonda não utiliza diverter, e não precisa de centralização no furo, embora e essa última seja uma prática adequada. A sua faixa de atuação vai de 10 a 750 1/min e apresenta baixa resolução. Seu uso pode ser em condições estáticas (pontuais) ou dinâmicas, idealmente com movimentação ascendente no furo, garantindo velocidade constante de deslocamento.

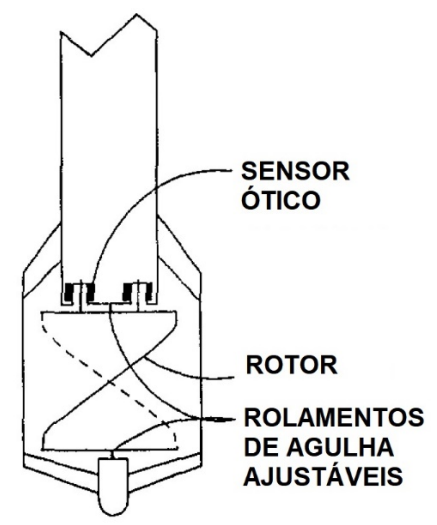

Figura 3.10. Princípio de funcionamento da sonda SF (YOUNG \& PEARSON, 1995)

A evolução dos softwares de modelagem e análise de dados tem expandido as capacidades das técnicas de flowmeters. O Serviço Geológico Americano (United States Geological Survey - USGS) disponibiliza em seu site um programa para analisar os dados de ensaios com flowmeters, denominado "Flow-Log Analysis of Single Holes" (FLASH). DayLewis et al. (2011) elaboraram esse programa a partir das formulações desenvolvidas por Paillet (1998), que é executado por meio de uma planilha Microsoft Excel, via programação em Visual Basic for Applications (VBA) para fazer a simulação de fluxo. A simulação utiliza nos cálculos duas condições de fluxo para comparação, geralmente ambiente e induzido (bombeamento ou injeção).

O uso da ferramenta FLASH possibilita estimar parâmetros como transmissividade ou raio de influência do poço, e transmissividade e carga hidráulica das zonas de fluxo interpretadas. O código se baseia em uma solução analítica para fluxo radial em estado estacionário para múltiplas camadas desenvolvida por Paillet (1998) (Equação 3.10 e Equação $3.11)$. 


$$
\begin{aligned}
& Q_{i}^{a}=-\frac{2 \pi T_{i}^{\text {fator }} T^{\text {total }}\left(h_{w}^{a}-h_{i}^{0}\right)}{\ln \left(\frac{r_{0}}{r_{w}}\right)} \\
& Q_{i}^{S}=-\frac{2 \pi T_{i}^{\text {fator }} T^{\text {total }}\left(h_{w}^{S}-h_{i}^{0}\right)}{\ln \left(\frac{r_{0}}{r_{w}}\right)}
\end{aligned}
$$

Equação 3.11

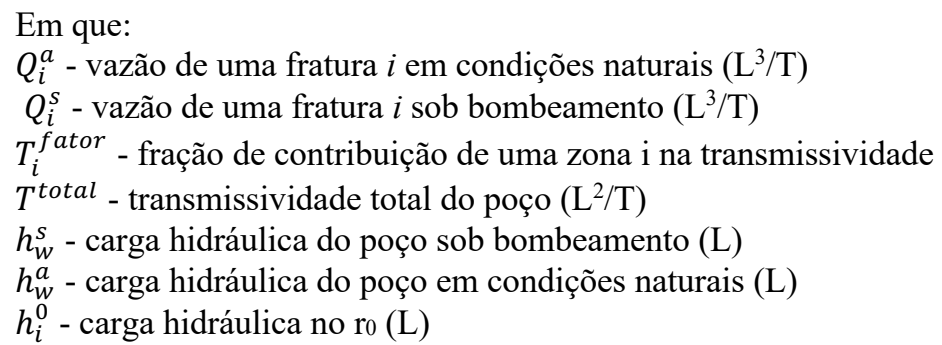

\subsection{Ensaios hidráulicos com obturadores}

Para este trabalho, obturadores são equipamentos utilizados em estudos hidrogeológicos e ambientais para isolar intervalos de interesse (referidos muitas vezes como intervalos discretos nesta pesquisa) em perfurações e poços tubulares, e coletar dados hidráulicos, físicos e químicos. Quando inflado, o obturador forma um selo contra a parede do furo/poço, formando um isolamento hidráulico e dividindo o poço em níveis (três quando inflado um par de obturadores e dois quando inflado apenas um obturador). Os dados hidráulicos que podem ser obtidos com obturadores são carga hidráulica (dos três níveis), transmissividade, armazenamento e características físico-químicas da água em trechos discretos do furo/poço. Também podem ser obtidos dados de qualidade da água por meio da coleta de amostras para análise em laboratório.

Ensaios de permeabilidade com obturadores, para determinar a abertura efetiva das fraturas, datam de 1966 (Snow, 1965). Louis e Pernot (1972) construíram um sistema de ensaios de injeção com obturadores para quantificar a permeabilidade de fraturas em um repositório de resíduos nucleares. Também a serviço da indústria nuclear, Gale e Witherspon (1979) criaram uma abordagem para a caracterização hidráulica de maciços rochosos, cujos ensaios foram aprimorados de Louis e Pernot (1972). Desde então, muitos autores descrevem melhorias em equipamentos e configurações para utilização de obturadores em investigações hidrogeológicas 
e de contaminação em meios fraturados (HOLLOWAY; WADDELL, 2008; NOVAKOWSKI et al., 2006; QUINN; CHERRY; PARKER, 2012; SHAPIRO, 2001).

No Brasil, o uso de obturadores aplicados à hidrogeologia e contaminação é incipiente. Foram encontrados apenas três trabalhos que fizeram uso destas técnicas (FANTI et al., 2017; L'APICCIRELLA, 2009; TRESSOLDI, 1991; WAHNFRIED, 2010). A maior parte do material disponível é da área de mineração e geologia de engenharia, que utilizam uma abordagem menos detalhada e de menor precisão, quando comparada aos estudos apresentados no início deste item.

Wahnfried (2010) foi um dos pioneiros na realização de ensaios hidráulicos com obturadores, em um estudo sobre a drenança entre o aquífero fraturado Serra Geral e o Sistema aquífero Guarani. O autor utilizou um conjunto de obturadores para realizar ensaios de bombeamento e coleta de amostras discretas. Desde então, poucos foram os trabalhos que utilizaram obturadores (FANTI et al., 2017; L'APICCIRELLA, 2009). Em ambos casos, o método de trabalho e a configuração dos equipamentos não obteve dados em alta resolução e representativos, como nos estudos apresentados por pares internacionais (e.g. LANE et al., 2002; MULDOON; BRADBURY, 2005; QUINN; CHERRY; PARKER, 2016).

Quando comparados os estudos nacionais e internacionais fica claro que há uma considerável lacuna tecnológica e prática entre eles. Isto evidencia a necessidade de incorporação aos estudos nacionais o conhecimento já desenvolvido no exterior.

O uso de obturadores em estudos de hidrogeologia e contaminação é amplamente difundido na América do Norte e Europa, em instituições governamentais, de pesquisa e prestadores de serviço. Quando manuseados adequadamente, geram dados quantitativos e representativos das propriedades hidráulicas do aquífero, como: transmissividade da matriz e da fratura, abertura hidráulica da fratura, conectividade, armazenamento, potencial hidráulico (carga hidráulica) e velocidade de fluxo da água subterrânea (RECLAMATION BUREAU, 2001).

Configurações e métodos variados foram desenvolvidos, por diferentes autores, para obter parâmetros hidráulicos de aquíferos fraturados em diferentes escalas e resolução. A técnica mais adequada varia em função dos objetivos e do escopo do trabalho. Quinn et al. (2012) resumem quatro dos principais ensaios com obturadores realizados por muitos autores (Figura 3.11), também utilizados nesta pesquisa e descritos a seguir: 


\begin{tabular}{|c|c|c|c|c|c|}
\hline Ensaio & $\begin{array}{l}\text { Resultado } \\
\text { típico do } \\
\text { ensaio }\end{array}$ & $\begin{array}{l}\text { Método de } \\
\text { interpretação }\end{array}$ & $\begin{array}{l}\text { Análise dos } \\
\text { resultados }\end{array}$ & $\begin{array}{l}\text { Carga e } \\
\text { fluxo }\end{array}$ & Vantagem \\
\hline $\begin{array}{c}\text { Carga } \\
\text { constante }\end{array}$ & $\underset{\text { Time }}{\longrightarrow}$ & $\begin{array}{c}\text { Thiem } \\
T=\frac{Q}{2 \pi \Delta H} \ln \left(\frac{r_{o}}{r_{w}}\right)\end{array}$ & $\mathrm{dH}$ & $\begin{array}{l}\text { Carga e fluxo } \\
\text { constante para } \\
\text { cada estágio }\end{array}$ & $\begin{array}{l}\text { Valida a lei } \\
\text { de Darcy }\end{array}$ \\
\hline $\begin{array}{c}\text { Slug/bail } \\
\text { instantâneo }\end{array}$ & $\underset{\text { Tempo }}{\text { Bail }}$ & $\begin{array}{l}\text { Hvorslev fluxo radial } \\
T=\frac{m\left(A_{x s}\right)}{2 \pi} \ln \left(\frac{r_{o}}{r_{w}}\right)\end{array}$ & $\ln \left(\frac{\Delta t}{\Delta t}\right)$ & $\begin{array}{c}\text { Carga e } \\
\text { fluxo variam }\end{array}$ & $\begin{array}{l}\text { Ensaio } \\
\text { rápido }\end{array}$ \\
\hline $\begin{array}{l}\text { Bombeamento } \\
\text { com vazão } \\
\text { constante }\end{array}$ & Tempo & $\begin{array}{l}\text { Cooper-Jacob } \\
T=\frac{2.3 Q}{4 \pi \Delta s}\end{array}$ & Log tempo & $\begin{array}{l}\text { Carga variada } \\
\text { e fluxo } \\
\text { constante }\end{array}$ & $\begin{array}{l}\text { Investiga } \\
\text { grandes } \\
\text { volumes }\end{array}$ \\
\hline $\begin{array}{l}\text { Recuperação } \\
\text { após } \\
\text { bombeamento }\end{array}$ & Tempo & $\begin{array}{c}\text { Recuperação de } \\
\text { Theis } \\
T=\frac{2.3 Q}{4 \pi \Delta s^{\prime}}\end{array}$ & $\log t / t^{\prime}$ & $\begin{array}{c}\text { Carga e } \\
\text { fluxo variam }\end{array}$ & $\begin{array}{l}\text { Investiga } \\
\text { grandes } \\
\text { volumes }\end{array}$ \\
\hline \multicolumn{2}{|c|}{$\begin{array}{l}\mathrm{T}-\text { transmissividade } \\
\mathrm{Q}-\text { vazão } \\
\mathrm{r}_{\mathrm{w}}-\text { raio do poço } \\
\mathrm{r}_{0}-\text { raio de influência }\end{array}$} & \multicolumn{2}{|c|}{$\begin{array}{l}S \text { - rebaixamento } \\
S^{\prime} \text { - rebaixamento residual } \\
A_{\mathrm{xs}}-\text { área da seção do poço } \\
\quad \text { temporário }\end{array}$} & \multicolumn{2}{|c|}{$\begin{array}{l}\mathrm{dH}-\text { carga aplicada } \\
\triangle \mathrm{H}_{0}-\text { carga inicial aplicada } \\
\triangle \mathrm{H} \text { - carga no tempo } \mathrm{t} \\
\mathrm{m} \text { - inclinação da reta }\end{array}$} \\
\hline
\end{tabular}

Figura 3.11. Ensaios hidráulicos realizados com obturadores (QUINN; CHERRY; PARKER, 2012)

\section{Carga constante}

Injeção de água com diferentes vazões, mantidas constantes, até que seja alcançada a estabilização da carga hidráulica. Quantifica a transmissividade do intervalo num raio de influência local e permite distinguir a transição entre fluxo linear e não linear (HOLLOWAY; WADDELL, 2008; QUINN; PARKER; CHERRY, 2011; VAN DER KAMP, 2001). A solução analítica utilizada para a interpretação deste tipo de ensaio é Thiem (THIEM, 1906 apud FETTER, 2001).

\section{Ensaio de pulso (slug e bail)}

Ensaios análogos que consistem na alteração instantânea da carga hidráulica no intervalado isolado, para obter a transmissividade. Este distúrbio pode ser causado por um tarugo, injeção de água, rebaixamento (bail) ou elevação (slug) da coluna de água. São ensaios de raio de influência local (alguns metros), de curta duração (em geral, menos de uma hora) e que não geram efluentes (HOLLOWAY; WADDELL, 2008; QUINN; CHERRY; PARKER, 
2012; VAN DER KAMP, 2001). A interpretação dos ensaios de pulso utilizou Hvorslev (HVORSLEV, 1951).

\section{Injeção e bombeamento}

Ensaios análogos cujo bombeamento ou injeção de água é feito com vazão constante, e a carga hidráulica monitorada no próprio poço ou, quando disponível, em poços de observação (BECKER; FISHER, 2008; HOLLOWAY; WADDELL, 2008; QUINN; CHERRY; PARKER, 2012; WAHNFRIED, 2010). Determina a transmissividade (curta duração, poucas horas) e o armazenamento (longa duração, acima de 24 horas). O raio de influência pode alcançar centenas de metros. A interpretação do ensaio de bombeamento utiliza Cooper-Jacob e a recuperação aplicando Theis (FETTER, 2001). 


\section{MATERIAIS E MÉTODOS}

Para responder as questões centrais estabelecidas no objetivo, foi adotado um método de trabalho que se desenvolve em dois sentidos, um de desenvolvimento e aperfeiçoamento de equipamento e técnicas, e outro de aplicação das técnicas já consagradas. O desenvolvimento se deu tanto no campo de construção e aprimoramento de equipamentos como no aperfeiçoamento de técnicas de processamento e interpretação de dados por meio de programação. Com relação à aplicação das técnicas consagradas, o caminho percorrido teve início com a aquisição dos equipamentos (e.g. sondas geofísicas), coleta de dados em campo em situações diversas (características construtivas dos poços e hidrogeológicas), processamento e interpretação dos dados. Portanto, o método de trabalho também foi parte central do desenvolvimento desta pesquisa. A seguir são detalhados cada um dos materiais e métodos utilizados nesta pesquisa.

Este capítulo foi organizado com base na sequência de trabalho para a caracterização de aquíferos fraturados utilizando poços tubulares. A primeira parte se dedica às técnicas de perfilagem geofísica de poços, e a segunda ao uso de obturadores para a realização de ensaios hidráulicos e amostragem de água subterrânea.

\subsection{Perfilagem geofísica}

Foram utilizadas dez técnicas geofísicas de quatro fabricantes (Tabela 4.1). As especificações dos equipamentos, configurações e técnicas de aplicação, processamento e interpretação são descritos em detalhe neste item. Todas as atividades de coleta de dados em campo nesta pesquisa tiveram como referência a cota da boca do poço (elevação com relação a um datum ou uma cota relativa).

O processamento e a interpretação dos dados foram realizados no software WellCad, que também é uma ferramenta de organização e visualização integrada de dados. Os procedimentos realizados no WellCad foram concentrados e descritos em um item à parte (4.1.10), de modo a facilitar a sua organização e apresentação. No entanto, cabe ressaltar que o processamento dos dados é realizado, geralmente, logo após uma ou um conjunto de atividades geofísicas, especialmente nos casos em que o planejamento da atividade seguinte depende dos dados gerados na anterior. 
Tabela 4.1. Técnicas geofísicas e fornecedores utilizados

\begin{tabular}{|c|c|c|c|}
\hline $\begin{array}{c}\text { Técnica geofísica (nome } \\
\text { em inglês) }\end{array}$ & $\begin{array}{c}\text { Abreviação/ } \\
\text { nome utilizado } \\
\text { neste trabalho }\end{array}$ & Fabricante & $\begin{array}{l}\text { Preço } \\
\text { aproximado } \\
\text { (USD)* }\end{array}$ \\
\hline $\begin{array}{l}\text { Câmera de vídeo- } \\
\text { inspeção R-cam 1300XS }\end{array}$ & Câmera & $\begin{array}{l}\text { Laval Underground } \\
\text { Surveys }\end{array}$ & $16.000,00$ \\
\hline $\begin{array}{l}\text { Cáliper mecânico de três } \\
\text { braços ( } 3 \text { arm caliper) }\end{array}$ & Cáliper & $\begin{array}{l}\text { Mount Sopris Instruments } \\
\text { Robertson Geologging }\end{array}$ & $8.000,00$ \\
\hline $\begin{array}{l}\text { Gama natural (natural } \\
\text { gamma) }\end{array}$ & Gama & $\begin{array}{l}\text { Mount Sopris Instruments } \\
\text { Robertson Geologging }\end{array}$ & $6.500,00$ \\
\hline $\begin{array}{l}\text { Resistividade de dupla } \\
\text { indução (dual induction } \\
\text { normal resistivity) }\end{array}$ & Resistividade & Mount Sopris Instruments & - \\
\hline $\begin{array}{l}\text { Televisionamento ótico } \\
\text { (optical televiewer) }\end{array}$ & OTV & $\begin{array}{l}\text { Mount Sopris Instruments } \\
\text { Robertson Geologging }\end{array}$ & $30.000,00$ \\
\hline $\begin{array}{l}\text { Televisionamento } \\
\text { acústico (acoustic } \\
\text { televiewer) }\end{array}$ & ATV & $\begin{array}{l}\text { Mount Sopris Instruments } \\
\text { Robertson Geologging }\end{array}$ & $\begin{array}{c}34.000,00 \mathrm{a} \\
36.000,00\end{array}$ \\
\hline $\begin{array}{l}\text { Temperatura e } \\
\text { condutividade elétrica do } \\
\text { fluido (fluid temperature } \\
\text { and conductivity) }\end{array}$ & FTC & Mount Sopris Instruments & $6.000,00$ \\
\hline $\begin{array}{l}\text { Flowmeter de pulso de } \\
\text { calor (heat pulse } \\
\text { flowmeter) }\end{array}$ & HPF & $\begin{array}{l}\text { Mount Sopris Instruments } \\
\text { Robertson Geologging }\end{array}$ & $\begin{array}{l}7.000,00 \mathrm{a} \\
12.000,00\end{array}$ \\
\hline $\begin{array}{l}\text { Flowmeter } \\
\text { eletromagnético }{ }^{1} \\
\text { (Electromagnetic } \\
\text { flowmeter) }\end{array}$ & EMF & Century Geophysical & - \\
\hline $\begin{array}{l}\text { Flowmeter de turbina } \\
\text { (spin flowmeter) }\end{array}$ & SF & Mount Sopris Instruments & $7.500,00$ \\
\hline
\end{tabular}

* valor Ex Works sem levar em conta os impostos para importação, pesquisa realizada entre 2017 e 2019

\subsubsection{Filmagem com câmera}

A filmagem do poço com a câmera geralmente é a primeira atividade realizada. A câmera verifica os aspectos construtivos de poços (posição do tubo, filtro e profundidade da perfuração), a integridade do tubo de revestimento e da perfuração, além de contribuir para a observação de feições estruturais ${ }^{2}$, geológicas ${ }^{3}$ e hidráulicas ${ }^{4}$.

\footnotetext{
${ }^{1} \mathrm{O}$ EMF possui sensores de temperatura e resistividade elétrica de fluido integrados

${ }^{2}$ Ocorrência de fraturas, dobras, foliação e zonas de quebra.

${ }^{3}$ Tipo de rocha, presença de minerais e cor da rocha.

${ }^{4}$ Nível d'água, turbidez da água, presença de sujeira e, em alguns casos, entradas de água e escorrimentos na parede do poço.
} 
A câmera utilizada neste trabalho foi fabricada pela empresa Laval Underground Surveys, modelo R-Cam 1300XS. Trata-se de um equipamento portátil composto pela câmera com visada frontal e lateral com iluminação em LED, centralizador (diâmetros de 2,5 a 12”), guincho (500 m de cabo), controlador e bateria (Figura 4.1). Como a qualidade da imagem registrada depende da turbidez da água, é desejável que seja realizada a limpeza do poço antes da filmagem.

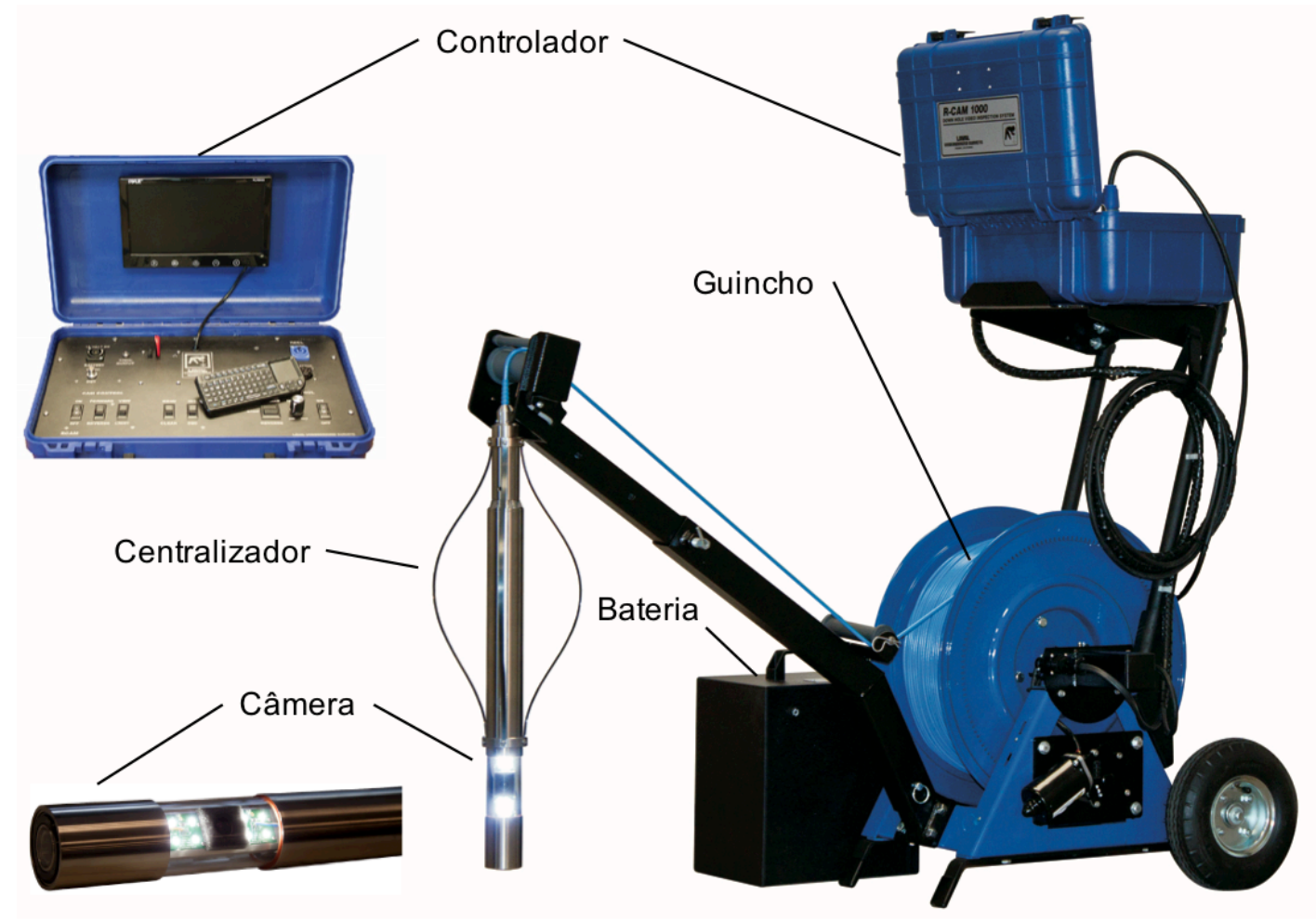

Figura 4.1. Componentes do sistema de filmagem com câmera (LUS, 2019)

Esta câmera não permite a filmagem frontal e lateral simultânea, a alternância entre as visadas é feita por meio do controlador, também utilizado para girar a câmera lateral em $360^{\circ}$. Impende ressaltar que este equipamento não possui sensores de orientação ou inclinação e, portanto, não é indicada para a interpretação das feições observadas (e.g. direção e mergulho de fraturas). A seguir é descrito o procedimento adotado para a filmagem com a câmera:

1. ajustar o centralizador e inserir a câmera no poço/furo e definir o referencial de profundidade da sonda com relação à boca do poço (a referência pode ser a câmera frontal ou lateral);

2. proceder à filmagem das feições de interesse ao longo do poço, alternando entre a visada frontal e lateral nos locais de interesse; 
3. recolher a câmera até o ponto de início (referencial zero) e verificar se o registro da profundidade está de acordo com o valor inicial (tomar nota); e

4. proceder a limpeza dos componentes que entraram no furo com sabão e água.

Os dados gerados podem ser visualizados no programa MDVR Player ou convertidos para a extensão AVI e MP4, que podem ser reproduzidos em outros softwares de reprodução de vídeo. O MDVR dispõe de um recurso que gera imagens a partir do vídeo, que podem ilustrar relatórios ou serem importadas no WellCad.

\subsubsection{Componentes e acessórios de superfície para a perfilagem geofísica}

Os componentes e acessórios de superfície para perfilagem geofísica consistem basicamente em guincho, cabo de geofísica, registrador de profundidade (encoder), tripé e polia, data logger (sistema de aquisição de dados), cabos de comunicação, computador e software. Como foram utilizados diferentes modelos e marcas de equipamentos, algumas particularidades de cada sistema que tem influência na operação e aquisição de dados serão comentadas individualmente.

Os componentes e acessórios de superfície da Mount Sopris Instruments (MSI) são: guincho portátil modelo 4MXB-1000 com recolhedor de cabo e registrador de profundidade; $480 \mathrm{~m}$ de cabo mono condutor de 4,76 mm de diâmetro; tripé; sistema de aquisição de dados Matrix (data logger); computador com sistema operacional Windows; e software Logger Suit. Um desenho esquemático é apresentado na Figura 4.2.

Os componentes e acessórios de superfície da Robertson Geologging (RG) são: guincho de $500 \mathrm{~m} ; 530 \mathrm{~m}$ de cabo de geofísica de 4,76 mm de diâmetro; tripé com registrador de profundidade na polia; bateria $12 \mathrm{~V}$; micrologger2 e Emindlogger (data loggers); computador com sistema operacional Windows; e software Winlogger e optv.exe para a perfilagem ótica.

A principal diferença entre os dois conjuntos de superfície utilizados é a guia de recolhimento do cabo e o registrador de profundidade. No caso da RG, não há guia de recolhimento e o registrador é instalado no tripé. Já nos equipamentos da MSI, o registrador é instalado na guia de recolhimento do cabo que, além de garantir o recolhimento organizado do cabo no tambor do guincho, apresenta um sistema de molas que não permite que o registrador gire em falso. Isso faz com que o sistema de registro de profundidade da MSI seja mais confiável em caso de perda de tensão no cabo ou no caso do cabo não estar perfeitamente 
organizado no tambor. Outro aspecto que diferencia os sistemas é a alimentação dos equipamentos: corrente contínua $12 \mathrm{~V}$ para a RG; e corrente alternada $220 \mathrm{~V}$ para a MSI.

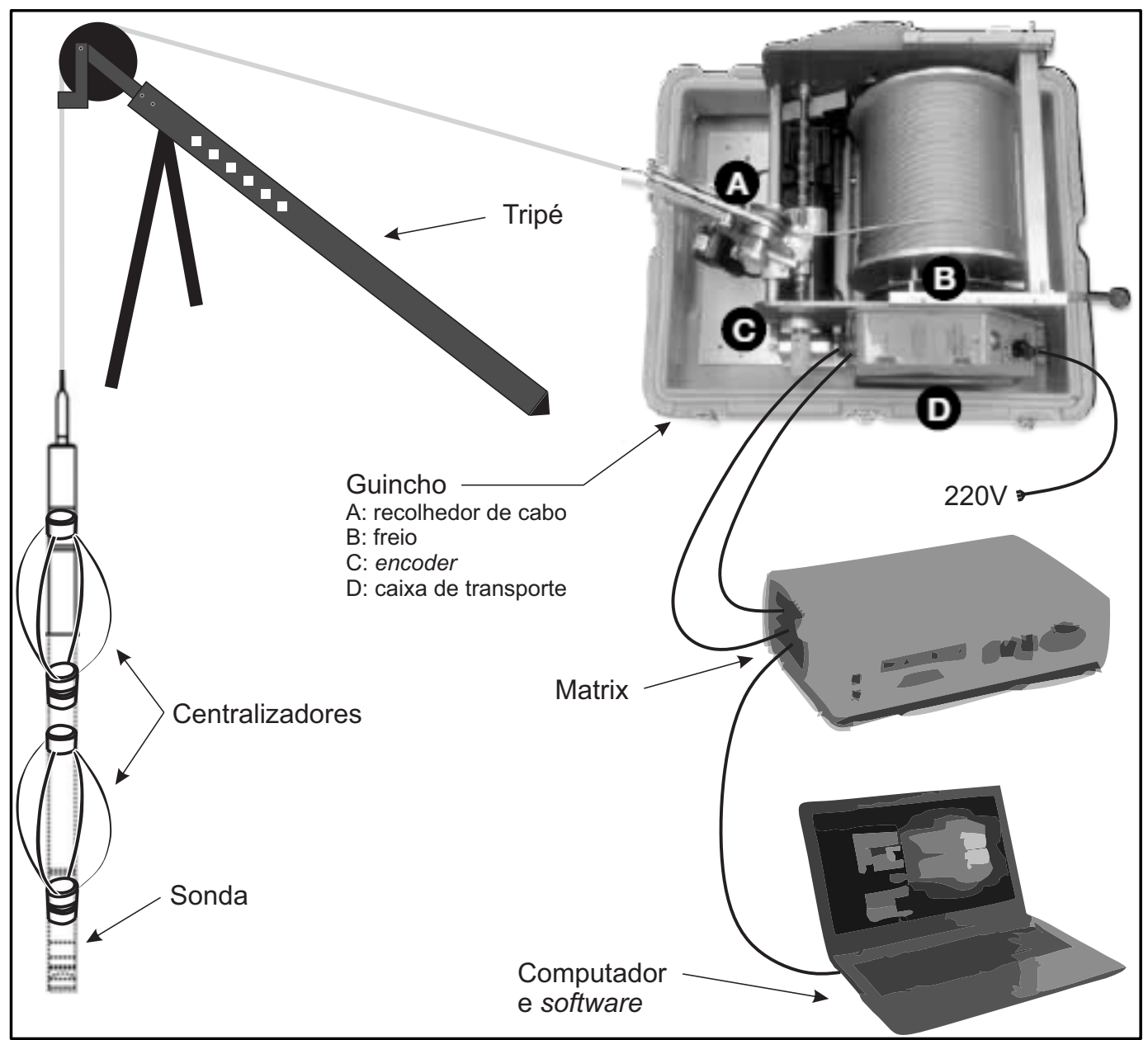

Figura 4.2. Desenho esquemático dos componentes de superfície para operação das sondas da MSI

Os procedimentos padrão de montagem e operação dos componentes de superfície para operação das sondas são descritos a seguir:

1. posicionar o guincho a uma distância de 3 a $5 \mathrm{~m}$ da boca do poço e alinhar o centro do tambor com o centro da boca do poço;

2. montar o tripé alinhado com o centro do furo/poço e o guincho;

3. comunicar a sonda com o computador e realizar um teste de funcionamento;

4. inserir a sonda no poço e definir o referencial de profundidade da sonda com a boca do poço; 
5. preencher o cabeçalho da perfilagem com os dados do furo, da sonda, do operador, configurações utilizadas e comentários que possam ser relevantes para o processamento ou identificação do trabalho

6. realizar a perfilagem;

7. recolher a sonda até o ponto de início (referencial zero) e verificar se o registro da profundidade está de acordo com o valor inicial (tomar nota);

8. retirar a sonda do furo;

9. desconectar a sonda e os cabos e proceder à desmobilização dos demais componentes do sistema caso tenham se encerrado as atividades de geofísica no poço; e

10. efetuar a limpeza dos componentes que entraram no furo/poço com sabão e água em abundância.

\subsubsection{Cáliper}

Foram utilizados dois modelos de cáliper neste trabalho, o I002037 da RG (Figura 4.3) que tem incorporado o gama (descrito no item 4.1.4), e o QL40-CAL da MSI. Estas sondas têm capacidade de medir diâmetros na faixa de 40 a $736 \mathrm{~mm}$.

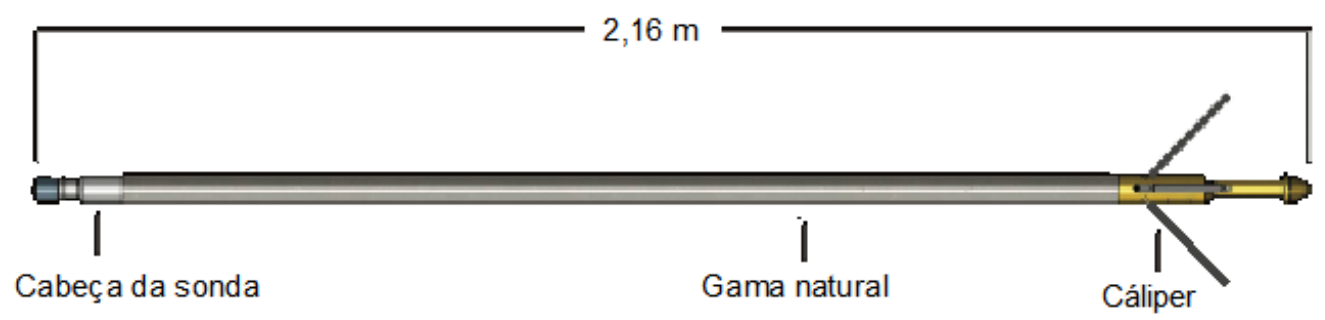

Figura 4.3. Cáliper de 3 braços com gama natural (RG, 2019)

A perfilagem com o cáliper tem início com a abertura dos braços na profundidade máxima alcançada e o recolhimento da sonda até a profundidade desejada. A variação do diâmetro do furo é medida a partir da movimentação dos braços, que registram o perfil de diâmetro médio. O procedimento de perfilagem com o cáliper é descrito a seguir:

1. realizar os passos 1 a 5 do item 4.1.2; 
2. fazer a aferição do cáliper com tubos de diâmetro similares aos que se espera encontrar ao longo da perfilagem. Caso as medidas apresentem erro acima do limite aceitável, proceder a calibração da sonda (Figura 4.4);
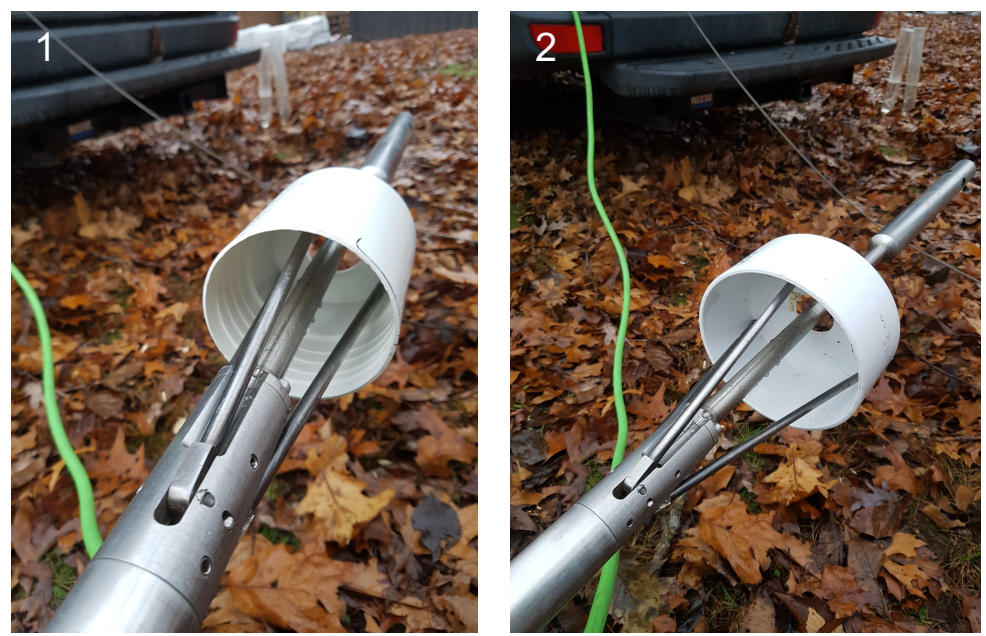

Figura 4.4. Aferição e calibração do cáliper da MSI

3. inserir a sonda no poço e definir o referencial de profundidade da sonda com a boca do poço;

4. movimentar a sonda até a profundidade desejada, em geral até a profundidade máxima do furo ou quando a sonda não descer mais. É importante, durante este processo, monitorar o registro da profundidade e a tensão do cabo. A perda de tenção configura indício de que a sonda ficou travada em alguma irregularidade ou obstrução do poço;

5. abrir os braços da sonda e iniciar a gravação dos dados;

6. recolher a sonda com velocidade constante a $6 \mathrm{~m} / \mathrm{min}$; e

7. realizar os passos 7 a 10 do item 4.1.2.

Os arquivos devem ser salvos com a identificação do poço e, posteriormente, importados no WellCad para serem processados e interpretados conforme será discutido no item 4.1.10. 


\subsubsection{Gama}

A perfilagem gama foi realizada com a sonda cáliper da RG (Figura 4.3) e com a sonda QL40-GR da MSI (Figura 4.5). Essa ferramenta é de grande utilidade para a identificação de litologias em bacias sedimentares (rochas sedimentares fraturadas), embora em rochas magmáticas e metamórficas não seja de grande utilidade. Por outro lado, o gama pode ser utilizado para balizar o modelo conceitual estratigráfico no trecho sedimentar em que o poço se encontra revestido caso esta seja a situação encontrada.

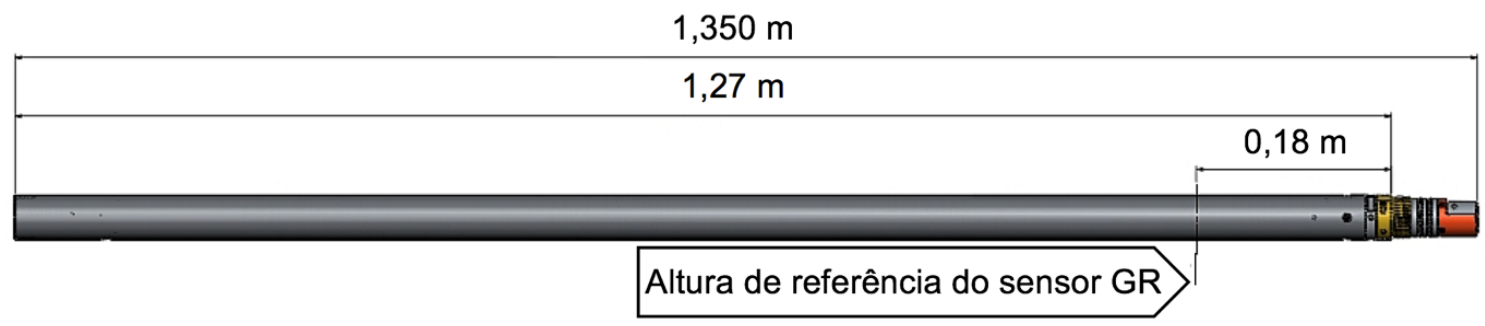

Figura 4.5. Sonda gama natural modelo QL40-GR da MSI (MSI, 2019)

Nos casos em que se utilizou o gama natural com o cáliper da RG, a configuração e operação dos equipamentos foi a mesma descrita no Item 4.1.3. Quando utilizado o gama natural da MSI, a sonda foi acoplada à sonda acústica com um adaptador próprio para isso. $\mathrm{O}$ procedimento de utilização dessa sonda é abordado, em detalhe, no item 4.1.6, que descreve a operação da sonda acústica.

\subsubsection{Televisionamento Ótico (OTV)}

A perfilagem ótica foi realizada com dois modelos de sonda, o Hi-OPTV I017187 da RG, e o QL40-OBI-2G da MSI (Figura 4.6). Ambas sondas geram uma imagem colorida de $360^{\circ}$ em alta resolução da parede do poço/furo com orientação para o norte magnético, ou, em furos inclinados, para o lado de maior elevação. Esse tipo de sonda é composta por três acelerômetros e um magnetômetro triaxial, um anel de lâmpadas LED, uma câmera de alta resolução e um refletor hiperbólico. 


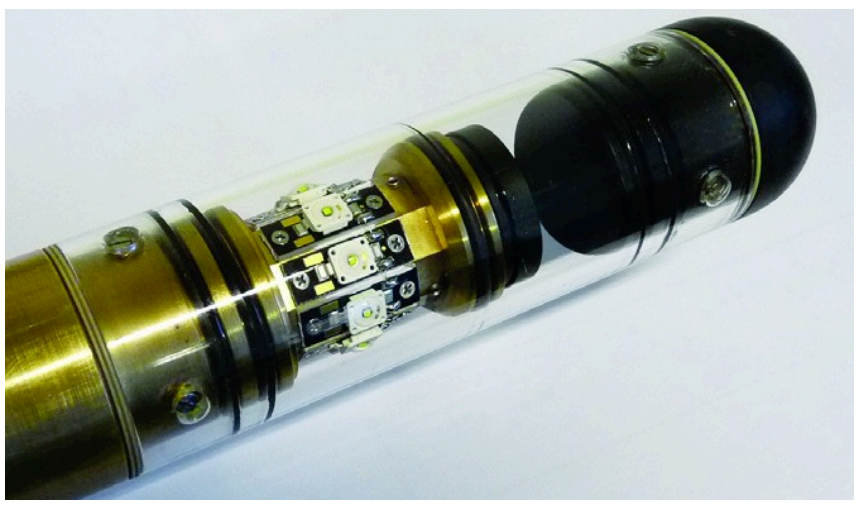

$2,11 \mathrm{~m}$

Figura 4.6. Sonda ótica modelo QL40-OBI-2G da MSI (MSI, 2019)

A qualidade da imagem depende da turbidez da água, incrustação nas paredes do furo/poço e centralização. Preferencialmente, as perfilagens são realizadas subindo a sonda no furo. O intervalo de registro mais utilizado é de $1 \mathrm{~mm}$ e a velocidade de perfilagem varia de 1,5 a $3 \mathrm{~m} / \mathrm{min}$.

O procedimento de execução da perfilagem ótica é descrito a seguir:

1. realizar os passos 1 a 5 do Item 4.1.2. Antes de inserir a sonda no furo montar o par de centralizadores não magnéticos na sonda;

2. movimentar a sonda até a profundidade desejada do poço/furo. É importante, durante este processo, monitorar o registro da profundidade e a tenção do cabo. A perda de tenção configura indício de que a sonda ficou travada em alguma irregularidade do poço;

3. iniciar a gravação dos dados e em seguida a perfilagem; e

4. realizar os passos 7 a 10 do item 4.1.2.

Os arquivos foram salvos com a identificação do poço e, posteriormente, importados no WellCad para serem tratados e interpretados conforme discutido no item 4.1.10.

\subsubsection{ATV}

A perfilagem acústica foi realizada com dois modelos de sonda, o HRAT I002184 da RG, e o QL40-ABI-2G da MSI (Figura 4.7). Esse tipo de sonda é composta por três acelerômetros e um magnetômetro triaxial, que permitem medir a direção e mergulho 
verdadeiros das estruturas observáveis. A qualidade da imagem que é gerada com essa sonda é altamente dependente da sua centralização no furo. As perfilagens acústicas foram realizadas durante a subida da sonda com velocidade de até $3,5 \mathrm{~m} / \mathrm{min}$, sempre dentro da água.

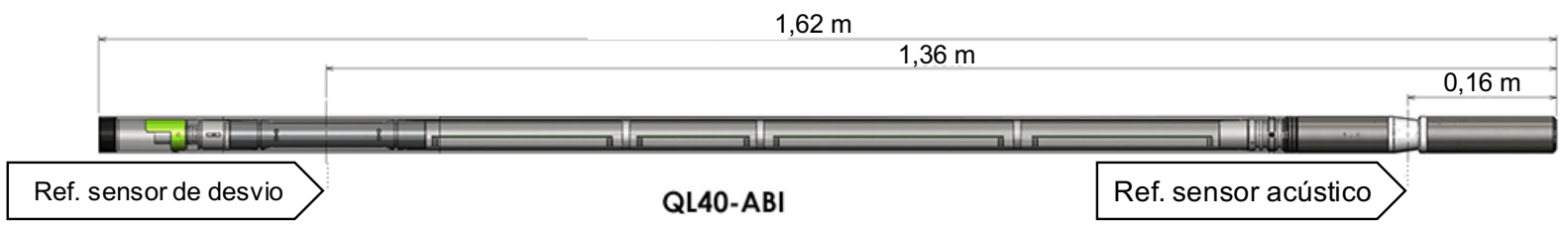

Figura 4.7. Sonda acústica modelo QL40-ABI-2G da MSI (MSI, 2019)

O procedimento para perfilagem com esta sonda é descrito a seguir:

1. realizar os passos 1 a 5 do Item 4.1.2. Antes de inserir a sonda no furo montar o par de centralizadores não magnéticos na sonda;

2. movimentar a sonda até a profundidade desejada do poço/furo. É importante, durante este processo, monitorar o registro da profundidade e a tenção do cabo. A perda de tenção configura indício de que a sonda ficou travada em alguma irregularidade do poço;

3. iniciar a gravação dos dados e em seguida a perfilagem; e

4. realizar os passos 7 a 10 do item 4.1.2.

Os arquivos foram salvos com a identificação do poço e depois importados no WellCad para serem tratados e interpretados conforme discutido no Item 4.1.10.

\subsubsection{Resistividade de dupla indução (curta e longa)}

O perfil de resistividade de dupla indução (resistividade) foi realizado com a sonda QL40-IND da MSI (Figura 4.8). Esta sonda não necessita centralizador e a perfilagem pode ser realizada tanto subindo como descendo.

\section{$1,925 \mathrm{~m}$}

Figura 4.8. Sonda de resistividade de dupla indução modelo QL40-IND da MSI (MSI, 2019)

O procedimento para perfilagem com esta sonda é descrito a seguir:

1. realizar os passos 1 a 8 do item 4.1.2; 
2. fazer a aferição da sonda no ar (levantar a sonda na vertical com a ponta para cima) para registrar o valor zero logo após retirar a sonda do poço. É importante que não haja interferências eletromagnéticas no entorno. A leitura do ponto zero serve para compensar valores fora da calibração no processamento dos dados;

3. realizar os passos 9 a 10 do Item 4.1.2.

\subsubsection{FTCR}

A perfilagem de temperatura e condutividade elétrica foi realizada com a sonda QL40FTC da MSI (Figura 4.9). A sua faixa de operação vai de -20 a $80^{\circ} \mathrm{C}$ e de 5 a $300.000 \mu \mathrm{S} / \mathrm{cm}$. A condutividade elétrica do meio é diretamente proporcional à concentração de minerais dissolvidos (íons). Em conjunto com dados de localização de fraturas, gerados nos perfis de imageamento ótico e acústico, essas anomalias são indicativas de fluxo e contribuem para a caracterização da dinâmica de fluxo do poço.

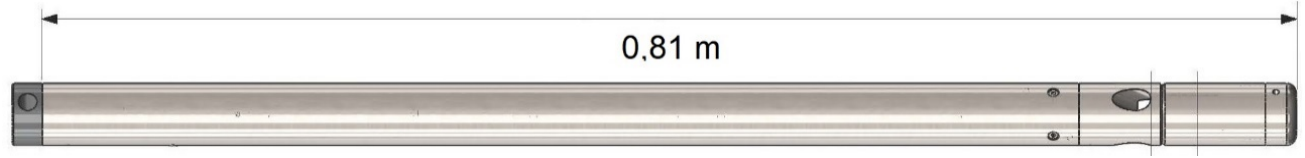

Figura 4.9. Sonda FTCR modelo QL40-FTC da MSI (MSI, 2019)

A identificação de zonas de fluxo com a sonda FTCR é refinada quando realizados ensaios em fluxo ambiente e induzido (bombeamento e/ou injeção de água). Neste trabalho o uso dessa sonda foi sempre combinado com as diferentes técnicas de flowmeter, auxiliando na identificação e interpretação das zonas hidraulicamente ativas, que é realizada pela comparação entre variação da vazão pelo flowmeter e características físico-químicas da água. No caso da sonda EMF da $\mathrm{CG}$, ela é equipada com sensores de temperatura $\left(0\right.$ a $\left.60^{\circ} \mathrm{C}\right)$ e resistividade $(0 \mathrm{a}$ 100 Ohm-m) do fluido, não havendo necessidade de utilizar outra sonda de FTCR.

Para a comparação entre os dados de resistividade e condutividade do fluido é necessário realizar a conversão de unidades conforme apresentado na Equação 4.1.

$$
\begin{gathered}
\text { Condutividade }\left(\frac{u S}{\mathrm{~cm}}\right)=\frac{10.000 \times 1}{\text { Resistividade }(\text { ohm }-\mathrm{m})} \\
\text { Equação } 4.1
\end{gathered}
$$

O procedimento para perfilagem com esta sonda é descrito a seguir:

1. realizar os passos 1 a 3 do Item 4.1.2; 
2. fazer a aferição da sonda com as soluções padrão para o sensor de condutividade ou resistividade, e a aferição da temperatura com um balde com água e gelo. Caso necessário, proceder a calibração da sonda seguindo o procedimento descrito no manual de operação da sonda;

3. inserir a sonda no poço e definir o referencial de profundidade da sonda com a boca do poço;

4. preencher o cabeçalho da perfilagem com os dados do furo, da sonda, do operador, configurações utilizadas e comentários que possam ser relevantes para o processamento ou identificação do trabalho

5. realizar a perfilagem no sentido descendente, para evitar distúrbio na coluna de fluido;

6. iniciar a injeção ou bombeamento de água e esperar o nível d'água estabilizar para realizar novamente a perfilagem. As vezes a estabilização química da coluna de água requer um tempo maior que o da estabilização do nível d'água para início da perfilagem;

7. realizar a perfilagem sentido ascendente ou descendente sob a condição de fluxo induzido; e

8. realizar os passos 7 a 10 do Item 4.1.2.

\subsubsection{Flowmeters}

Foram utilizados três tipos de flowmeters neste trabalho, Heat Pulse Flowmeter - HPF (medidor de vazão por pulso de calor), Eletromagnetic flowmeter - EMF (medidor de vazão eletromagnético) e Spinner Flowmeter - SF (medidor de vazão com hélice). Na maior parte dos trabalhos foi utilizado o HPF por ser o equipamento disponível no Centro de Pesquisa de águas Subterrâneas (CEPAS), sendo que os outros dois equipamentos foram utilizados em durante o intercâmbio realizado em 2018 nos EUA no departamento de hidrogeofísica do USGS.

As medições de fluxo com o HPF foram realizadas utilizando as sondas HPF-I002119 da RG e HFP-2293 da MSI (Figura 4.10). O uso desta sonda é planejado com base na localização das fraturas, variação e rugosidade da parede do furo (dados obtidos a partir do cáliper, ATV e OTV), e identificação de zonas hidraulicamente ativas (FTCR). O equipamento 
pode ser operado em poços de diâmetros variados (o centralizador e diverter fornecidos são para poços de 100 a $200 \mathrm{~mm}$ de diâmetro) e tem capacidade para medir vazões na faixa de 0,1 a 4,0 L/min. As medições realizadas com o flowmeter são pontuais (estacionárias), e a sonda não pode estar em movimento.

Para garantir melhor qualidade dos dados, é fundamental centralizar a ferramenta no poço e utilizar o diverter, que garante que todo o fluxo na seção do poço passe por dentro da sonda. A RG não fornece este tipo de aparato e, portanto, não foi utilizado diverter com essa sonda.

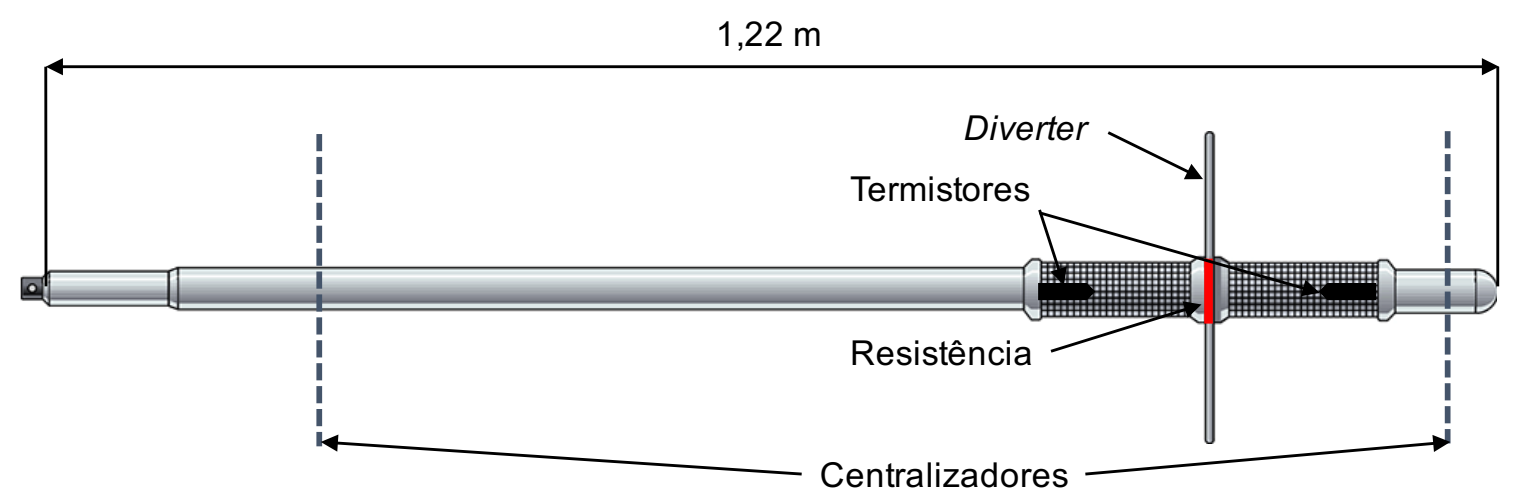

Figura 4.10. Sonda HPF modelo HFP-2293 da MSI (Modificado de MSI, 2019)

O EMF utilizado é o 9722E-M da CG (Figura 4.11), e permite a coleta de dados pontuais (medidas estacionárias), e dinâmicas (com a sonda em movimento). As medidas dinâmicas devem ser realizadas com velocidade de deslocamento constante e a interpretação dos dados precisa levar em consideração a vazão que resulta do deslocamento. Para isso, é necessário um trecho do furo em que o fluxo seja conhecidamente zero.

$1,42 \mathrm{~m}$

E-M Flowmeter e FTC

Figura 4.11. Sonda EMF modelo 9722E-M Flowmeter da CG (CG, 2019)

Na prática, a ferramenta é capaz de medir vazões de 0,5 a 40 1/min que passam pela seção interna da ferramenta, que tem $25 \mathrm{~mm}$ de diâmetro. A ferramenta requer centralização no furo e pode ser utilizada com diverter de borracha. Conforme mencionado anteriormente, a 
sonda 9722E-M Flowmeter tem sensores de temperatura e resistividade do fluido integrados em sua seção interna e esses registros são realizados simultaneamente às medições de fluxo.

O HPF e o EMF foram testados e calibrados em laboratório antes de sua utilização em campo. Para isso foi montada uma coluna de teste para fluxo ascendente e descende com vazão ajustável (Figura 4.12). O ensaio tem a finalidade de verificar os limites inferior e superior de detecção das sondas e verificar a linearidade das leituras (modelo utilizado para interpretação do fluxo no software da RG, CG e MSI). Para essa aferição foi utilizada a mesma configuração de equipamentos de campo.

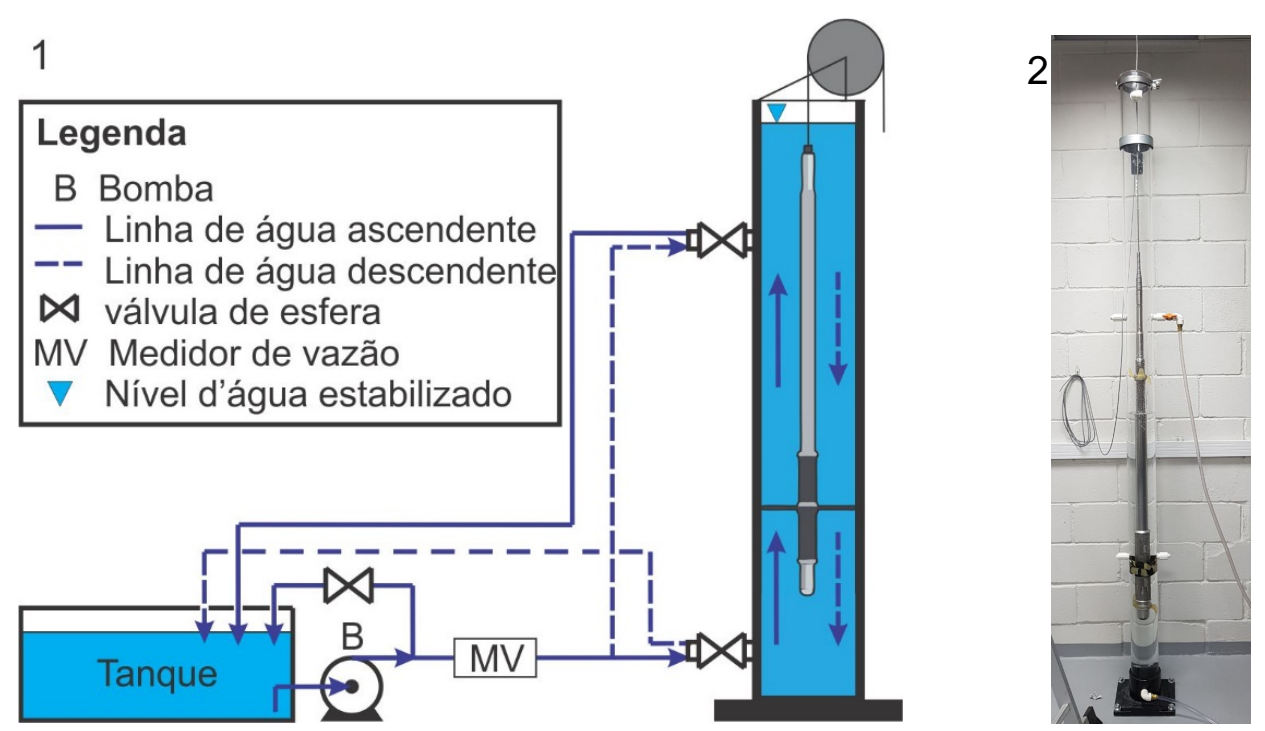

Figura 4.12. (1) aferição e calibração de flowmeters para medidas estáticas; (2) foto da calibração realizada em laboratório com HPF

O SF mede o sentido e a magnitude do fluxo de água em uma seção do furo a partir da rotação de uma hélice como resposta à passagem da água. O modelo utilizado neste trabalho foi o QL40-SFM da MSI (Figura 4.13) e as perfilagens foram realizadas em condições dinâmicas (com deslocamento da sonda), tanto nos ensaios em condição ambiente como com fluxo induzido.

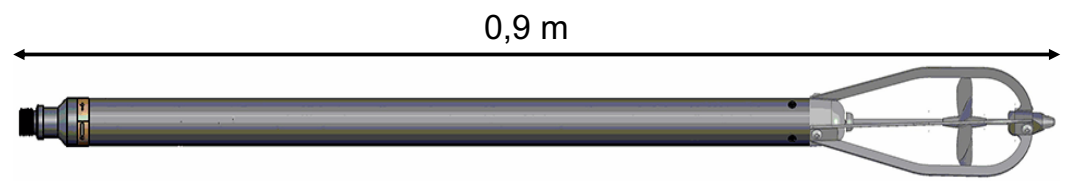

Figura 4.13. Sonda SF modelo QL40-SFM da MSI (MSI, 2019)

Neste trabalho foram realizados dois tipos de ensaios com os flowmeters. Primeiramente, medições de fluxo em condição ambiente, e em seguida medições com fluxo induzido por bombeamento ou injeção de água (Figura 4.14), fazendo com que sejam ativadas 
as fraturas mais transmissivas. Antes de cada um dos ensaios, é apropriado realizar a perfilagem de FTCR, conforme descrito no item anterior. O ensaio com fluxo induzido só deve ser iniciado após a estabilização do nível d'água. A vazão deve ser mantida constante durante todo o tempo do ensaio. No caso de variação da vazão ou do nível d'água, a correção deve ser realizada no processamento dos dados conforme descrito por BUSSE et al. (2016) e PAILLET (2004).

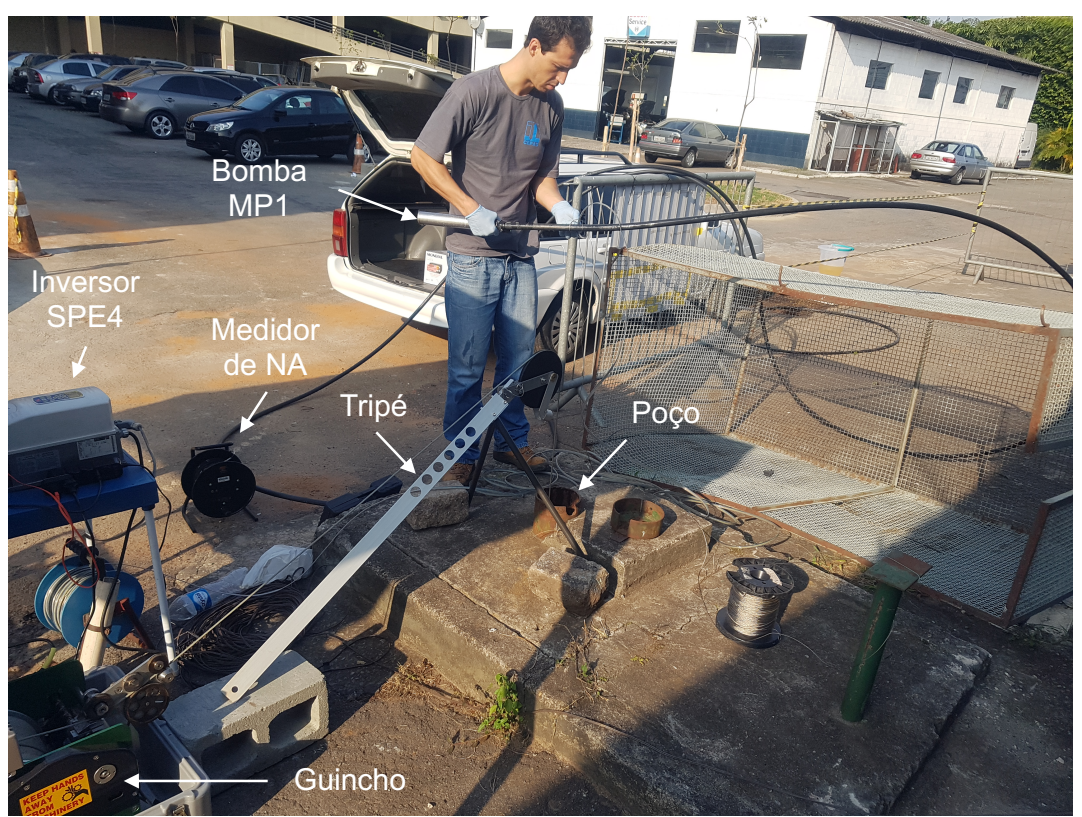

Figura 4.14. Ensaio com fluxo induzido (bombeamento) no poço 255 com o HFP-2293 da MSI

A seguir é descrito o procedimento para medição de fluxo com estas sondas:

1. realizar os passos 1 a 5 do Item 4.1.2. Antes de inserir as sondas no poço colocar o centralizador e o diverter, este segundo apenas para o HPF e EMF;

2. conforme já mencionado, é desejável realizar a perfilagem FTCR com fluxo ambiente antes de iniciar as medições com os flowmeters, exceto para o EMF que tem esses sensores integrados;

3. realizar as medições de fluxo ambiente. Recomenda-se a escolha de até dez pontos para medições estáticas em um furo. Os locais devem ser escolhidos a partir da identificação de estruturas com maior abertura e cuja seção transversal apresente diâmetro consistente com os demais pontos escolhidos e pouca irregularidade das paredes. Conforme forem identificadas zonas em que ocorre a variação do fluxo, pontos adicionais podem ser acrescentados;

a. HPF: posicionar a sonda em trechos acima e abaixo de fraturas com indício de fluxo ou abertura aparente mais expressiva. Os trechos selecionados para 
medição de fluxo devem ter diâmetro inferior ao diverter para evitar/minimizar vazamentos. Entre cada profundidade é importante aguardar a estabilização do fluxo, que é induzido pela movimentação da sonda no furo; e

b. EMF e SF: recomenda-se a realização das medições estáticas e dinâmicas para comparação. Em geral, as vazões com fluxo natural em um poço não são suficientes para gerar resposta na sonda SF;

i. medidas estáticas: mesmo procedimento que o HPF; e

ii. medidas dinâmicas: fazer a perfilagem com velocidade constante subindo a sonda no furo.

4. realizar as medições de fluxo zero tanto no topo como no fundo do furo/poço nas medições estáticas e dinâmicas. Essas medidas são utilizadas para aferição e correção dos dados na etapa de processamento;

5. iniciar o bombeamento ou injeção de água para o ensaio com fluxo induzido e monitorar a vazão e a variação do nível d'água até que ambos estejam estabilizados. É importante que se faça o registro destes parâmetros;

6. realizar a perfilagem FTCR com fluxo induzido antes de iniciar as medições com os flowmeters, exceto para o EMF que tem esses sensores integrados

7. realizar as medições de fluxo induzido nos mesmos pontos em que foram feitas as medições com fluxo ambiente. Conforme forem identificadas zonas de interesse não observadas anteriormente, novos pontos podem ser adicionados para detalhar as seções em que ocorre a variação do fluxo. As medições com fluxo induzido são realizadas da mesma maneira que com fluxo ambiente;

8. realizar as medições de fluxo zero no fundo do furo/poço e a medição de fluxo induzido na parte superior do poço, acima da zona de fluxo natural observada nas medições estáticas e dinâmicas (as medidas devem coincidir com a vazão de injeção ou bombeamento). Estas medidas servem para aferição e correção dos dados na etapa de processamento; e

9. realizar os passos 7 a 10 do Item 4.1.2. 
Os arquivos foram salvos com a identificação do poço e depois importados no WellCad para serem tratados e interpretados conforme discutido no Item 4.1.10. Os dados do ensaio com flowmeter devem ser registrados em uma ficha de campo para auxiliar a etapa de interpretação e processamento (Figura 4.15).

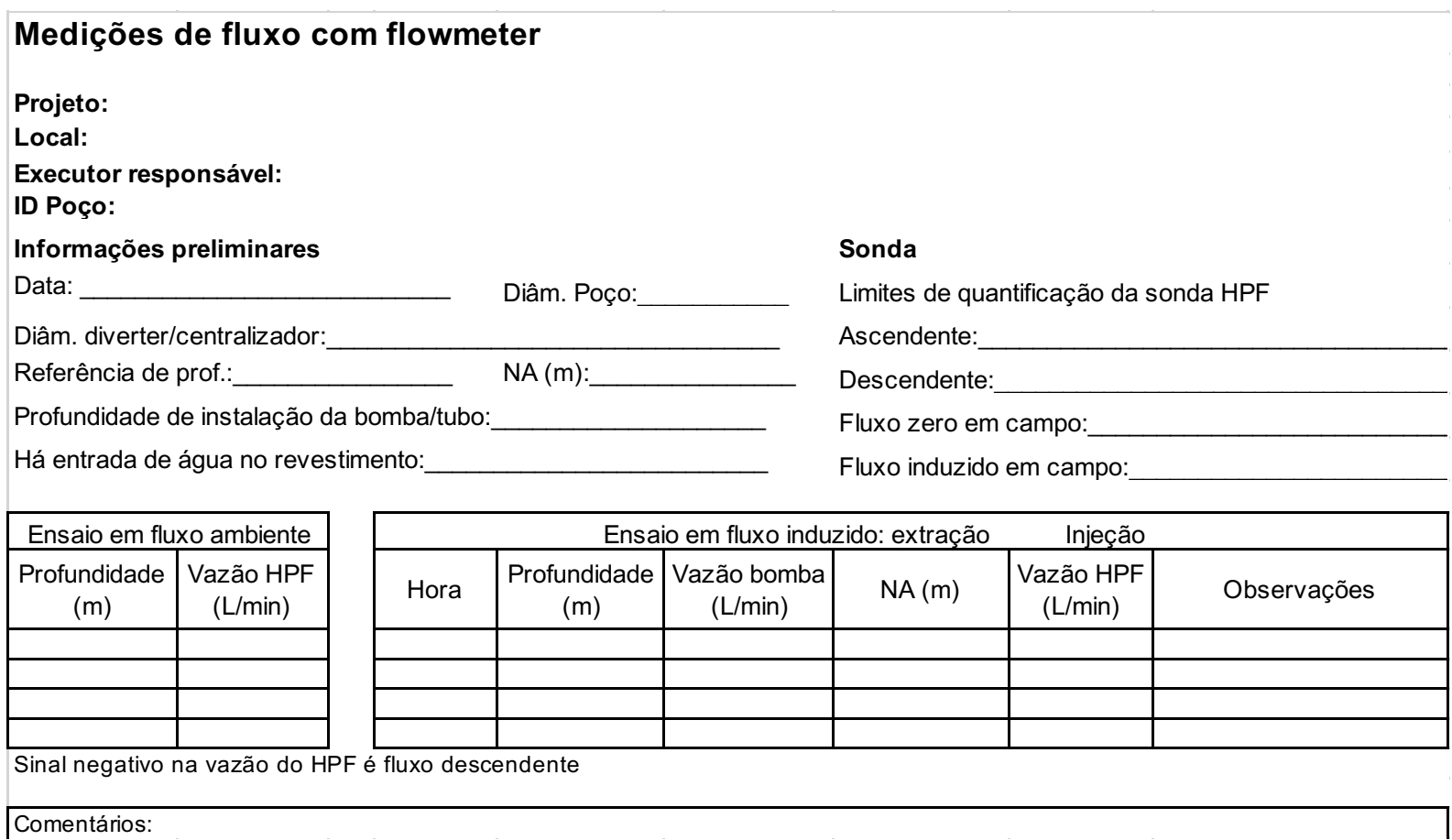

Figura 4.15. Ficha de campo para ensaio com flowmeter

4.1.10 Processamento e integração de dados geofísicos

O processamento dos dados geofísicos foi realizado no WellCad, um software que incorpora todos os recursos e ferramentas necessários para importar, editar, processar e exibir os dados de perfurações e de poços. Foi utilizada a versão 5.1 do software, com os módulos reader, crossplot, image, ISI e deviation, que dão suporte para todas as operações de tratamento e interpretação dos dados estruturais e hidrogeológicos das perfilagens descritas nesse capítulo. Uma licença gratuita do software foi disponibilizada pela Advanced Logic Technology (ALT) para o CEPAS como parte de um acordo de pesquisa. Além do WellCad, foi utilizado o software FLASH-R (DAY-LEWIS et al., 2011; BARBOSA et al., no prelo) para a modelagem de dados hidráulicos dos flowmeters, o que possibilitou a determinação dos parâmetros raio de influência do poço, transmissividade e carga hidráulica das zonas de fluxo interpretadas. A seguir é apresentado o procedimento de processamento de dados aplicado neste trabalho para todas os dados geofísicos: 
1. preencher o cabeçalho com os dados do furo/poço (cadastro do poço, perfil construtivo e dados da filmagem e do cáliper);

2. importar os dados geofísicos;

3. ajustar as profundidades dos logs importados de acordo com os dados disponíveis (logs, dados construtivos, filmagem do poço etc.). É comum que ocorram pequenas divergências nas medidas de profundidade entre perfis, especialmente quando utilizados guinchos de fabricantes diferentes. Nesses casos, um dos perfis deve ser escolhido como referência e os demais ajustados em relação a ele;

a. ajustar a unidade em que o dado foi gerado e a escala de apresentação;

b. filtrar os dados ("Filter Logs") com ruído ou valores discrepantes; e

c. interpolar os logs ("Interpolate Logs") quando observada a existência de trechos sem informação por falha do equipamento ou da gravação. Essa ferramenta realiza uma interpolação linear nos trechos sem informação.

4. cáliper;

a. verificar se os valores do cáliper estão coerentes com os dados de campo; e

b. Caso necessário fazer a correção dos valores medidos pelo cáliper com base em uma nova calibração ou outro perfil que possa servir de base para o reprocessamento.

5. gama;

a. poços com revestimento metálico causam redução do sinal e um ajuste via "Fomula Log" pode ser realizado somando a diferença observada imediatamente após a entrada no revestimento.

6. OTV e ATV ("Image and Structure Processing Module");

a. calcular a direção e magnitude do desvio do poço (“Borehole Deviation”)

b. centralizar o perfil ("Centralize Process") para corrigir os efeitos da descentralização da sonda durante a perfilagem (perfis de tempo de trânsito e amplitude). Para que essa correção seja realizada de maneira adequada, é importante excluir trechos de alargamento do furo que não foram causados 
pela descentralização (e.g. washouts, breakouts), definindo limites superior e inferior para o processo de correção;

c. estimar a velocidade de propagação do som no fluido ("Estimate Fluid Velocity") para obter valores representativos na conversão do tempo de trânsito da onda acústica em dados de cáliper para a perfilagem acústica. Para isso, deve ser utilizado um trecho do poço que se conheça com precisão o diâmetro (e.g. trechos do revestimento). O resultado deste processo é um "Mud Log" contendo valores de velocidade que podem ser utilizados como entrada no processo de cálculo do cáliper (“Computation Of Caliper Data Process");

d. gerar o cáliper ("Calculate Caliper”) a partir do tempo de trânsito do sinal acústico. Para tanto são necessários quatro parâmetros: unidade em que o tempo de transito foi gravado; velocidade de propagação do sinal no fluido (valor tabelado ou calculado no item anterior); raio da ferramenta de perfilagem (19 mm para o QL40-ABI-2G e $24 \mathrm{~mm}$ para o HRAT I002184); tempo de trânsito do sinal acústico dentro da sonda (time window em $\mu$ s), selecionar o $\log$ WindTime no menu;

e. identificar breakouts, se houver, selecionando estruturas lineares em perfis de imagem como quebras na parede do poço;

f. interpretar os dados das perfilagens acústica e ótica ("Image \& Structure Interpretation Workspace - ISI Workspace”);

i. configurar a área de trabalho: perfis tipo amplitude; cáliper médio (unidade em mm); “Apparent to True" selecionar o azimute e o tilt com a orientação para o norte; recalcular o azimute com a declinação do norte magnético;

ii. selecionar as fraturas automaticamente (usando um algoritmo) ou manualmente. Fazer uma triagem manual na seleção automática quando utilizado este recurso; e 
iii. classificar as fraturas quanto à sua abertura aparente (fratura preenchida, estreita, $<10 \mathrm{~mm}$, e espessa $\geq 10 \mathrm{~mm}$ ). Nessa etapa $\mathrm{o}$ OTV ou a filmagem com a câmera pode auxiliar na interpretação.

7. resistividade;

a. subtrair o valor da leitura zero (aferição de campo no ar) dos valores do perfil de resistividade curta e longa.

8. FTCR;

a. ajustar a unidade em que o dado foi gerado e a escala de apresentação para poder comparar as leituras de temperatura e condutividade ou resistividade. A conversão entre condutividade e resistividade utiliza a Equação 4.1

9. avaliação integrada de dados;

a. Selecionar os pontos para leitura com os flowmeters. Os critérios são: variações observadas com a sonda FTCR; indícios de fluxo (imagens de água escorrendo ou feições típicas de fluxo, oxidação e manchas de escorrimento); fraturas com abertura aparente proeminente, e elevado grau de fraturamento. Além desses pontos, sempre é incluído ao menos um trecho para medição na base do revestimento e um trecho logo abaixo do contato com a rocha. Para o posicionamento da sonda, deve-se evitar trechos irregularidade da parede do furo, onde o diverter pode perder a eficácia, bem como entradas ou saídas de água, que podem causar distúrbio no fluxo que passa pelo conjunto de sensores.

10. flowmeters (HPF, EMF e SF); e

Os dados dos flowmeters (HPF, EMF e SF) são processados direto no WellCad. Antes de fazer a importação, os dados devem ser conferidos e exportados para uma extensão que o software reconheça.

a. importar os dados dos ensaios estáticos e dinâmicos com fluxo ambiente e induzido. Registrar a vazão de injeção ou bombeamento e a velocidade de movimentação da sonda para o processamento dos dados;

b. proceder a correção dos dados caso necessário (BUSSE et al., 2016; PAILLET, 2004); 
i. diferenciar medidas cujo fluxo é baixo daquelas em que não há fluxo;

ii. corrigir os dados em que há vazamento pelo diverter (quando utilizado) ou ajustar a vazão pelo diâmetro da seção (quando não utilizado o diverter);

iii. normalização do fluxo com base em trechos onde a vazão é conhecida (geralmente teste de fluxo zero no fundo e induzido no revestimento); e

iv. remover o fluxo resultante da movimentação da sonda no furo nas medidas dinâmicas.

c. plotar os perfis da sonda FTCR junto com os dados dos flowmeter para auxiliar na interpretação, quando disponíveis. É importante que os perfis estejam na mesma unidade de medida, especialmente quando comparando resultados de resistividade e condutividade;

d. análise e interpretação dos dados;

i. identificar as zonas de entrada e saída de água e comparar com os dados de temperatura e condutividade elétrica; e

ii. verificar se as alterações de fluxo se correlacionam com a presença de estruturas ou se são efeito da variação no diâmetro do poço/furo.

e. modelagem de fluxo com dados do flowmeter;

Os dados gerados pelo flowmeter são modelados no programa FLASH ou FLASH-R do USGS, discutido em DAY-LEWIS et al. (2011) e BARBOSA et al. (2020), para obter os parâmetros raio de influência do poço, transmissividade e carga hidráulica das zonas de fluxo interpretadas. Os passos para essa análise são descritos a seguir:

i. entrar os dados básicos do ensaio: tipo de aquífero; elevação do ponto de referência para as medidas; diâmetro do poço; nível d'água estático; nível d'água dinâmico; profundidade da base do revestimento; profundidade total do poço; e transmissividade total do poço ou raio de influência.

ii. importar os dados brutos do ensaio com flowmeter; 
iii. entrar com as zonas de fluxo interpretadas; e

iv. simular os parâmetros de taxa da transmissividade e carga hidráulica relativa para cada zona interpretada até que os dados interpretados e o modelo apresentem erro médio quadrático satisfatório $(<1)$. $\mathrm{O}$ recurso de otimização faz um cálculo automático dos valores que apresentam menor erro quadrático médio. A simulação permite o uso da regularização para restringir os dados de saída do modelo dentro de limites estabelecidos pelo usuário, quando os valores são discrepantes do observado em campo.

v. plotar os dados de transmissividade e carga hidráulica das zonas em um perfil do WellCad.

11. avaliação integrada de dados.

A partir da comparação conjunta de todos os perfis gerados são selecionados os trechos para ensaios hidráulicos e amostragem com obturadores. Essa seleção pode ser feita a partir de uma classificação em ordem de importância com base nos seguintes critérios: dados de flowmeter, transmissividade, carga hidráulica (zona produtora ou saída de água) ou simplesmente resposta hidráulica; respostas da sonda FTCR; feições de fluxo observadas com a câmera e perfilagem ótica; diâmetro e irregularidade na parede do poço; abertura aparente das fraturas, grupo de fraturas e densidade de fraturas. Além dos parâmetros técnicos descritos, a quantidade de intervalos para a realização de ensaios hidráulicos e amostragem com obturadores pode variar de acordo com o projeto, seus objetivos, tempo de execução e orçamento.

\subsection{Ensaios hidráulicos e amostragem com obturadores}

Este item foi dividido em três seções: (1) considerações sobre a técnica; (2) materiais utilizados para a execução de ensaio hidráulicos e amostragem de água; e (3) métodos e procedimentos de coleta de dados em campo. A combinação de todos os componentes e funcionamento integrado do sistema é apresentado no capítulo de resultados, na seção que trata do desenvolvimento e construção da unidade móvel de ensaios hidráulicos e amostragem (Mobile Unit for Sampling and Testing - MUST). 
4.2.1 Considerações sobre o uso de obturadores para obtenção de parâmetros hidráulicos e hidroquímicos

Os parâmetros hidráulicos (carga hidráulica, transmissividade e armazenamento) são obtidos com um par de obturadores, que podem ser acionados separadamente por linhas de ar ou água independentes. Após inflados, é necessário verificar a eficiência do isolamento, que está sujeito a três aspectos: (1) características dos equipamentos; (2) características da parede do furo (diâmetro, irregularidade e rugosidade da rocha); e (3) conexões naturais da rede de fraturas, que podem causar um curto circuito entre os intervalos mesmo que os aspectos 1 e 2 não apresentem problemas.

O ensaio de estanqueidade pode ser qualquer tipo de distúrbio hidráulico no intervalo alvo, com o monitoramento dos intervalos vizinhos. A ausência de resposta é indício de que um bom selo foi estabelecido. Casos de vazamento podem ser de dois tipos, pelo interstício entre parede do furo e o elemento de borracha dos obturadores ou pela rede de fraturas (Figura 4.16). No primeiro caso, é possível aumentar a pressão nos obturadores ou alterar a profundidade da composição para estancar o vazamento. No segundo caso não há o que fazer já que essa é uma condição natural do aquífero, exceto por fazer uma correção na etapa de processamento dos dados a partir de uma regressão linear, procedimento similar ao ensaio em furo aberto com o flowmeter.

Uma vez isolado o intervalo, pode ser obtido o primeiro parâmetro, a carga hidráulica. A relação de cargas depende da estabilização destas. O tempo de estabilização depende da transmissividade do intervalo e da diferença entre a carga inicial (carga média do poço somada ao distúrbio gerado pela expansão dos obturadores) e a carga discreta do intervalo. Zonas pouco transmissivas demandam maior tempo de estabilização. Nos casos em que apenas uma fratura é hidraulicamente ativa no intervalo obturado, a carga discreta é a carga da própria fratura. Nos casos em que existe mais de uma fratura, a carga discreta do intervalo é função das transmissividades e cargas individuais de cada fratura conforme demonstrado por SOKOL $(1963)$. 

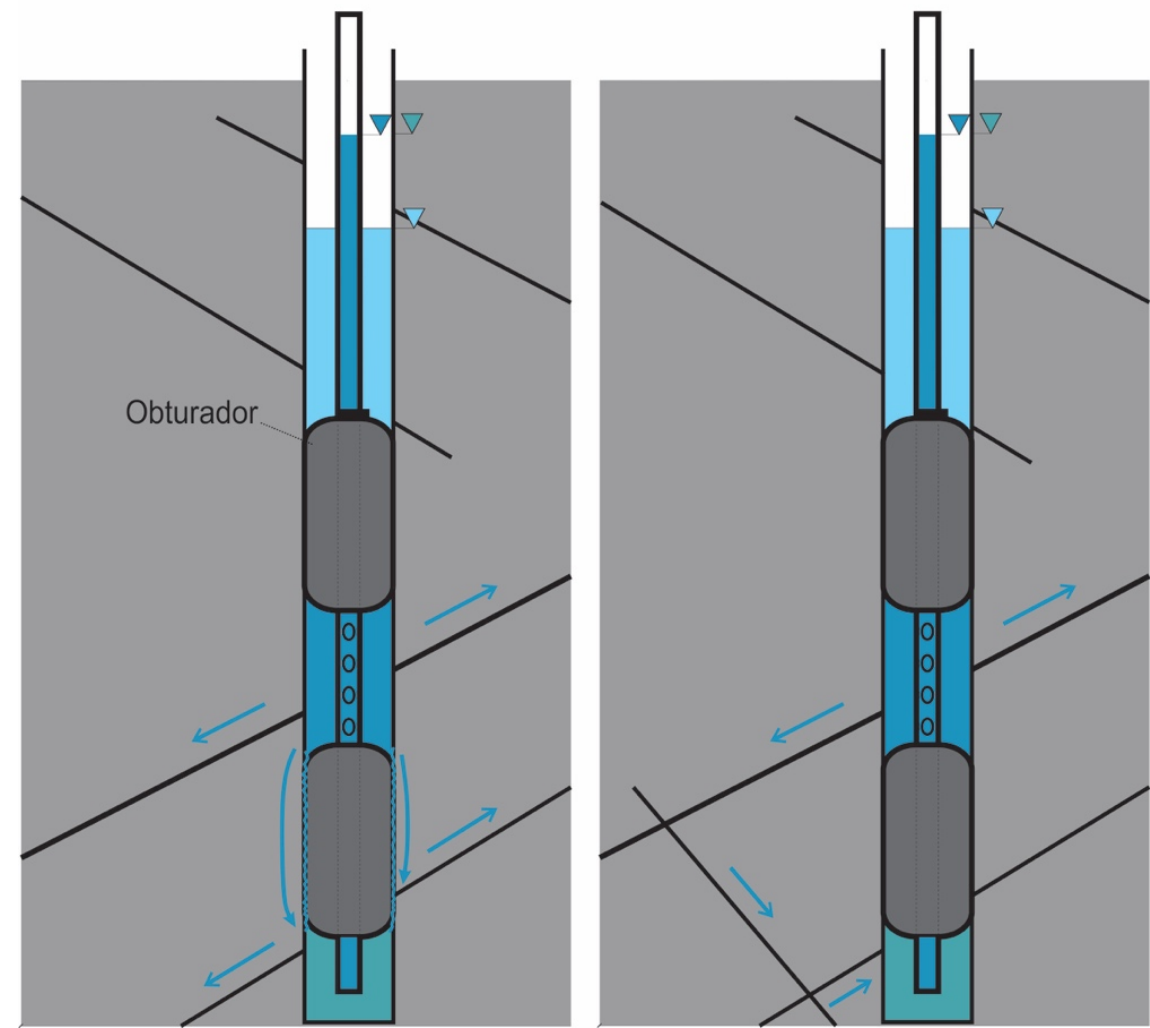

Figura 4.16. Vazamento entre os intervalos obturados pela parede do furo e pela rede de fraturas

Conhecer as limitações do sistema de medição é imprescindível para o processamento e interpretação dos dados de carga hidráulica, o sentido de fluxo e a magnitude do gradiente devem levar em consideração o erro associado ao sistema de medição. A leitura em duplicidade proporciona maior confiabilidade dos dados, por isso obter leituras de carga hidráulica com transdutores e medidor de nível é uma vantagem. A leitura em duplicidade pode ser utilizada para aferição e calibração do sistema e não precisa ser realizada para cada medida realizada ao longo do trabalho de campo.

Os demais ensaios hidráulicos (pulso, carga constante, e bombeamento) são realizados por meio de um distúrbio no intervalo isolado e o monitoramento da resposta da pressão, até que o equilíbrio (ou quase equilíbrio) seja reestabelecido. Para todos os ensaios mencionados, esse distúrbio pode ser causado pela injeção ou extração de água. No caso do ensaio de pulso, também pode ser utilizado um sistema pneumático (pressurização ou vácuo) para induzir o distúrbio hidráulico, com a vantagem de não gerar efluentes (extração de água) nem causar alteração química na água (injeção de água).

Um aspecto prático importante na realização de ensaios hidráulicos é a profundidade do nível d'água. Níveis profundos requerem bombas de maior capacidade de recalque. Além disso, 
é preciso manter a coluna de água acima da bomba para o funcionamento correto. Com relação à injeção, a diferença de cota entre um tanque reservatório de água na superfície e o nível d'água do intervalo pode criar um gradiente muito elevado, que dificulta o controle da pressão e da vazão aplicada. Distúrbios com pressão acima de um metro de coluna de água (QUINN; PARKER; CHERRY, 2013) quase sempre se enquadram no regime de fluxo turbulento (a maior parte das soluções analíticas são aplicadas ao regime laminar), além de poderem causar modificações nas conexões hidráulicas da rede de fraturas. Portanto, deve-se evitar distúrbios com variação da carga superiores a 1 metro de coluna de água.

Cada ensaio possui suas respectivas premissas, que precisam ser consideradas na etapa de projeto e execução, para que a interpretação seja adequada ao dado gerado. Os principais aspectos práticos a serem considerados são: ensaio de pulso, deslocamento instantâneo da coluna de água, ou pressão, no intervalo; carga constante, fazer a injeção/extração de água sob pressão para evitar o efeito de armazenamento de água no tubo/mangueira, que atua como poço temporário, e aguardar a estabilização da pressão e da vazão; ensaio de bombeamento, manter a vazão de injeção/extração constante ao longo do ensaio.

Com relação à amostragem de água em trechos discretos, alguns aspectos já foram abordados (e.g. implicações da profundidade do nível d’água, sistema de controle da profundidade e vazamentos), além dos quais existem basicamente duas questões que devem ser consideradas: a representatividade da amostra, e a técnica de amostragem.

A representatividade da amostra, sem levar em consideração neste momento questões operacionais, está relacionada à escolha de intervalos com base na hidráulica atual do furo. Esse conhecimento é construído ao longo da etapa geofísica e de ensaios hidráulicos com obturadores (carga hidráulica relativa, transmissividade, feições de fluxo e demais características específicas do site). Trechos com carga hidráulica superior à carga média do poço fornecem água e, portanto, representam um compartimento hidráulico da rede de fraturas. Por outro lado, fraturas com carga inferior à média do poço recebem a água de mistura do poço e, portanto, tem um volume de água de mistura distribuído no seu compartimento da rede de fraturas. Essa condição faz com que a confiabilidade na representatividade das amostras de fraturas que fornecem água para o poço seja maior que a de zonas que recebem água.

A configuração e componentes utilizados na amostragem precisam levar em consideração cinco aspectos: (1) a profundidade do nível d'água, conforme já discutido nos ensaios hidráulicos, e o equipamento a ser utilizado (bomba elétrica, pneumática ou amostrador descartável); (2) o método de amostragem pode requerer o monitoramento de parâmetros físico- 
químicos e adoção de faixas de vazão (e.g. método de baixa vazão, descrito pela norma NBR 15847:2010, embora não seja direcionado a poços em meios fraturados); (3) a necessidade de limpeza/descontaminação ou troca do material utilizado na amostragem (bomba, conexões, válvulas e mangueira); (4) volume de purga para retirar a água de mistura que ficou estagnada no intervalo isolado, ou que adentrou na rede de fraturas do intervalo pela diferença de carga; e (5) característica dos parâmetros físicos e/ou químicos a serem analisados (e.g. compostos voláteis podem evaporar com o aquecimento da água, borbulhamento com gás ou turbilhonamento da amostra).

\subsubsection{Materiais adquiridos e desenvolvidos para o uso de obturadores}

A realização de ensaios hidráulicos e amostragem com obturadores demanda uma série de componentes e equipamentos especializados. A descrição desse ferramental foi organizada em duas categorias, aqueles que são inseridos no furo/poço, e os de superfície. Um resumo dos principais componentes é apresentado na Figura 4.17.

\section{Equipamentos que são inseridos no poco}

Integram a composição: dois conjuntos de obturadores para furos/poços com diâmetro de 10 a $22 \mathrm{~cm}$; um mini-obturador para furos/poços com diâmetro de 5 a $8 \mathrm{~cm}$; transdutores de pressão para monitorar acima, abaixo e entre o conjunto de obturadores; dois passa cabos para permitir a passagem dos cabos dos sensores e linha de ar para os níveis inferiores; tubo central perfurado para comunicar o intervalo entre os obturadores com a superfície; tubo central que forma o poço temporário; e olhal para fixação da corrente. Esses componentes são ilustrados na Figura 4.18. 
Equipamentos inseridos no furo/poço

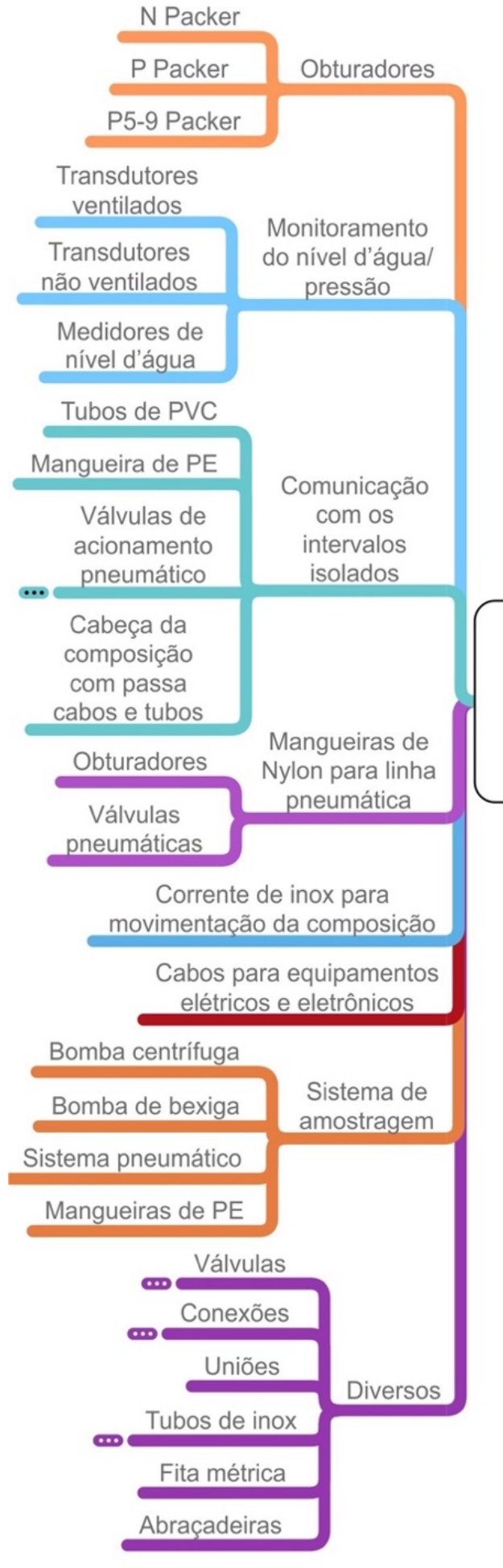

\section{Equipamentos de superfície}

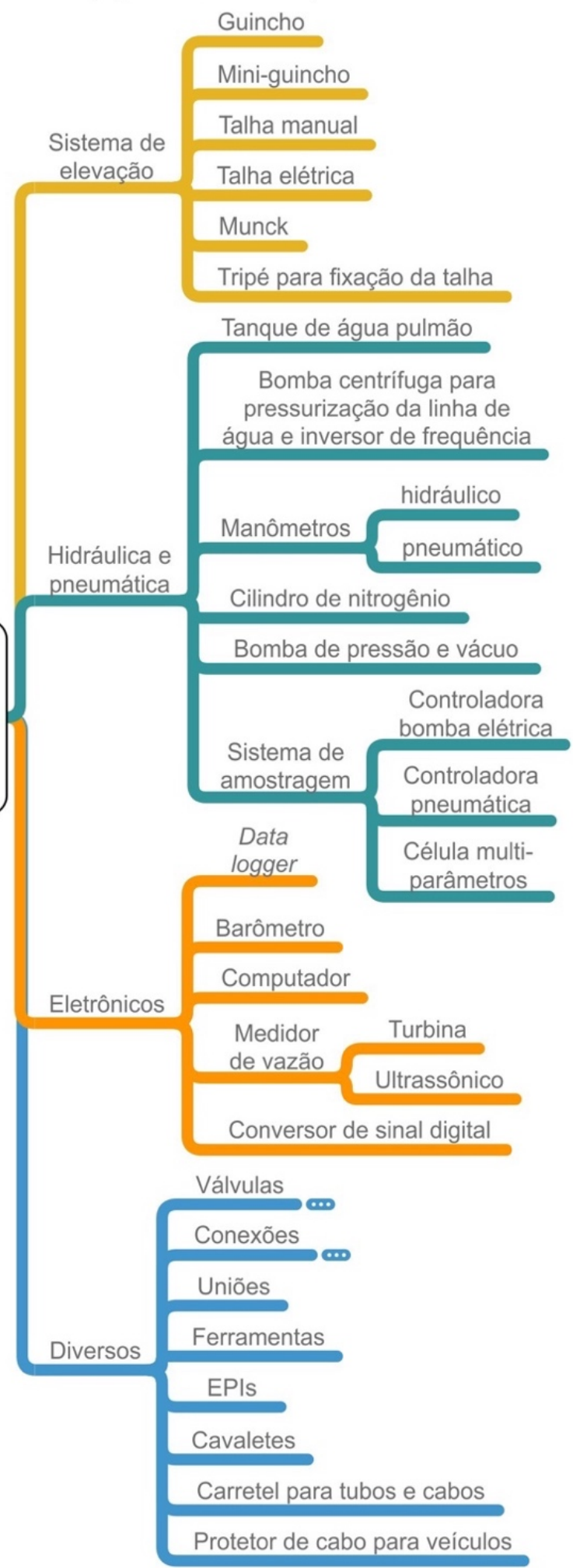

Figura 4.17. Equipamentos para a realização de ensaios hidráulicos e amostragem com obturadores 


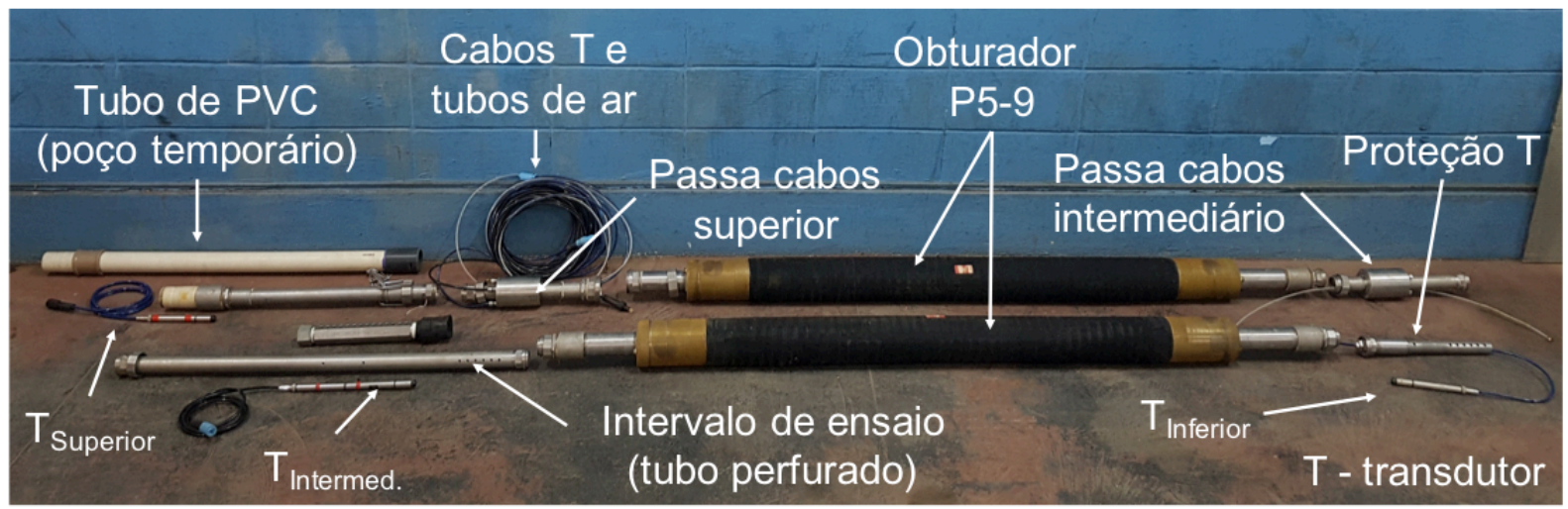

Figura 4.18. Componentes que são inseridos no poço com obturadores

Os componentes mais relevantes são detalhados a seguir:

\section{Obturadores}

Dois pares de obturadores foram adquiridos, o modelo P Packer e o P5-9 Packer da RST Instruments. Um mini-obturador, $\mathrm{N}$ Packer, também foi adquirido da mesma empresa para a realização de ensaio de injeção e carga constante. Esses equipamentos são ilustrados na Figura 4.19. Os obturadores são inflados com ar comprido, gás nitrogênio ou água e têm um lado fixo e outro móvel, que desliza sobre o corpo em aço inoxidável ao expandir o elemento de borracha.

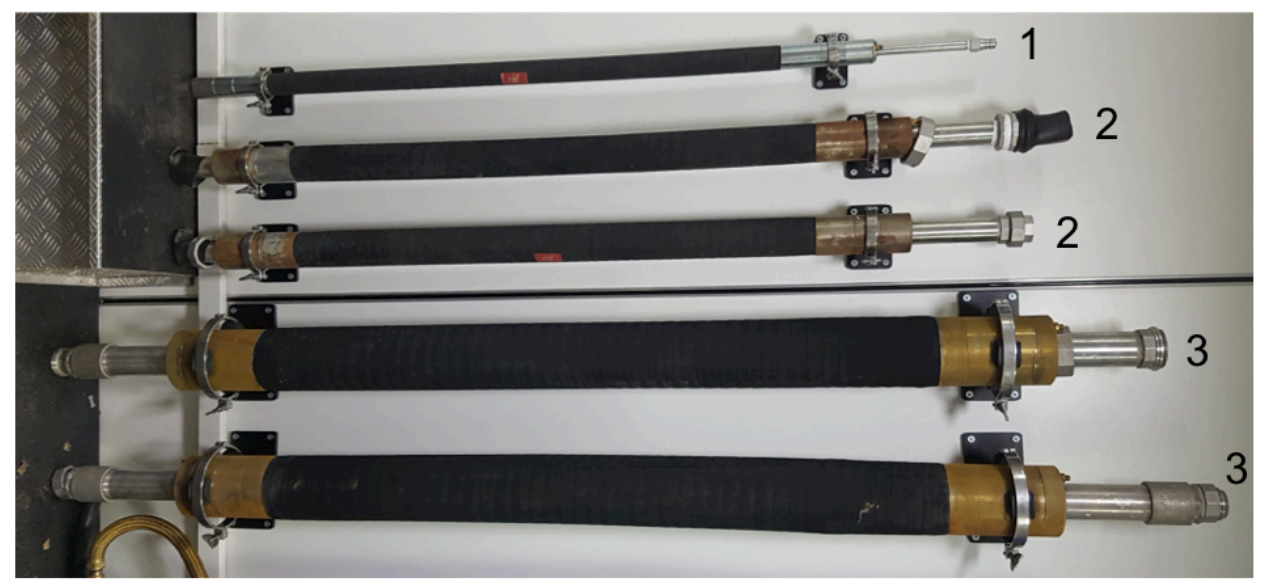

Figura 4.19. Modelos de obturadores utilizados, (1) N Packer; (2) P Packer; e (3) P5-9 Packer

O intervalo entre os obturadores pode variar de acordo com a necessidade do projeto e é definido a partir da avaliação do espaçamento das fraturas e zonas de interesse na etapa de geofísica de poço. O intervalo mínimo é de $1 \mathrm{~m}$ e pode ser ampliado acrescentando-se um tubo de $50 \mathrm{~mm}$ de diâmetro em aço inoxidável no comprimento desejado, com uma união do mesmo material. Contudo, o intervalo entre os obturadores sempre deve conter o tubo perfurado para que haja comunicação com o intervalo de ensaio. 


\section{Equipamentos para monitoramento do nível d'água ou pressão}

Foram utilizados três modelos de medidores de nível d'água para monitorar as variações na coluna de água nos intervalos isolados. Dois fabricados pela Solinst, modelo 102 de $6 \mathrm{~mm}$ de diâmetro com $50 \mathrm{~m}$ de cabo coaxial, e modelo 102 de $10 \mathrm{~mm}$ de diâmetro com $100 \mathrm{~m}$ de cabo coaxial. E um fabricado pela Sauber system com sensor de $18 \mathrm{~mm}$ de diâmetro e $50 \mathrm{~m}$ de cabo tipo fita.

Ao todo foram utilizados quatro modelos de transdutores de pressão, dois analógicos e dois digitais (que possuem um data logger interno). Os sensores analógicos têm seus fios conectados direto ao data logger CR1000 da Campbel Scientificl e os digitais utilizam um conversor de sinal digital que é conectado ao CR1000.

Os transdutores digitais foram adquiridos da Instruments North West (INW), modelos PT2X e CT2X, e possuem um processador interno com comunicação digital (SDI-12 ou RS485 Modbus). Esses sensores têm um software próprio para configuração e calibração que se comunica direto com o computador via cabo USB. Eles não dispõem de bateria interna e precisam de alimentação externa para funcionarem. Os transdutores analógicos são do modelo PDCR 1830 da Druck e modelo MTM3213 da PMC Engineering (PMC). As principais características desses sensores são apresentadas na Tabela 4.2.

Tabela 4.2 Características dos transdutores utilizados com os obturadores

\begin{tabular}{|l|c|c|c|c|c|}
\hline \multicolumn{1}{|c|}{ Sensores } & PT2X & CT2X & PDCR 1830 & PDCR 1830 & MTM3123 \\
\hline Ventilado & não & não & não & não & sim \\
\hline Precisão (\% FS) & 0,05 & 0,05 & 0,1 & 0,1 & 0,1 \\
\hline Precisão (cm) & 17 & 17 & $<1$ & 1 & 1 \\
\hline Resolução (\% FS) & 0,0034 & 0,0034 & ND & ND & ND \\
\hline Resolução (cm) & 1,1 & 1,1 & $<1$ & $<1$ & $<1$ \\
\hline Faixa de trabalho (mH2O) & 0 a 345 & 0 a 345 & 0 a 7 & 0 a 10 & 0 a 10 \\
\hline $\begin{array}{l}\text { Diâmetro externo da } \\
\text { sonda (mm) }\end{array}$ & 19 & 19 & 17 & 17 & 10 \\
\hline $\begin{array}{l}\text { Digital (D) / Analógico } \\
\text { (A) }\end{array}$ & $\mathrm{D}$ & $\mathrm{D}$ & $\mathrm{A}$ & $\mathrm{A}$ & $\mathrm{A}$ \\
\hline sensor de temperatura & $\operatorname{sim}$ & $\operatorname{sim}$ & não & não & não \\
\hline $\begin{array}{l}\text { Compensação da pressão } \\
\text { pela temperatura }\end{array}$ & $\operatorname{sim}$ & $\operatorname{sim}$ & não & não & não \\
\hline Alimentação de energia & Externa & Externa & Externa & Externa & Externa \\
\hline
\end{tabular}




\section{Comunicação com os intervalos isolados}

A comunicação com os intervalos isolados é feita por meio de mangueiras de polietileno (PE) de $20 \mathrm{~mm}$ de diâmetro e/ou tubos de PVC de $50 \mathrm{~mm}$ de diâmetro, que formam um poço temporário quando inflados os obturadores (ilustrado na Figura 4.16).

No caso dos tubos de $\mathrm{PVC}$, foi desenvolvido um sistema de encaixe rápido e vedação com O'ring, que garante a estanqueidade no encaixe de cada tubo, cuja extensão vai de dois a um metro (Figura 4.20). Vazamentos nesses tubos podem alterar o resultado dos ensaios hidráulicos. Após a construção desses tubos, foi realizada uma verificação individual de forma a garantir sua estanqueidade antes do seu uso em campo.

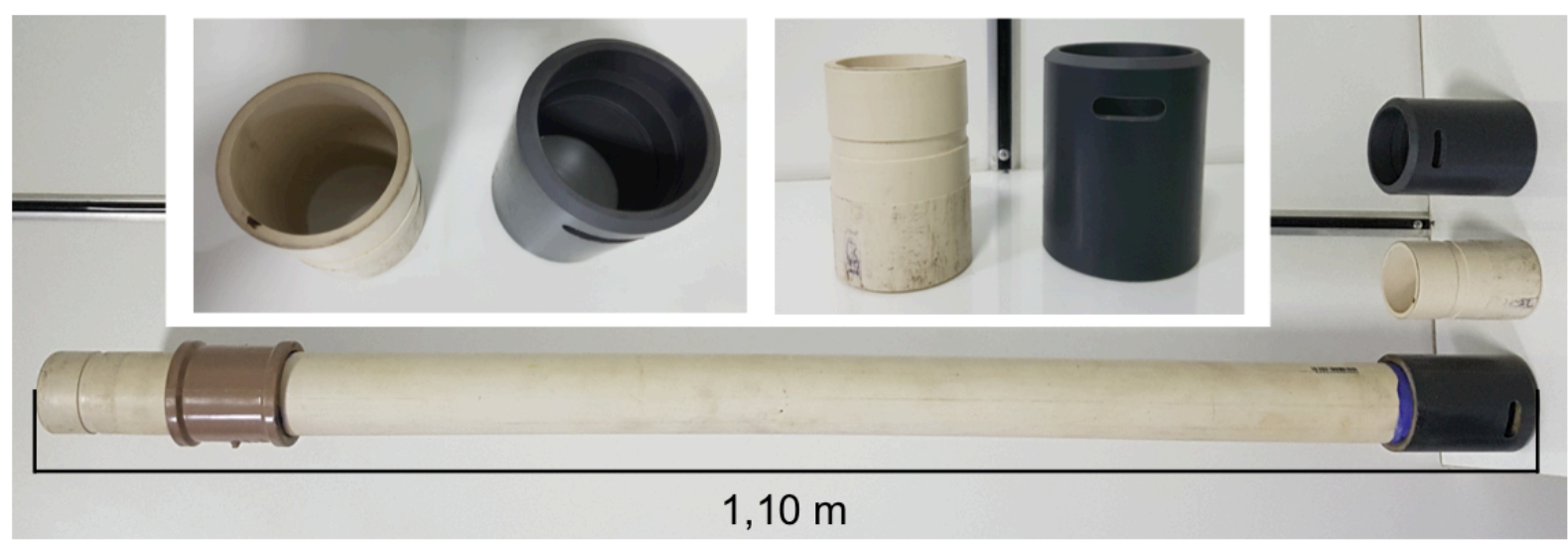

Figura 4.20. Tubo desenvolvido para o fácil acoplamento com vedação de $O$ 'ring entre a cabeça (tubo branco sch 40) e a luva (tubo cinza sch 80). Quando inflados os obturadores, o tubo funciona como poço temporário e permite a comunicação da superfície com o intervalo

Também foram utilizadas válvulas para abrir e fechar a comunicação entre intervalos e as mangueiras em algumas configurações utilizadas. Foram adquiridos os modelos SS-92S4-C e SS8BK-1C da Swagelok (Figura 4.21). As válvulas são abertas por acionamento pneumático com pressão diferencial de 5 e 6 bar respectivamente (pressão de abertura acrescida da pressão hidrostática). 


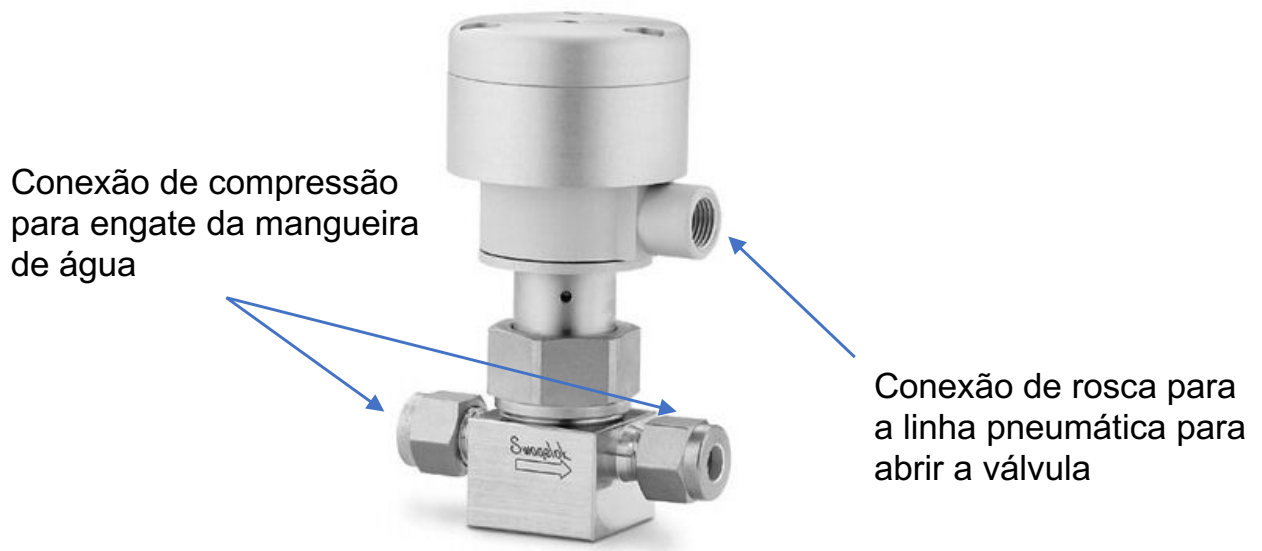

Figura 4.21. Válvula de acionamento pneumático SS8BK-1C da Swagelok (Swagelok, 2019)

\section{Cabeça da composição com passa cabos e tubos}

Foram construídas em aço inoxidável duas cabeças para a composição de obturadores (uma para cada tamanho de conjunto), nas quais foram soldadas alças para fixação da corrente, utilizada para a movimentação. Foram usinadas roscas de diferentes tamanhos para conectar todas as mangueiras, cabos elétricos, eletrônicos e tubos utilizados com a composição (Figura 4.22). Os diâmetros das peças variam de 90 a120 mm. Também foi construído um conjunto de prensa cabo para a base da composição com a finalidade de vedar o cabo do transdutor inferior quando este é posicionado no intervalo inferior.
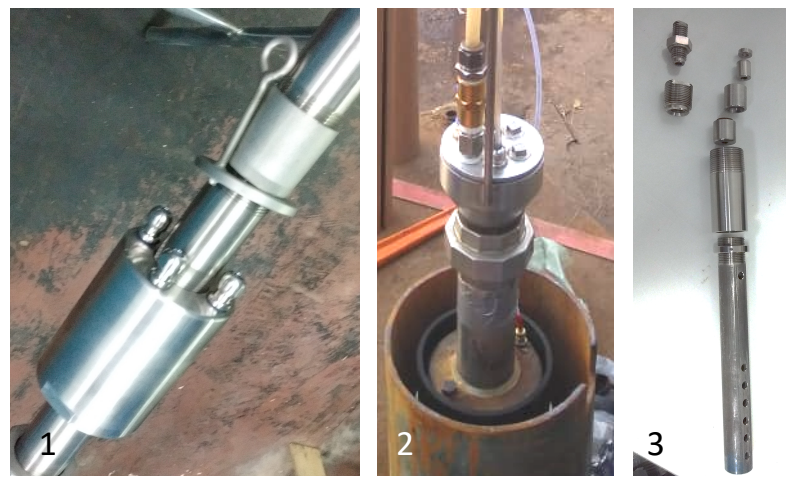

Figura 4.22. (1) cabeça da composição para o conjunto de obturadores P Packer; (2) cabeça da composição para o conjunto de obturadores P5-9 Packer; e (3) prensa cabo para isolamento do intervalo inferior com uma proteção para o transdutor

\section{Equipamentos de superfície}

\section{Sistema de elevação}

O sistema de elevação é composto por: guincho de elevação ou talha elétrica de corrente; mini-guincho; e tripé em alumínio ou estrutura de aço (Figura 4.23). Estes são os componentes responsáveis pela movimentação dos equipamentos dentro do poço. 
O guincho de elevação tem a função de movimentar a composição que é inserida no poço e tem capacidade de carga operacional de $550 \mathrm{Kg}$ e carga máxima de tração de $1.500 \mathrm{Kg}$. Acoplado à polia interna, o guincho dispõe de um contador de profundidade com saída para uma tela em LED, que permite sua visualização durante a operação. A corrente utilizada é feita de aço inoxidável e suporta até $2.000 \mathrm{Kg}$.

A talha elétrica apresenta as mesmas características de trabalho do guincho e utiliza a mesma medida de corrente. O tripé de alumínio chega a $4 \mathrm{~m}$ de altura quando montado e suporta até $3.000 \mathrm{Kg}$. Em seu olhal pode ser acoplada uma polia ou a talha elétrica para fazer a elevação da composição.

O mini-guincho tem a função de elevar o mini-obturador dentro do tubo de PVC, que serve de poço temporário, ou a bomba de amostragem para a realização de ensaios hidráulicos e amostragem de água. Sua carga operacional é de $50 \mathrm{Kg}$, e a carga máxima de tração $120 \mathrm{Kg}$. A elevação pode ser feita utilizando a mangueira conectada à bomba e ao mini-obturador ou por meio de cabo de aço, este segundo mais recomendado.

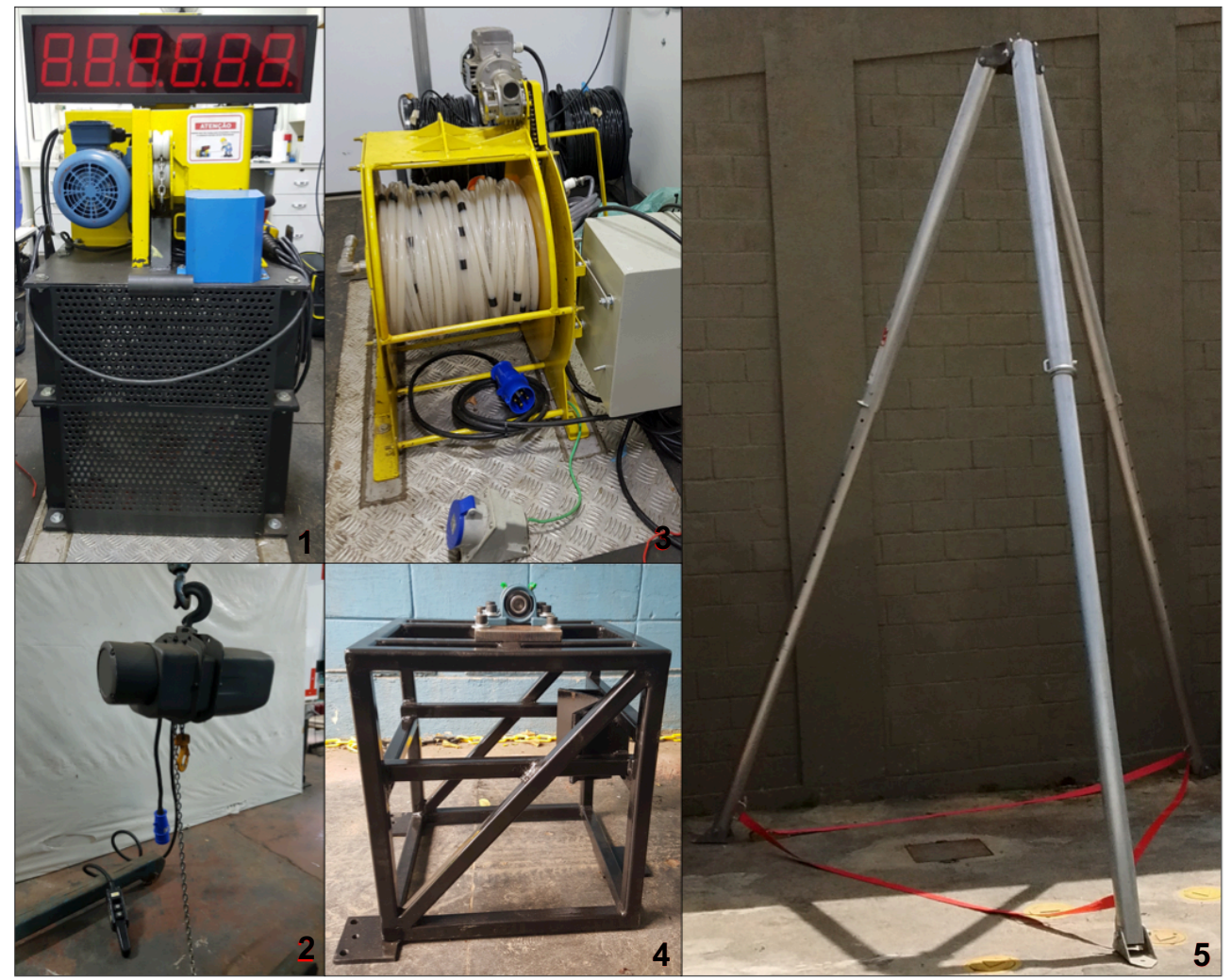

Figura 4.23. Componentes do sistema de elevação (1) Guincho de corrente; (2) talha de corrente; (3) miniguincho; (4) estrutura de aço para utilização do guincho; e (5) tripé em alumínio para utilização da talha elétrica 


\section{Componentes hidráulicos e pneumáticos}

Os componentes hidráulicos são: bomba centrífuga Grundfos MP1 e inversor de frequência SPE; medidor de vazão ultrassônico; medidor de nível d'água; tanque de água com capacidade de 100 L; bomba centrífuga para pressurização da linha de água para os ensaios de injeção de água; e sistema de tubulações e registros para o controle de injeção e bombeamento de água (Figura 4.24).

O medidor de vazão ultrassônico modelo UFM145 foi adquirido da FMM CCEI (FMS), pode ser alimentado por corrente contínua e alternada bivolt. O medidor é composto por um data logger próprio, par de transdutores e cabo de alimentação (Figura 4.24, números 4 e 5). A fixação dos transdutores que medem o fluxo é feita na parte externa do tubo. O UFM145 tem capacidade para medir vazões de 0,1 a 4.000 1/s em tubos de diâmetros de 12,5 a 6.000 mm. As medições são projetadas em um painel de LED e um sinal 4-20 mA pode ser enviado ao CR1000 para registro e visualização em tempo real junto com os demais sensores.
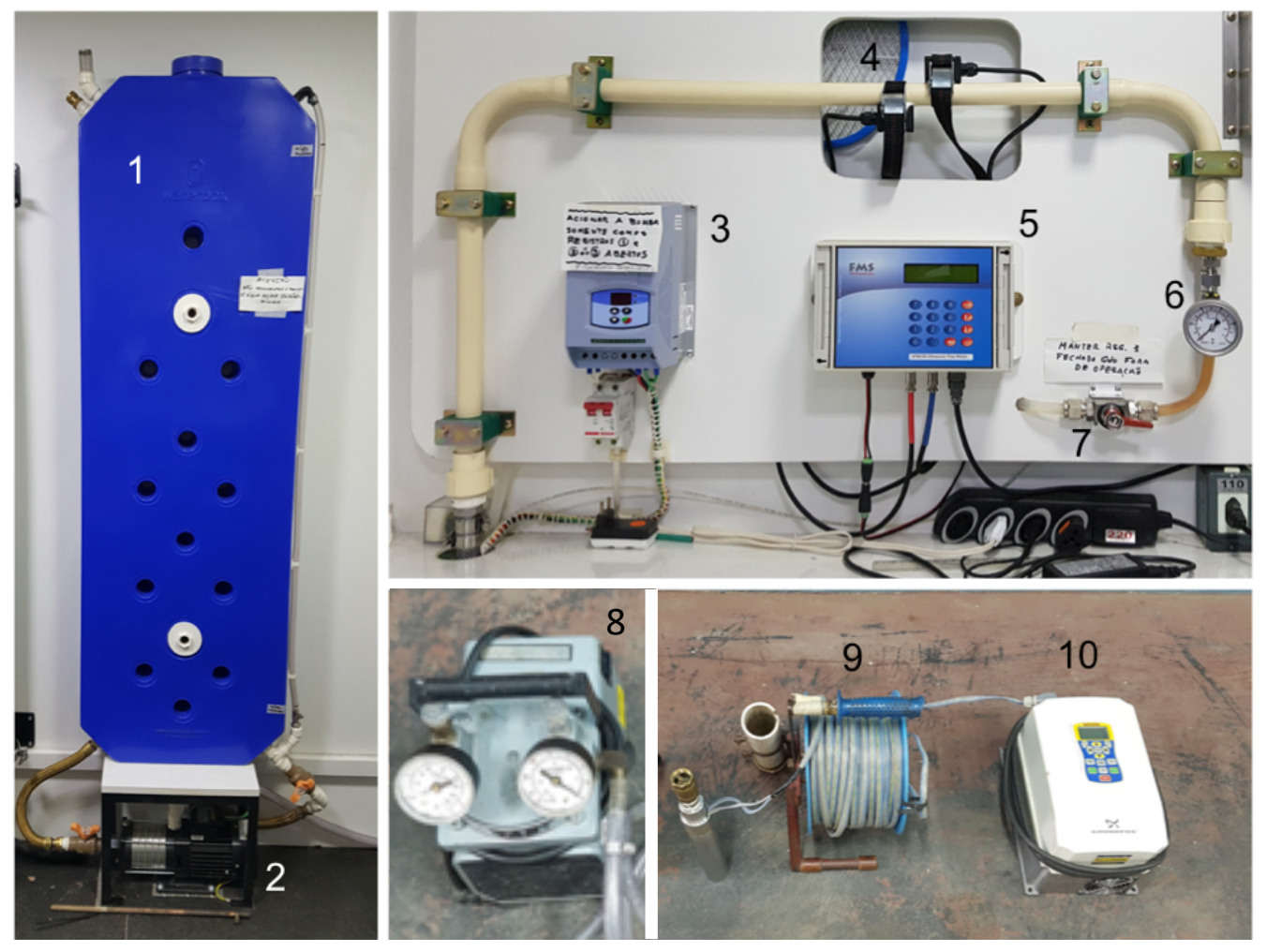

Figura 4.24. Componentes hidráulicos: (1) tanque pulmão para regularização da pressão de entrada na bomba (2) bomba centrifuga de pressurização da linha de injeção; (3) inversor de frequência utilizado para controlar a bomba centrífuga; (4 e 5) medidor de vazão ultrassônico; (6 e 7) manômetro e registro da linha de injeção de água; (8) bomba de pressão e vácuo utilizada no ensaio de pulso pneumático; (9 e 10) bomba Grundfos MP1 e inversor de frequência para controlar a vazão 
A bomba elétrica utilizada é o modelo MP1 fabricada pela Grundfos e possui capacidade de recalque de até $90 \mathrm{~m}$ (Figura 4.25). Essa bomba centrífuga foi desenvolvida para a coleta de amostras de água subterrânea em poços de $50 \mathrm{~mm}$ de diâmetro. O inversor SE1 regula a vazão de bombeamento com o ajuste da frequência do rotor. Seu funcionamento requer uma voltagem de entrada monofásica de $220 \mathrm{~V}$ e na frequência máxima demanda uma corrente de $5 \mathrm{~A}$.

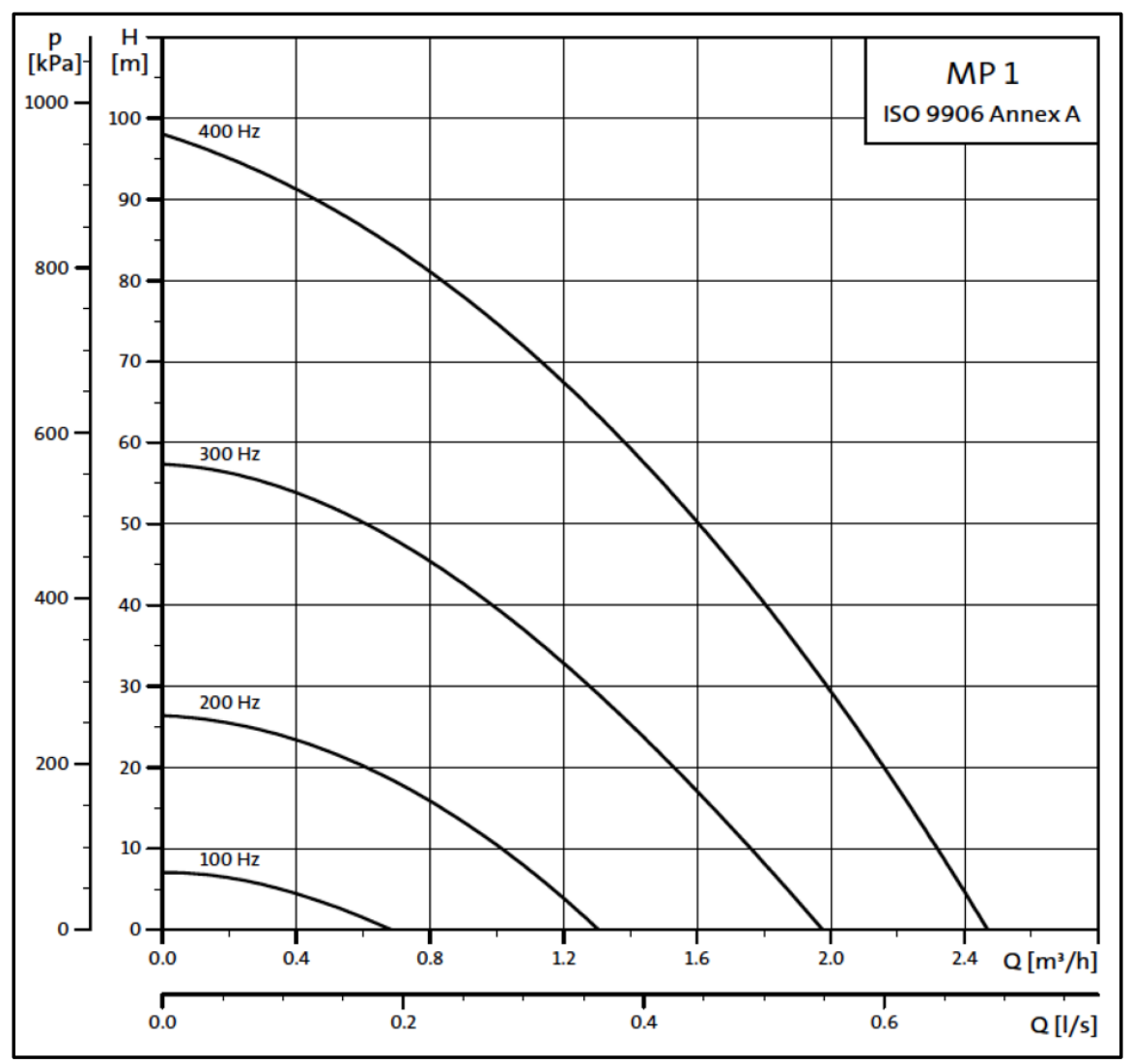

Figura 4.25. Curvas características da MP1 (Grundfos, 2019)

Os componentes pneumáticos são: cilindros para gás nitrogênio com capacidade de 50 L; regulador de pressão para alimentar a linha pneumática; conjunto de mangueiras e registros (Figura 4.26). O sistema pneumático de amostragem de água é composto por um conjunto de válvulas de retenção, controladora de ar eletrônica (regula o tempo de injeção e pressão de ar na linha), e cilindro de gás nitrogênio. Um desenho esquemático desse sistema é apresentado na Figura 4.27. 

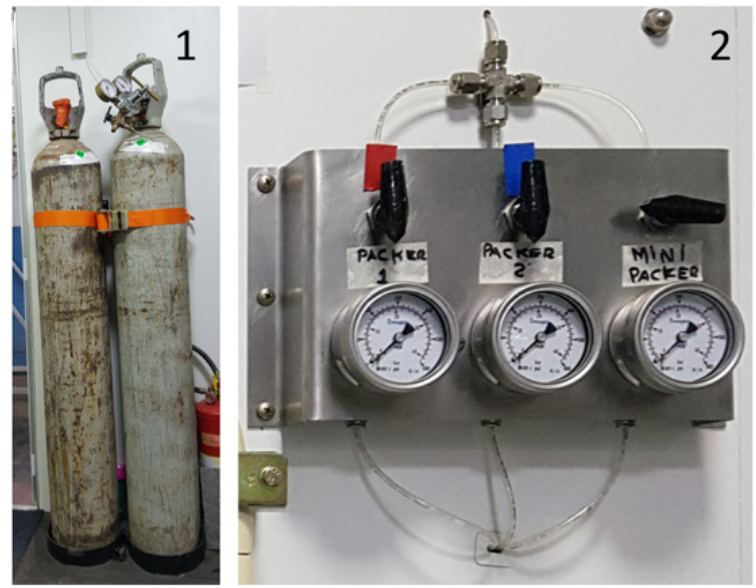

Figura 4.26. Componentes pneumáticos: (1) cilindros de nitrogênio de 50 1; e (2) registros e manômetros utilizados para inflar os obturadores, fazer amostragem e abrir as válvulas pneumáticas

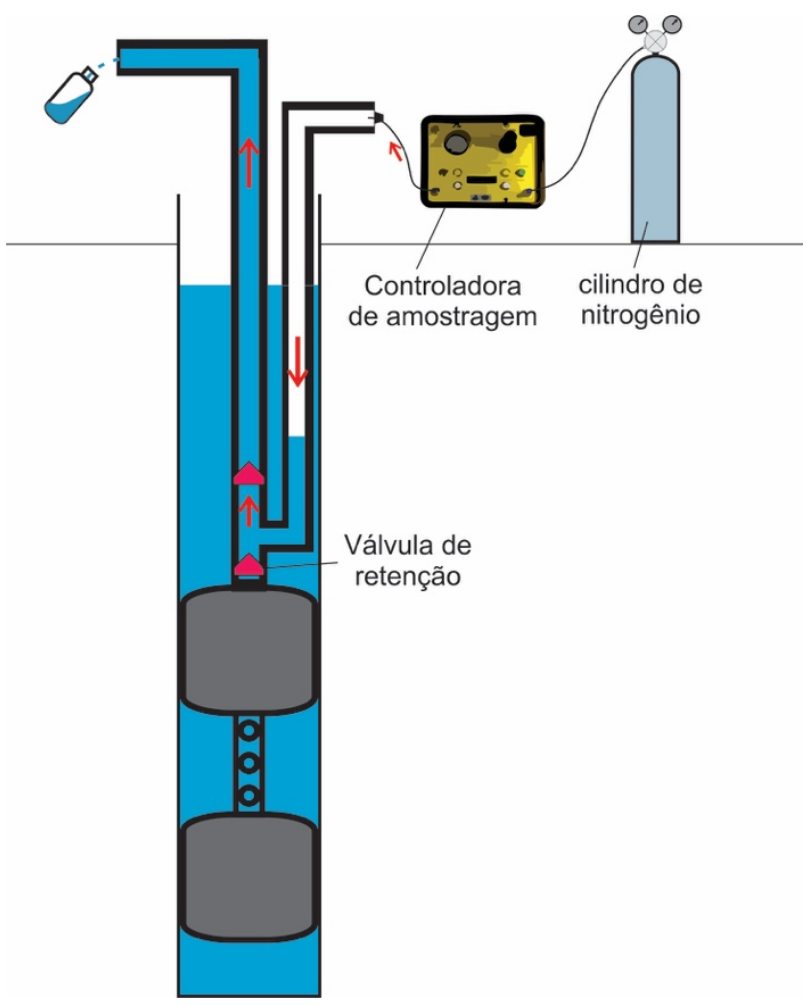

Figura 4.27. Sistema de amostragem de baixa vazão com válvulas de retenção e controladora de pressão alimentada com gás nitrogênio

\section{Sensores e componentes eletrônicos}

Os componentes eletrônicos são: data logger CR1000 da Campbell Scientific que integra a leitura e registro de todos os sensores utilizados; computador com software Loggernet; sensores de pressão já mencionados nos componentes inseridos no poço; barômetro modelo 61302 da Young, que é utilizado para fazer compensação barométrica dos registros de pressão dos transdutores; medidor de vazão tipo turbina; e medidor de vazão ultrassônico da FMS, já mencionado neste item. 
O CR1000 (Figura 4.28) pode trabalhar com praticamente todos os tipos de sensores com uma resposta elétrica. Os sinais elétricos são recebidos e convertidos em formato ASCII ou binário e armazenados em sua memória digital, até que sejam transferidos para um computador por meio de um cabo RS232.

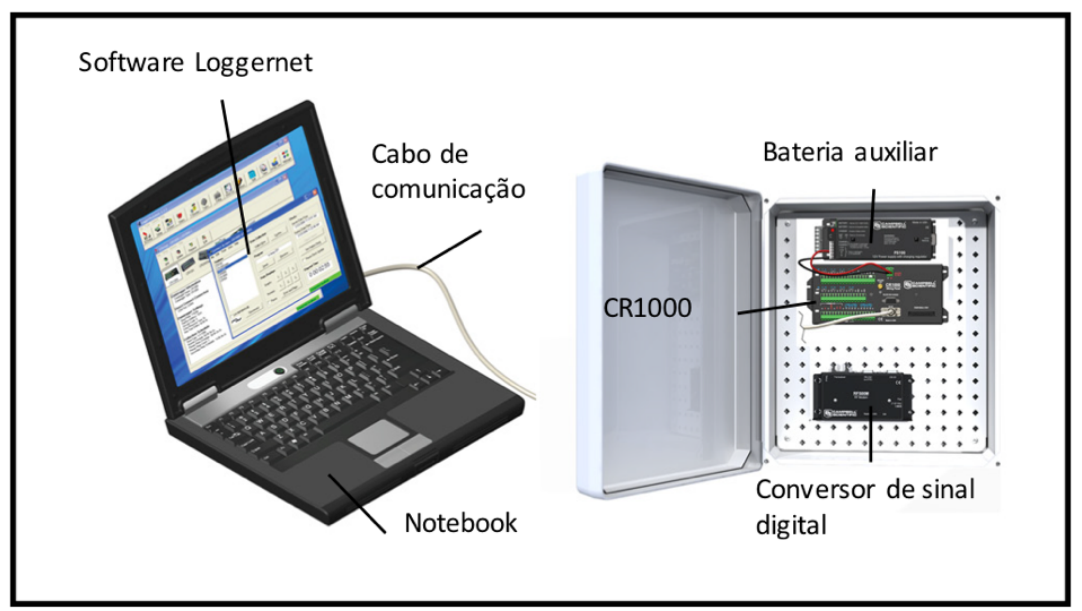

Figura 4.28. Sistema de comunicação e processamento de dados composto pelo CR1000, conversor de sinal digital, computador e software

O CR1000 dispõe de entradas analógicas, entrada/saída CSI/O e RS232 que podem ser utilizadas a depender do tipo de sensor utilizado. Sua alimentação é de $12 \mathrm{~V}$ (variação aceitável 9,6 a 16 V) e possui saídas de 5 e 12 V. Na operação da MUST, a alimentação do CR1000 é feita de duas maneiras, por uma fonte $12 \mathrm{~V}$ ligada ao estabilizador durante a operação diária e por baterias ( 8 baterias tamanho D2 de 1,5 V). A identificação das portas e layout do CR1000 são apresentadas na Figura 4.29.

A interface de comunicação do CR1000 com o computador é realizada por meio do software para Windows LoggerNet (Figura 4.30). No setup é configurado um data logger específico e no connect é estabelecida a comunicação. Toda a parte de programação do data logger e leitura dos sensores é realizada pela interface de programação do CRBasic Editor, como será descrito a seguir. 


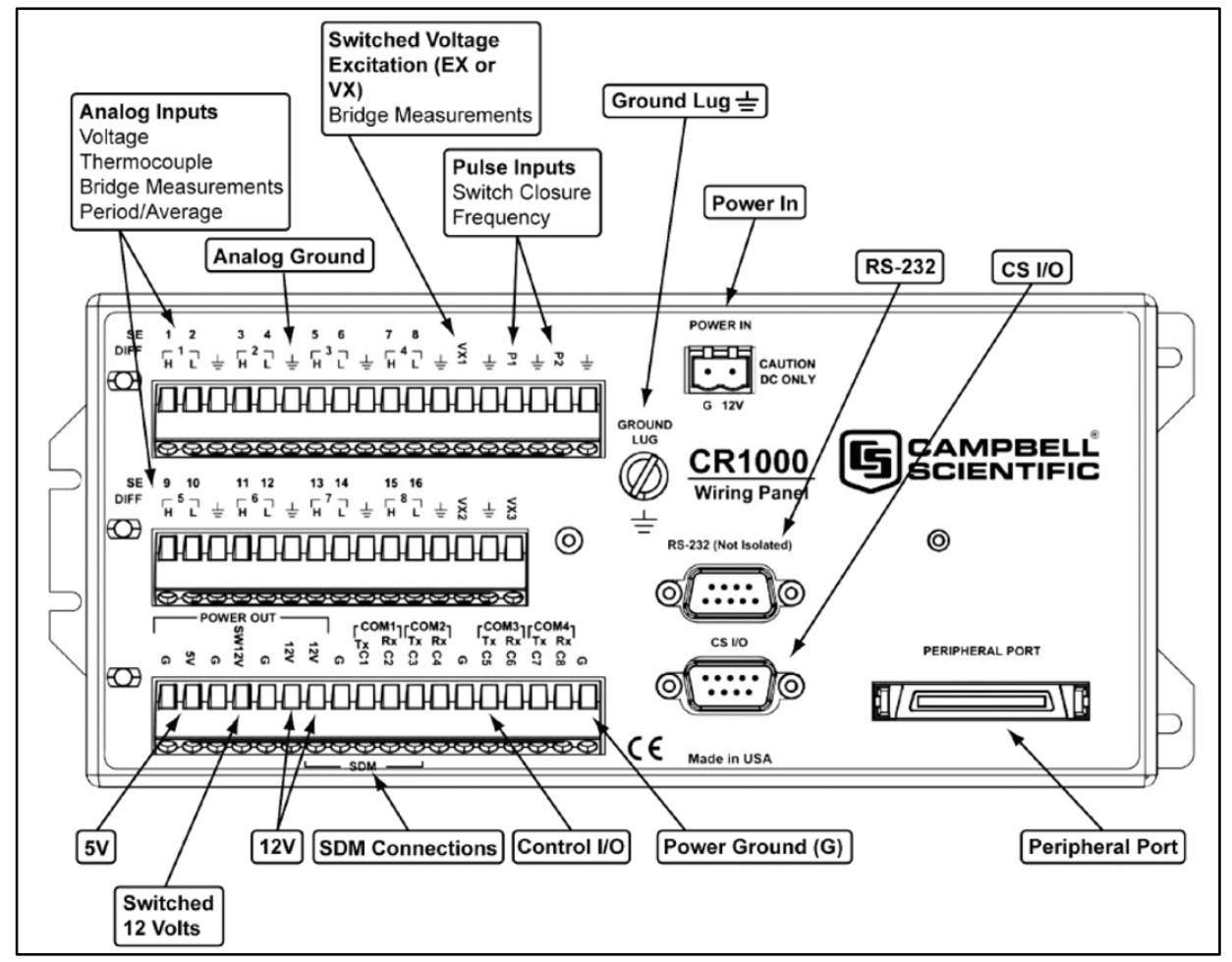

Figura 4.29. Entradas, saídas e conexões do CR1000 (Campbell, 2019)

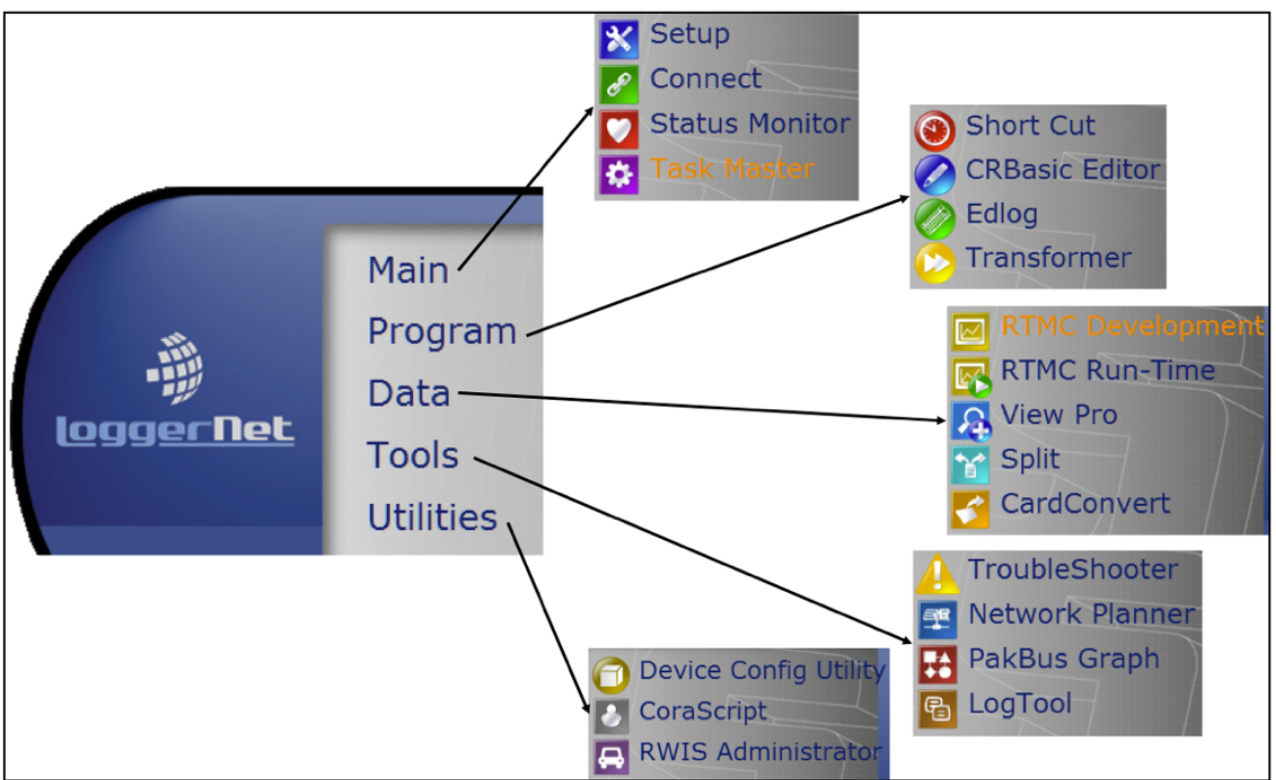

Figura 4.30. Interface do software LoggerNet

O barômetro modelo 61302 da Young possui saída analógica e suas características são apresentadas na Figura 4.31, bem como sua configuração de conexão com o CR1000. 


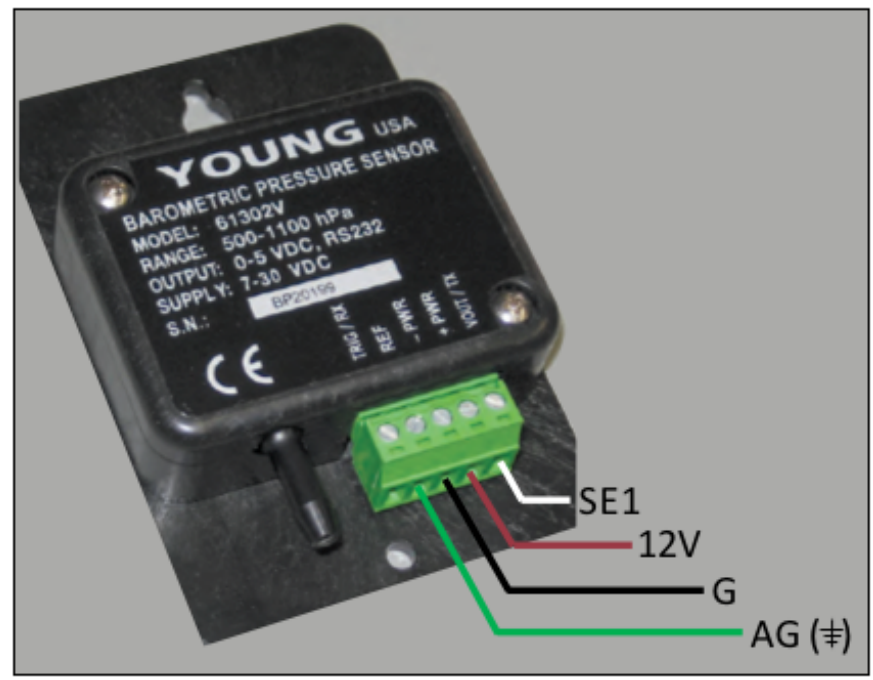

Figura 4.31. Características do barômetro 61302 da Young

\subsubsection{Método para a realização de ensaios hidráulicos e amostragem}

Com base nos intervalos de interesse identificados na etapa de geofísica são planejados os intervalos a serem ensaiados com os obturadores. Embora seja possível a alteração do espaçamento entre obturadores durante a realização de ensaios em um poço, na prática, isso requer muitas horas de trabalho em campo. Portanto, quanto menor o número de alterações na configuração da composição após iniciados os ensaios, maior a produtividade. A dificuldade para alterar a configuração da composição é ainda maior quando o sistema de movimentação da composição não possibilita sua inserção no poço em uma única manobra, o que geralmente acontece nos casos em que não é utilizado um sistema de elevação com pelo menos 6,5 m de altura.

As características e especificidades da unidade móvel que foi desenvolvida para este trabalho são apresentadas no capítulo de resultados. Neste capítulo são descritas as etapas e método de trabalho genérico que compreendem o uso de obturadores.

\section{Montagem da composição}

A configuração da composição deve levar em consideração as características do poço (variação do diâmetro, profundidade total e profundidade do nível d'água), e os tipos de ensaios e amostragem a serem realizados. A montagem da composição de obturadores requer alguns cuidados. Todos os equipamentos e componentes são inspecionados visualmente, e os transdutores e válvulas são testados. Caso necessário, os transdutores e válvulas de retenção reguláveis devem ser calibrados. Uma vez definida a melhor configuração para o trabalho, todos os componentes são montados e inseridos no poço. 
Geralmente a montagem envolve: um par de obturadores separados por um tubo perfurado; dois transdutores de pressão montados nos intervalos intermediário e inferior ou conectados a mangueiras que comunicam com esses intervalos; sistema de amostragem no intervalo intermediário; cabeça da composição para acoplar o sistema de movimentação e mangueiras e cabos. O transdutor que monitora o nível superior sempre é inserido pela boca do poço antes de inflar os obturadores.

\section{Ensaio de funcionamento de sistema}

Um primeiro ensaio de funcionamento de todos os componentes é realizado na boca do poço. Essa é uma etapa essencial para verificar problemas de montagem e falha nos componentes e equipamentos da composição. Uma simples conexão mal apertada, ou uma mangueira desconectada, pode causar problemas em profundidade, embora seja facilmente resolvido com os equipamentos ainda em superfície. O roteiro de testes é descrito a seguir:

1. inserir a composição toda dentro do poço e preparar todos os componentes para iniciar a descida;

2. inflar os obturadores com pressão de 10 bar, pressão diferencial máxima de trabalho utilizada durante a operação, e aguardar até que a pressão e a expansão das borrachas estabilizem;

3. fechar a linha de pressurização dos obturadores e verificar se há variação na pressão das borrachas (com os manômetros), por pelo menos uma hora, para se certificar que não há vazamento nos obturadores ou na linha pneumática. É boa prática percorrer as linhas de ar e procurar por ruídos de vazamento, normalmente audíveis nessa faixa de pressão;

4. ainda com os obturadores inflados, encher o intervalo entre os obturadores com água (o volume de água necessário depende do diâmetro do poço e do espaçamento entre os obturadores);

5. fechar todas as saídas de água conectadas ao intervalo intermediário e pressurizar o intervalo com água;

6. fechar o registro da linha de água e utilizar um manômetro para acompanhar a variação da pressão por pelo menos uma hora;

7. fazer uma inspeção visual nas linhas de água e na cabeça da composição procurando por vazamentos de água; 
8. verificar se a pressão de água no sistema medida pelo manômetro é coerente com a leitura no transdutor de pressão posiciona/conectado ao intervalo intermediário;

9. caso sejam identificados vazamentos que não possam ser resolvidos durante o ensaio, despressurizar e o sistema, realizar o reparo e repetir o ensaio; e

10. caso nenhum vazamento de ar ou água seja observado, despressurizar o sistema e preparar para a movimentação da composição.

\section{Movimentação}

Uma vez concluído com sucesso o ensaio de todo o sistema, a movimentação da composição pode ser iniciada. Quando dentro da água, é necessário realizar a equalização da pressão interna dos obturadores com a coluna de água, evitando que as borrachas amassem ou inflem (Equação 4.2). Conforme é realizada a movimentação da composição, são adicionados ou retirados os tubos e mangueiras utilizados para comunicar o sistema com a superfície.

$$
P_{\text {obturador }}=(\text { Profundidade composição }- \text { Profundidade nível d'água }) \times 0,1
$$

Equação 4.2

Pobturador - pressão que deve ser aplicada no obturador em bar Observação: A diferença de peso específico da água em função da temperatura e salinidade foi considerada desprezível para esta operação. A diferença de pressão entre o obturador e a coluna de água, ou leitura do sensor, nunca deve ser superior a 1 bar

\section{Ensaio de estanqueidade de um trecho alvo}

Após o posicionamento da composição no intervalo alvo, os obturadores podem ser inflados. A pressão diferencial utilizada é de 7 bar, que deve ser somada à pressão da coluna de água (Equação 4.2). Geralmente, no ensaio de estanqueidade é aplicado um pulso de aumento da pressão no intervalo. Segundo QUINN, CHERRY e PARKER, (2012), essa pressurização do intervalo promove a limpeza das fraturas que podem ter acumulado sujeira proveniente do poço. O procedimento para isolamento e ensaio de estanqueidade é descrito a seguir:

1. Antes de inflar os obturadores, registrar a pressão dos transdutores de pressão e medir a profundidade do nível d'água. O transdutor que monitora o nível superior é inserido direto da superfície pela boca do poço e fixado para não mudar o seu referencial durante o ensaio. É importante se certificar de que os dados dos transdutores estão sendo gravados no data logger.

2. Inflar os obturadores com pressão diferencial de 7 bar; 
3. Acompanhar a resposta da pressão durante o processo de isolamento e estabilização de cargas (Figura 4.32);

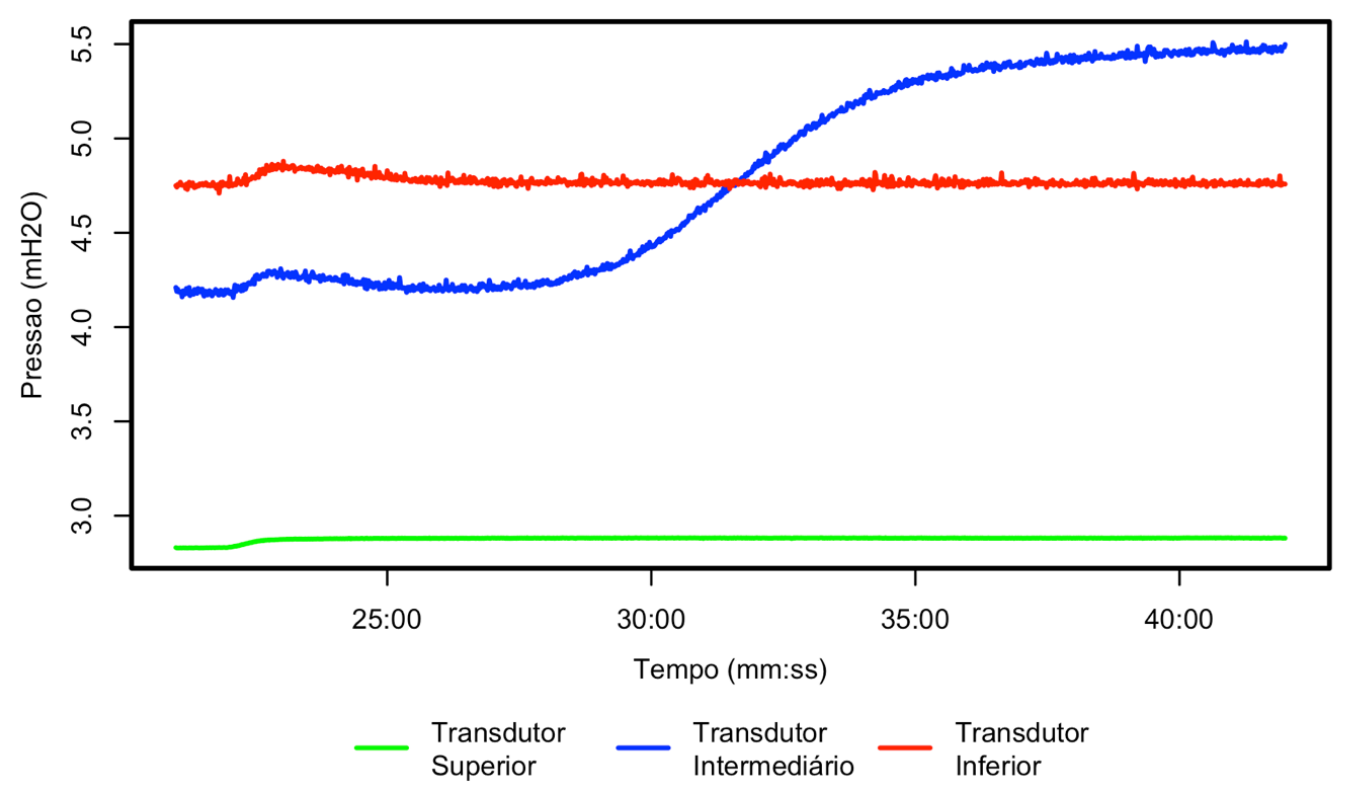

Figura 4.32. Processo de isolamento de um intervalo e estabilização da carga hidráulica

4. Após a estabilização parcial (curva de pressão próxima ao eixo horizontal) dos três níveis (quando inflados dois obturadores) preparar um ensaio de pulso. Esse pode ser pneumático ou hidráulico com incremento ou redução da pressão no intervalo alvo

5. Realizar o ensaio de pulso com pelo menos um metro de coluna de água de distúrbio. A vantagem do pulso de pressão de ar é que em zonas de baixa transmissividade o ensaio pode ser interrompido sem a necessidade de aguardar longos períodos até a estabilização da pressão

6. Acompanhar a pressão nos níveis superior e inferior ao intervalo ensaiado. Existem quatro respostas possíveis durante este tipo de ensaio:

a. Sem vazamento e sem fluxo no intervalo: Não há variação da pressão nos níveis superior e inferior, portanto não há vazamento, e o distúrbio causado no intervalo intermediário permanece estável, sem indício de retornar à pressão original (Figura 4.33); 


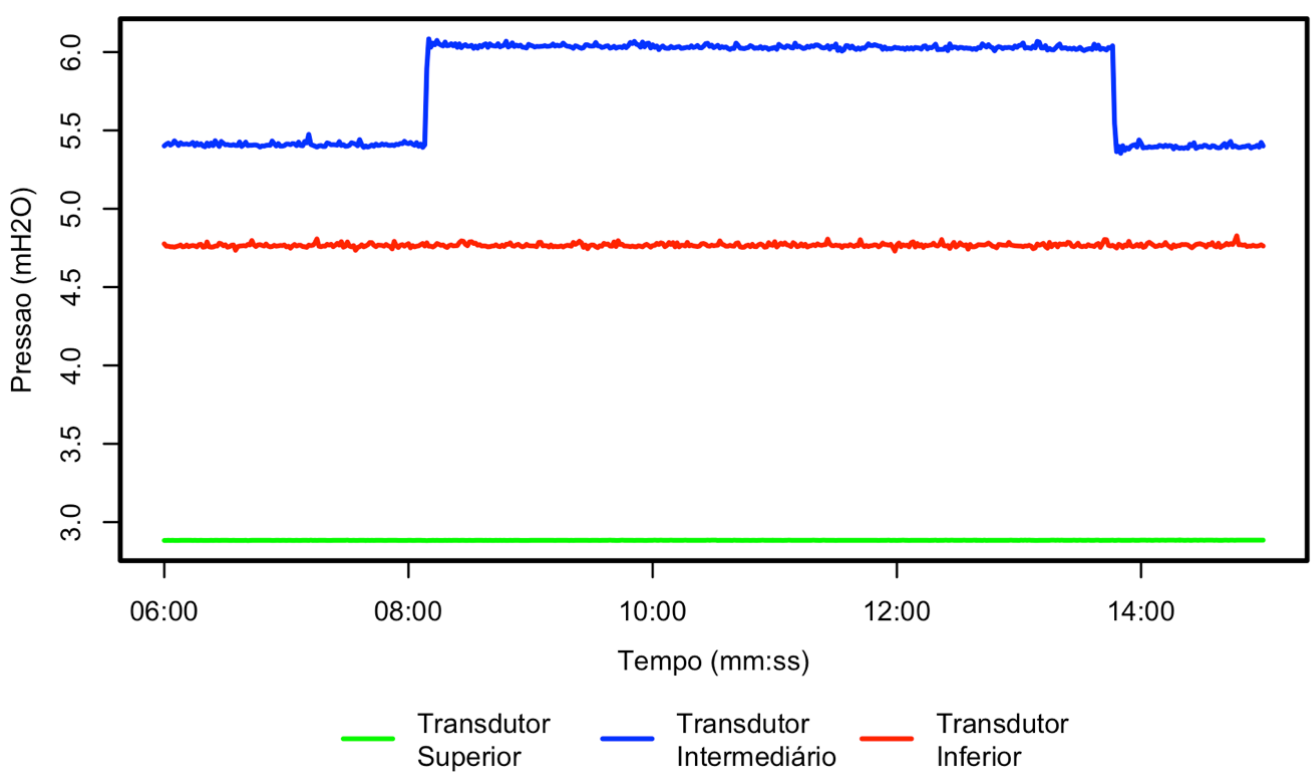

Figura 4.33. Ensaio de estanqueidade em um intervalo que não apresentou fluxo. Foram aguardados 6 min e nenhuma alteração da pressão no intervalo intermediário foi observada

b. Sem vazamento e com fluxo no intervalo: Não há variação da pressão nos níveis superior e inferior, portanto não há vazamento, e o distúrbio causado no intervalo intermediário tende a retornar à pressão inicial (Figura 4.34);

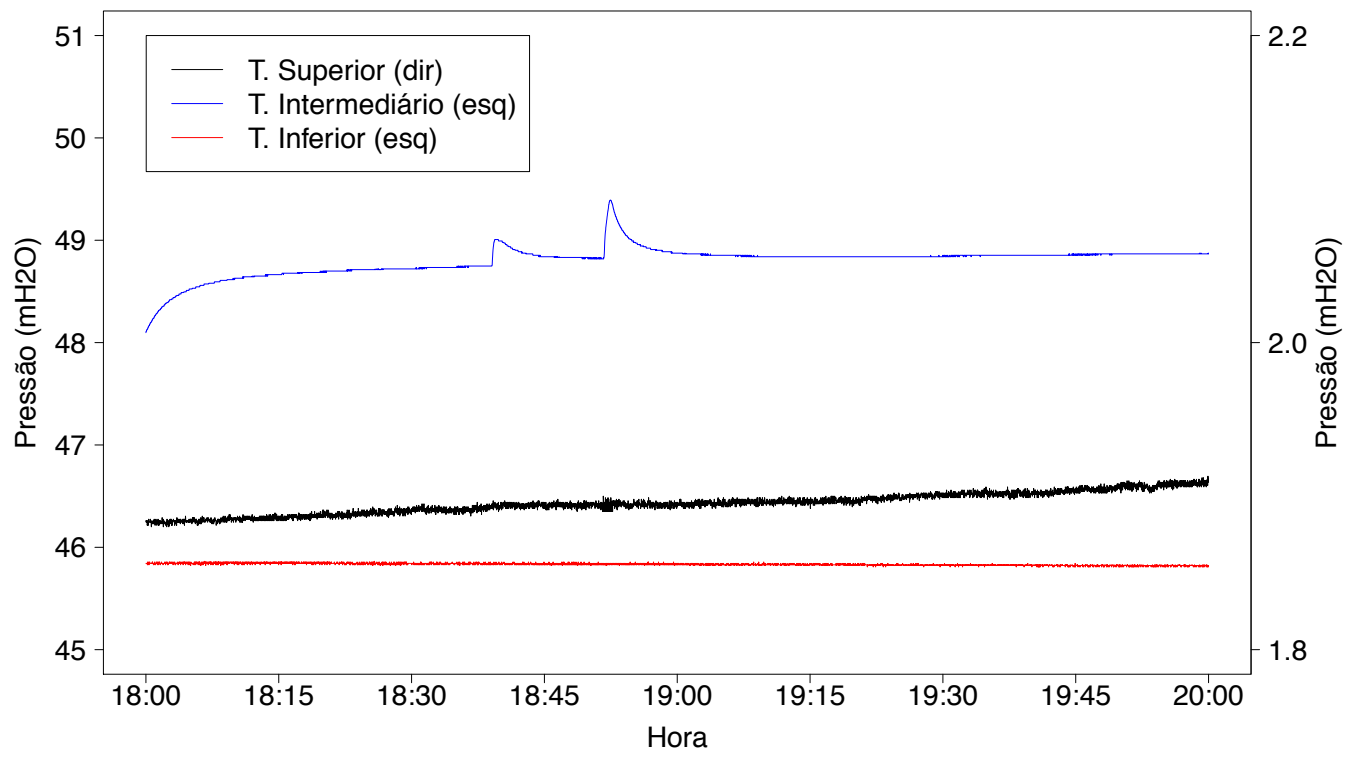

Figura 4.34. Dois ensaios de pulso com injeção de água em um intervalo. Não foram observados vazamentos para os níveis adjacentes

c. Com vazamento no intervalo superior: variação da pressão no intervalo de ensaio e vazamento para o nível superior (Figura 4.35); 


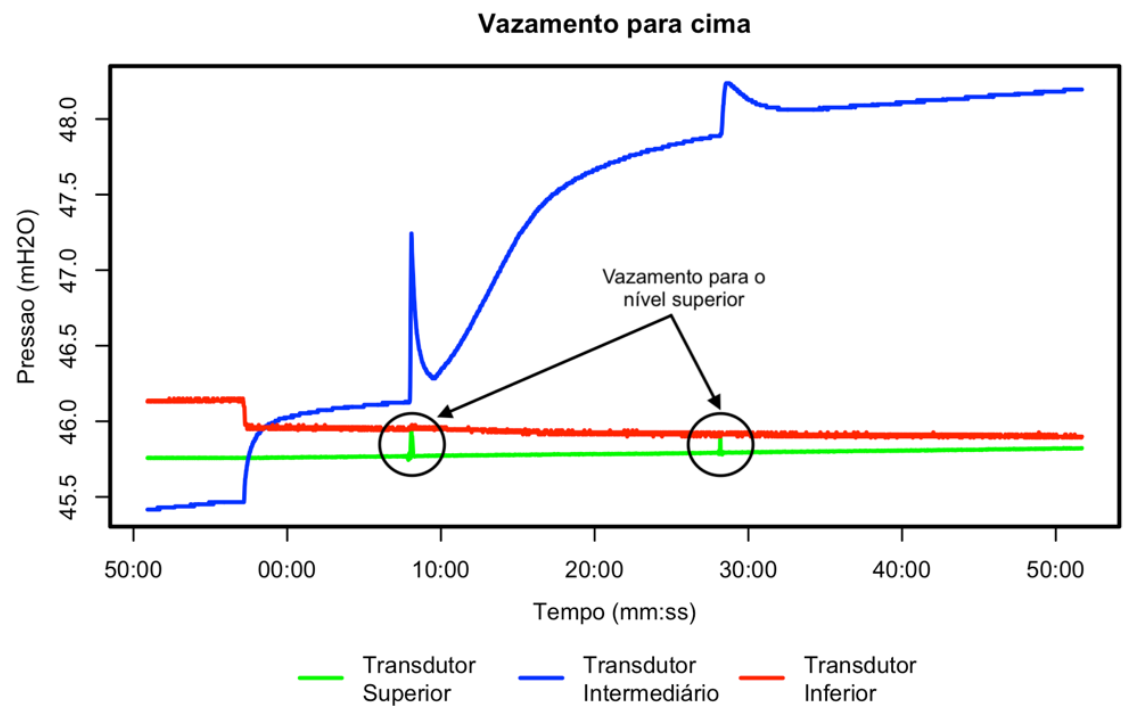

Figura 4.35. Processo de isolamento de um intervalo e ensaio de estanqueidade com vazamento para o nível superior. Após constatado vazamento a pressão no obturador foi aumentada e um novo ensaio foi realizado, que mesmo assim apresentou vazamento

d. Com vazamento no intervalo inferior: variação da pressão no intervalo de ensaio e vazamento para o nível inferior (Figura 4.36); e

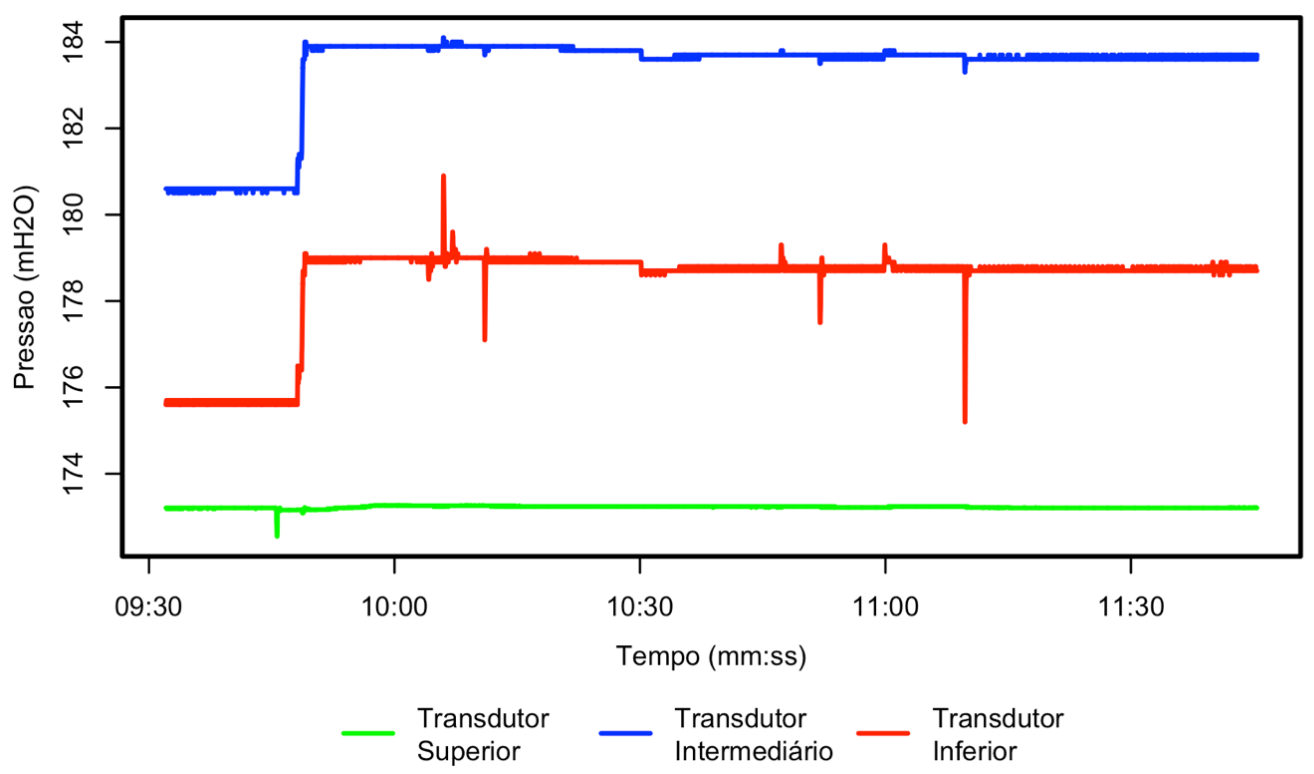

Figura 4.36. Processo de isolamento de um intervalo e ensaio de estanqueidade com vazamento para o nível inferior

e. Com vazamento nos dois intervalos: variação da pressão observada nos três intervalos. 
O registro do ensaio de estanqueidade é importante para documentar e organizar os dados obtidos em campo, um modelo de ficha de campo é apresentado na Figura 4.37.

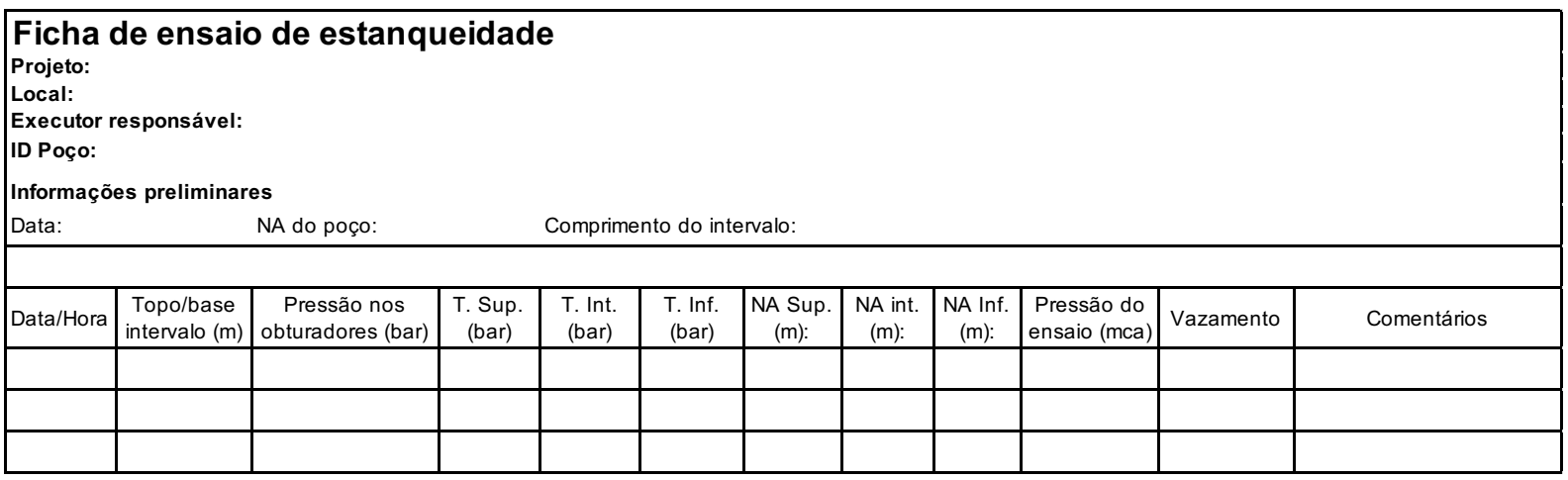

Figura 4.37. Modelo de ficha de campo para o ensaio de estanqueidade de intervalos isolados

Caso o intervalo obturado não apresente fluxo (quando não há vazamento ou quando o intervalo com vazamento também não apresenta fluxo), pode ser classificado como não transmissivo (ou abaixo do limite de quantificação), e a composição é movimentada para o próximo intervalo. Vazamentos pelo obturador costumam apresentar uma resposta quase que instantânea nos transdutores dos níveis adjacentes. Quando isso ocorre, duas ações podem ser tomadas: (1) aumentar a pressão no obturador cujo vazamento foi observado; e caso o problema não seja resolvido, (2) realizar o reposicionamento da composição, com base nos perfís geofísicos, e repetir o procedimento do ensaio de estanqueidade e ensaio.

Quando não se obtém um isolamento satisfatório, mesmo com repetidas tentativas de reposicionamento, pode-se utilizar apenas um dos obturadores, que tenha apresentado um bom selo, para obter os dados hidráulicos de todo o trecho. Posteriormente, os dados obtidos podem ser comparados com os demais ensaios realizados para avaliar a diferença de transmissividade por meio de uma regressão linear. Contudo, a comparação entre ensaios deste tipo deve levar em consideração a precisão do método. Variações abaixo de uma ordem de magnitude podem representar imprecisão do método, e não zonas distintas.

\section{Medição de cargas hidráulicas}

A medição de cargas hidráulicas em dois ou três níveis é realizada tanto pelo registro de pressão nos transdutores como por medidas de nível d'água com um medidor do tipo fita. $\mathrm{O}$ procedimento para determinar a carga hidráulica é descrito a seguir:

1. registrar as pressões medidas nos transdutores e o nível d'água com o medidor antes de inflar os obturadores. É importante se certificar de que os dados dos transdutores estão sendo gravados no data logger; 
2. inflar os obturadores e esperar a estabilização das cargas hidráulicas nos três níveis;

3. registrar as pressões medidas nos transdutores, e os níveis d'água medidos com o medidor, nos três níveis; e

4. calcular a variação da pressão, ou da coluna de água, para cada um dos níveis. Corrigir todas as leituras para um mesmo ponto de referência, no caso a cota da boca do poço. No caso dos transdutores, as leituras são de coluna de água sobre o transdutor, e deve-se acrescentar a profundidade do nível d'água para obter a carga hidráulica. No caso do medidor de nível, basta subtrair a leitura da cota da boca do poço (Figura 4.38).

Um aspecto importante a ser observado em medições de carga hidráulica é a questão da estabilização da pressão no intervalo. Zonas com baixa transmissividade podem levar muitas horas ou mesmo dias até atingir o equilíbrio e, portanto, esse dado deve ser avaliado com cuidado, especialmente quando as diferenças entre cargas forem pequenas. Podem existir, também, trechos em que a transmissividade é zero, ou muito próximo disso - nesses casos, não é possível fazer o registro de carga hidráulica. Outro aspecto que pode ter grande impacto em medições de carga hidráulica é a existência de influências externas, como bombeamento de poços nas imediações da área de estudo, que podem afetar a estabilização.

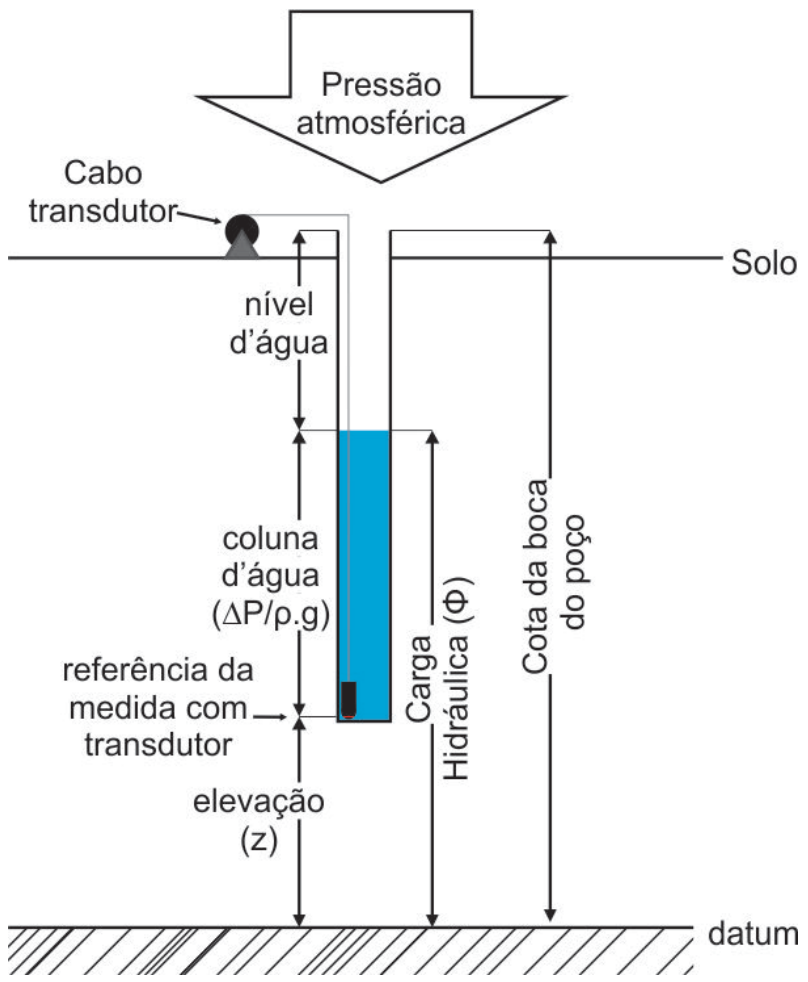

Figura 4.38. Referência para o cálculo da carga hidráulica a partir das medidas de pressão e nível d'água 


\section{Ensaio hidráulico}

Para este projeto foram utilizados quatro tipos de ensaios hidráulicos, a depender das características de cada intervalo obturado. O critério de escolha é a transmissividade, que pode ser estimada a partir da resposta do intervalo ao ensaio de estanqueidade. Intervalos com transmissividade muito baixa a média são ensaiados preferencialmente pelo método de carga constante ou de pulso. Já os trechos com transmissividade elevada são ensaiados por bombeamento e recuperação.

\section{Ensaio de pulso}

Os ensaios de pulso são os primeiros a serem realizados, uma vez que a configuração é a mesma utilizada no ensaio de estanqueidade. Em geral, é realizada uma sequência de pulsos, pelo menos três, com deslocamentos variados da coluna de água, ou pressão. O ensaio com água é feito com a injeção de um pulso, o que seria equivalente ao ensaio denominado slug test. O ensaio pneumático (Figura 4.39) permite tanto a aplicação de vácuo como pressão no intervalo ensaiado, equivalentes aos ensaios slug e bail test, respectivamente. Esses ensaios são análogos e devem resultar em valores semelhantes de transmissividade.

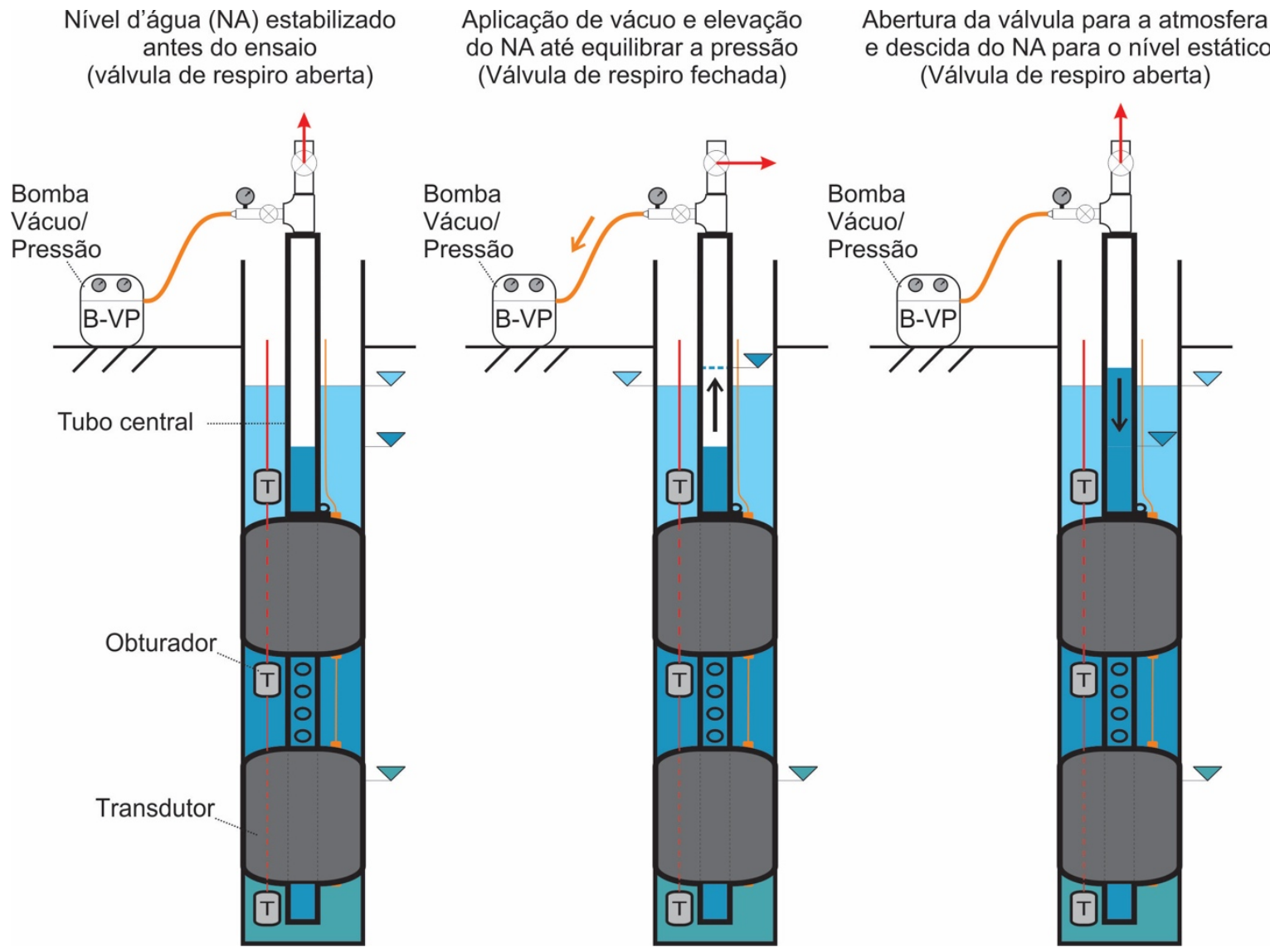

Figura 4.39. Etapas do ensaio de pulso com aplicação de vácuo no intervalo isolado 
O procedimento para a realização dos ensaios é descrito a seguir:

\section{Pulso com água}

1. encher o tanque pulmão de água e verificar se todos os registros estão abertos;

2. registrar os valores de pressão e nível d'água nos três intervalos. É importante se certificar de que os dados dos transdutores estão sendo gravados no data logger;

3. fechar a linha de amostragem de água (bomba centrífuga ou pneumática) para evitar o efeito de vasos comunicantes. É desejável que a mangueira esteja preenchida com água até a superfície, de modo que a pressão na válvula de retenção, localizada na cabeça da composição, seja superior à pressão do ensaio;

4. o pulso de água pode ser realizado por gravidade ou sob pressão, este segundo requer a pressurização da linha de água com uma bomba centrífuga ou tanque de nitrogênio;

5. abrir a válvula pneumática que comunica a linha de injeção com o intervalo;

6. assim que for observada a resposta de pressão de aproximadamente 0,1 bar no transdutor do intervalo intermediário, deve-se fechar a válvula pneumática;

7. acompanhar a estabilização da pressão no intervalo intermediário;

8. repetir o ensaio com deslocamentos de 0,07 e 0,04 bar; e

9. baixar o arquivo dos dados de ambos os ensaios e salvar com a identificação do trecho e tipo de ensaios realizados.

Um exemplo de ensaio de pulso com água é apresentado na Figura 4.34.

\section{Pulso com ar}

1. registrar os valores de pressão e nível d'água nos três intervalos. É importante se certificar de que os dados dos transdutores estão sendo gravados no data logger;

2. quando aplicável, fechar a linha de amostragem de água (bomba centrífuga ou pneumática) para evitar o efeito de vasos comunicantes. É desejável que a mangueira esteja preenchida com água até a superfície, de modo que a pressão na válvula de retenção, localizada na cabeça da composição, seja superior à pressão de ensaio;

3. acoplar o aparato de ensaio pneumático no tubo ou mangueira de comunicação com o intervalo de ensaio (Figura 4.40); 

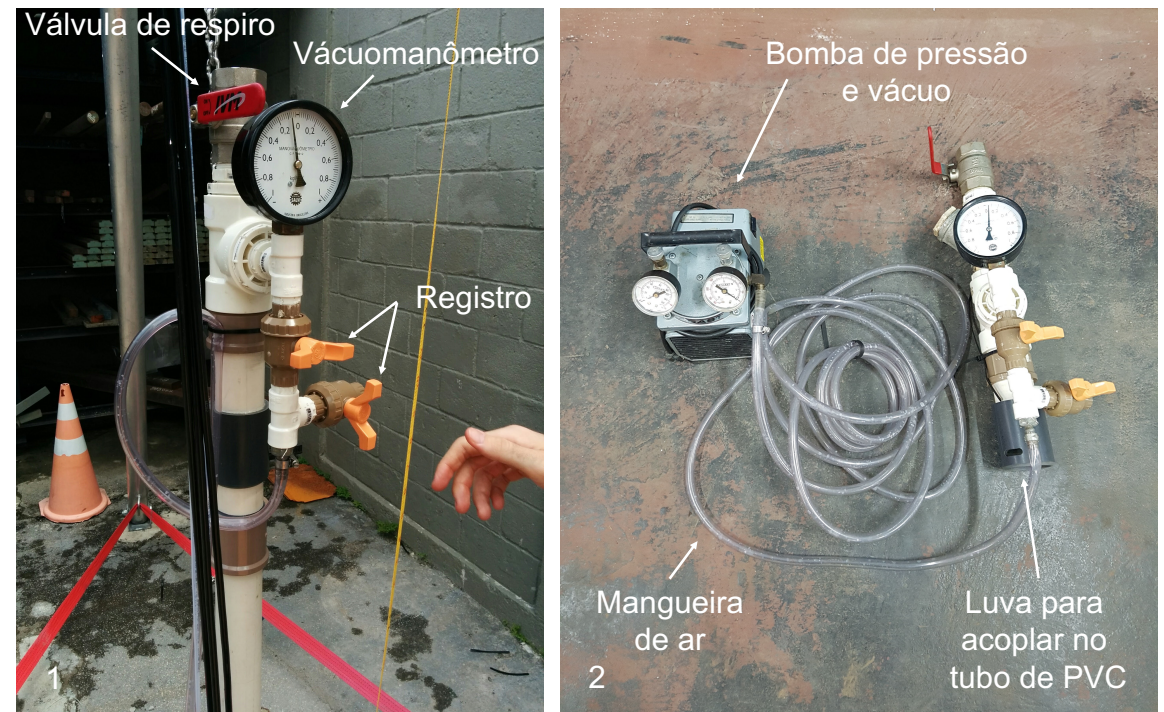

Figura 4.40. Equipamento utilizado para o ensaio de pulso pneumático; (1) operação durante um ensaio; e (2) detalhe dos componentes

4. conectar a mangueira na saída de pressão da bomba de diafragma;

5. fechar a válvula de respiro para pressurizar o intervalo;

6. aplicar pressão de 0,1 bar e fechar a válvula de alimentação de ar;

7. aguardar a estabilização da pressão no intervalo, o ar comprimido empurra a água para a formação até que seja alcançado o equilíbrio. $\mathrm{O}$ monitoramento desse processo se dá em tempo real por meio do gráfico configurado no software Loggernet;

8. abrir a válvula de respiro para a pressão atmosférica de modo que a água possa retornar ao seu nível hidrostático. É nesse instante que o ensaio de elevação (tipo bail) tem início;

9. aguardar até que o nível d'água estabilize;

10. registrar os dados do ensaio na ficha de campo (Figura 4.41); 


\section{Ficha de campo de ensaio de pulso}

Projeto:

Local:

Executor responsável:

ID Poço:

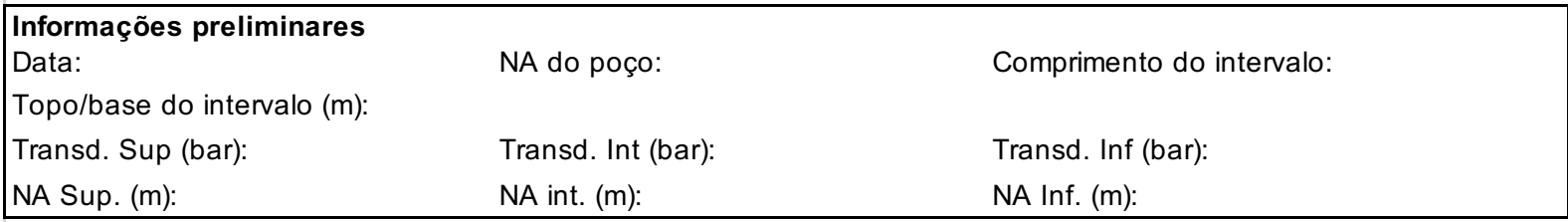

Aumento da pressão/coluna de água

Ensaio 1

Início:

Fim:

Pressão na linha:

Pressão no gráfico:

$\triangle \mathrm{HO}(\mathrm{mH} 2 \mathrm{O}):$

Figura 4.41. Ficha de campo para registro do ensaio de pulso

11. repetir os procedimentos de 3 a 7 com pressões de 0,07 e 0,04 bar;

12. inverter a saída da bomba do aparato para aplicar vácuo ao invés de pressão e repetir os procedimentos de 3 a 7 de maneira análoga; e

13. baixar o arquivo dos dados dos ensaios e salvar com a identificação do trecho e tipo de ensaios realizados.

Um exemplo de ensaio de pulso com ar é apresentado na Figura 4.42.

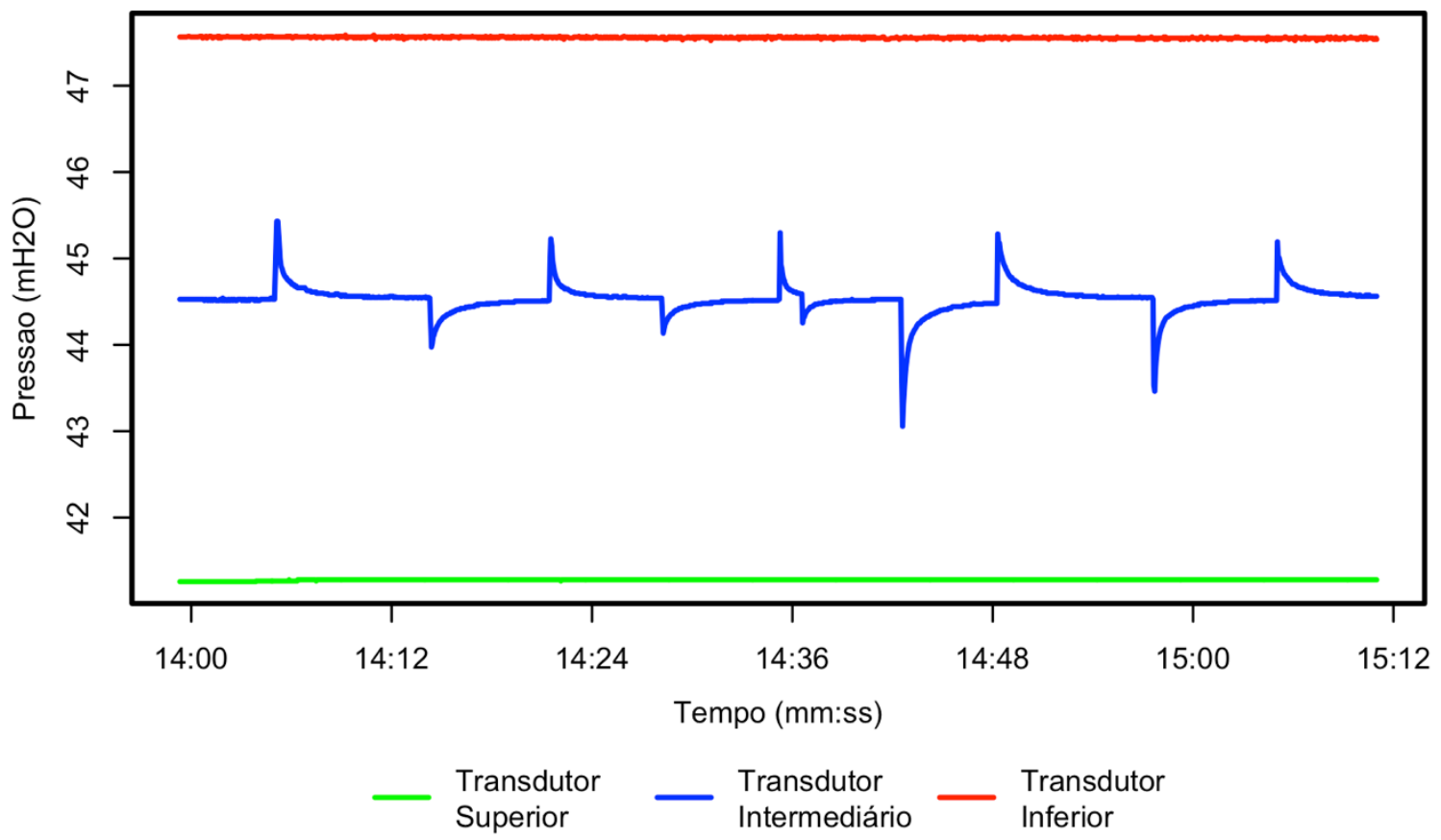

Figura 4.42. Ensaio de pulso pneumático em um intervalo do poço $255 \mathrm{sem}$ vazamento para os níveis adjacentes. Ensaio de elevação das 14:00 às 14:38 e ensaio de rebaixamento das 14:38 às 15:12 
A interpretação dos ensaios de pulso utilizou Hvorslev (HVORSLEV, 1951), cuja solução analítica é apresentada na Equação 4.3. As premissas adotadas foram: (1) a vazão pode ser calculada a partir da variação do nível d'água no poço temporário Equação 4.4; (2) o fluxo é constante Equação 4.5; (3) o fluxo é radial Equação 4.6; e (4) se encontra dentro do regime laminar. O tempo inicial do ensaio é determinado a partir da vazão máxima (calculada pela Equação 4.4), conforme discutido por Quinn, Cherry e Parker (2012) e ilustrado na Figura 4.43. A partir da transmissividade obtida para cada um dos intervalos ensaiados, pode-se calcular a abertura hidráulica equivalente da fratura com base na lei cúbica (Equação 3.4).

$$
T=\frac{m A_{x s}}{2 \pi} \ln \left(\frac{r_{0}}{r_{w}}\right)
$$

Equação 4.3

$$
\begin{gathered}
Q=\left(\pi r_{c}^{2}\right) \frac{d(\Delta H)}{d t} \\
\text { Equação } 4.4 \\
Q_{(t)}=F K \Delta H_{(t)}
\end{gathered}
$$

Equação 4.5

$$
F=\frac{2 \pi L}{\ln \left(\frac{r_{0}}{r_{w}}\right)}
$$

Equação 4.6

Em que:

$\mathrm{m}$ - inclinação da reta

Axs - área da seção do poço $\left(\mathrm{L}^{2}\right)$

ro - raio de influência $(\mathrm{L})$

rw - raio do poço/perfuração (L)

rc - raio do poço temporário (L)

F - fator do formato do poço ("shape fator")

$\mathrm{L}$ - comprimento do intervalo ensaiado (L)

$\Delta \mathrm{H}$ - variação da carga $(\mathrm{L})$ 


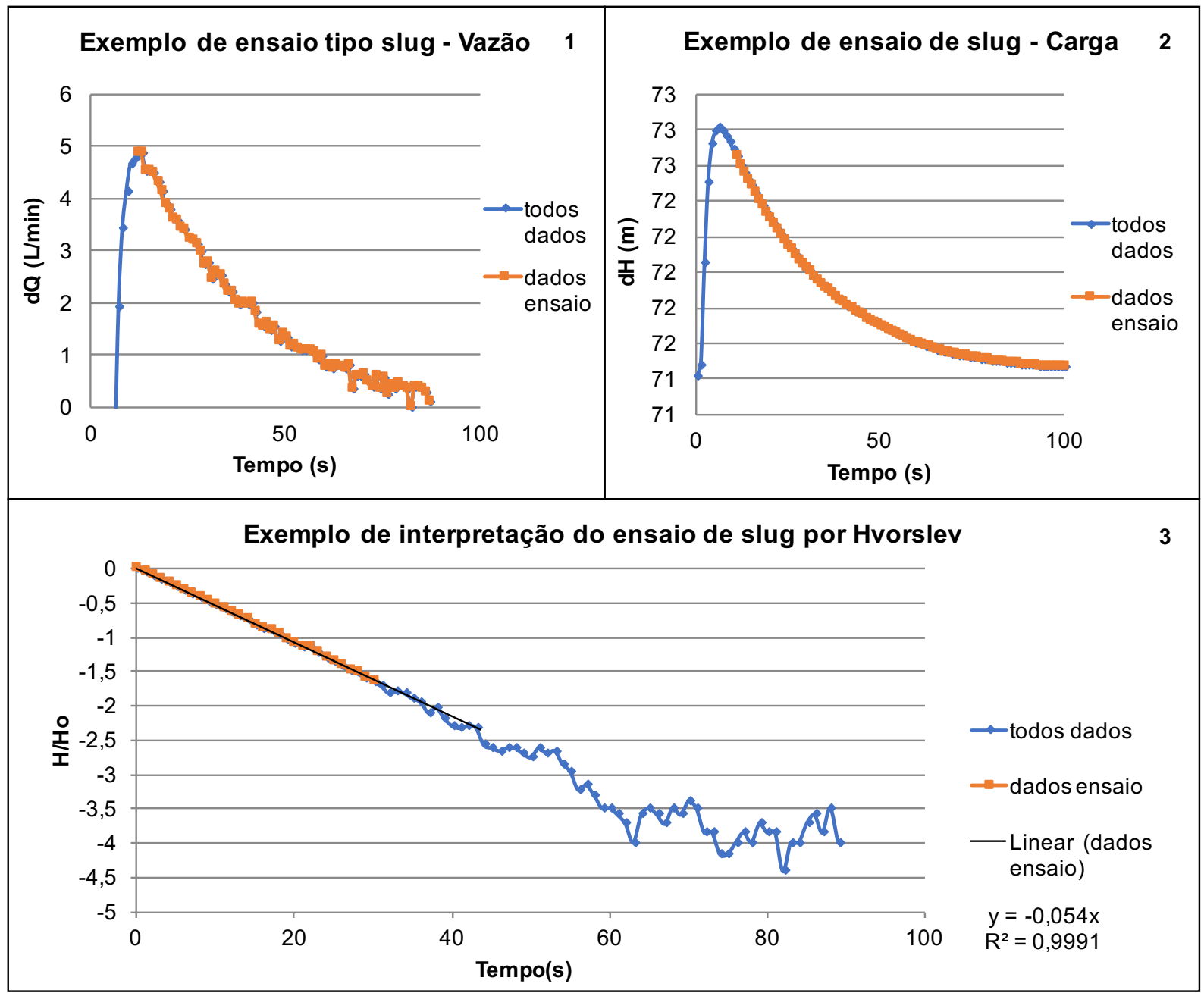

Figura 4.43. Resultados e interpretação para o ensaio de pulso com rebaixamento por Hvorslev: 1) variação da vazão em função do tempo calculada a partir de $\mathrm{dH}$, início do ensaio na vazão máxima; 2) variação da carga no tempo, dados do ensaio utilizados na interpretação; 3) dados do ensaio com maior representatividade para determinação da inclinação da reta

\section{Ensaio de carga constante}

Este ensaio é realizado pela injeção de água no intervalo obturado a uma vazão constante, até que a carga hidráulica estabilize. Esse processo é repetido de três a cinco vezes em diferentes vazões. O resultado deste ensaio é utilizado para calcular a transmissividade de fraturas com baixa e média permeabilidade $\left(\mathrm{E}^{-8} \mathrm{a} \mathrm{E}^{-4}\right)$ e identificar a transição entre o fluxo laminar e turbulento, uma vez que a variação da carga pela vazão é uma função linear no regime laminar. Para garantir que o fluxo de água que é registrado no medidor de vazão é o mesmo que entra na fratura, o ensaio precisa ser realizado sob pressão. Para isso pode-se utilizar uma linha de injeção de água ou o mini-obturador. O procedimento para a realização do ensaio de carga constante após isolamento do trecho é descrito a seguir: 


\section{Utilizando o tubo de PVC e o mini-obturador}

1. medir a profundidade do nível d'água e ajustar a válvula de retenção para uma pressão superior à coluna de água, para evitar que ao descer o mini-obturador no tubo de PVC a água escoe para o intervalo obturado;

2. registrar os dados de pressão e nível d'água nos três intervalos. É importante certificar-se que os dados dos transdutores estão sendo gravados no data logger;

3. fechar linha de amostragem de água (bomba centrífuga ou pneumática) para evitar o efeito de vasos comunicantes. É desejável que a mangueira esteja preenchida com água até a superfície, de modo que a pressão na válvula de retenção, localizada na cabeça da composição, seja superior à pressão de ensaio;

4. descer o mini-obturador no tubo de PVC três metros abaixo do nível d'água;

5. inflar o mini-obturador com pressão de 5 bar e aguardar a estabilização da pressão no intervalo;

6. iniciar a injeção de água com vazão que proporcione a elevação da carga em até 10 cm de coluna de água. O acompanhamento da vazão e pressão (medidor de vazão eletrônico e transdutor) é feito pelo computador conectado ao data logger;

7. monitorar a vazão e a elevação da pressão até que ambas estabilizem;

8. monitorar se há alteração da pressão nos intervalos superior e inferior para garantir que não há vazamento ou curto circuito pela formação;

9. repetir os passos 6 a 8 de duas a quatro vezes, com valores de vazão superiores e distintos, podendo chegar até a um aumento diferencial de pressão de $1 \mathrm{~m}$ de coluna de água desde o início do ensaio; e

10. ao término do ensaio, baixar os dados do ensaio e salvar com a identificação do poço, intervalo e nome do ensaio.

\section{Utilizando apenas a linha de injeção de água}

11. encher o tanque pulmão de água e verificar se todos os registros estão abertos;

12. registrar os dados de pressão e nível d'água nos três intervalos. É importante certificar-se que os dados dos transdutores estão sendo gravados no data logger; 
13. fechar a linha de amostragem de água (bomba centrífuga ou pneumática) para evitar o efeito de vasos comunicantes. É desejável que a mangueira esteja preenchida com água até a superfície, de modo que a pressão na válvula de retenção, localizada na cabeça da composição, seja superior à pressão de ensaio;

14. a injeção de água pode ser realizada por gravidade ou sob pressão, o segundo requer a pressurização da linha de água com uma bomba centrífuga;

15. abrir a válvula pneumática que comunica a linha de injeção com o intervalo;

16. iniciar a injeção de água com vazão que proporcione a elevação da carga em até 10 cm de coluna de água. O acompanhamento da vazão e pressão é feito pelo computador conectado ao data logger;

17. monitorar a vazão e a elevação da pressão até que ambas estabilizem;

18. monitorar se há alteração da pressão nos intervalos superior e inferior para garantir que não há vazamento ou curto circuito pela formação;

19. repetir os passos 6 a 8 de duas a quatro vezes, com valores de vazão superiores e distintos, podendo chegar até a um aumento diferencial da pressão de $1 \mathrm{~m}$ de coluna de água desde o início do ensaio;

20. ao término do ensaio, desligar a bomba, fechar o registro de injeção de água e fechar a válvula pneumática; e

21. baixar os dados do ensaio e salvar com a identificação do poço, intervalo e nome do ensaio.

Um exemplo de ensaio de carga constante é apresentado na Figura 4.44. 


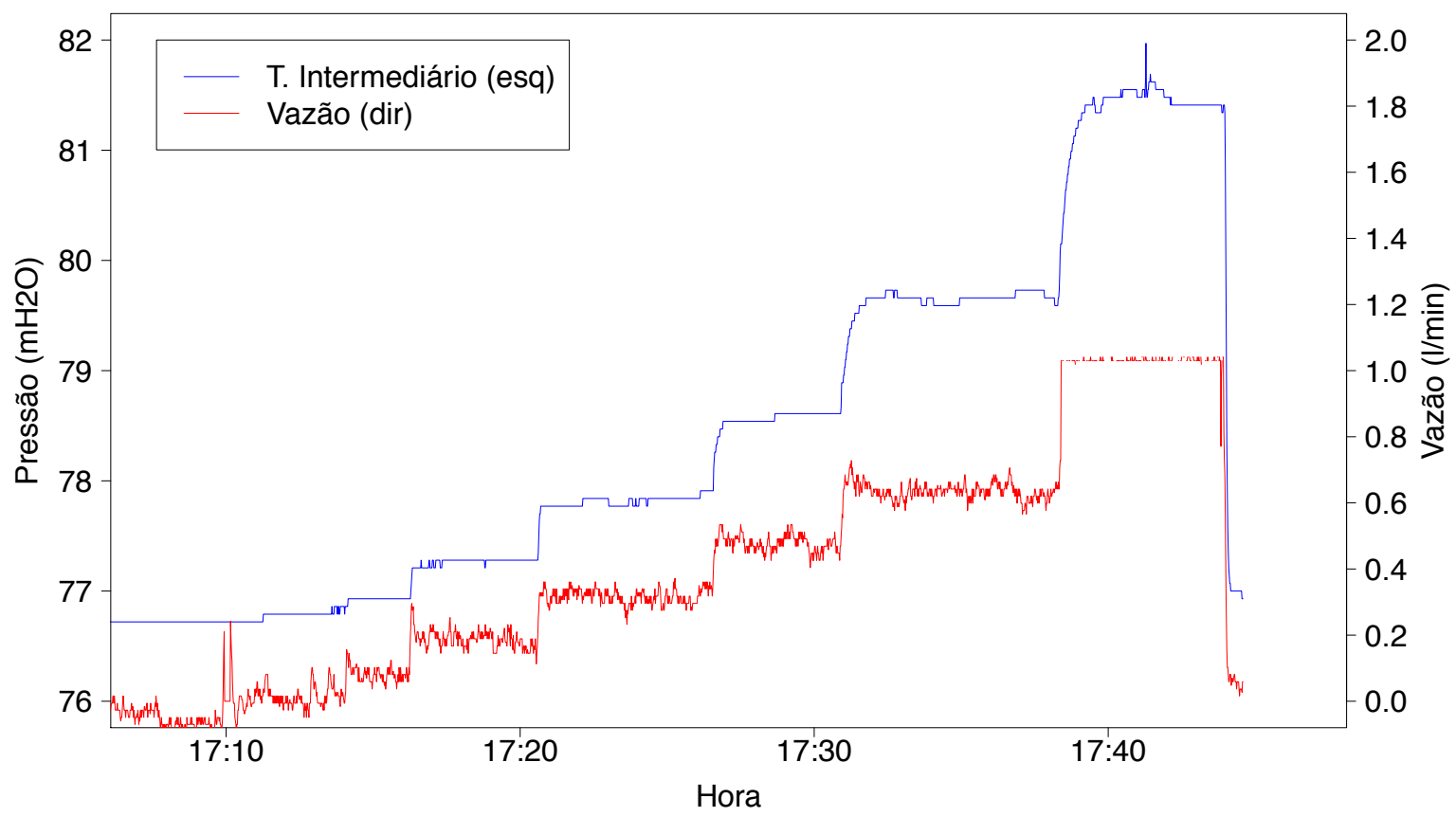

Figura 4.44. Resultado de um ensaio de carga constante no poço P1 com seis vazões de injeção

Os parâmetros dos ensaios de carga constante são registrados na ficha de campo (Figura 4.45). A interpretação dos ensaios é feita por meio da equação de Thiem (THIEM, 1906 apud FETTER, 2001) para fluxo estacionário em aquíferos confinados (Equação 4.7). O raio de influência utilizado é de $30 \mathrm{~m}$ para transmissividades acima de E-5 e de $3 \mathrm{~m}$ para valores inferiores conforme discutido por Quinn et al. (2016). A transmissividade é calculada para cada faixa de vazão do ensaio. Em seguida, são plotados em um gráfico todos os resultados obtidos da variação da carga pela vazão. Os pontos devem formar uma reta com progressão linear enquanto o fluxo for laminar. A partir do ponto em que a reta deixa de ser linear a transmissividade deve cair por conta da transição de fluxo laminar para turbulento (Figura 4.46). Com isso, pode ser validada a condição do fluxo laminar e escolhido o melhor valor de transmissividade para o intervalo. Em seguida foi calculada a abertura hidráulica equivalente da fratura com base na lei cúbica (Equação 3.4).

$$
T=\frac{Q}{2 \pi \Delta H} \ln \left(\frac{r_{0}}{r_{w}}\right)
$$

Equação 4.7

Em que:

$\mathrm{T}$ - transmissividade $\left(\mathrm{L}^{2} / \mathrm{T}\right)$

$\mathrm{Q}$ - vazão $\left(\mathrm{L}^{3} / \mathrm{T}\right)$

$\Delta \mathrm{H}$ - variação da carga $(\mathrm{L})$

$\mathrm{r}_{\mathrm{o}}$ - raio de influência $(\mathrm{L})$

$\mathrm{r}_{\mathrm{W}}$ - raio do poço/perfuração (L) 


\begin{tabular}{|c|c|c|c|c|c|}
\hline \multicolumn{6}{|c|}{$\begin{array}{l}\text { Projeto: } \\
\text { Local } \\
\text { Executor responsável } \\
\text { ID Poço: } \\
\end{array}$} \\
\hline $\begin{array}{l}\text { Informaçõe } \\
\text { Data: } \\
\text { Topo/base } \\
\text { Transd. Su } \\
\text { NA Sup. (m } \\
\end{array}$ & inares & $\begin{array}{l}\text { NA do poço: } \\
\text { Transd. Int (bar): } \\
\text { NA int. (m): }\end{array}$ & & $\begin{array}{l}\text { NAint (m): } \\
\text { Transd. Inf (bar): } \\
\text { NA Inf. (m): }\end{array}$ & \\
\hline Rodada & Início & Duração do ensaio & $\begin{array}{c}\text { Pressão } \\
\text { estabilizada (bar) }\end{array}$ & $\begin{array}{c}\text { Pressão estabilizada } \\
\text { (mH2O) }\end{array}$ & $\begin{array}{c}\text { Vazão estabilizada } \\
\text { (L/min) }\end{array}$ \\
\hline 1 & & & & & \\
\hline 2 & & & & & \\
\hline 3 & & & & & \\
\hline 4 & & & & & \\
\hline 5 & & & & & \\
\hline
\end{tabular}

Figura 4.45. Ficha de campo para registro dos dados de ensaio de carga constante

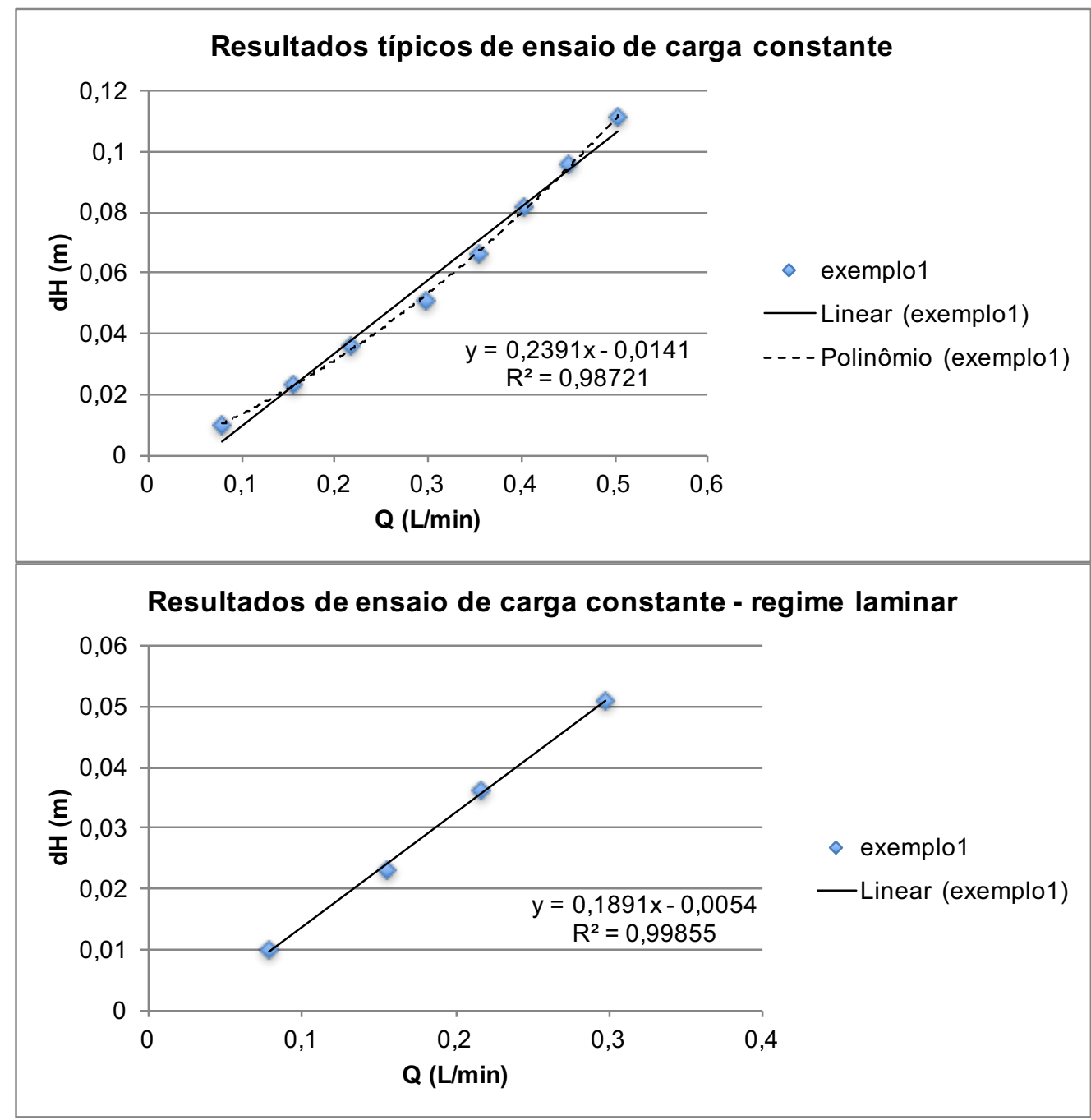

Figura 4.46. Exemplo de resultados para ensaio de carga constante. Acima, resultados obtidos para todas as vazões utilizadas no ensaio e linhas de tendência linear e polinomial e abaixo apenas resultados dentro do regime laminar que pode ser representado por uma expressão linear 


\section{Ensaio de bombeamento e recuperação}

O ensaio de bombeamento pode ser realizado de duas maneiras, por injeção ou por retirada de água, configurando ensaios análogos. Quando é feita a injeção de água sob pressão, não é preciso levar em consideração a eficiência do poço e perdas no sistema, já que a vazão medida é a mesma que flui para o trecho isolado. Contudo, a vazão máxima de injeção da MUST é de 10 l/min, portanto, para zonas com transmissividade elevada, é necessária a retirada de água com a bomba MP1, que pode chegar a uma vazão de $40 \mathrm{~L} / \mathrm{min}$ na configuração utilizada, dependendo do nível d'água e transmissividade do intervalo. Os parâmetros do ensaio de bombeamento são registrados na ficha de campo (Figura 4.47), e o procedimento utilizando a bomba centrifuga submersa é descrito a seguir:

1. medir a profundidade do nível d'água e ajustar a válvula de retenção para uma pressão superior à coluna de água, para evitar que ao descer o mini-obturador no tubo de PVC a água escoe para o intervalo obturado;

2. registrar os dados de pressão e nível d'água nos três intervalos. É importante certificar-se que os dados dos transdutores estão sendo gravados no data logger;

3. acoplar a válvula de retenção na saída da bomba e à mangueira a ser utilizada quando a bomba for inserida dentro do tubo de PVC;

4. posicionar a bomba próxima à composição quando utilizados os tubos de PVC;

5. iniciar a retirada de água e monitorar a vazão e a variação da pressão nos três transdutores pelo computador. É importante que não ocorra vazamento para os níveis superior e inferior;

6. aguardar até que a variação da pressão esteja próxima da estabilização;

7. interromper a retirada de água para iniciar o ensaio de recuperação e acompanhar o reestabelecimento do nível d'água até a profundidade inicial; e

8. baixar o arquivo dos dados de ambos os ensaios e salvar com a identificação do trecho e tipo de ensaios realizados. 


\section{Ficha de campo de ensaio de bombeamento}

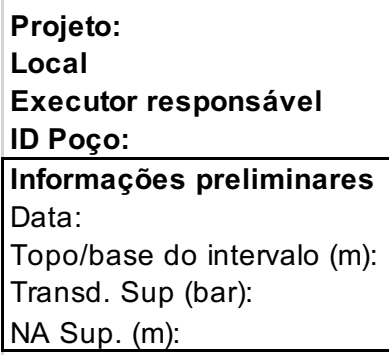

\begin{tabular}{|l|l|c|c|c|}
\hline Ensaio \\
\hline Hora & Vazão (L/min) & $\begin{array}{c}\text { Nível } \\
\text { d'água }(\mathrm{m})\end{array}$ & $\begin{array}{c}\text { Resposta nos } \\
\text { demais intervalos }\end{array}$ & Comentários \\
\hline & & & & \\
\hline & & & & \\
\hline & & & & \\
\hline & & & & \\
\hline
\end{tabular}

Figura 4.47. Ficha de campo para registro dos dados de ensaio de bombeamento

Para o ensaio de injeção, o procedimento é o mesmo que para o de carga constante, sendo utilizada apenas uma vazão constante mais elevada ao longo de todo o ensaio. A duração depende da estabilização do nível d'água e a interpretação do T pode ser feito tanto aplicando Theis, para estabilização rápida, como Cooper-Jacob. No caso da utilização de Cooper-Jacob, a inclinação da reta do rebaixamento pelo tempo em logaritmo é utilizada na (Equação 4.8) para determinar a transmissividade.

$$
\begin{gathered}
T=\frac{2,3 Q}{4 \pi \Delta s} \\
\text { Equação } 4.8
\end{gathered}
$$

O ensaio de recuperação é realizado na sequência da retirada ou injeção de água, uma vez que se trata de uma consequência da interrupção de ambos. Para garantir a qualidade dos dados, é importante que, ao cessar a retirada de água, não ocorra o retorno da água presente na mangueira para a formação, por isso é utilizada uma válvula de retenção junto à bomba, ou uma válvula de acionamento pneumático, no caso de injeção. A interpretação deste ensaio é realizada por meio da equação de Theis, cuja transmissividade é calculada pela Equação 4.8, utilizando a inclinação da reta do rebaixamento pelo log do tempo. 


\section{Amostragem}

A amostragem com obturadores tem a finalidade de caracterizar os aspectos físicos e químicos da água subterrânea em porções discretas do poço e permitir uma análise comparativa entre intervalos discretos. A água bombeada é retirada predominantemente das fraturas com maior transmissividade no intervalo, independentemente da profundidade de captação (SHAPIRO, 2002). Esses dados podem ser utilizados para confirmar o modelo conceitual de fluxo do poço baseado no HPF e ensaios com obturadores. Também podem servir para avaliar a origem da água subterrânea em diferentes profundidades, e avaliar a presença e concentração de contaminação no aquífero - como, por exemplo, quais os tipos de contaminantes e se há estratificação de contaminantes no poço.

Para que uma amostra seja representativa do intervalo, é fundamental que não haja vazamento durante a amostragem. Antes de iniciar o processo de purga, são registrados os dados de pressão dos transdutores e medidas de nível d'água nos três níveis. É importante que a amostragem seja realizada antes de qualquer ensaio de injeção de água, evitando a alteração das características físicas e químicas das amostras.

Após inflados os obturadores, é preciso realizar a purga da água de mistura que preenche o sistema. A água retida no intervalo, nos tubos e nas mangueiras é uma mistura proveniente de várias fraturas e não pode ser considerada representativa de um trecho específico. Em algumas situações o bombeamento para purga, que precede a amostragem, pode ser utilizado como teste de bombeamento, descrito anteriormente. O volume mínimo de purga deve garantir que toda essa água de mistura seja renovada (Equação 4.9). Durante a purga, são monitorados os parâmetros físico-químicos $(\mathrm{pH}$; temperatura; potencial de oxi-redução; condutividade elétrica; sólidos dissolvidos totais; vazão; e profundidade do nível d'água). Quando estes parâmetros apresentam pouca variação, pode-se iniciar a amostragem.

$$
V=h_{1} \pi r_{1}^{2}+h_{2} \pi r_{2}^{2}
$$

Equação 4.9

Em que:

$\mathrm{V}$ - volume de purga $\left(\mathrm{L}^{3}\right)$

h1 - espaçamento entre os obturadores (L)

r1 - raio da perfuração (L)

h2 - distância entre a composição e o nível d'água (L)

r2 - raio do tubo de PVC (L) 
Quando os compostos químicos de interesse para análise química são voláteis, é utilizado o método de amostragem de baixa vazão (0,1 1/min; PULS e BARCELONA, 1996). Nos casos em que os compostos de interesse não são voláteis, a vazão de amostragem varia de 0,5 e 1 1/min. Os procedimentos de campo para a realização da amostragem discreta são descritos a seguir:

1. fazer a calibração da sonda multiparâmetros;

2. calcular o volume de purga para o intervalo;

3. posicionar a bomba próxima à cabeça da composição quando utilizados os tubos de PVC;

4. realizar a purga e monitorar os parâmetros físico-químicos em intervalos de $10 \mathrm{~min}$ até que a estabilização dos parâmetros seja alcançada e até que o volume mínimo seja purgado;

5. após a estabilização, registrar os dados da purga e reduzir a vazão para a vazão de amostragem;

6. realizar a coleta das alíquotas começando pelos compostos voláteis direto da mangueira de PE, antes da célula de fluxo, para evitar contaminação cruzada. No caso dos compostos voláteis é importante não haver bolha nos frascos;

7. armazenar os frascos na caixa térmica refrigerada e enviar para o laboratório para análise acompanhadas da cadeia de custódia; e

8. proceder à descontaminação dos materiais utilizados (sonda multiparâmetros, célula de fluxo, bomba e válvula de retenção) com água em abundância e sabão.

Quando a configuração de trabalho tem a bomba acoplada à composição a etapa 3 não é realizada. Geralmente nesses casos a descontaminação da bomba e o descarte dos materiais de consumo só são feitos ao término do trabalho, quando os equipamentos são retirados do poço.

Após terminada a purga mínima, a vazão de amostragem é regulada para vazões inferiores a 0,6 L/min. Durante este processo, o monitoramento dos parâmetros físico-químicos continua, bem como seu registro (Figura 4.48). O monitoramento do rebaixamento é realizado por meio do transdutor, e confirmado com o medidor de nível. A vazão é monitorada com balde graduado e cronômetro ou com o medidor de vazão. O monitoramento dos parâmetros físico- 
químicos de campo é feito com a sonda multiparâmetros. As mangueiras utilizadas para a purga e para a amostragem são descartadas logo após cada coleta ou término do trabalho.

\section{Ficha de amostragem de água subterrânea}

Projeto:

Local

Equipe de amostragem

\begin{tabular}{|l|}
\hline \multicolumn{1}{|c|}{ Informações preliminares } \\
\hline ID do poço: \\
\hline Trecho amostrado: \\
\hline Condições meteorológicas: \\
\hline Método de amostragem: \\
\hline Diâmetro do poço temporário: \\
\hline Isolamento do trecho: \\
\hline Relação de carga hidráulica: \\
\hline Transmissividade: \\
\hline
\end{tabular}
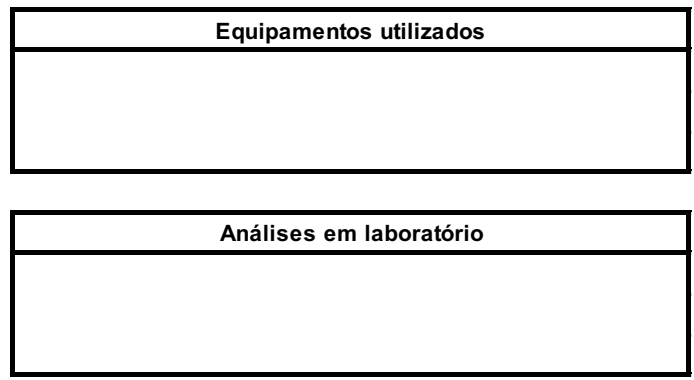

\begin{tabular}{|c|}
\hline Informações da purga \\
\hline Data da purga: \\
\hline NA inicial / final: \\
\hline Início / fim da purga: \\
\hline Profundidade de captação: \\
\hline Vazão de purga (L/min): \\
\hline Volume de purga (L): \\
\hline $\begin{array}{c}\text { Características organolépticas } \\
\text { da água: }\end{array}$ \\
\hline
\end{tabular}

\begin{tabular}{|c|}
\hline Informações da amostragem \\
\hline ID da amostra: \\
\hline Data da amostragem: \\
\hline Horário de coleta: \\
\hline Profundidade de captação: \\
\hline NA inicial / final: \\
\hline $\begin{array}{c}\text { Características organolépticas } \\
\text { da água: }\end{array}$ \\
\hline Comentários: \\
\hline
\end{tabular}

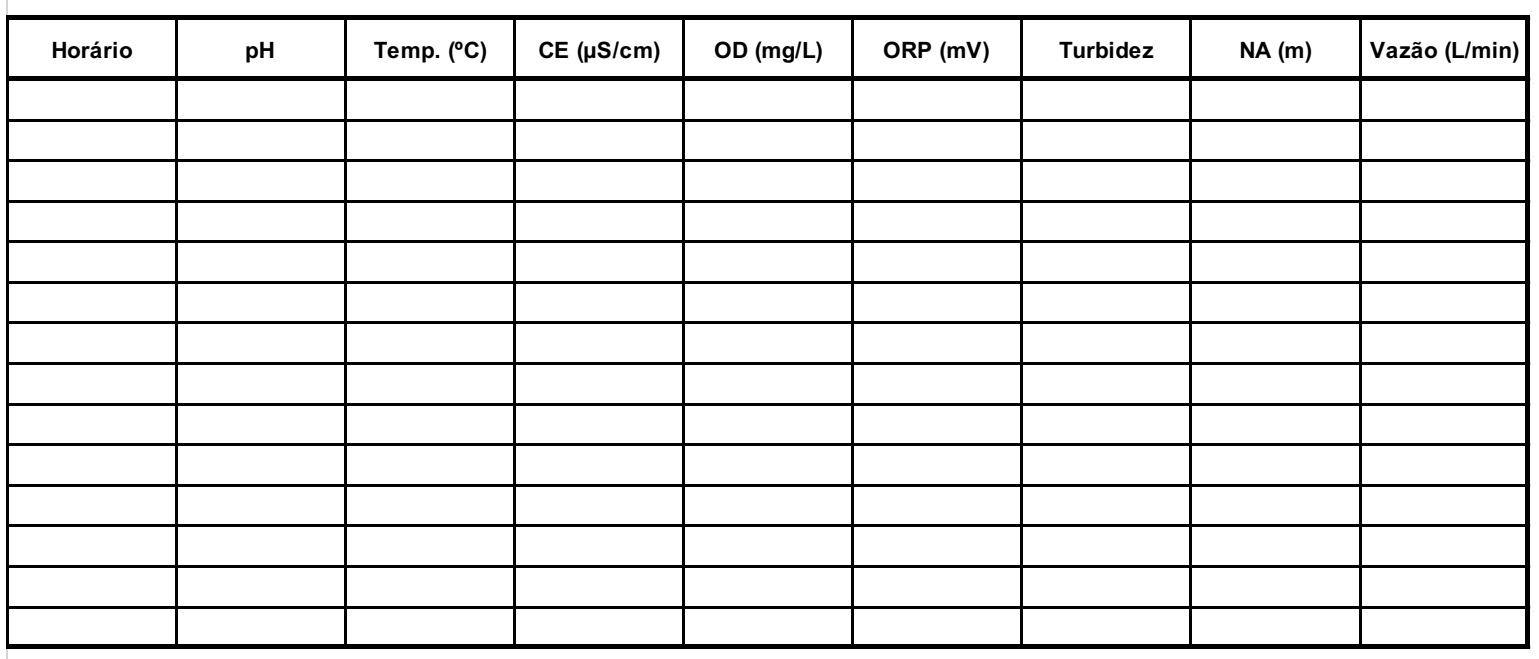

\begin{tabular}{|l|c|c|c|c|c|c|c|c|}
\hline $\begin{array}{c}\text { Critério de } \\
\text { estabilização }\end{array}$ & $+/-0,2$ un & $+/-0,5^{\circ} \mathrm{C}$ & $+/-5 \%$ & $+/-10 \%$ & $+/-20 \mathrm{mV}$ & $\begin{array}{c}+/-10 \% \text { ou } \\
<10 \mathrm{NTUs}\end{array}$ & - \\
\hline
\end{tabular}

CE- Condutividade Elétrica $\quad$ NA - Nível d'água $\quad$ FT - Amostra filtrada
O volume de água por metro no tubo de 2" é $2,1 \mathrm{~L}$ e o Volume entre os obturadores por metro 19L

Figura 4.48. Ficha para registro dos dados de amostragem de água subterrânea 


\subsection{Construção da unidade móvel de ensaios hidráulicos e amostragem (MUST)}

A ideia de construir uma unidade móvel de ensaios hidráulicos e amostragem para aquíferos fraturados (Figura 4.49 e ), denominada Mobile Unit for Sampling and Testing (MUST), teve início em 2014, durante uma primeira tentativa de realização de ensaios hidráulicos que não obteve resultados satisfatórios. Inicialmente, o projeto da MUST foi desenvolvido com base no equipamento do grupo de pesquisa G360, da Universidade de Guelph, conforme descrito por Quinn et al. (2012). Todos os componentes são armazenados e transportados em um trailer, rebocado por uma caminhonete, que é autossuficiente para a realização de todos os ensaios descritos no item anterior. Esta característica configura um sistema versátil e de baixo custo, o que tornou o projeto viável.
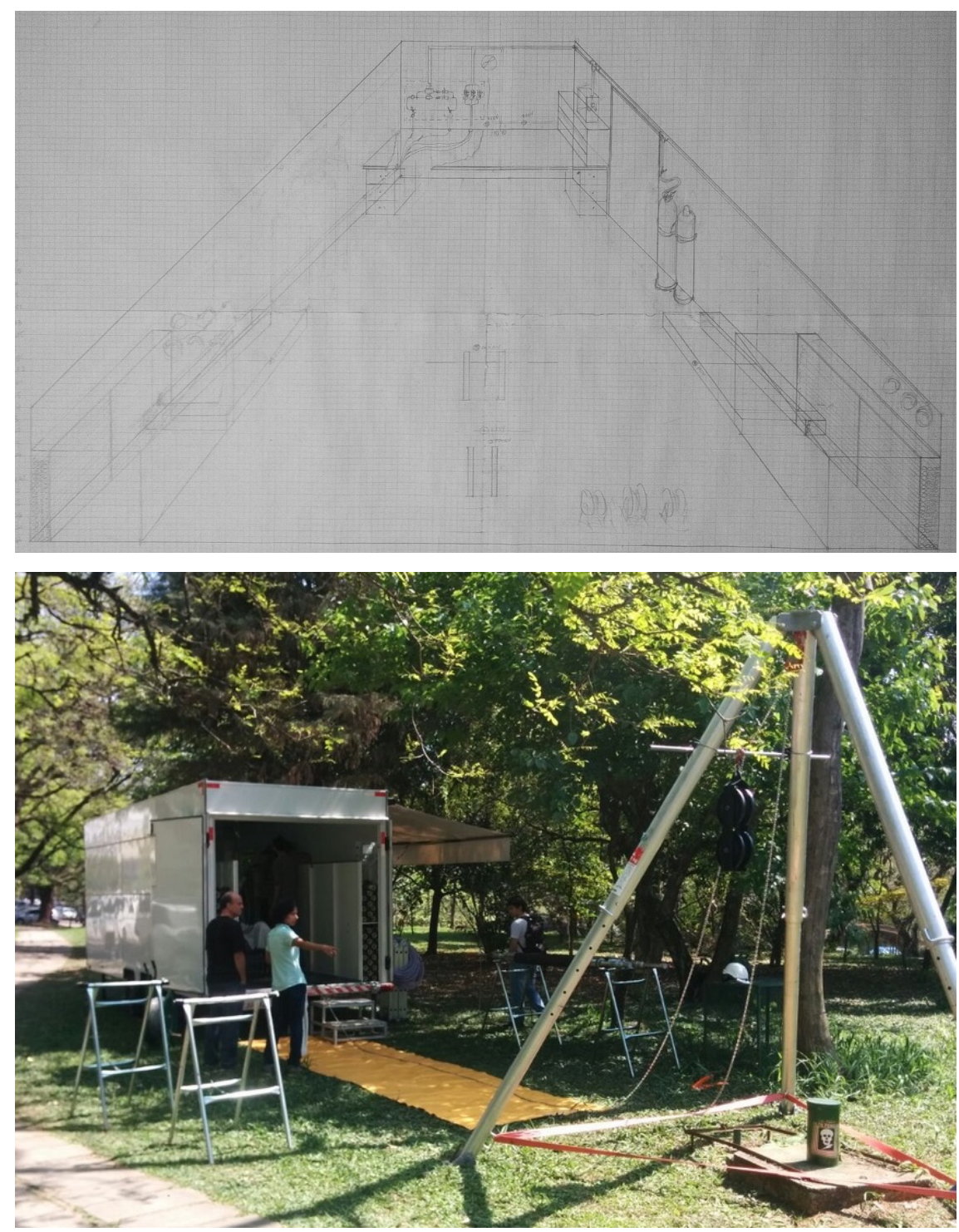

Figura 4.49. Construção da unidade móvel de ensaios hidráulicos e amostragem denominada Mobile Unit for Sampling and Testing (MUST). Projeto da MUST (acima) e ensaio no poço do Instituto de Geociências (abaixo) 
Atualmente, não existe outra unidade móvel no Brasil, da qual se tenha conhecimento, com capacidade para a realização de múltiplos ensaios hidráulicos e amostragens. Os trabalhos em âmbito nacional que fazem uso de obturadores para a caracterização hidrogeológica e hidroquímica em estudos ambientais são poucos, e se limitam ao uso do equipamento e realização de poucos ensaios (FANTI et al., 2017; L'APICCIRELLA, 2009; TRESSOLDI, 1991; WAHNFRIED, 2010). Destaca-se o pioneirismo na construção da primeira versão nacional de unidade móvel de pesquisa, para a qual os principais desafios foram: (1) orçamento e prazo para desenvolvimento do projeto; (2) conhecimento prático dos materiais e métodos de ensaio com obturadores; (3) desenvolvimento da rede de fornecedores de materiais e equipamentos.

A construção da MUST foi realizada em cerca de um ano. A maior parte deste período foi dispendido para encontrar fornecedores e realizar o processo de aquisição, com fornecedores nacional e internacional. Buscou-se utilizar sempre o máximo de componentes e fornecedores nacionais, no entanto, alguns componentes são encontrados apenas no exterior, como é o caso dos obturadores, transdutores, data logger, dentre outros.

Apesar de toda a bibliografia disponível com relação ao uso de obturadores, detalhes técnicos e operacionais são pouco discutidos em profundidade. A grande quantidade de componentes que são combinados para a realização de múltiplos ensaios, faz do projeto, que é conceitualmente simples, um grande desafio. Muitos dos materiais necessários à realização dos ensaios não são encontrados com facilidade no mercado nacional e mesmo no internacional, por serem muito específicos. Muitos componentes tiveram de ser adaptados ou desenvolvidos (e.g. sistema de passa cabos e tubos; tubos de PVC; integração de sensores de diferentes tipos e fabricantes).

A falta de experiência em ensaios hidráulicos utilizando obturadores resultou em muito retrabalho e aprendizado prático. Apesar de todo o tempo gasto na etapa de projeto e desenvolvimento, parte do processo de construção da MUST foi experimental. Ao longo do caminho foram testadas diferentes configurações de trabalho e equipamentos, conforme será discutido nos resultados, que diferenciam a MUST de outras unidades de ensaio hidráulico.

O desenvolvimento da MUST é um processo de melhoria contínua, foram testadas diversas configurações e formas de realização dos ensaios e amostragens propostos. As configurações utilizadas diferenciam-se principalmente nos seguintes sistemas: controle de profundidade da composição; monitoramento da pressão nos intervalos ensaiados; realização dos ensaios hidráulicos; e coleta de amostras de água. 


\section{RESULTADOS}

\subsection{FLASH-R}

Uma nova versão do programa de computador FLASH (Flow Log Analysis of Single Holes - análise de perfis de fluxo em um furo) foi desenvolvida para a análise de perfis de fluxo vertical de poço para estimar a transmissividade e carga hidráulica de fraturas (ou camadas). $\mathrm{O}$ programa é escrito em $\mathrm{R}$, uma linguagem de programação de código aberto, com uma interface de usuário dinâmica compatível com qualquer sistema operacional e plataforma digital. $\mathrm{O}$ artigo que apresenta essa nova versão do programa foi aceito para publicação na revista "Groundwater" no formato Methods Note. A apresentação dos resultados obtidos no desenvolvimento do FLASH-R se limitou a um resumo do que foi realizado. Para maiores informações, o leitor pode acessar o artigo que descreve toda a teoria e prática da aplicação do FLASH-R no Item 0.

Esta nova versão supera os problemas e as limitações enfrentadas pelos usuários com a primeira versão do FLASH, como: (1) necessidade de comprar software privado e versões compatíveis; (2) problemas de segurança com macros e programação; e (3) acesso ao código fonte para realizar modificações em configurações avançadas, que geralmente requerem privilégios administrativos. Como um código-fonte aberto, a ferramenta pode ser personalizada e aprimorada pelos usuários, e as atualizações podem ser facilmente incorporadas. Recursos foram adicionados para aprimorar o processamento de dados, incluindo (1) ferramentas avançadas de otimização, (2) análise da incerteza dos resultados da otimização, (3) função para importação de dados brutos; e (4) documentação das características do ensaio no programa.

\subsection{Aplicação do método de investigação}

A maior parte dos poços estudados (29 de 33 poços) foram perfurados para produção de água, e apenas quatro para fins acadêmico científicos. O contexto em que os trabalhos foram desenvolvidos compreendem casos de áreas contaminadas, estudos hidrogeológicos para abastecimento público, e desenvolvimento de pesquisa.

A diversidade de cenários levou à consolidação do método de trabalho para aquíferos fraturados por meio de poços de tubulares. O método é dividido em três etapas: preliminar; geofísica; e ensaios hidráulicos e amostragem com obturadores (Figura 5.1). 
Sequência de atividades da etapa preliminar

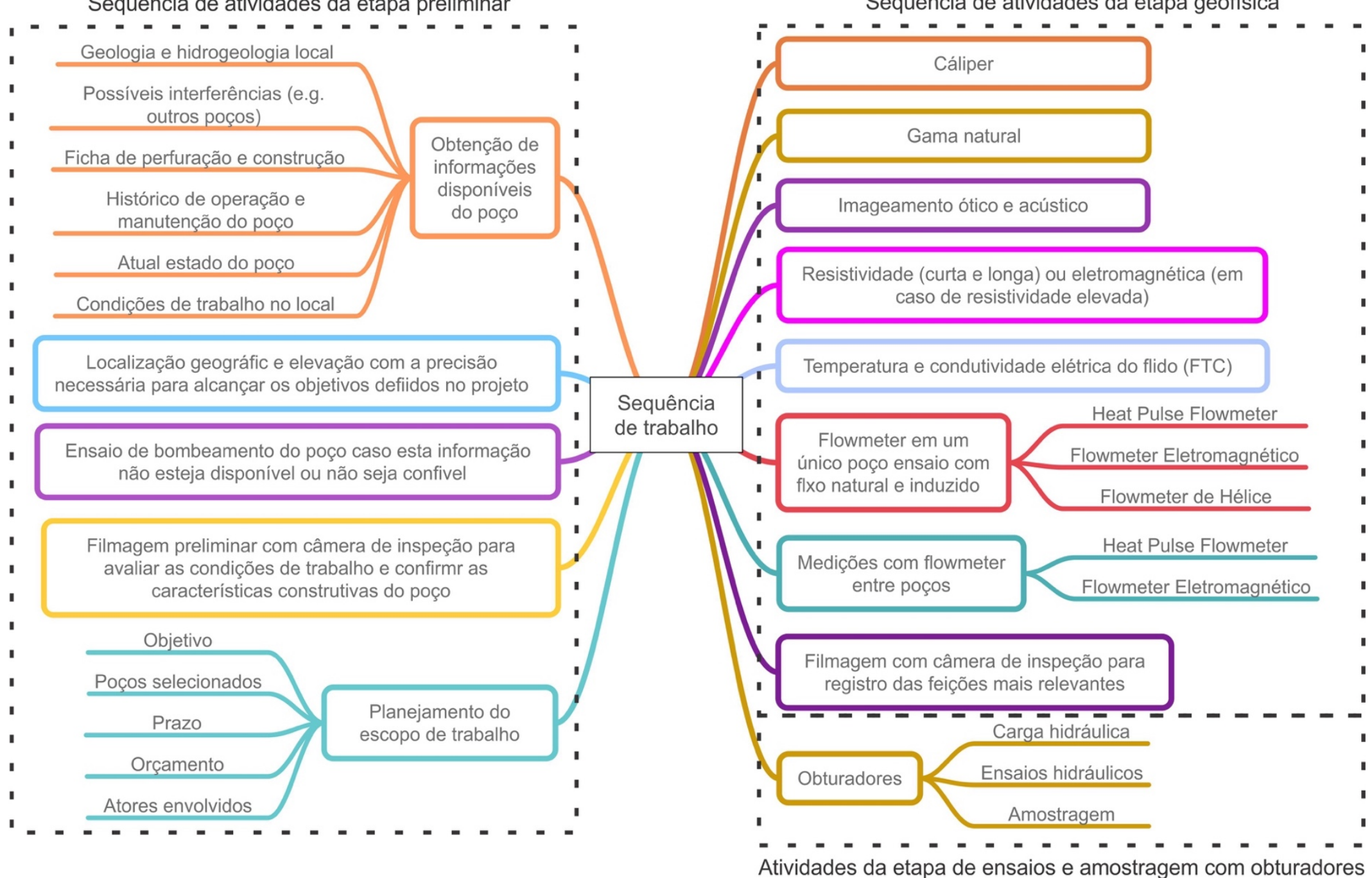

Figura 5.1. Método de trabalho adequado para a investigação de aquíferos fraturados utilizando poços tubulares 
As atividades descritas neste método são aplicáveis a diferentes escalas de trabalho. Impende ressaltar que a escolha dos ensaios é planejada levando em consideração esta característica do projeto. Em geral, o uso do poço para atividades de caracterização não deve resultar na perda de sua função principal, que é produzir água. Tendo isso como premissa, não foi considerada a possibilidade de conversão do poço em um sistema de monitoramento multinível ou mesmo o uso de revestimento flexível para impedir o fluxo entre diferentes compartimentos do aquífero através do furo (CHERRY; PARKER; KELLER, 2007).

\subsubsection{Etapa preliminar}

A etapa preliminar consiste em obter os dados básicos do poço e alinhar o escopo aos objetivos, para que os resultados atendam às demandas do projeto. Estes são importantes para o planejamento adequado das atividades da etapa principal. Os dados básicos são aqueles disponíveis no cadastro de poços, como:

1. dados cadastrais do usuário;

2. localização do empreendimento: coordenadas geográficas e cota do poço;

3. características do uso: tipo de poço, uso da água, nível d'água, vazão de exploração;

4. aspectos construtivos: revestimento (tubo liso e filtro), pré-filtro, cimentação;

5. geologia: perfil geológico e estratigráfico;

6. ensaio de bombeamento;

7. análises químicas;

8. histórico de operação e manutenção do poço; e

9. outros trabalhos já realizados: por exemplo, perfilagens geofísicas.

$\mathrm{Na}$ ausência dos dados básicos, a localização do poço no espaço (coordenadas geográficas e cota) e a sua condutividade hidráulica (obtida geralmente do ensaio de bombeamento) devem ser obtidos, pois são necessários para a interpretação de alguns dos ensaios. Algumas informações atualizadas também são importantes, como:

1. situação do empreendimento: área industrial, comercial ou residencial, e funcionamento;

2. situação atual do poço: se está equipado, em operação ou desligado;

3. riscos de contaminação por fontes superficiais (Figura 5.2) ou subterrâneas;

4. possíveis interferências: poços de produção próximos, sistemas de rebaixamento de aquífero e sistemas de remediação; e 
5. condição de trabalho atual: espaço aberto ou fechado, dentro ou fora da propriedade (rua, calçada), acessibilidade e utilidades (água, energia, sinal de internet, oficina, depósito de materiais).
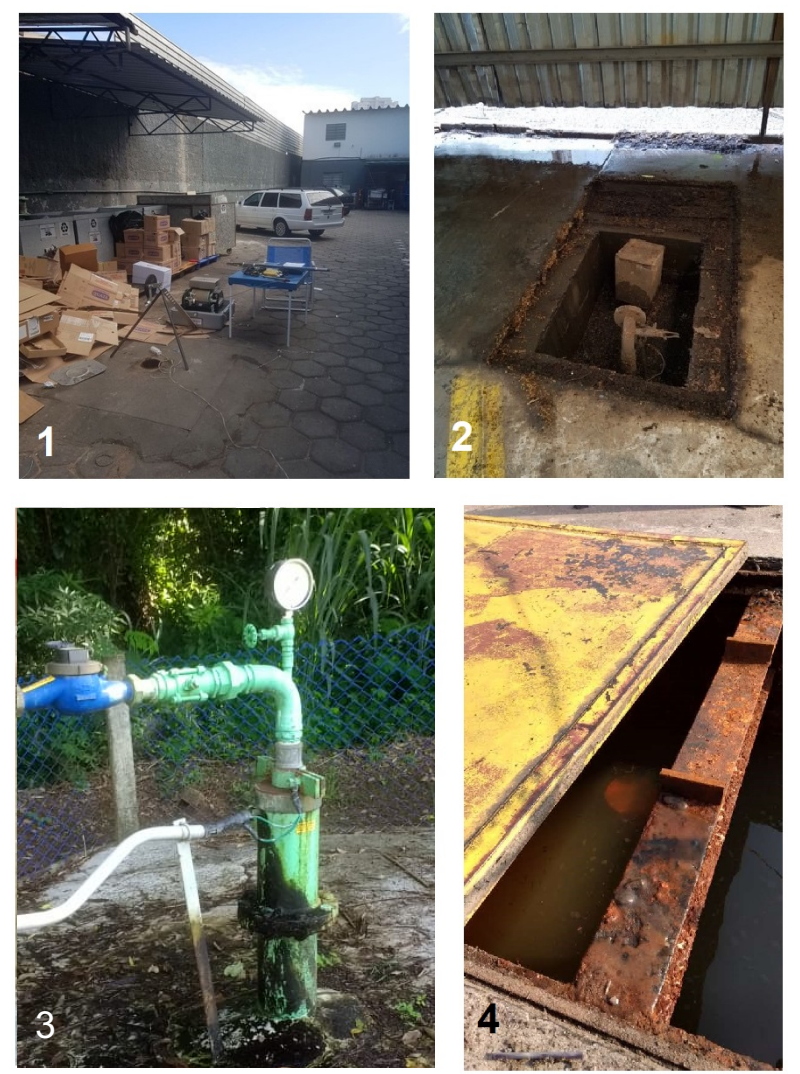

Figura 5.2. Exemplo das condições de conservação e proteção de alguns dos poços em que foram realizados os trabalhos. (1) poço localizado ao lado do depósito de lixo, sem proteção sanitária recebendo toda a água que escorria pelo pátio da empresa; (2) poço sem tampa (coberto com uma lata) recebendo toda a sujeira carregada pela água da chuva que acumulava ; (3) poço construído dentro dos padrões exigidos por norma; (4) poço abaixo do piso com água vertendo para seu interior e carregando toda a sujeira acumulada no pátio.

Independentemente da disponibilidade das informações mencionadas, é importante a inspeção com a câmera nos poços antes de planejar o escopo completo do trabalho. Essa é uma mobilização rápida e de baixo custo, que avalia se o poço está em condições seguras de trabalho, identifica/confirma as características construtivas básicas e avalia a necessidade de limpeza. Confirmadas as condições favoráveis à execução do trabalho, o planejamento do trabalho é feito levando em consideração as questões básicas do projeto, como objetivo, prazo de execução, orçamento disponível e atores envolvidos no processo.

A identificação de problemas na etapa preliminar é imprescindível. O poço 255 é um exemplo, no qual o diâmetro do revestimento é inferior ao da perfuração na rocha. Essa 
característica dificultou a centralização das sondas no furo e o isolamento hidráulico, prejudicando a qualidade das atividades subsequentes (e.g. ATV e HPF).

Em outro caso, foi planejado um cronograma de trabalho para que durante os ensaios em um dos poços da área o outro ficasse desligado, não causando interferência. Desta forma, uma condição específica da área de estudo foi identificada e contornada.

\subsubsection{Etapa de geofísica}

O escopo de trabalho da etapa geofísica contempla uma série de atividades para a caracterização dos seguintes aspectos:

1. construtivos e físicos do poço;

2. características da rocha;

3. feições estruturais; e

4. propriedades hidráulicas.

\section{Aspectos construtivos e físicos do poço}

Os aspectos construtivos e físicos de um poço podem ser caracterizados por meio de quatro sondas: câmera, cáliper, televisionamento ótico e acústico. Nenhuma das sondas abrange individualmente de maneira adequada todos esses aspectos, que são:

1. extensão do tubo de revestimento (contato tubo/rocha);

2. ocorrência de tubo filtro;

3. problemas com o revestimento (desgaste, buracos ou rompimento);

4. perfil de variação do diâmetro da perfuração e do revestimento;

5. profundidade atual do furo;

6. zonas de quebra na rocha;

7. inclinação e desvio do furo; e

8. obstruções ou condições que coloquem em risco as atividades de investigação (e.g. caimentos de rocha e equipamentos presos no poço).

Embora todas as ferramentas sejam importantes e complementares, a mais versátil para essa tarefa é a câmera, que permite identificar todos os aspectos construtivos do poço, inclusive a ocorrência de obstruções e condições de risco fora e dentro da água. Além disso, devido ao seu valor relativamente menor, esse é o primeiro equipamento a ser utilizado para a avaliação preliminar, identificando possíveis riscos e problemas para as atividades subsequentes. 
Em contrapartida, a câmera não gera dados quantitativos de variação do diâmetro, uma das informações mais importante desta etapa. Essa informação é essencial para o planejamento de outras atividades e o processamento de dados de outras sondas. O formato em que os dados são gerados, vídeo e fotos, dificultam uma análise visual comparativa com as outras sondas. A qualidade das imagens, além de terem baixa resolução, também podem ser afetadas pela turbidez da água e a presença de materiais em suspensão ou incrustados na parede do furo (Figura 5.3).
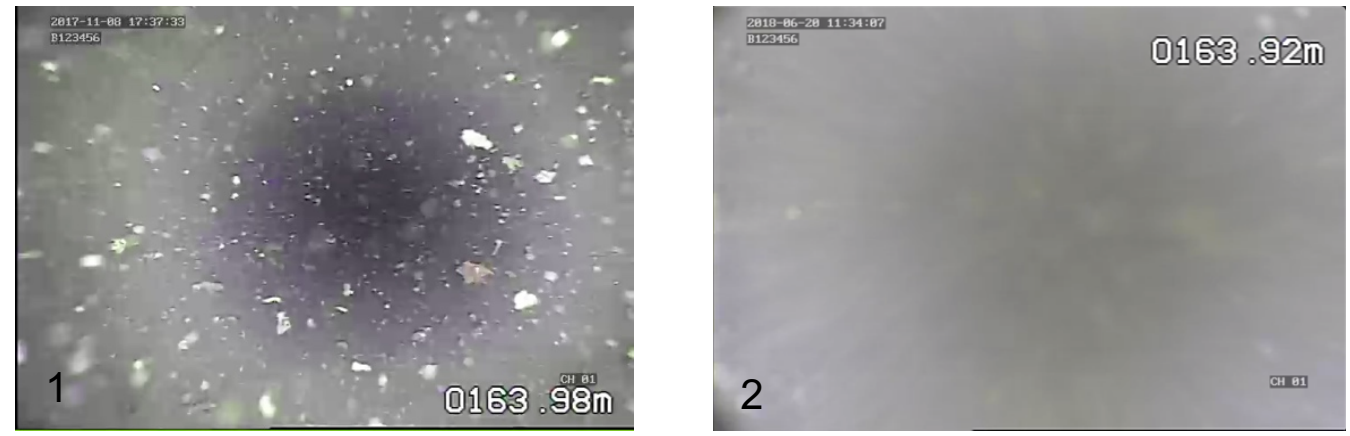

Figura 5.3. Exemplo de imagens captada pela câmera com (1) materiais em suspensão e (2) turbidez elevada

O cáliper faz o registro do perfil de variação do diâmetro médio. Por se tratar de uma medida física, quando bem calibrado, o dado é confiável e permite a identificação da transição entre a rocha, o tubo de revestimento e o tubo filtro. Embora seja pouco provável o registro de furos no revestimento por essa ferramenta, em casos extremos de rompimento isso fica bastante evidente.

O cáliper não é a ferramenta mais adequada para a identificação da profundidade total do furo ou possíveis obstruções. A sonda é baixada sem centralizador, ficando facilmente presa em irregularidades do poço. O poço 255, por exemplo, durante a descida da sonda ficou presa em uma cavidade na parede do poço, não sendo possível saber se a sonda chegou ao fundo ou parou antes.

A sonda acústica pode ser utilizada para registrar todos os aspectos construtivos, exceto a profundidade total do furo e a ocorrência de obstruções e situações de risco. Por se tratar de um equipamento relativamente caro e delicado, impactos na extremidade inferior da sonda (cabeça acústica) podem danificá-la. Um de seus pontos fortes é o registro do perfil de variação tridimensional do diâmetro do furo. A sonda não é afetada pela sujeira do poço, e precisa estar submersa em água para funcionar.

É importante ressaltar que a qualidade da imagem acústica é altamente dependente da centralização da sonda no furo, e paredes muito irregulares causam a dispersão ou perda da 
resposta do sinal acústico. Na maior parte dos trabalhos, a interpretação dos dados da sonda acústica foi realizada em conjunto com as imagens da câmera (Figura 5.4).

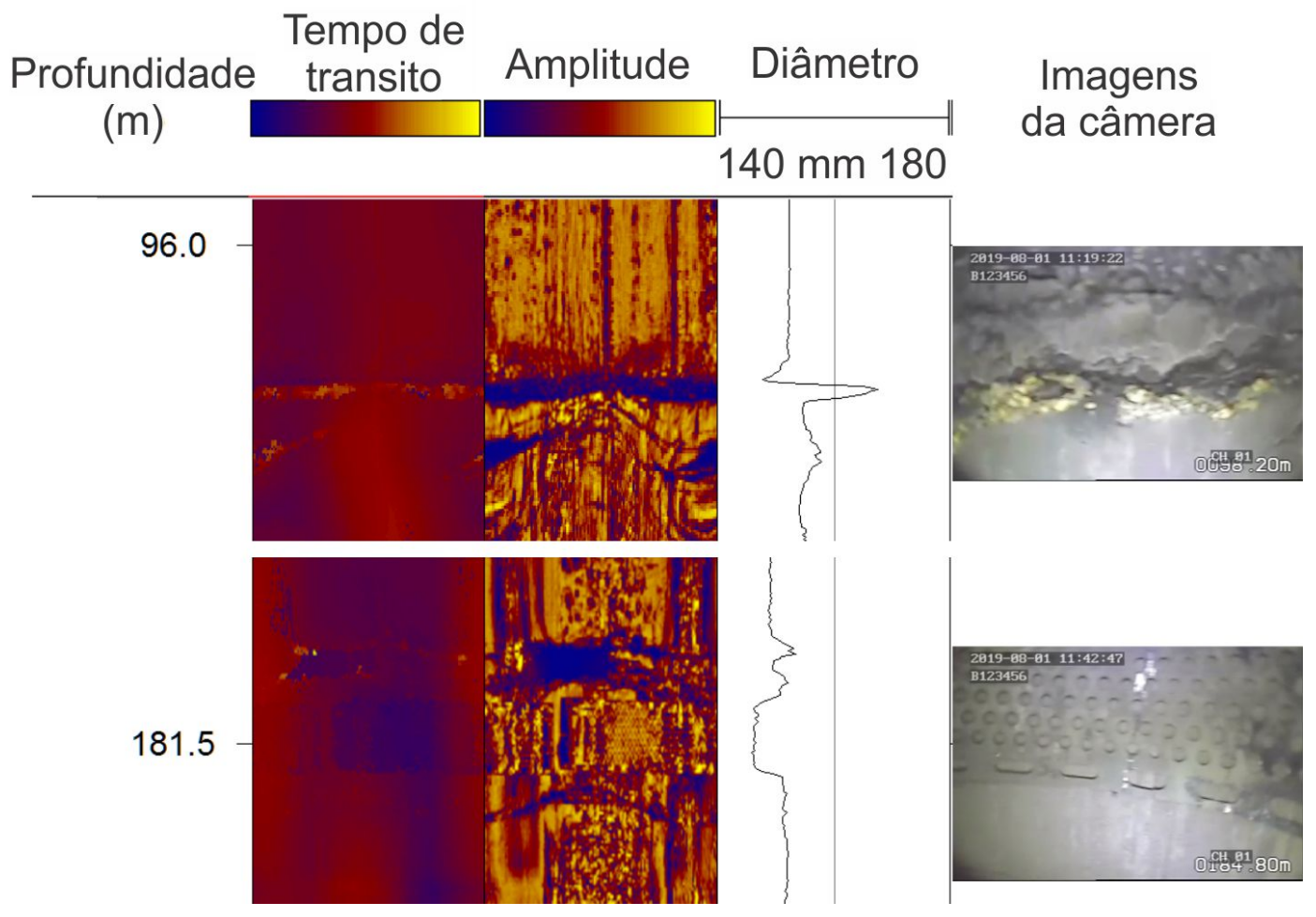

Figura 5.4. Exemplo de combinação dos dados da sonda acústica (tempo de trânsito e amplitude do sinal acústico), cáliper e imagens da câmera

A sonda ótica produz imagens nítidas em condições normais de turbidez, o que permite a identificação de todos os aspectos visuais, além da inclinação e desvio do furo. A qualidade das imagens é superior à da câmera, mas seu formato de visualização não é adequado para a observação das características construtivas e físicas do poço. Como essa sonda não faz medidas de variação de diâmetro, ela precisa ser utilizada em conjunto com o cáliper ou a sonda acústica.

\section{Características da rocha}

As características mais relevantes são: tipos de rocha; composição mineral; presença de corpos intrusivos e grau de intemperismo ou de alteração dos minerais. As principais sondas que fornecem este tipo de informação são a câmera, televisionamento ótico e acústico, resistividade elétrica e gama natural.

Em condições de baixa turbidez, o televisionamento ótico é a melhor ferramenta para visualizar as características citadas. A sonda gera uma imagem contínua de alta resolução em $360^{\circ}$ (Figura 5.5). A câmera gera um vídeo que pode ser congelado em imagens, no entanto a qualidade é muito inferior e tem um campo focal limitado. Sendo assim, o televisionamento ótico é muito superior à câmera. 

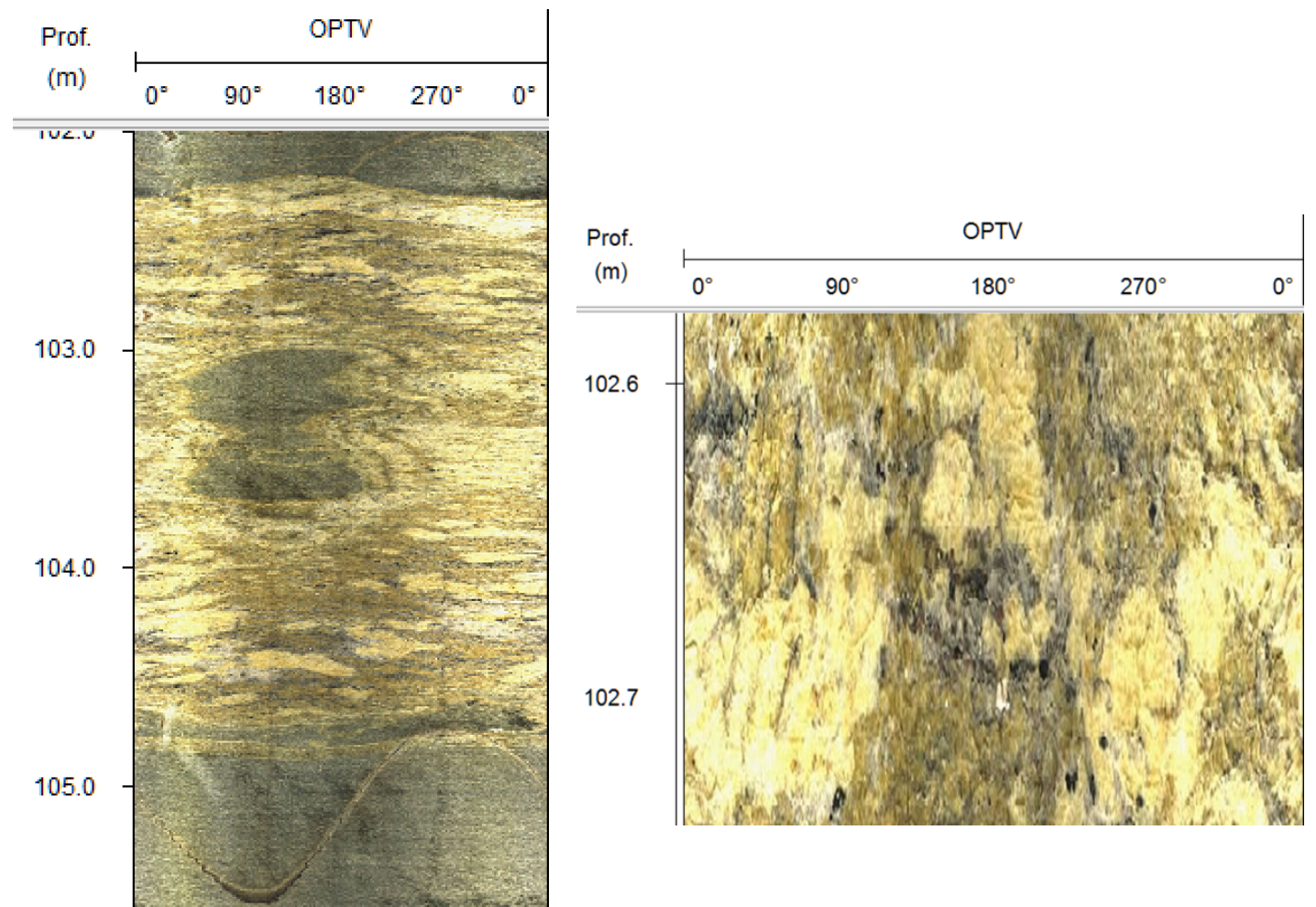

Figura 5.5. Exemplo de imagem gerada com o OTV. À direita a imagem foi ampliada 15 vezes para visualização das características da rocha

As sondas acústica, resistividade elétrica e gama fornecem medidas indiretas de propriedades da rocha, que podem ser utilizadas na caracterização estratigráfica do aquífero. A amplitude do sinal acústico por exemplo, é afetada pela dureza e rugosidade do material e, assim como no caso dos poços da Área M, pode ser utilizada para identificar mudança litológica, embora forneça poucos elementos para a classificação litológica.

Na maior parte dos casos, a caracterização da rocha não é um aspecto tão importante, e geralmente serve para confirmar as descrições apresentadas no relatório de perfuração do poço. Não obstante, casos em que não há informações litológicas disponíveis, ou que a descrição é pouco confiável, a perfilagem ótica é a mais indicada para caracterizar a rocha.

\section{Feições estruturais}

A identificação de feições estruturais pode ser realizada por quatro sondas: televisionamento ótico, acústico, cáliper e câmera. Destas, apenas as duas primeiras servem para a caracterização das estruturas, e o televisionamento ótico depende de um perfil de variação do diâmetro do furo para determinar com precisão o ângulo de mergulho das feições observadas.

Dessa forma, a sonda que apresenta melhor aplicabilidade para essa finalidade é a acústica, apesar de suas limitações. A sonda acústica identifica as feições estruturais por meio 
da amplitude e do tempo de trânsito do sinal acústico, gerando um perfil tridimensional do diâmetro do poço. Além disso, essa sonda é a única que identifica estruturas do tipo breakouts, indicativos da direção atual dos esforços que atuam sobre a rocha.

A sonda acústica é muito eficaz na detecção de fraturas, entretanto outras feições como, fraturas preenchidas, deformações dúcteis da rocha, presença de bandamentos e foliações é limitada. Essa sonda não funciona fora da água. A qualidade da imagem acústica é muito sensível à centralização da sonda, de forma que irregularidades do furo podem prejudicar e até impossibilitar o uso da ferramenta. Nesses cenários, o cáliper pode ser uma ferramenta útil para calibrar os dados dos televisionamentos ótico e acústico.

A perfilagem com o cáliper gera um perfil contínuo da variação do diâmetro do poço e indica a ocorrência de fraturas quando ocorre um aumento pontual no diâmetro do furo. Da perspectiva de técnicas para caracterização estrutural, o cáliper é uma ferramenta complementar, que ajuda na interpretação do televisionamento acústico e principalmente o ótico.

A perfilagem ótica, em condições ideais de visibilidade, é a melhor ferramenta para identificar e caracterizar feições estruturais, pois a resolução e a qualidade da imagem superam as outras técnicas. Alguns exemplos das diferenças entre as sondas de televisionamento ótico, acústico e cáliper de três braços são apresentados na Figura 5.6. 


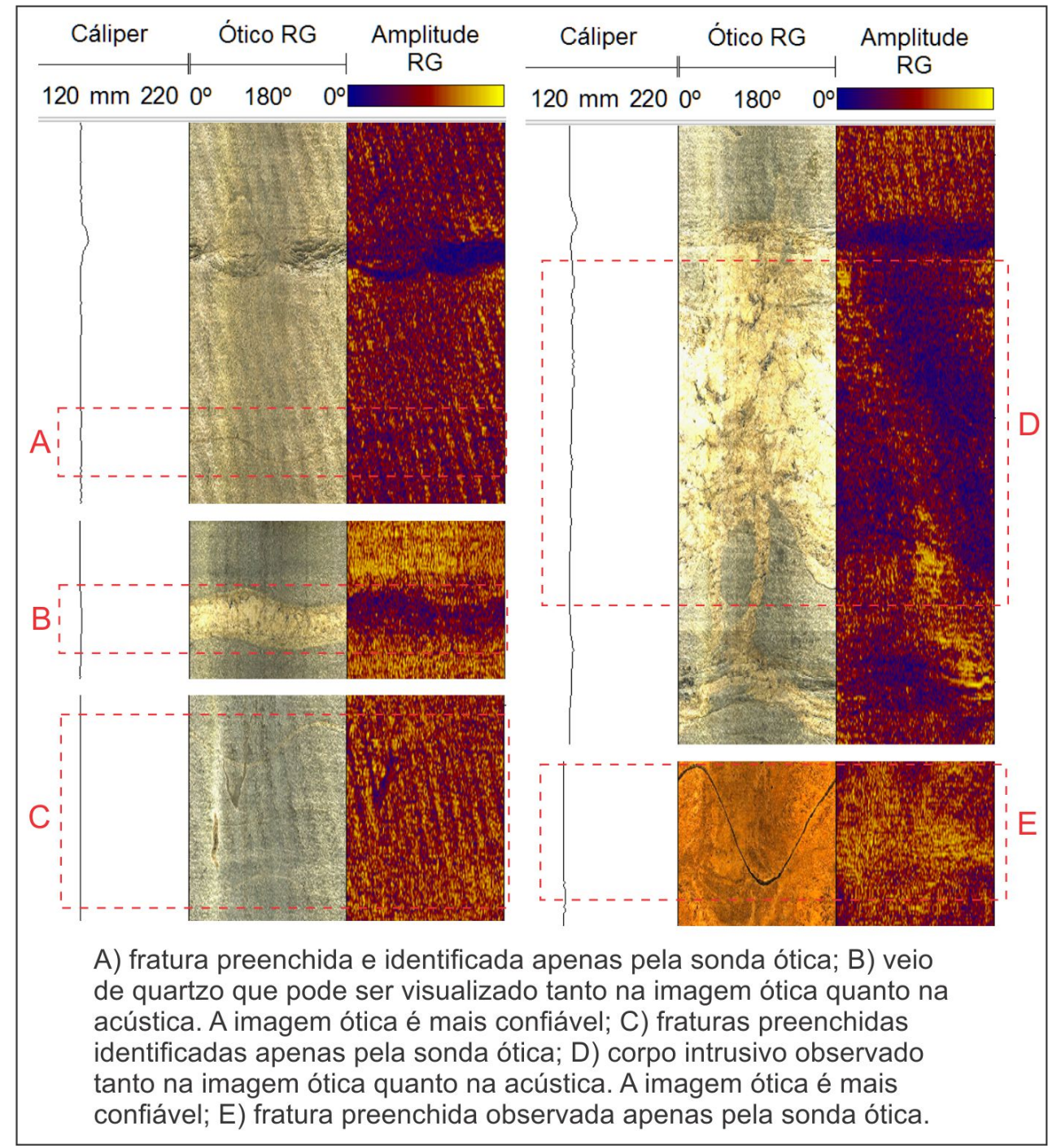

Figura 5.6. Exemplos das diferenças entre as sondas de televisionamento ótico, acústico e cáliper

\section{Propriedades hidráulicas}

A determinação das propriedades hidráulicas foram o foco principal deste trabalho, e existem uma série de atividades que contribuem para o modelo conceitual de fluxo do poço e do aquífero.

Com relação à etapa preliminar, as informações mais importantes relacionadas diretamente à hidráulica são: indícios de zonas produtivas identificadas durante a perfuração do poço (perda de água ou de lama de recirculação); nível dinâmico e estático do poço; resultado do ensaio de bombeamento; e a existência de outros poços próximos ao local do trabalho (tanto em operação quanto desativados).

$\mathrm{Na}$ etapa geofísica, praticamente todas as atividades contribuem para a caracterização da dinâmica de fluxo. Um exemplo disso são as imagens geradas pelo OTV e pela câmera que identificaram feições de fluxo em seis dos poços estudados (Figura 5.7). 


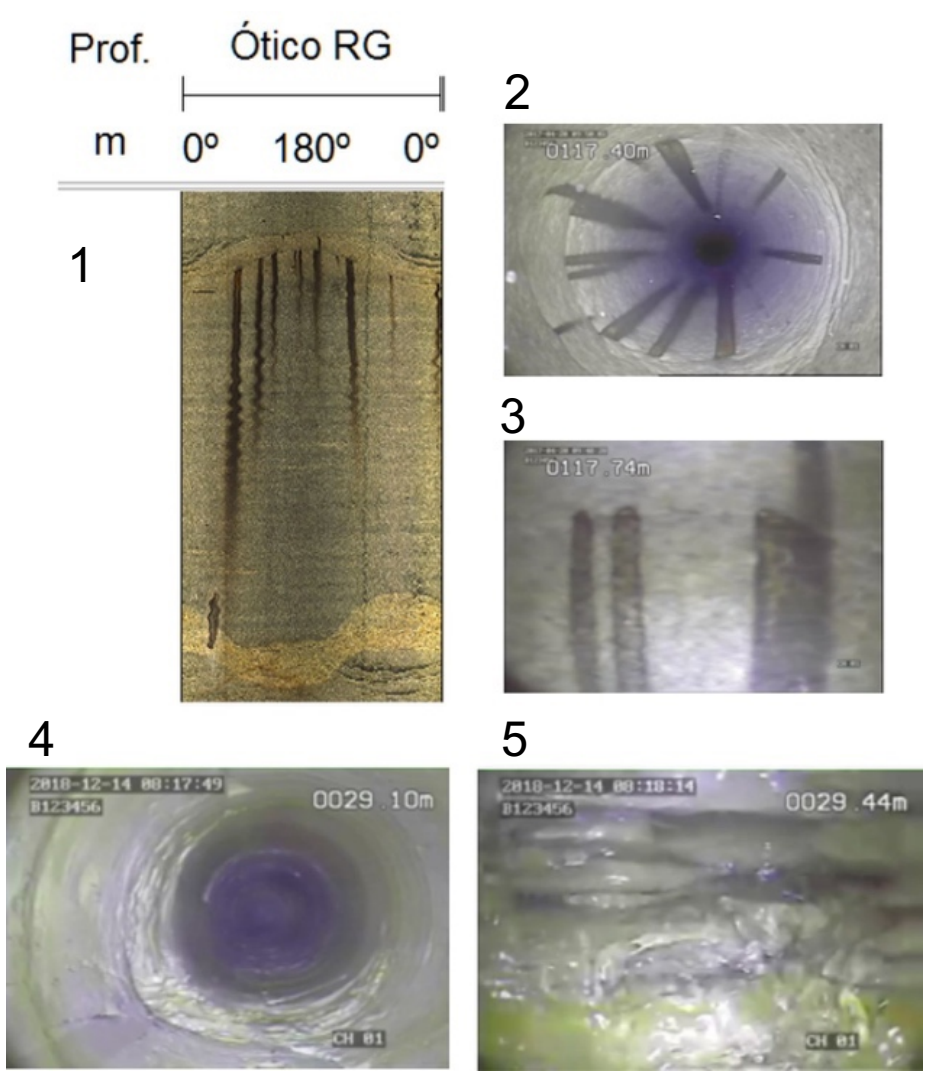

Figura 5.7. Exemplo de feições de fluxo identificadas com o OTV (1) e a câmera (2 a 5). As imagens 1 a 3 são da mesma feição de fluxo observada no poço 1204 da Área S

O uso dos dados estruturais e de variação do diâmetro também são importantes para selecionar os trechos com menor chance de vazamento nos ensaios com flowmeter.

A caracterização de fluxo por técnicas geofísicas apresenta uma limitação metodológica, resultado da sua aplicação em furos abertos. As fraturas mais transmissivas controlam a dinâmica de fluxo no poço, tornando as demais menos evidentes. As técnicas de caracterização hidráulica utilizadas foram FTCR e flowmeters (HPF, EMF e SF).

O ensaio realizado com a sonda FTCR no poço B1, em condições de fluxo ambiente e induzido, possibilitou a identificação de três zonas hidraulicamente ativas (Figura 5.8). Em condições ambiente, a água entra no poço pela zona 1 e sai pela 3 . No ensaio com injeção de água, a zona 2 absorveu a maior da água. A comparação entre esses dois ensaios permite inferir que: a zona mais transmissiva é a zona 2; ela, provavelmente, controla o nível d'água do poço, por isso não participa do fluxo ambiente (gradiente baixo); e que o fluxo é descendente em condição ambiente. 


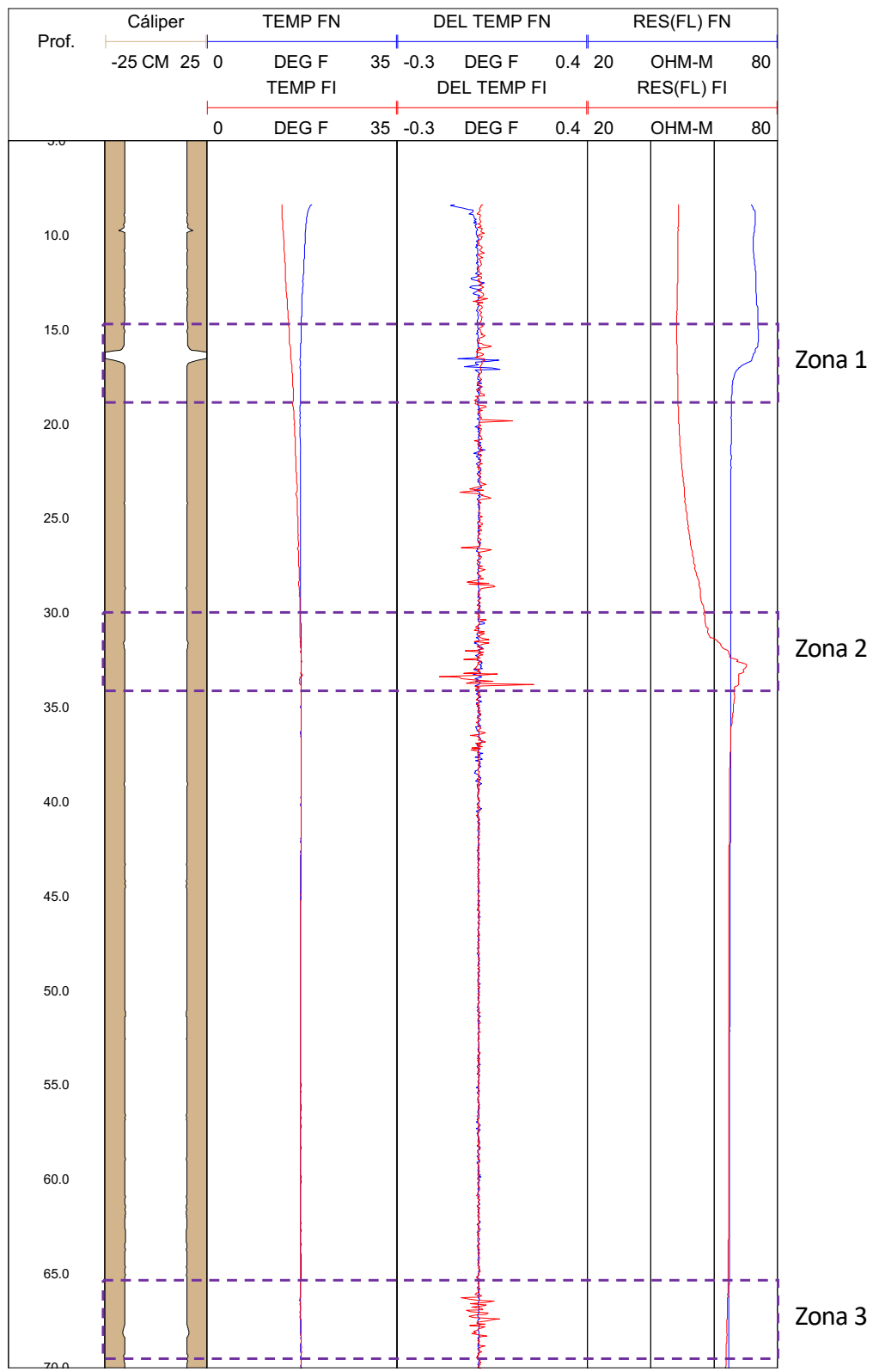

Figura 5.8. Análise comparativa entre dados gerados pela sonda FTCR em condições de fluxo ambiente (azul) e induzido (vermelho). Foram identificadas três zonas hidraulicamente ativas no poço B3

Ensaios com os três flowmeter e a sonda FTCR foram realizados no estudo de caso da Área U, com equipamentos do USGS, que possibilitou a comparação entre as técnicas (Figura 5.9). Dentre as três sondas utilizadas, a que apresentou melhor resultados foi o EMF, seguido pelo HPF e por último o SF. Embora o HPF tenha boa resolução e apresente resultados bastante consistentes, sua faixa de atuação é muito restrita (de 0,1 a 5 1/min). O EMF tem uma faixa de trabalho maior (0,5 a 120 1/min), e permite a realização de medição dinâmica (perfil de fluxo) e estacionária (pontual). Outra vantagem dessa sonda é ter integrado o sensor de temperatura e resistividade do fluido, facilitando a operação e aumentando a produtividade na coleta de dados. 
A SF se mostrou uma ferramenta menos precisa que as outras duas, e é aplicável em condições de vazão elevada (acima de 5 1/min).

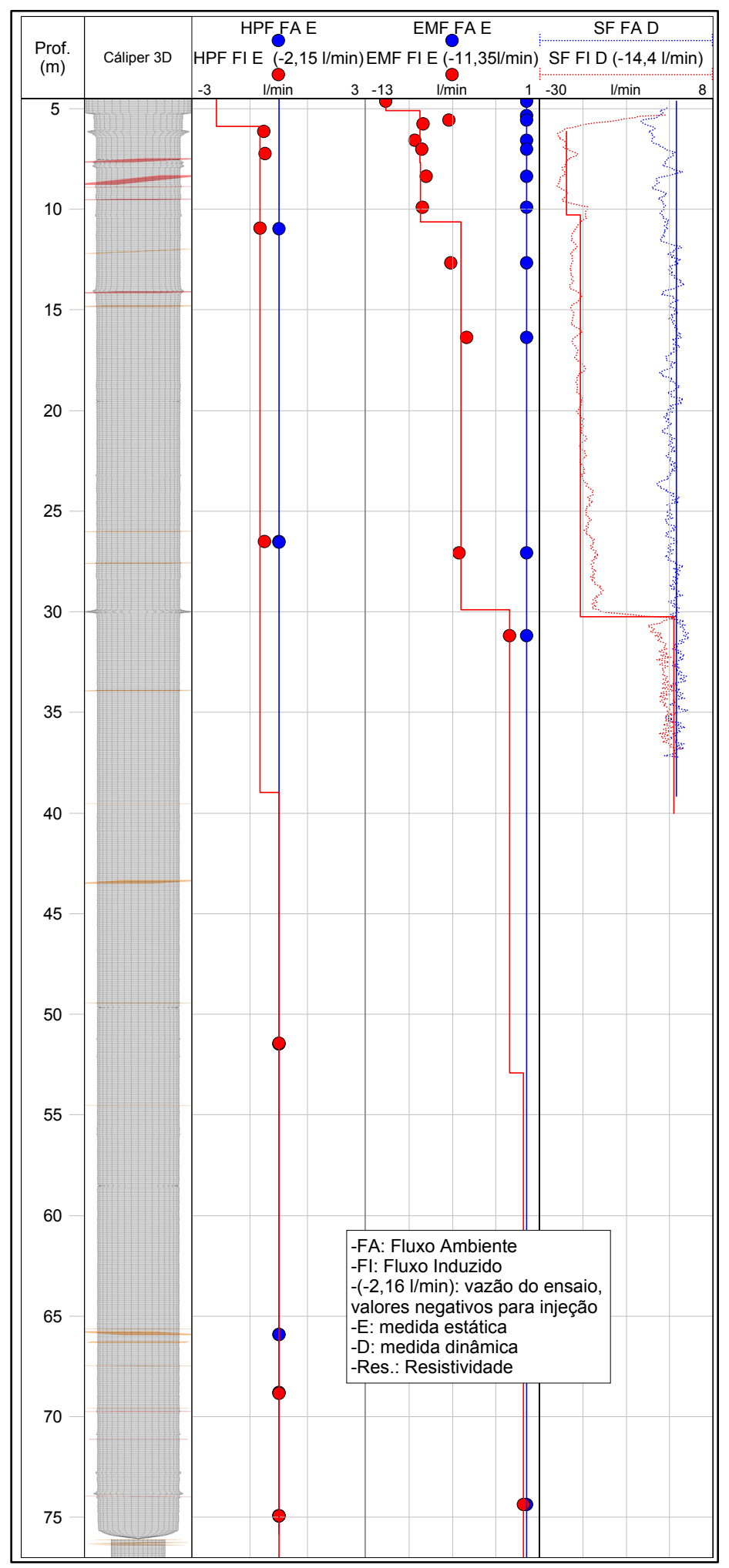

Figura 5.9. Perfil de fluxo gerado com dados dos flowmeters para o poço B3. Neste perfil pode ser observada a diferença de resposta que cada sonda apresenta para um mesmo poço. A vazão utilizada para o ensaio com fluxo induzido foi diferente para cada sonda 
Com relação ao modelo de HPF utilizado, os dados obtidos com a sonda da MSI apresentaram resultados mais coerentes e consistentes que os produzidos com a sonda da RG. Além disso, o uso de diverter se mostrou eficiente para minimizar os efeitos de variação do diâmetro, rugosidade da parede do poço e descentralização da sonda no furo. A realização de ensaios em condições ambiente e de fluxo induzido (extração ou injeção de água) é fundamental para entender a dinâmica de fluxo do poço. Ensaios somente na condição ambiente podem não detectar a principal zona produtora de água do poço conforme é demonstrado na Figura 5.9 e nos estudos de caso.

Alguns cuidados são necessários para que os dados obtidos com o flowmeter sejam representativos da condição de fluxo no poço e resultem em uma modelagem consistente, são estes: fazer a aferição e calibração da sonda em laboratório com regularidade, ou sempre que observada discrepância nas leituras de fluxo zero e vazão conhecida; selecionar trechos para medidas estáticas em que a parede do poço seja uniforme e com diâmetros similares para minimizar o efeito do vazamento no diverter; aguardar a estabilização do fluxo após movimentação da sonda (fluxo natural e induzido), e de extração ou injeção de água (fluxo induzido); ajustar a vazão de extração ou injeção de água para valores dentro do limite de quantificação da sonda; monitorar variações na vazão de extração ou injeção de água e do nível d'água; e fazer a calibração de campo em zonas de ausência de fluxo e de fluxo conhecido.

Além das questões operacionais, o uso de modelos matemáticos para interpretação dos ensaios com flowmeter é a única forma de obter o máximo de informações que este tipo de técnica pode oferecer (DAY-LEWIS et al., 2011; PAILLET, 2004, 1998; PAILLET; OLLILA, 1994). Para isso, os dados devem ser coletados seguindo os procedimentos de campo descritos no Item 4. Mesmo tomando todos os cuidados durante a etapa de campo, existem não idealidades nos poços e falhas de equipamentos que fazem necessário o ajuste dos dados na etapa de processamento e interpretação antes de rodar um modelo (BUSSE et al., 2016; PAILLET, 2004).

Nos casos em que os dados foram produzidos tomando todos os cuidados necessários (Item 4.1.9), a modelagem de fluxo do flowmeter (HPF e EMF) demonstrou boa correlação com os dados produzidos com obturadores, como será demonstrado nos estudos de caso. Nos casos de poços com problemas construtivos e ensaios sem controle rigoroso dos procedimentos de campo, não foram obtidos resultados satisfatórios nas modelagens. Este tipo de situação é ilustrado no caso da Área S. 


\subsubsection{Unidade móvel de ensaios hidráulicos e amostragem MUST}

A unidade móvel de ensaios hidráulicos e amostragem com obturadores (MUST) é o resultado da integração de todos os componentes apresentados no Item 4.2.2. Apesar do enfoque dado aos aquíferos fraturados, seu uso em poços tubulares revestidos com múltiplas seções filtrantes em aquífero sedimentar também é possível. Conforme mencionado anteriormente, o desenvolvimento da MUST é um processo de melhoria contínua, que pode ser adaptado e modificado para utilizar novas configurações de equipamentos e realizar outros tipos de ensaios.

Todos os componentes da MUST são armazenados e transportados em um trailer de 6 $\mathrm{m}$ de comprimento, 2,4 $\mathrm{m}$ de largura e $3 \mathrm{~m}$ de altura. $\mathrm{O}$ trailer é rebocado por uma caminhonete com engate de bola. Para o funcionamento adequado de todos os recursos, o local de trabalho deve dispor de: ponto de energia com tensão $220 \mathrm{~V}$ trifásico (potência de $10 \mathrm{KVA}$ ); ponto de água; e fornecimento de cilindros de nitrogênio ou linha de ar pressurizado (40 bar).

A movimentação da composição de obturadores pode ser realizada de duas formas, utilizando um guincho de arraste ou uma talha (Figura 5.10). Quando utilizado o guincho (instalado dentro do trailer), o centro da traseira do trailer precisa estar alinhado com o poço, a uma distância de 3 a $5 \mathrm{~m}$. Quando utilizada a talha elétrica isso não é necessário, embora o trailer nessa posição facilite a operação. Uma comparação entre as vantagens e desvantagens de cada sistema é apresentada na Tabela 5.1.

Tabela 5.1 Comparação entre sistemas de movimentação da composição no poço

\begin{tabular}{|c|c|c|}
\hline Sistema & Guincho & Talha \\
\hline 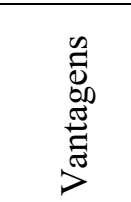 & $\begin{array}{l}\text { - Operação de dentro do trailer, sistema } \\
\text { pronto para uso } \\
\text { - Menor susceptibilidade às intempéries } \\
\text { climáticas }\end{array}$ & $\begin{array}{l}\text { - Estabilidade do sistema de elevação } \\
\text { - O trailer não precisa estar muito próximo } \\
\text { ou alinhado com o poço }\end{array}$ \\
\hline 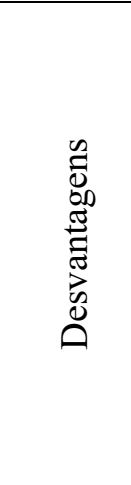 & $\begin{array}{l}\text { - Necessita de alinhamento com a boca do } \\
\text { poço com distância de } 3 \text { a } 5 \mathrm{~m} \\
\text { - Maior instabilidade da estrutura devido à } \\
\text { componente horizontal da força que atua } \\
\text { sobre o tripé, quando este é utilizado, } \\
\text { colocando em risco os equipamentos e } \\
\text { operadores } \\
\text { - Dificulta a montagem da composição e } \\
\text { gerenciamento dos tubos, cabos e } \\
\text { mangueiras quando utilizada a estrutura de } \\
\text { aço }\end{array}$ & $\begin{array}{l}\text { - Os equipamentos pesados precisam ser } \\
\text { carregados e montados na boca do poço. } \\
\text { Maior risco ergonômico e desgaste físico } \\
\text { dos operadores } \\
\text { - Maior susceptibilidade a intempéries e } \\
\text { choques mecânicos durante a montagem }\end{array}$ \\
\hline
\end{tabular}



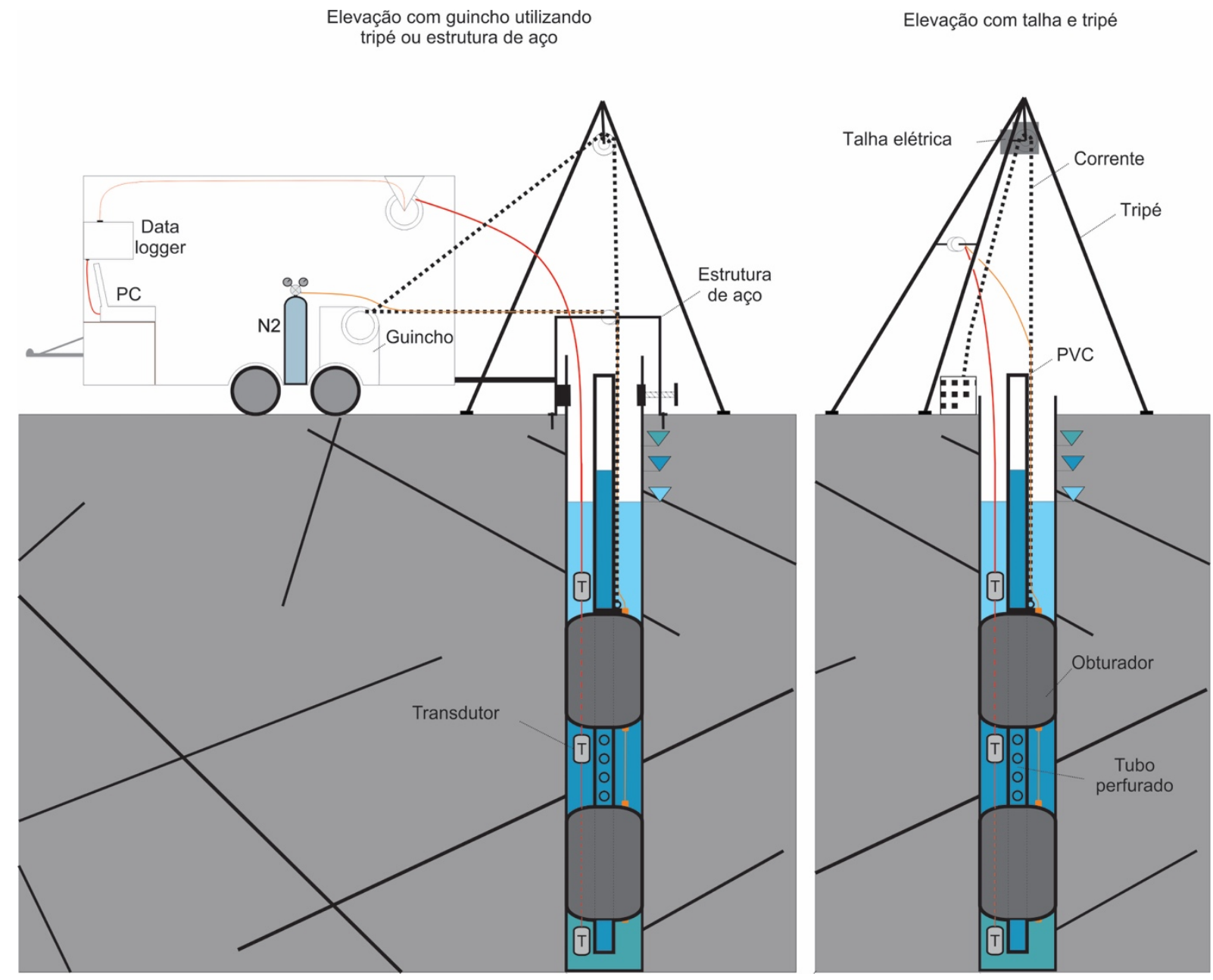

Figura 5.10. Sistemas de movimentação da composição que foram utilizados

Após realizar alguns trabalhos com ambos sistemas de movimentação, optou-se por utilizar, definitivamente, a talha elétrica, uma vez que o quesito segurança dos operadores é prioridade para a realização de trabalhos de campo, e a estrutura de aço não se mostrou uma solução prática (Figura 5.11). Uma outra possibilidade é o uso de um caminhão munck para movimentação da composição com tubos de aço ao invés de corrente. No entanto, a locação deste tipo de equipamento aumenta o custo operacional e não foi avaliado como uma opção viável para este projeto.

O registro e controle da profundidade é outro aspecto importante para a movimentação e posicionamento da composição de obturadores nos intervalos de interesse. Embora seja um detalhe operacional, este aspecto tem grande impacto na qualidade e resultado do trabalho, especialmente quando o intervalo entre obturadores é menor. O erro de profundidade nunca deve ser maior ou igual ao intervalo obturado, pelo contrário, a margem de erro deve ser somada ao intervalo, garantindo que a seção de interesse seja isolada. 

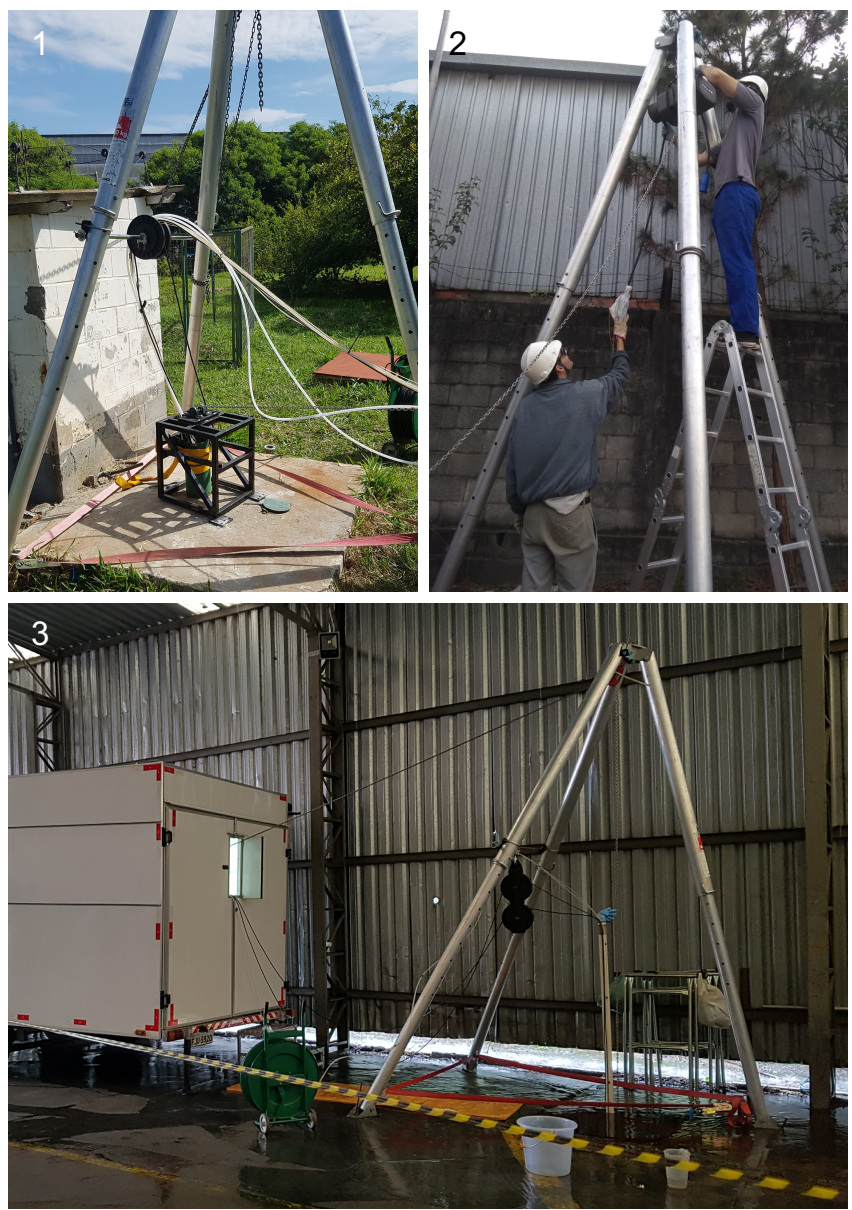

Figura 5.11. Sistemas de movimentação da composição de obturadores: (1) guincho de corrente localizado dentro do trailer e estrutura de aço fixada na cabeça do poço, tripé utilizado apenas para montagem da composição; (2) talha elétrica fixada no topo do tripé; (3) guincho de corrente localizado dentro do trailer e tripé

Inicialmente, o registro de profundidade foi realizado por um contador de giro eletrônico, integrado ao guincho. Durante a aferição desse sistema foi observado um desvio de até $15 \mathrm{~m}$ (5\% de erro). Após muitas tentativas de calibração sem sucesso, decidiu-se que esse sistema seria utilizado apenas como uma referência aproximada. No projeto da talha foi solicitado ao fabricante um sistema parecido de medição, mas com erro máximo de 1\%, após meses de atraso o fabricante informou que não seria possível entregar este tipo de sistema com as características especificadas.

Dada a imprecisão do contador eletrônico, nos primeiros trabalhos foram utilizados os transdutores acoplados à composição para fazer o controle da profundidade, uma vez que a precisão dos sensores é inferior a $20 \mathrm{~cm}$ de erro. Esse controle se mostrou confiável, embora ineficiente, por necessitar que os sensores estivessem conectados ao data logger para leitura da pressão - durante a movimentação os sensores são desligados para que o carretel possa girar 
livremente. O posicionamento preciso, utilizando transdutores, requer cálculos, que precisam levar em consideração a profundidade do nível d'água e a pressão atmosférica. Além disso, caso ocorra qualquer problema com o sensor ou sistema de leitura (e.g. cabo ser danificado) perde-se o referencial de profundidade.

Por fim, optou-se por uma trena reforçada para controlar a profundidade, que foi fixada na cabeça da composição e amarrada na corrente em intervalos regulares. Esta configuração apresentou um erro de 10 a $30 \mathrm{~cm}$ em relação às medidas dos transdutores, além de ser prática e de baixo custo. Portanto, o espaçamento entre obturadores deve levar em consideração um erro de até $50 \mathrm{~cm}$.

Os ensaios hidráulicos realizados pela MUST possibilitam a quantificação da transmissividade na faixa de $E^{-3}$ a $^{-8} \mathrm{~m}^{2} / \mathrm{s}$ para ensaios tipo pulso e carga constante, e até $\mathrm{E}^{-2}$ $\mathrm{m}^{2} / \mathrm{s}$ para ensaios de bombeamento. Esses valores foram estimados a partir da equação de Thiem (Equação 4.7), assumindo a premissa de fluxo radial horizontal isotrópico nas fraturas que interceptam o intervalo isolado. A solução de Thiem (THIEM, 1906 apud FETTER, 2001) foi desenvolvida, originalmente, para ensaios de bombeamento com poços de observação, mas é comumente utilizada para aquíferos fraturados. $\mathrm{O}$ raio de influência utilizado no cálculo variou de acordo com a transmissividade do intervalo, $3 \mathrm{~m}$ para valores abaixo de $\mathrm{E}^{-5} \mathrm{~m}^{2} / \mathrm{s}$ e 30 $\mathrm{m}$ para valores até $\mathrm{E}^{-5} \mathrm{~m}^{2} / \mathrm{s}$. Pelo fato do raio de influência estar dentro de uma função logarítmica normal, variações de até uma ordem de grandeza tem impacto menor que $30 \%$ no valor da transmissividade.

Para o cálculo da faixa de transmissividade que a MUST consegue quantificar, foram considerados os seguintes cenários: (1) ensaio de carga constante com variação da pressão de 0,03 a 30 m, e vazão de injeção: 0,1 a 3 1/min; (2) ensaio de bombeamento com variação mínima da carga hidráulica de $0,03 \mathrm{~m}$, e vazão de bombeamento máxima de 30 1/min (vazão máxima de bombeamento em condições reais de campo com o nível d'água inferior a 10 metros).

Com relação aos ensaios e amostragem, foram testadas duas configurações principais na MUST. Nos subitens seguintes serão apresentadas as particularidades de cada uma delas, dificuldades e vantagens. O enfoque desta seção é a integração dos componentes e não as características individuais dos equipamentos, já apresentados no capítulo de materiais e método. 


\section{Configuração A de operação da MUST}

A configuração "A” (Figura 5.12) utilizou tubos de PVC de $50 \mathrm{~mm}$ para comunicar o intervalo de ensaio com a superfície, e os transdutores de pressão ficam posicionados em cada um dos intervalos isolados. Os principais aspectos dessa configuração são resumidos na Figura 5.13

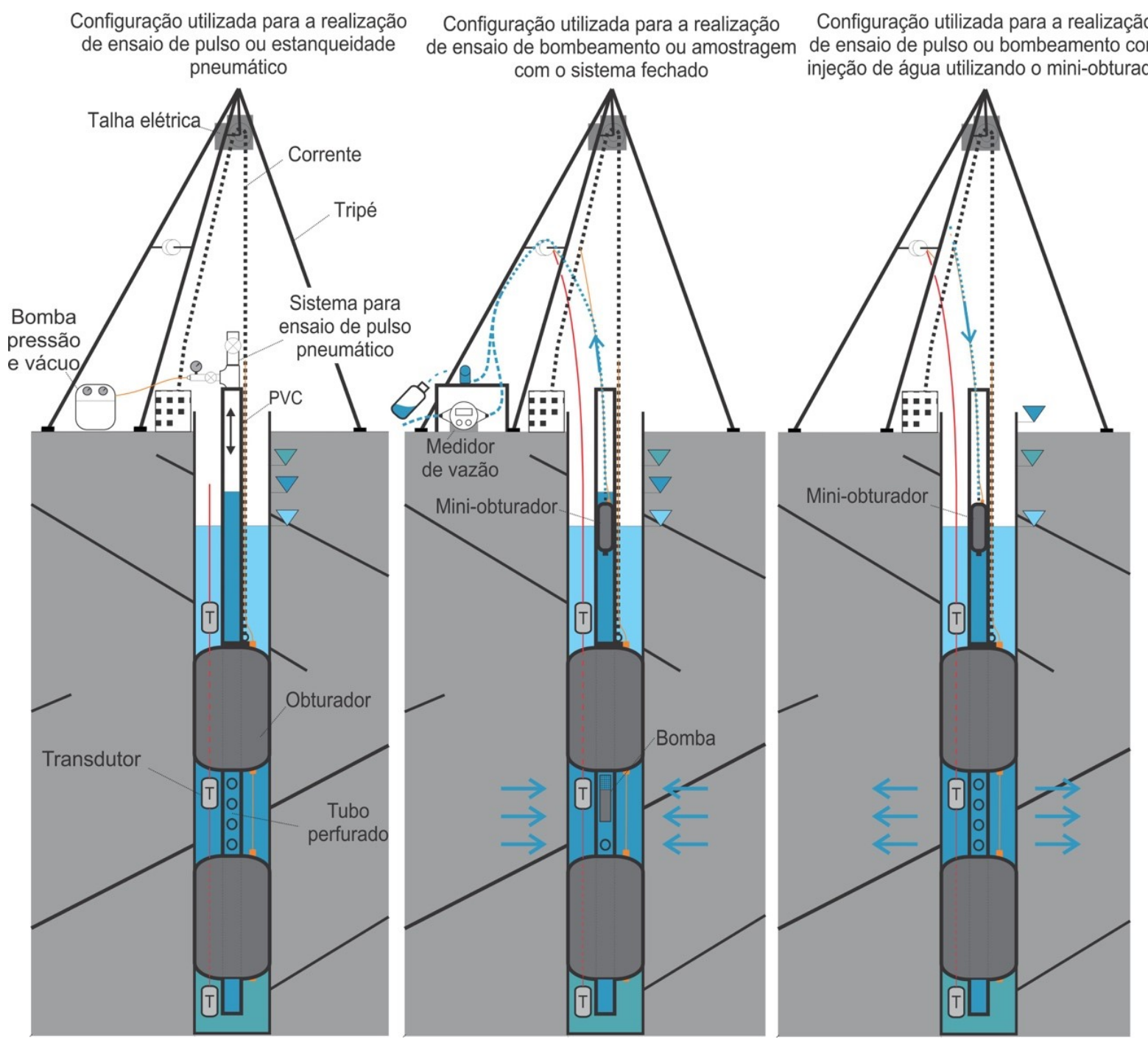

Figura 5.12. Configuração A da MUST 


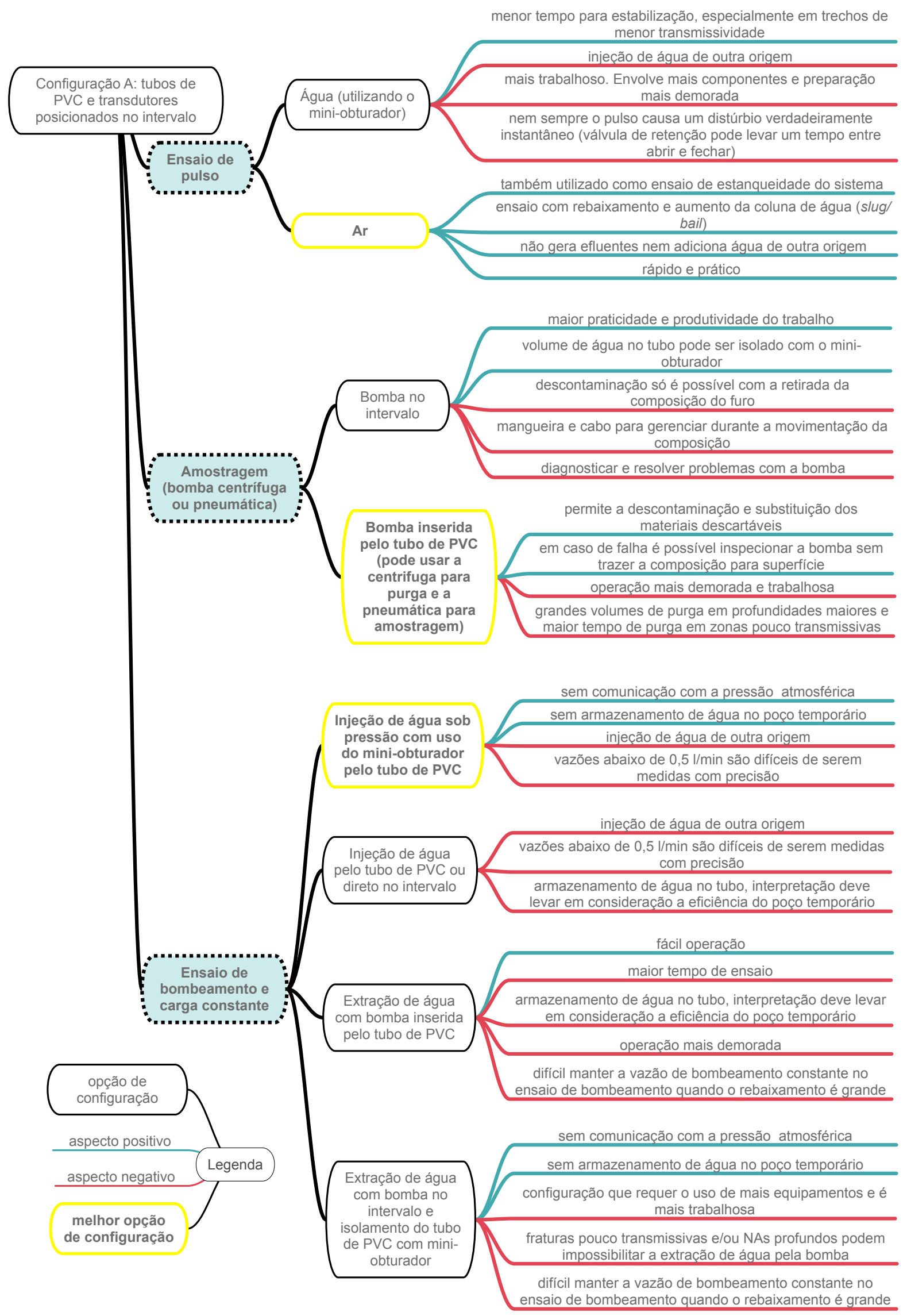

Figura 5.13. Características de operação da configuração A da MUST 


\section{Montagem}

O posicionamento dos transdutores no intervalo isolado (intermediário) e inferior, requer pelo menos uma emenda nos seus cabos para a montagem da composição na configuração A. Emendas em cabos elétricos e eletrônicos estão sujeitos a falha no selo e corrosão por água. Além disso, o cabo dos sensores é amarrado ao tubo de PVC e pode ser prensado contra a parede do furo durante a operação.

O uso dos tubos de PVC, como poço temporário, possibilita o acesso de equipamentos maiores ao intervalo isolado, como a bomba (para ensaio ou amostragem) ou o mini-obturador. Outra vantagem é um maior controle sobre a movimentação da composição no furo, pois os tubos são estruturas rígidas que se movimentam sempre junto da composição, e possibilitam empurrar a composição para baixo caso necessário, o que não é possível com mangueiras. Por outro lado, a movimentação da composição se torna mais lenta, dada a necessidade de acoplar uma barra de tubo a cada dois metros de deslocamento. $\mathrm{O}$ uso de tubos também requer limpeza, de preferência ao término de cada operação, o que aumenta o tempo de trabalho de campo.

\section{Ensaio de pulso com água ou ar}

O ensaio de pulso é o primeiro a ser realizado, e serve tanto para avaliar a efetividade do selo estabelecido pelos obturadores, como para uma primeira estimativa da transmissividade do intervalo. Esse ensaio pode ser realizado de duas formas, com um pulso de ar (imprimindo pressão ou vácuo no intervalo) ou de água (injeção de água). O pulso de ar é mais rápido e simples de ser executado, e requer apenas que o sistema pneumático seja acoplado ao tubo de PVC. Já o pulso de água requer a injeção com o mini-obturador inflado abaixo do nível d'água, e com regulagem adequada da válvula de retenção na sua ponta.

Em geral, no ensaio de estanqueidade a coluna de água é deslocada de 3 a $5 \mathrm{~m}$. O volume do distúrbio causado no intervalo isolado é de, aproximadamente, dois litros por metro de coluna de água deslocada (para um tubo de $50 \mathrm{~mm}$ ). Esse volume é suficiente para indicar se foi obtido um bom isolamento, e o quão transmissivo é o intervalo testado. A partir desse primeiro ensaio podem ser dimensionadas as cargas a serem aplicadas em outros pulsos (obter valores de transmissividade a partir de deslocamentos variados é uma prática recomendada).

A comparação entre as duas técnicas de ensaio indica que o pulso de ar é mais vantajoso: preparação rápida e fácil; deslocamento da coluna de água tanto para cima como para baixo; não gera efluentes; não adiciona água ao poço; e pode ser interrompido caso se aplique pressão elevada em intervalos pouco transmissivos (geralmente fora do regime de fluxo laminar), sem necessidade de aguardar a estabilização total. A desvantagem em relação ao pulso com água é 
que, após montados os sistemas, o tempo de execução é o dobro, uma vez que o ensaio pneumático só tem início após a estabilização da pressão de ar. Em zonas de baixa transmissividade o tempo de estabilização pode ser muito superior ao de preparação do pulso com água.

O ensaio de pulso com água também apresenta bons resultados, mas o principal problema observado é que o distúrbio gerado nem sempre é instantâneo, devido à inercia de abertura e fechamento da válvula de retenção e a pressurização do sistema. Com relação à alteração das características químicas pela injeção, isso não é significativo, devido ao volume de água injetado, geralmente inferior a dez litros, que ficam na parte superior do tubo.

\section{Ensaio de bombeamento e carga constante}

Podem ser realizados com quatro configurações, conforme apresentado na Figura 5.13. Injeção ou extração de água, com o sistema aberto ou fechado para a atmosfera. Quando realizados ensaios em sistema fechado, o processo de estabilização e propagação da pressão é mais rápido, já que não ocorre o fenômeno de armazenamento de água no poço (deslocamento da coluna de água).

O ensaio de carga constante pode ser realizado de duas maneiras, com injeção ou extração de água. A injeção de água requer o uso de menos equipamentos (menos componentes para gerenciar), além de ser mais fácil para o controle da vazão. Em contrapartida, o monitoramento da injeção é mais difícil para baixas vazões (são poucos os medidores que apresentam leitura consistente abaixo de 0,5 1/min). Usar mais de um sensor de vazão é a solução nesse caso, apesar de dificultar a operação.

Para realizar a extração de água, a bomba centrífuga geralmente desce pelo tubo de PVC. Caso a bomba seja montada junto da composição (único jeito de manter o sistema fechado com o uso do mini-obturador) é preciso gerenciar uma mangueira e o cabo de energia, além do tubo de PVC, na movimentação da composição. A principal dificuldade para a extração de água é a regulagem da vazão, que diminui conforme o nível d'água é rebaixado, especialmente em intervalos pouco transmissivos. Em locais onde o nível d'água está mais profundo que 70 metros, a bomba MP1 opera no seu limite e não apresenta bons resultados.

O ensaio de bombeamento pode ser realizado com injeção ou extração de água, e as características do poço devem ser levadas em consideração. O ensaio de bombeamento é vantajoso quando a transmissividade do intervalo é muito elevada (superior a $\mathrm{E}^{-4}$ ), e o ensaio de pulso ou carga constante não são suficientes para causar um distúrbio significativo. Isso aconteceu apenas em um dos intervalos testados. 
A dificuldade de realizar um ensaio de bombeamento é o volume injetado/retirado do poço (acima de $1 \mathrm{~m}^{3}$ para um único intervalo), especialmente em sítios contaminados. Nesses casos, a água retirada precisa ser armazenada e descartada de forma adequada. Já a injeção de grandes volumes de água no poço pode resultar em alteração das características físicas e químicas da amostra. Em alguns casos isso não é um problema, se realizada a amostragem antes do ensaio. Os ensaios de carga constante também estão sujeitos a esses efeitos, embora em menor escala.

\section{Amostragem de água}

A amostragem de água subterrânea pode ser realizada a partir de duas configurações, com a bomba posicionada no intervalo ou inserida pelo tubo de PVC. Ambas abordagens apresentam aspectos positivos e negativos conforme ilustrado na Figura 5.13.

Descer a bomba pelo tubo de PVC é mais seguro e vantajoso, devido a menor quantidade de tubos e cabos que desçam no furo, o que reduz o risco de acidentes e falhas dos equipamentos. Outra vantagem é o acesso à bomba para diagnostico e reparo (ou troca), não são raros os casos em que a bomba não funciona adequadamente. $\mathrm{O}$ acesso via tubo de PVC também permite alternar entre bomba centrifuga e pneumática, atendendo a um maior número de cenários.

Em relação ao procedimento de amostragem, o acesso facilitado ao intervalo pelo tubo de PVC possibilita limpar/descontaminar a bomba e trocar os materiais descartáveis entre cada intervalo amostrado, sem a necessidade de trazer a composição para a superfície. Por último, também é possível alterar entre uma bomba de maior vazão para a purga (e.g. bomba MP1), e outra de baixa vazão para a amostragem (e.g. pneumática).

Apesar de não ser possível isolar a água armazenada no tubo de PVC com o miniobturador e inserir a bomba no tubo simultaneamente, a purga pode ser executada de maneira eficiente. Para isso, é importante posicionar a bomba o mais próximo da composição, e aguardar a estabilização do nível d'água no tubo durante o bombeamento, momento a partir do qual toda a água captada pela bomba é proveniente das fraturas do intervalo. Nesse caso, o volume da purga pode ser ajustado para o volume do intervalo e dos tubos até a cota da bomba.

\section{Configuração B de operação da MUST}

A configuração B (Figura 5.14 e Figura 5.15) utilizou mangueiras de PE de $20 \mathrm{~mm}$ para comunicar o intervalo de ensaio com a superfície. Nesse caso, os transdutores podem ser posicionados nos intervalos isolados (como na configuração A) ou inseridos nas mangueiras 
(mini-transdutores para pressões de até 10 metros de coluna d'água). Os principais aspectos dessa configuração são resumidos na (Figura 5.16).

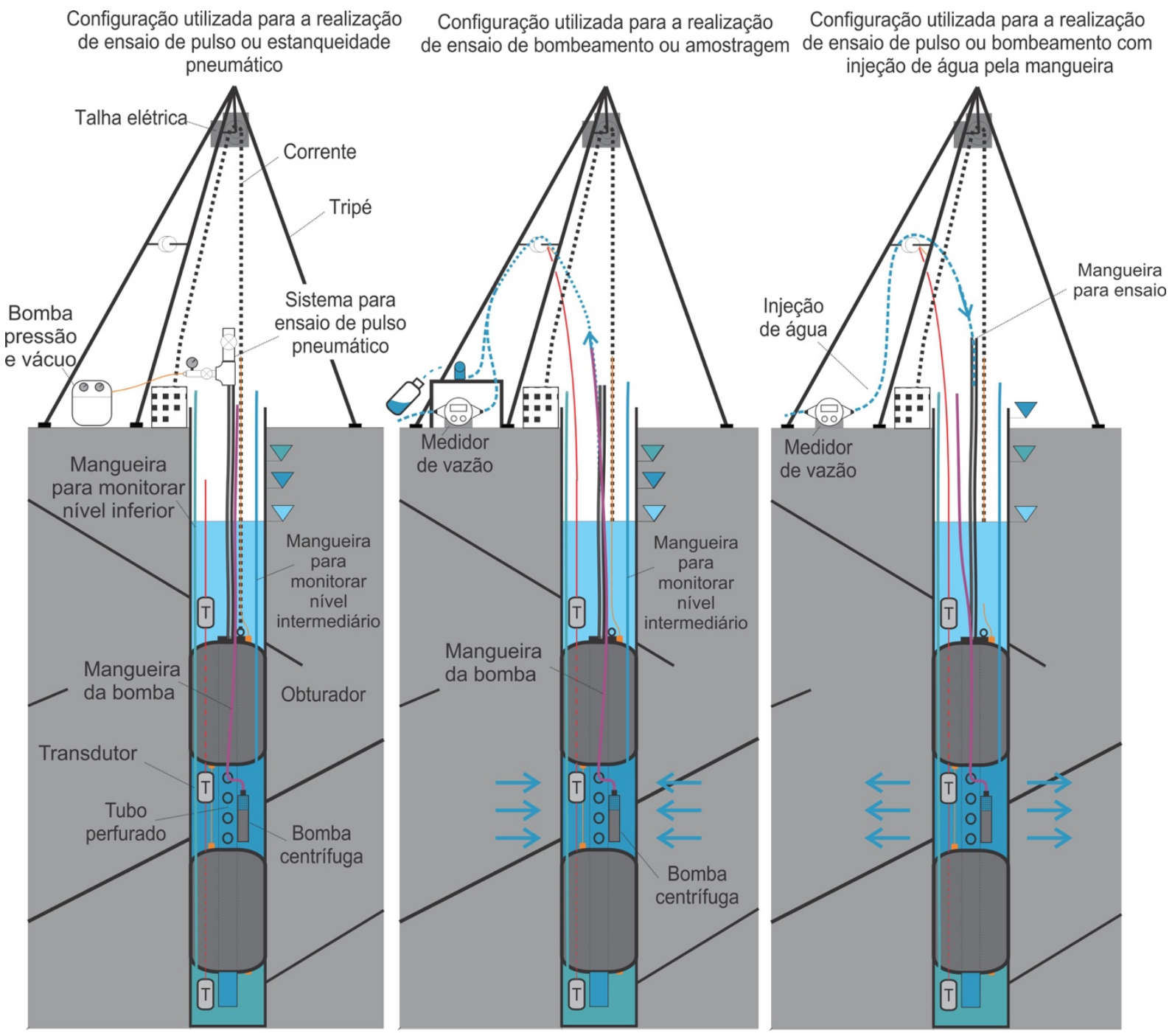

Figura 5.14. Configuração B da MUST 

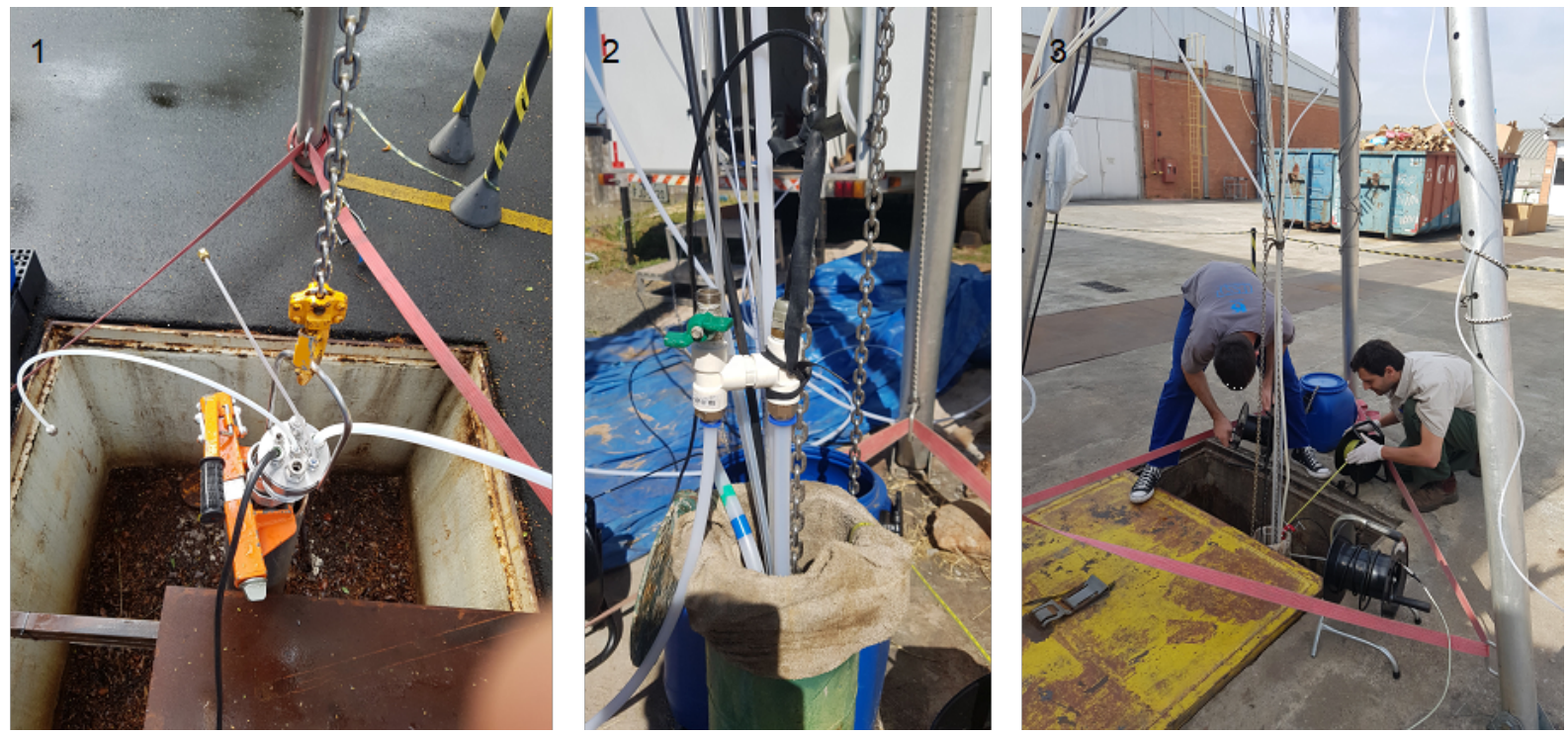

Figura 5.15. Detalhes da montagem e operação da configuração B. (1) detalhe da montagem das mangueiras e cabos que comunicam com o intervalo e conectam na bomba; (2) sistema de ensaio de pulso com ar acoplado à mangueira de PE de $20 \mathrm{~mm}$; (3) monitoramento da carga hidráulica com transdutores e medidor de nível

O posicionamento dos transdutores nos intervalos ou inseridos da superfície altera a forma de trabalho e tipos de ensaios que podem ser realizados nesta configuração. A Tabela 5.2 resume os aspectos positivos e negativos das duas opções.

Tabela 5.2. Aspectos positivos e negativos das duas opções de posicionamento dos transdutores

\begin{tabular}{|c|c|c|}
\hline & Transdutor acoplado ao intervalo & $\begin{array}{l}\text { Transdutor inserido na mangueira a partir da } \\
\text { superfície }\end{array}$ \\
\hline 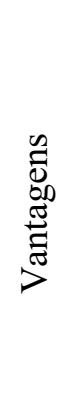 & $\begin{array}{l}\text { - Permite a realização de ensaios com o } \\
\text { sistema fechado (sem armazenamento de } \\
\text { água na mangueira) } \\
\text { - Também utilizados como segunda } \\
\text { medida de profundidade da composição } \\
\text { - Praticidade na operação }\end{array}$ & $\begin{array}{l}\text { - Cabos sem emendas } \\
\text { - Resolução dessimétrica das medidas } \\
\text { - Aferição e substituição de sensores com } \\
\text { problema podem ser realizadas sem retirar a } \\
\text { composição do poço } \\
\text { - Possibilita o uso de medidor de nível para } \\
\text { confirmar as leituras dos transdutores ou realizar } \\
\text { ensaios } \\
\text { - Montagem mais simples da composição }\end{array}$ \\
\hline 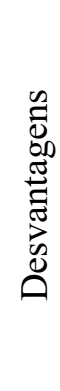 & $\begin{array}{l}\text { - Necessita de emendas no cabo do } \\
\text { transdutor } \\
\text { - Falhas nos transdutores não podem ser } \\
\text { verificadas ou resolvidas sem sacar a } \\
\text { composição do poço } \\
\text { - Menor precisão e resolução das leituras } \\
\text { de pressão } \\
\text { - Cabos dos transdutores ficam mais } \\
\text { susceptíveis a acidentes }\end{array}$ & $\begin{array}{l}\text { - Não permite a realização de ensaios em sistema } \\
\text { fechado (sem armazenamento no tubo) } \\
\text { - Requer o uso de mangueiras de maior diâmetro } \\
\text { descendo junto da composição } \\
\text { - Menos opções de modelos e fabricantes } \\
\text { - Operação mais demorada }\end{array}$ \\
\hline
\end{tabular}




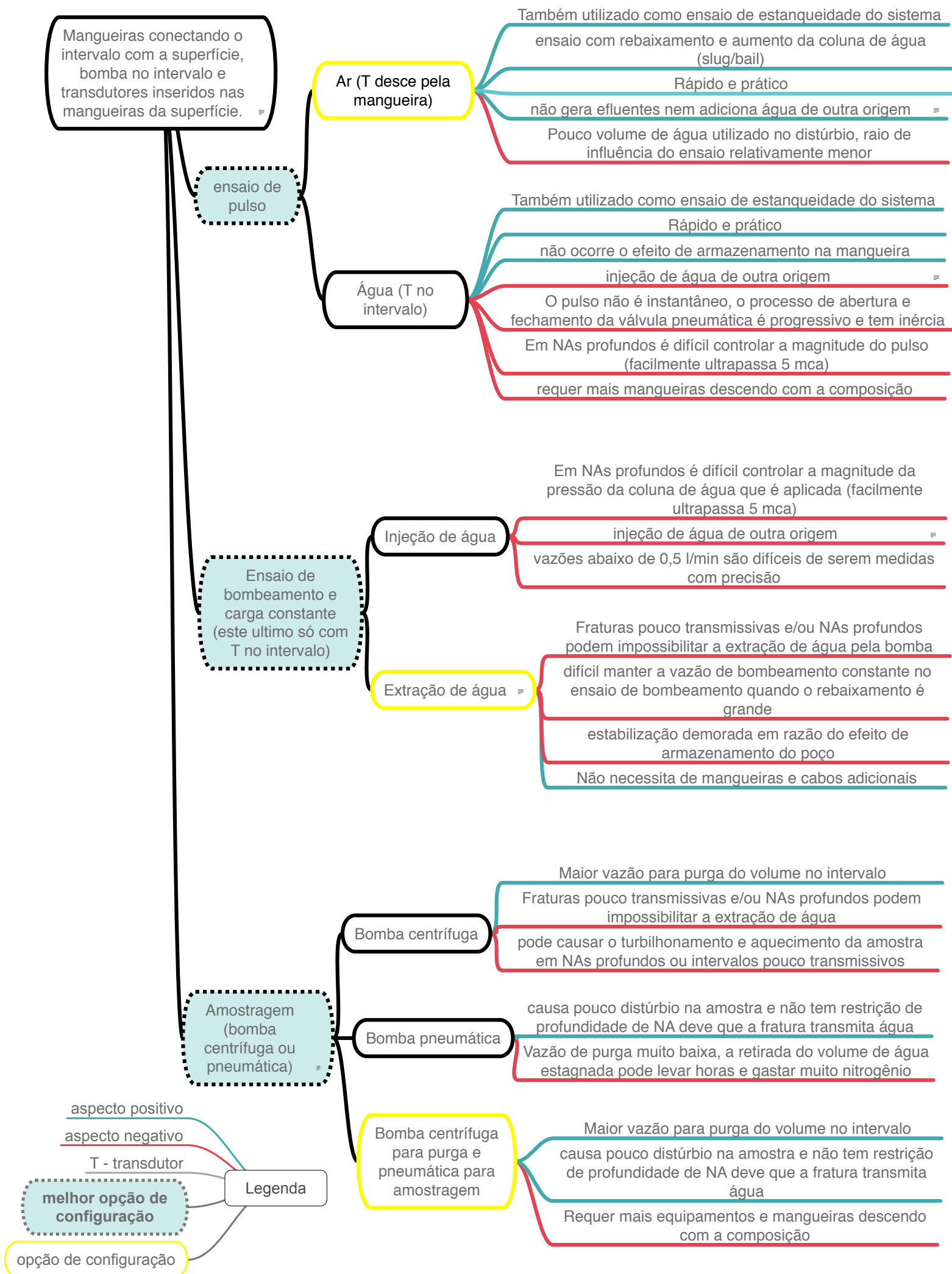

Figura 5.16. Características de operação da configuração B da MUST 
A montagem da composição de obturadores com os transdutores acoplados ao intervalo requer ao menos uma emenda no cabo. A montagem com mangueiras é mais simples e requer apenas estanqueidade nas conexões e emendas. O gerenciamento de mangueiras de maior calibre (20 mm) durante a movimentação da composição é mais trabalhoso do que os cabos dos sensores. Por outro lado, não há risco de dano aos sensores, que são inseridos apenas na hora de inflar os obturadores.

Em ambos os casos, o acesso ao intervalo isolado para a realização dos ensaios é feito por mangueiras. Ensaios em sistema fechado requerem o uso de válvulas pneumáticas para abrir e fechar a comunicação com os intervalos. Nessas configurações, a injeção de água também requer o uso de uma terceira válvula pneumática. Quanto maior o número de equipamento e componentes acoplados à composição, maior a chance de problemas operacionais, vazamentos e falha nos equipamentos.

O uso de três válvulas pneumáticas na cabeça da composição não se mostrou vantajoso por quatro motivos: (1) maior frequência de problemas operacionais com relação a vazamento de ar e água no sistema (conexões e mangueiras); (2) maior quantidade de mangueiras para gerenciar durante a movimentação da composição; (3) manutenção constante das válvulas, especialmente em poços com quantidade elevada de material em suspensão, em alguns casos foi necessário interromper o trabalho e trazer a composição para a superfície para fazer a desobstrução das válvulas; e (4) o tempo de operação não apresentou redução significativa.

\section{Ensaio de pulso com água ou ar}

Assim como na configuração $\mathrm{A}$, o ensaio de pulso pode ser realizado com ar (imprimindo pressão ou vácuo ao intervalo) ou água (injeção de água). O pulso de ar requer apenas que o sistema pneumático seja acoplado à mangueira. Já o pulso de água pode ser realizado direto por uma mangueira conectada ao intervalo, com a abertura da válvula pneumática.

O ensaio pneumático com mangueira gera um distúrbio de 0,3 litros a cada metro de coluna de água deslocada. Para o ensaio de estanqueidade, procura-se fazer um distúrbio superior a um litro, de modo que a resposta nos intervalos adjacentes, caso ocorra vazamento, seja detectada pelos sensores. Para a configuração com sensores posicionados no intervalo, o ensaio pneumático de estanqueidade não apresenta vantagem sobre o pulso de água. Para o ensaio de transmissividade, embora o volume de aquífero testado seja pequeno (distúrbio inferior ou igual a 1 metro de coluna de água), os resultados obtidos são coerentes com os outros ensaios hidráulicos que foram realizados nos estudos de caso. 
O ensaio com injeção de água pode ser utilizado tanto para avaliar a estanqueidade do intervalo como para estimar a transmissividade. A grande vantagem desse método é a estabilização rápida, por ser realizado em sistema fechado e não haver armazenamento na mangueira. Por outro lado, são observadas duas dificuldades operacionais. A primeira é o processo de abertura e fechamento da válvula pneumática, que não é instantâneo. A segunda é que em condições de nível d'água profundo, é difícil controlar a magnitude do pulso, que ultrapassa os 5 metros de coluna de água com facilidade. Em relação à injeção de água diretamente no intervalo, o volume não é expressivo e pode ser retirado pela purga antes da amostragem.

A comparação entre as duas técnicas indica que o ensaio pneumático é mais vantajoso, especialmente em poços com nível d'água profundo. Contudo, a principal vantagem é o fato do transdutor estar separado da composição.

\section{Ensaio de bombeamento e carga constante}

O ensaio de carga constante nesta configuração pode ser realizado tanto com o transdutor no intervalo como na mangueira. A vantagem do primeiro é que o ensaio pode ser realizado em sistema fechado, cuja estabilização é mais rápida por não haver efeito de armazenamento.

De maneira geral, as características desse ensaio se assemelham à configuração A. A principal diferença é que a extração de água só pode ser realizada com a bomba posicionada no intervalo, e a injeção de água necessita do uso de uma válvula pneumática na linha de água.

\section{Amostragem}

Para a amostragem, a configuração B é mais simples. Bomba centrifuga (e.g. MP1) e pneumática são acopladas à composição e podem ser utilizadas em conjunto ou separadamente.

As vantagens dessa configuração são: pequeno volume de água retido no sistema, somente a água do intervalo obturado e nas mangueiras; aumento na produtividade de campo, uma vez que todos os componentes estão prontos para uso após isolado o intervalo de interesse.

A desvantagem é a inacessibilidade à bomba durante a operação, sendo que qualquer intervenção nos equipamentos requer que a composição esteja na superfície. Isso pode ser necessário para realizar a limpeza/descontaminação do sistema de amostragem, troca da mangueira, diagnóstico de problemas com as bombas e execução de reparos quando necessário. 


\subsection{ESTUDOS DE CASO}

O funcionamento geral dos equipamentos e componentes utilizados neste trabalho já foram descritos no capítulo 4 de materiais e métodos, portanto, nos estudos de caso serão apresentadas apenas as configurações específicas utilizadas para evitar repetição. O mesmo é válido para o processamento dos dados geofísicos e ensaios hidráulicos.

Ao todo, foram realizados trabalhos em 15 áreas de estudo, somando um total de 33 poços, 29 deles tubulares e 4 perfurados para pesquisa. Como o objetivo desta tese é a aplicação e o desenvolvimento de métodos de trabalho para a caracterização de aquíferos fraturados, os estudos de caso que são apresentados neste capítulo são aqueles que têm maior relevância para a discussão e fundamentação do método proposto. A Tabela 5.3 sintetiza as principais características e resultados da aplicação do método. 
Tabela 5.3. Principais características e resultados dos três estudos de caso apresentados

\begin{tabular}{|c|c|c|c|c|c|}
\hline $\begin{array}{l}\text { Estudos } \\
\text { de caso }\end{array}$ & $\begin{array}{c}\text { Número de poços } \\
\text { estudados }\end{array}$ & Tipo de rocha & $\begin{array}{l}\text { Objetivo do } \\
\text { trabalho }\end{array}$ & Técnicas utilizadas & Principais resultados \\
\hline Área $\mathrm{S}$ & $\begin{array}{c}3 \text { poços (apenas } \\
\text { dois apresentados } \\
\text { no estudo de } \\
\text { caso) }\end{array}$ & $\begin{array}{c}\text { Rocha } \\
\text { gnáissica com } \\
\text { intrusão de } \\
\text { corpos } \\
\text { granitoides }\end{array}$ & $\begin{array}{l}\text { Estudo } \\
\text { ambiental } \\
\text { regional }\end{array}$ & $\begin{array}{l}\text { Câmera; cáliper; } \\
\text { gama; ótico e } \\
\text { acústico; HPF; e } \\
\text { MUST } \\
\text { (configuração A). }\end{array}$ & $\begin{array}{l}\text { - Características construtivas dos poços e falha nos } \\
\text { procedimentos de campo prejudicaram a qualidade do trabalho, } \\
\text { principalmente em um dos poços. As atividades mais } \\
\text { impactadas foram o ATV e o HPF. } \\
\text { - Não foi observada estratificação nas características químicas } \\
\text { da água. }\end{array}$ \\
\hline Área U & $\begin{array}{l}3 \text { poços (apenas } \\
\text { um apresentado } \\
\text { no estudo de } \\
\text { caso) }\end{array}$ & $\begin{array}{l}\text { Rocha } \\
\text { gnáissica }\end{array}$ & $\begin{array}{l}\text { Testar } \\
\text { equipamentos } \\
\text { e comparar } \\
\text { técnicas de } \\
\text { campo }\end{array}$ & $\begin{array}{l}\text { Cáliper; } \\
\text { resistividade (curta } \\
\text { e longa); FTCR; } \\
\text { gama; ATV e OTV; } \\
\text { HPF; EMF; e SF. }\end{array}$ & $\begin{array}{l}\text { - Os dados da sonda FTC auxiliaram na interpretação das zonas } \\
\text { de fluxo, mas não foram decisivas para o processamento dos } \\
\text { dados dos flowmeters } \\
\text { - A comparação entre as três técnicas de flowmeter se } \\
\text { mostraram coerentes, HPF e EMF apresentaram resultados } \\
\text { similares no FLASH } \\
\text { - Os dados do SF apresentaram muito ruído e não foram } \\
\text { modelados no FLASH. }\end{array}$ \\
\hline
\end{tabular}




\subsection{1 Área S}

Localização: distrito de Santo Amaro, Região Metropolitana de São Paulo, São Paulo

Empreendimento: empreendimento comercial instalado em uma antiga planta industrial

Objetivo do trabalho: projeto de pesquisa voltado à investigação regional da contaminação de um antigo bairro industrial, com dois objetivos principais: (1) entender a dinâmica de fluxo do aquífero fraturado e fazer um panorama da contaminação regional; (2) testar e aprimorar técnicas e métodos de caracterização de aquíferos fraturados em colaboração com parceiros internacionais. Foi no âmbito desse projeto que foram adquiridos os primeiros equipamentos geofísicos e teve início o desenvolvimento da MUST.

Contexto geológico: A região metropolitana de São Paulo está no contexto geológico da bacia sedimentar de São Paulo, sobre o embasamento cristalino que integra a Província Mantiqueira (Almeida et al., 1977).

A porção central da região metropolitana de São Paulo, que inclui a Área S, está sobre o Complexo Embu, que é formado por gnaisses migmatizados, migmatitos, xistos, filitos, e corpos lenticulares de quartzo, anfibolitos e rochas calciossilicáticas. O complexo Embu aparece associado a uma grande quantidade de batólitos a blocos de menor proporção de granitoides. Devido à sua maior resistência relativa ao intemperismo, esses granitoides sustentam altos morfológicos, com menor tendência a serem recobertos por sedimentos da bacia (Coutinho, 1980).

Estrutura disponível: três poços tubulares $(255,256$ e 1204) que no passado foram utilizados para abastecimento, e que estão desativados devido à constatação da presença de contaminantes na água. Uma característica do local é a existência de outros poços tubulares em propriedades vizinhas. As distâncias entre os poços variam, estando o mais próximo cerca de $100 \mathrm{~m}$. Um resumo das características mais relevantes dos poços é apresentado na Tabela 5.4. 
Tabela 5.4. Resumo dos dados dos poços 255, 256 e 1204 da Área S obtidos no cadastro de poços

\begin{tabular}{|c|c|c|c|c|}
\hline Características & Poço & Poço 255 & Poço 256 & Poço 1204 \\
\hline \multirow{2}{*}{ Gerais } & $\begin{array}{l}\text { Aquífero } \\
\text { explorado }\end{array}$ & Cristalino & Cristalino & Cristalino \\
\hline & $\begin{array}{c}\text { Data da } \\
\text { construção }\end{array}$ & 1979 & 1987 & 2002 \\
\hline \multirow[b]{3}{*}{ Perfuração } & Método & Percussão & Percussão & Roto percussão \\
\hline & $\begin{array}{c}\text { Profundidade } \\
\text { total }\end{array}$ & $300 \mathrm{~m}$ & $300 \mathrm{~m}$ & 260,7 \\
\hline & Diâmetro & $\begin{array}{l}\text { - } 8,4 \mathrm{~m}: 304 \mathrm{~mm} \\
\text { - } 80 \mathrm{~m}: 254 \mathrm{~mm} \\
\text { - } 120 \mathrm{~m}: 203,2 \mathrm{~mm} \\
\text { - } 300 \mathrm{~m}: 152,4 \mathrm{~mm}\end{array}$ & $\begin{array}{l}\text { - } 8 \mathrm{~m}: 406,4 \mathrm{~mm} \\
\text { - } 45 \mathrm{~m}: 330,2 \mathrm{~mm} \\
\text { - } 63,7 \mathrm{~m}: 254 \mathrm{~mm} \\
-150 \mathrm{~m}: 203,2 \mathrm{~mm} \\
-300 \mathrm{~m}: 152,4 \mathrm{~mm}\end{array}$ & $\begin{array}{l}-6 \mathrm{~m}: 444,5 \mathrm{~mm} \\
-46 \mathrm{~m}: 311,15 \mathrm{~mm} \\
-50,7 \mathrm{~m}: 216 \mathrm{~mm} \\
-260,7 \mathrm{~m}: 152,4 \mathrm{~mm}\end{array}$ \\
\hline \multirow{3}{*}{$\begin{array}{l}\text { Descrição } \\
\text { geológica }\end{array}$} & $\begin{array}{l}\text { Sedimentos da } \\
\text { Formação São } \\
\text { Paulo }\end{array}$ & - & 0 a $26 \mathrm{~m}$ & 0 a $44 \mathrm{~m}$ \\
\hline & Rocha alterada & 0 a $8 \mathrm{~m}$ & $26 \mathrm{a} 46 \mathrm{~m}$ & 44 a $50 \mathrm{~m}$ \\
\hline & $\begin{array}{c}\text { Embasamento } \\
\text { cristalino } \\
\text { (granito } \\
\text { gnaisse) } \\
\end{array}$ & 38 a $160 \mathrm{~m}$ & 46 a $300 \mathrm{~m}$ & 50 a $260,7 \mathrm{~m}$ \\
\hline \multirow{3}{*}{ Revestimento } & Material & Aço preto & Aço preto & Aço preto \\
\hline & Extensão & Não informado & $-0,4$ a $63,7 \mathrm{~m}$ & $-0,3$ a $50,7 \mathrm{~m}$ \\
\hline & Diâmetro & Não informado & $203,2 \mathrm{~mm}$ & $152,4 \mathrm{~mm}$ \\
\hline \multirow{6}{*}{$\begin{array}{c}\text { Características } \\
\text { hidráulicas }\end{array}$} & Nível estático & $79,5 \mathrm{~m}$ & $64 \mathrm{~m}$ & $98,75 \mathrm{~m}$ \\
\hline & $\begin{array}{c}\text { Vazão do } \\
\text { ensaio de } \\
\text { bombeamento }\end{array}$ & $4,08 \mathrm{~m}^{3} / \mathrm{h}$ & $11,67 \mathrm{~m}^{3} / \mathrm{h}$ & $14,4 \mathrm{~m}^{3} / \mathrm{h}$ \\
\hline & Nível dinâmico & $143,8 \mathrm{~m}$ & $92,3 \mathrm{~m}$ & $194,95 \mathrm{~m}$ \\
\hline & $\begin{array}{c}\text { Profundidade } \\
\text { de instalação da } \\
\text { bomba }\end{array}$ & $150 \mathrm{~m}$ & $144 \mathrm{~m}$ & $210 \mathrm{~m}$ \\
\hline & $\begin{array}{c}\text { Vazão } \\
\text { específica }\end{array}$ & Não informado & $1,2 \mathrm{~m} 3 / \mathrm{h} / \mathrm{m}$ & $0,15 \mathrm{~m} 3 / \mathrm{h} / \mathrm{m}$ \\
\hline & $\begin{array}{c}\text { Rebaixamento } \\
\text { específico }\end{array}$ & Não informado & Não informado & $6,68 \mathrm{~m} / \mathrm{m}^{3} / \mathrm{h}$ \\
\hline
\end{tabular}

Escopo: o trabalho foi realizado nos três poços, e contemplou a execução de nove atividades de campo, divididas em três etapas. Duas etapas geofísicas com equipamentos de fabricantes diferentes e a terceira de ensaios hidráulicos e amostragem com obturadores.

A primeira etapa geofísica compreendeu as seguintes técnicas, em ordem de execução: cáliper com gama; OTV e ATV; e HPF. As sondas utilizadas nesta etapa foram fabricadas pela RG e os trabalhos de campo realizados em parceria com o Instituto de Pesquisas Tecnológicas (IPT). 
A segunda etapa geofísica compreendeu as seguintes técnicas, em ordem de execução: câmera; gama e acústico; e HPF. A câmera é da marca LUS e as demais da MSI.

Na terceira etapa foi utilizada a MUST para medir as cargas hidráulicas, realizar ensaios hidráulicos de pulso e carga constante, e coletar amostras de água em trechos discretos. Os intervalos para ensaio e amostragem foram selecionados com base nas etapas de geofísica. Foi realizado o maior número de ensaios possíveis para validar a etapa geofísica como critério para escolha dos intervalos de interesse.

Método: As características específicas do método de trabalho foram:

1. cáliper com gama $(\mathrm{RG})$;

2. perfilagem ótica e acústica $(\mathrm{RG})$;

a. centralizador metálico não magnético duplo para furos de 203,2 e 254 mm.

3. perfilagem acústica combinada com gama (MSI-ABI-GR);

a. centralizador metálico não magnético duplo para furos de 203,2 mm.

4. $\operatorname{HPF}(\mathrm{RG})$;
a. centralizador de $152,4 \mathrm{~mm}$;
b. não foi utilizado diverter;
c. ensaios com fluxo ambiente (FA); e
d. aferição de campo para fluxo zero.

5. HPF (MSI); e

a. centralizador de borracha duplo para furos de 203,2 mm;

b. diverter de borracha para furos de $203,2 \mathrm{~mm}$;

c. ensaios com fluxo ambiente (FA) e fluxo induzido (FI), extração de água com bomba centrífuga;

d. aferição de campo para fluxo zero e induzido; e

e. modelagem com FLASH-R. A transmissividade total do poço foi interpretada a partir do bombeamento para o ensaio com o HPF (FI).

6. MUST.

a. obturadores P5-9; 
b. espaçamento entre obturadores de $2,3 \mathrm{~m}$, determinado com base na avaliação integrada dos perfis gerados na etapa geofísica;

c. pressão diferencial para isolamento dos intervalos selecionados 7 a 10 bar;

d. registro da profundidade com transdutor de pressão;

e. um transdutor posicionado em cada um dos três intervalos para monitoramento da pressão;

f. ensaio hidráulico de pulso com sistema pneumático de pressão e vácuo acoplados a tubos de PVC de $50 \mathrm{~mm}$ para a conexão com o intervalo intermediário, formando um poço temporário quando inflados os obturadores;

g. os ensaios de carga constante utilizaram um mini-obturador para injeção de água sob pressão, acessando o intervalo pelo tubo de PVC de $50 \mathrm{~mm}$, evitando o efeito de armazenamento de água no poço; e

h. amostragem de água por baixa vazão com bomba centrifuga. A bomba foi inserida no tubo de PVC e baixada até a cabeça da composição para que a purga fosse iniciada antes da coleta. O volume de purga foi calculado com base no volume de água de mistura que preenchia a tubulação e o intervalo isolado.

Resultados: Os resultados são apresentados de maneira sucinta para cada técnica na sua sequência de execução, destacando os aspectos mais relevantes para esta pesquisa. Como os poços 255 e 256 apresentaram resultados parecidos, apenas o 255 será detalhado neste estudo de caso.

Poço 255: A Tabela 5.5 resume os resultados obtidos, que são detalhados na sequência.

Durante a descida do cáliper foi encontrada uma obstrução em 224 m que impediu o avanço da sonda, no cadastro do poço a perfuração foi até $300 \mathrm{~m}$. A perfilagem confirmou os três diâmetros de perfuração, dois deles maiores que o revestimento, indicados no cadastro, até a profundidade de $120 \mathrm{~m}$. Em condições normais, a perfuração na rocha é realizada somente após instalação e cimentação do tubo de revestimento. Esta condição atípica dificulta as atividades de caracterização por apresentar uma restrição à descida de equipamentos com centralizadores no tamanho adequado ao furo. 
Durante a filmagem, a turbidez da água estava elevada, assim como o acúmulo de sujeira na parede do poço, muitas vezes impedindo inclusive o registro de estruturas e características da rocha. Na profundidade de $222 \mathrm{~m}$ foi observada uma quebra na rocha típica de zonas de fraqueza (breakout), associada a esforços neotectônicos que atuam sobre o maciço. Em $224 \mathrm{~m}$ a câmera cai dentro de uma cavidade e não consegue avançar (Figura 5.17), mesma profundidade em que o cáliper parou.

Tabela 5.5. Atividades realizadas e principais resultados para o poço 255 da Área $S$

\begin{tabular}{|c|c|c|c|}
\hline Atividade & $\begin{array}{l}\text { Dados } \\
\text { coletados }\end{array}$ & Resultados & Comentários \\
\hline Cáliper RG & 0 a $224 \mathrm{~m}$ & - Diâm.: 150 a 396 mm & $\begin{array}{l}\text { Em } 224 \text { m o cáliper para de descer (na } \\
\text { ficha o poco tem } 300 \mathrm{~m} \text { ) }\end{array}$ \\
\hline Câmera & 0 a $220 \mathrm{~m}$ & $\begin{array}{l}\text { - NA: } 4,5 \mathrm{~m} \\
\text { - Contato tubo/rocha: } 27 \mathrm{~m}\end{array}$ & $\begin{array}{l}\text { em } 225 \text { m a câmera entra em uma } \\
\text { cavidade e não desce mais }\end{array}$ \\
\hline Gama RG & 0 a $224 \mathrm{~m}$ & 35 a 800 CPS & \multirow{2}{*}{$\begin{array}{l}\text { Dados coerentes, não parece haver } \\
\text { mudança litológica na resposta do gama }\end{array}$} \\
\hline Gama MSI & 25 a $288 \mathrm{~m}$ & 117 a 755 CPS & \\
\hline OTV RG & 27 a 220 m & $\begin{array}{l}\text { - Tubo/rocha: } 27 \mathrm{~m} \\
\text { - } \mathrm{N}^{\mathrm{o}} \text { fraturas: } 217\end{array}$ & $\begin{array}{l}\text { O trecho de maior diâmetro ficou com } \\
\text { uma mancha escura ( } 30 \text { a } 80 \mathrm{~m} \text { ) e no } \\
\text { mais profundo a imagem ficou com } \\
\text { pouca resolução devido à turbidez }\end{array}$ \\
\hline ATV RG & 0 a $225 \mathrm{~m}$ & $\begin{array}{l}\text { - Tubo/rocha: } 27,95 \mathrm{~m} \\
\text { - No fraturas: } 217^{*} \\
\text { - Diâm.: } 201 \text { a } 258 \mathrm{~mm} \\
\text { - Desvio do poco: } 1,2 \mathrm{~m}\end{array}$ & $\begin{array}{c}\text { Entre } 77 \text { e } 103 \text { m parece haver uma } \\
\text { diferença da rocha em relação ao resto } \\
\text { do poço }\end{array}$ \\
\hline ATV MSI & 0 a $288 \mathrm{~m}$ & $\begin{array}{l}\text { - Tubo/rocha: } 26,66 \mathrm{~m} \\
\text { - No fraturas: } 234^{*} \\
\text { - Diâm.: } 122 \text { a } 188 \mathrm{~mm}(224 \\
\text { a } 228 \mathrm{~m}) \\
\text { - Desvio do poço: } 13,7 \mathrm{~m}\end{array}$ & $\begin{array}{c}\text { Os dados obtidos com o ATV só } \\
\text { apresentaram resultados satisfatórios a } \\
\text { partir de } 120 \mathrm{~m} \text { (quando o diâm. reduz } \\
\text { para } 152.4 \mathrm{~mm} \text { ) }\end{array}$ \\
\hline HPF RG & $\begin{array}{c}\text {-Fluxo } \\
\text { ambiente } 34 \\
\text { pontos }\end{array}$ & $\begin{array}{l}\text { - Fluxo ambiente } \\
\text { descendente }(30 \text { a } 222 \mathrm{~m})\end{array}$ & $\begin{array}{l}\text { Os dados oscilaram muito sem ter uma } \\
\text { coerência e apresentaram vazões muito } \\
\text { elevadas para fluxo ambiente }\end{array}$ \\
\hline HPF MSI & $\begin{array}{c}\text {-Fluxo } \\
\text { ambiente } 22 \\
\text { pontos; } \\
\text {-Fluxo } \\
\text { induzido } 29 \\
\text { pontos }\end{array}$ & $\begin{array}{l}\text { - Fluxo ambiente ascendente } \\
(25 \text { a } 80 \mathrm{~m}) \\
\text { - Fluxo ascendente com } \\
\text { entrada em } 162 \mathrm{~m}\end{array}$ & $\begin{array}{l}\text { Os dados do ensaio são consistentes, } \\
\text { mas ficaram prejudicados pela variação } \\
\text { do diâmetro do furo e falhas nos } \\
\text { procedimentos }\end{array}$ \\
\hline $\begin{array}{l}\text { Ensaio } \\
\text { hidráulico }\end{array}$ & 12 trechos & $\begin{array}{c}\text { - Transmissividade de } 5,7 \mathrm{E}^{-6} \\
\text { a } 6,5 \mathrm{E}^{-3} \mathrm{~m}^{2} / \mathrm{s} \\
\text { - Potencial de fluxo } \\
\text { descendente com diferencial } \\
\text { de pressão de } 47 \mathrm{~cm} \\
\end{array}$ & $\begin{array}{c}3 \text { trechos não apresentaram fluxo, um } \\
\text { deles foi o contato do revestimento com } \\
\text { a rocha }\end{array}$ \\
\hline Amostragem & 4 trechos & $\begin{array}{l}\text { Amostragem por baixa } \\
\text { vazão }\end{array}$ & $\begin{array}{l}\text { Não foi observada variação na } \\
\text { composição química das amostras }\end{array}$ \\
\hline
\end{tabular}

* o principal perfil utilizado na identificação de fraturas foi o OTV no trecho do poço que foi perfilado 
O intervalo perfilado com as sondas de imageamento da RG (ótica e acústica) foi de 26 a $220 \mathrm{~m}$, e de 26 a $288 \mathrm{~m}$ com as sondas da MSI (acústica e gama). Os dados obtidos com a sonda ótica apresentaram boa correlação com as observações da câmera. Os resultados das sondas acústicas ficaram prejudicados nos trechos em que o diâmetro do furo era maior que o revestimento do poço. As perfilagens com as sondas da RG foram realizadas cinco vezes até que se conseguisse passar o trecho do revestimento $(152,4 \mathrm{~mm})$ com centralizadores maiores (254 mm). Para isso foi utilizada uma fita para segurar os centralizadores fechados até que se chegasse no trecho do furo de maior diâmetro. O centralizador utilizado com a sonda da MSI foi de 152,4 mm, já que o de $203 \mathrm{~mm}$ não desceu no trecho do revestimento. A partir dos 120 $\mathrm{m}$ a imagem acústica melhorou devido à centralização da sonda no furo.
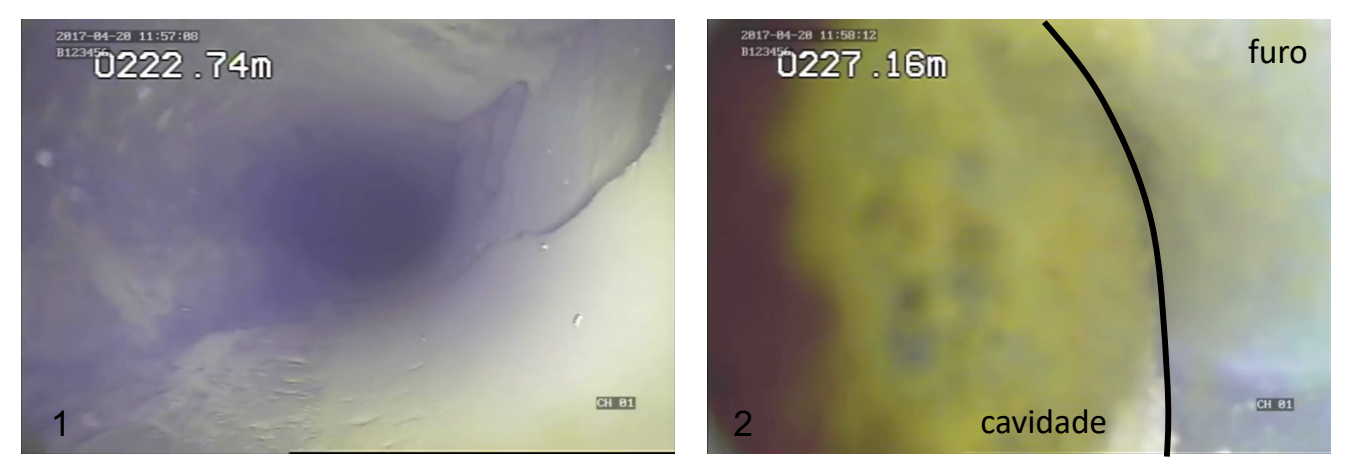

Figura 5.17. (1) zona de deformação do furo decorrente do esforço principal no maciço (breakout); (2) trecho em que a câmera entra em uma cavidade do furo e não avança mais no poço 255

O diâmetro da perfuração no trecho de rocha exposta variou de 130 a 396 mm. A seção do poço que foi perfilada $(265 \mathrm{~m})$ apresentou um desvio de $14 \mathrm{~m}$ para N315º, inclinação média de $5 \%$. No trecho em que o cáliper apresentou valor superior a $210 \mathrm{~mm}$, os resultados da sonda acústica da MSI ficaram comprometidos (27 a 120 m). Os resultados obtidos com a sonda da $\mathrm{RG}$, com centralizador de $254 \mathrm{~mm}$, foram satisfatórios no trecho de 80 a $120 \mathrm{~m}$, mas ficaram comprometidos de 30 e $80 \mathrm{~m}$, embora seja possível a observação das estruturas.

Os dados das sondas acústicas foram corrigidos utilizando o perfil do cáliper mecânico. Uma primeira tentativa de processar os dados somente com a resposta acústica apresentou resultados incompatíveis com as características do furo. Os perfis que utilizaram essa correção foram, cáliper acústico, desvio do poço e mergulho das estruturas.

A caracterização das estruturas foi realizada com base na perfilagem ótica até $220 \mathrm{~m}$, e a partir desta profundidade foi utilizada a imagem acústica (MSI). Foram identificadas 217 fraturas no primeiro trecho e 17 no segundo, totalizando 234 fraturas. Destas, 51 apresentaram abertura aparente superior a $10 \mathrm{~mm}$. O principal grupo de fraturas observado apresenta 
mergulho baixo $\left(\right.$ média $<30^{\circ}$ ) predominante para $\mathrm{N} 330^{\circ}$. Também é observado um grupo de alto ângulo de mergulho $\left(>60^{\circ}\right)$ para $\mathrm{N} 350^{\circ}$, cuja maior parte das fraturas apresenta abertura aparente inferior a $10 \mathrm{~mm}$.

A sonda gama de ambas as marcas (RG e MSI) apresentou resultados similares, e não foi obtida nenhuma resposta que pudesse indicar mudança litológica consistente.

As medições de fluxo ambiente (NA estático em 4,21 m) com a sonda da RG foram muito diferentes daquelas obtidas com a sonda da MSI. O fluxo da RG foi ascendente em todos os pontos, enquanto a MSI apresentou fluxo ascendente apenas no intervalo de 37 a $86 \mathrm{~m}$. A magnitude de vazão observada pela RG ultrapassa 10 1/min e não é consistente ao longo do perfil. Já a MSI fica em torno de $0,15 \mathrm{l} / \mathrm{min}$ de forma consistente entre intervalos adjacentes. É importante ressaltar que foi utilizado apenas um tamanho de diverter com a sonda da MSI, mesmo em profundidades em que o diâmetro estava acima de $250 \mathrm{~mm}$, o que pode resultar em medidas de fluxo subestimadas.

O ensaio com fluxo induzido (NA dinâmico em 12,55 m) com a sonda da MSI foi realizado com uma vazão de 34 1/min, apesar do limite superior de quantificação da sonda ser $5 \mathrm{l} / \mathrm{min}$. Isso porque no trecho mais largo do poço as tentativas de medir fluxo com vazões menores deram fluxo zero. Conforme pode ser observado na Figura 5.18, ocorrem duas variações no padrão de vazão. A primeira no trecho de 156 a 162 m, em que é observada a principal zona produtora de água do poço. A segunda entre 73 e 80 m, em que a vazão diminui consideravelmente e o cáliper aumenta devido ao diâmetro de perfuração.

A avaliação conjunta dos dados do HPF da MSI para fluxo ambiente e induzido possibilitou inferir que a principal zona produtora de água do poço está entre 156 e $162 \mathrm{~m}$. Por não ser observado fluxo natural nos trechos acima e abaixo dessa zona, o nível d'água estático do poço deve estar próximo à carga hidráulica desta zona.

Tentou-se fazer a interpretação do ensaio com flowmeter no FLASH-R, mas não foram obtidos resultados satisfatórios. Isso se deve à falha metodológica na realização dos ensaios e às características do furo, resultando em valores discrepantes na modelagem dos dados.

Foram realizados 19 ensaios hidráulicos em intervalos discretos do poço 255 , onze não foram transmissivos (ou inferiores a $\mathrm{E}^{-8} \mathrm{~m}^{2} / \mathrm{s}$ ). Nesses casos, os valores de carga hidráulica não foram considerados na interpretação do potencial de fluxo. Dos que apresentaram fluxo, apenas quatro foram amostrados, e todos apresentaram bom isolamento entre os três níveis no ensaio de estanqueidade. A Tabela 5.6 apresenta um resumo dos dados obtidos. 
Nota-se que os ensaios de carga constante apresentaram valor de transmissividade uma ordem de magnitude maior que os ensaios do tipo pulso. Este fato pode estar relacionado tanto ao melhor controle da variação da carga, garantindo que o fluxo seja mantido no domínio do fluxo laminar, como por utilizar uma solução analítica para fluxo estacionário, enquanto os ensaios de pulso são do tipo transiente e tem premissas diferentes conforme discutido no Item 3 da revisão bibliográfica. A relação de cargas hidráulicas indicou fluxo descendente no poço 255, ao contrário do indicado pelo HPF. A transmissividade variou de $3,7 \mathrm{E}^{-6}$ a $8 \mathrm{E}^{-4} \mathrm{~m}^{2} / \mathrm{s}$, sendo que a maior parte dos intervalos mais transmissivos estão na porção mais rasa do poço, entre 30 e $80 \mathrm{~m}$.

Tabela 5.6. Resultados dos ensaios hidráulicos com obturadores no poço 255

\begin{tabular}{|c|c|c|c|c|c|c|}
\hline $\begin{array}{l}\text { Intervalo } \\
\text { (m) }\end{array}$ & $\begin{array}{c}\text { Carga } \\
\text { hidráulica } \\
(\mathrm{m})\end{array}$ & $\begin{array}{c}\text { Transmissividade } \\
\left(\mathrm{m}^{2} / \mathrm{s}\right)\end{array}$ & $\begin{array}{c}\text { Abertura } \\
\text { da } \\
\text { fratura } \\
(\mathrm{mm}) \\
\end{array}$ & $\begin{array}{l}\text { Tipo de } \\
\text { ensaio }\end{array}$ & Amostragem & Comentários \\
\hline 22,3 a 24,6 & & \multicolumn{5}{|c|}{ Contato entre rocha e revestimento sem fluxo } \\
\hline 25,8 a 28,1 & 719,55 & $2,4 \mathrm{E}^{-5}$ & 0,31 & Pulso & $\begin{array}{c}\text { Baixa vazão } \\
\text { com bomba } \\
\text { centrífuga }\end{array}$ & 6 ensaios \\
\hline \multirow{2}{*}{$\begin{array}{c}38,79 \mathrm{a} \\
41,09\end{array}$} & \multirow{2}{*}{719,67} & $1,3 \mathrm{E}^{-4}$ & 0,54 & Pulso & \multirow{2}{*}{$\begin{array}{c}\text { Baixa vazão } \\
\text { com bomba } \\
\text { centrífuga }\end{array}$} & 4 ensaios \\
\hline & & $8,7 \mathrm{E}^{-4}$ & 1,02 & $\begin{array}{c}\text { Carga } \\
\text { constante }\end{array}$ & & $\begin{array}{c}4 \text { faixas de } \\
\text { vazão }\end{array}$ \\
\hline 50,6 a 52,9 & & \multicolumn{5}{|c|}{ Sem fluxo } \\
\hline \multirow[b]{2}{*}{59,72 a 62} & \multirow[b]{2}{*}{719,66} & $3,7 \mathrm{E}^{-5}$ & 0,36 & Pulso & \multirow{2}{*}{$\begin{array}{c}\text { Baixa vazão } \\
\text { com bomba } \\
\text { centrífuga }\end{array}$} & 3 ensaios \\
\hline & & $1,5 \mathrm{E}^{-4}$ & 0,57 & $\begin{array}{c}\text { Carga } \\
\text { constante }\end{array}$ & & $\begin{array}{c}5 \text { faixas de } \\
\text { vazão }\end{array}$ \\
\hline \multirow{2}{*}{$\begin{array}{l}76,73 \mathrm{a} \\
79,03\end{array}$} & \multirow{2}{*}{719,66} & $1,8 \mathrm{E}^{-5}$ & 0,28 & Pulso & $\begin{array}{c}\text { Não } \\
\text { amostrado }\end{array}$ & 5 ensaios \\
\hline & & $2,7 \mathrm{E}^{-4}$ & 0,69 & $\begin{array}{c}\text { Carga } \\
\text { constante }\end{array}$ & $\begin{array}{c}\text { Não } \\
\text { amostrado }\end{array}$ & $\begin{array}{c}3 \text { faixas de } \\
\text { vazão }\end{array}$ \\
\hline $\begin{array}{l}86,66 \mathrm{a} \\
88,96\end{array}$ & 719,37 & $7 \mathrm{E}^{-6}$ & 0,20 & Pulso & $\begin{array}{c}\text { Não } \\
\text { amostrado }\end{array}$ & 3 ensaios \\
\hline $\begin{array}{l}98,52 \mathrm{a} \\
100,82\end{array}$ & 719,27 & $1 \mathrm{E}^{-5}$ & 0,23 & Pulso & $\begin{array}{c}\text { Não } \\
\text { amostrado }\end{array}$ & 3 ensaios \\
\hline $\begin{array}{c}103,5 \mathrm{a} \\
150,7\end{array}$ & & \multicolumn{5}{|c|}{ Nove trechos ensaiados sem fluxo } \\
\hline $\begin{array}{c}159,99 \mathrm{a} \\
162,3\end{array}$ & 719,27 & $4 \mathrm{E}^{-5}$ & 0,37 & Pulso & $\begin{array}{c}\text { Não } \\
\text { amostrado }\end{array}$ & 3 ensaios \\
\hline$>162,3$ & 719,20 & $3,7 \mathrm{E}^{-6}$ & 0,17 & Pulso & $\begin{array}{c}\text { Baixa vazão } \\
\text { com bomba } \\
\text { centrífuga }\end{array}$ & 3 ensaios \\
\hline
\end{tabular}


As amostras de água coletadas não indicaram a presença de contaminantes em nenhum dos intervalos isolados. Também não foram observadas características hidroquímicas que pudessem diferenciar águas oriundas de diferentes estratos do aquífero. O histórico de intenso bombeamento da região no passado, e a atual restrição ao uso da água tem grande influência sobre as atuais características do aquífero fraturado. A recuperação do nível estático e as características específicas dessa região são discutidas por outros autores em maior detalhe (BARBOSA, 2015; SILVA, 2018). 


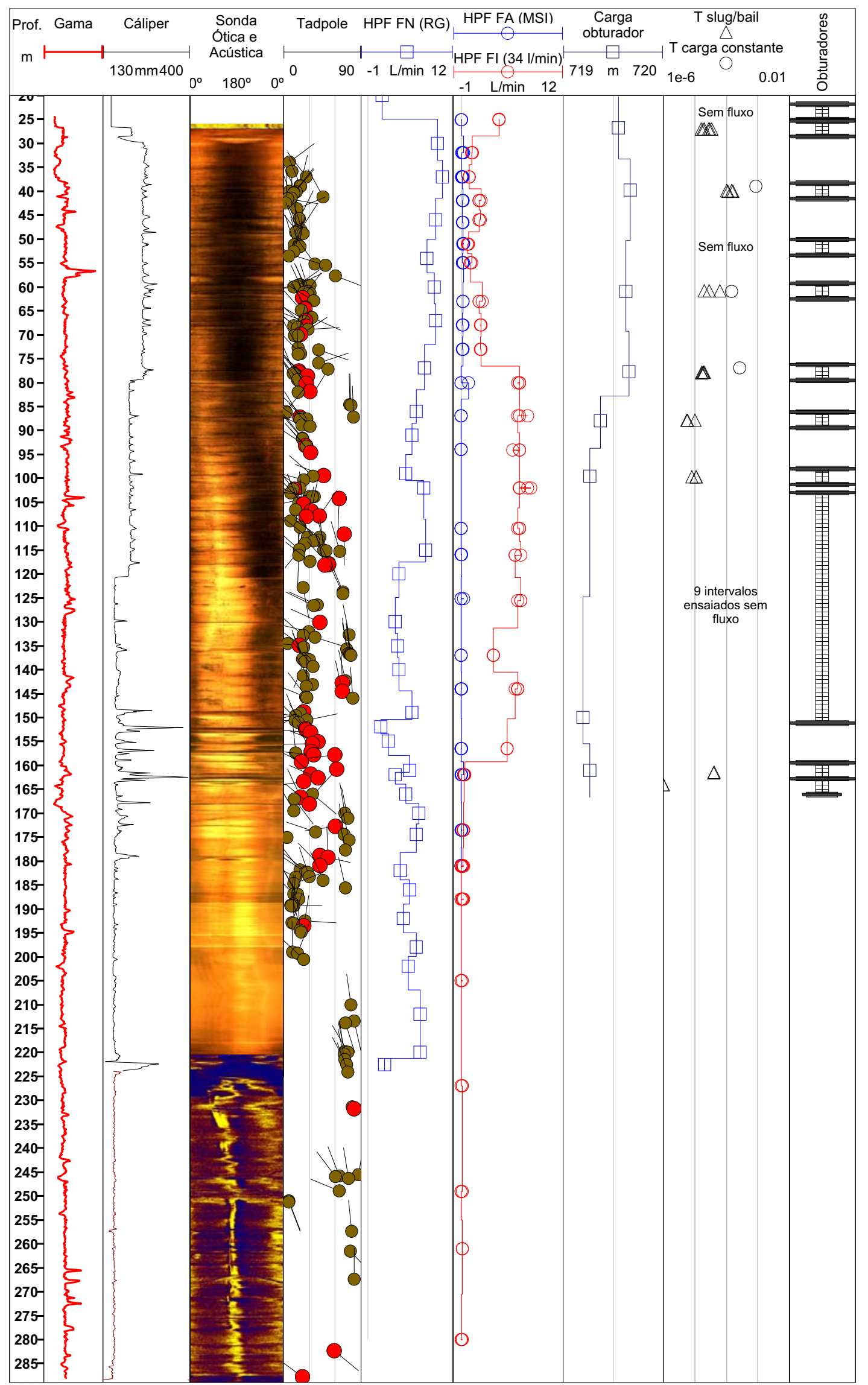

Figura 5.18. Perfil integrado do poço 255 da Área S (ATV, gama, HPF, FLASH e obturador) 
Poço 1204: A Tabela 5.7 apresenta um resumo dos resultados obtidos, que são detalhados na sequência.

Tabela 5.7. Atividades realizadas e principais resultados para o poço 1204 da Área S

\begin{tabular}{|c|c|c|c|}
\hline Atividade & Dados coletados & Resultados & Comentários \\
\hline Cáliper RG & 0 a $256 \mathrm{~m}$ & - Diâm.: 148 a 214 mm & $\begin{array}{l}\text { Em } 256 \mathrm{~m} \text { o cáliper para de } \\
\text { descer (na ficha o poço tem } \\
260 \mathrm{~m} \text { ) }\end{array}$ \\
\hline Câmera & 0 a $259 \mathrm{~m}$ & $\begin{array}{l}\text { - NA: } 5,6 \mathrm{~m} \\
\text { - Contato tubo/rocha: } 51,5 \mathrm{~m}\end{array}$ & $\begin{array}{l}\text { As imagens ficaram muito } \\
\text { boas, sem turbidez na água e } \\
\text { incrustações na parede do } \\
\text { furo em geral. Foram } \\
\text { observadas feições de fluxo }\end{array}$ \\
\hline Gama RG & 0 a $224 \mathrm{~m}$ & 25 a 616 CPS & \multirow{2}{*}{$\begin{array}{l}\text { Os dados foram coerentes, } \\
\text { não parece haver mudança } \\
\text { litológica na resposta do gama }\end{array}$} \\
\hline Gama MSI & 25 a $288 \mathrm{~m}$ & 23 a 536 CPS & \\
\hline OTV RG & 48 a $256 \mathrm{~m}$ & $\begin{array}{l}\text { - Tubo/rocha: } 50,7 \mathrm{~m} \\
\text { - } \mathrm{N}^{\mathrm{o}} \text { fraturas: } 266\end{array}$ & $\begin{array}{c}\text { A imagem ficou com boa } \\
\text { resolução e foram observadas } \\
\text { feições de fluxo e oxidação da } \\
\text { parede do furo }\end{array}$ \\
\hline ATV RG & 0 a $256 \mathrm{~m}$ & $\begin{array}{l}\text { - Tubo/rocha: } 43,9 \mathrm{~m} \\
\text { - No fraturas: } 266^{*} \\
\text { - Diâm.: } 220 \text { a } 290 \mathrm{~mm} \\
\text { - Desvio do poço: } 66 \mathrm{~m}\end{array}$ & $\begin{array}{l}\text { Os dados de diâmetro e } \\
\text { desvio do poço não } \\
\text { corresponderam com valores } \\
\text { realistas para o poço e } \\
\text { discordam da sonda da MSI } \\
\end{array}$ \\
\hline ATV MSI & 0 a $256 \mathrm{~m}$ & $\begin{array}{l}\text { - Tubo/rocha: } 47,7 \mathrm{~m} \\
\text { - } \mathrm{N}^{\mathrm{o}} \text { fraturas: } 266^{*} \\
\text { - Diâm.: } 145 \text { a } 210 \mathrm{~mm} \\
\text { - Desvio do poço: } 8,88 \mathrm{~m}\end{array}$ & $\begin{array}{l}\text { O cáliper não recuperou o } \\
\text { sinal em alguns pontos de } \\
\text { maior diâmetro da fratura. }\end{array}$ \\
\hline HPF RG & $\begin{array}{l}\text {-Fluxo ambiente } \\
70 \text { pontos }\end{array}$ & $\begin{array}{l}\text { - Fluxo ambiente ascendente } \\
\text { (45 a } 145 \mathrm{~m} \text { e } 204 \text { a } 256 \mathrm{~m} \text { ) }\end{array}$ & $\begin{array}{c}\text { Os dados oscilaram muito } \\
\text { sem ter uma coerência e } \\
\text { apresentaram vazões muito } \\
\text { elevadas para fluxo ambiente }\end{array}$ \\
\hline HPF MSI & $\begin{array}{l}\text {-Fluxo ambiente } \\
22 \text { pontos; } \\
\text {-Fluxo induzido } \\
29 \text { pontos }\end{array}$ & $\begin{array}{l}\text { - Fluxo ambiente descendente } \\
(115 \text { a } 228 \mathrm{~m}) \\
\text { - Fluxo induzido ascendente } \\
\text { com entrada em } 120,198 \mathrm{e} \\
245 \mathrm{~m}\end{array}$ & $\begin{array}{l}\text { Os dados oscilaram um pouco } \\
\text { mas foram consistentes. A } \\
\text { vazão de bombeamento estava } \\
\text { no limite da sonda }\end{array}$ \\
\hline $\begin{array}{l}\text { Ensaio } \\
\text { hidráulico }\end{array}$ & 12 trechos & $\begin{array}{l}\text { - Transmissividade de } 4 \mathrm{E}^{-5} \mathrm{a} \\
5 \mathrm{E}^{-4} \mathrm{~m}^{2} / \mathrm{s} \\
\text { - Potencial de fluxo } \\
\text { descendente com diferencial } \\
\text { de pressão de } 66 \mathrm{~cm}\end{array}$ & $\begin{array}{l}7 \text { trechos não apresentaram } \\
\text { fluxo, um deles foi o contato } \\
\text { do revestimento com a rocha }\end{array}$ \\
\hline Amostragem & 6 trechos & Amostragem por baixa vazão & $\begin{array}{l}\text { Apenas um dos intervalos } \\
\text { amostrados apresentou } \\
\text { presença de contaminante }\end{array}$ \\
\hline
\end{tabular}

* o principal perfil utilizado na identificação de fraturas foi o OTV no trecho do poço que foi perfilado 
A perfilagem com o cáliper não apresentou nenhuma obstrução ou problema construtivo no poço 1204. A profundidade máxima foi $256 \mathrm{~m}$, bem próximo do indicado no cadastro do DAEE (260 m). O diâmetro medido variou de 148 a 214 mm, apresentando boa correlação com o diâmetro de perfuração indicado no cadastro (152,4 mm).

Durante a filmagem não foi registrada nenhuma obstrução no poço ou aspectos que colocassem em risco a realização desta ou demais atividades. A profundidade máxima observada foi de $259 \mathrm{~m}$, três metros a mais do que o cáliper mecânico. A diferença neste caso é decorrente de imprecisão no sistema de registro de profundidade dos equipamentos. Os principais aspectos observados com a câmera foram, feições de fluxo de água em diferentes profundidades $(117,5,121,76$ e 123,5 m); incrustação na parede do furo; e aspectos construtivos do poço (Figura 5.19).
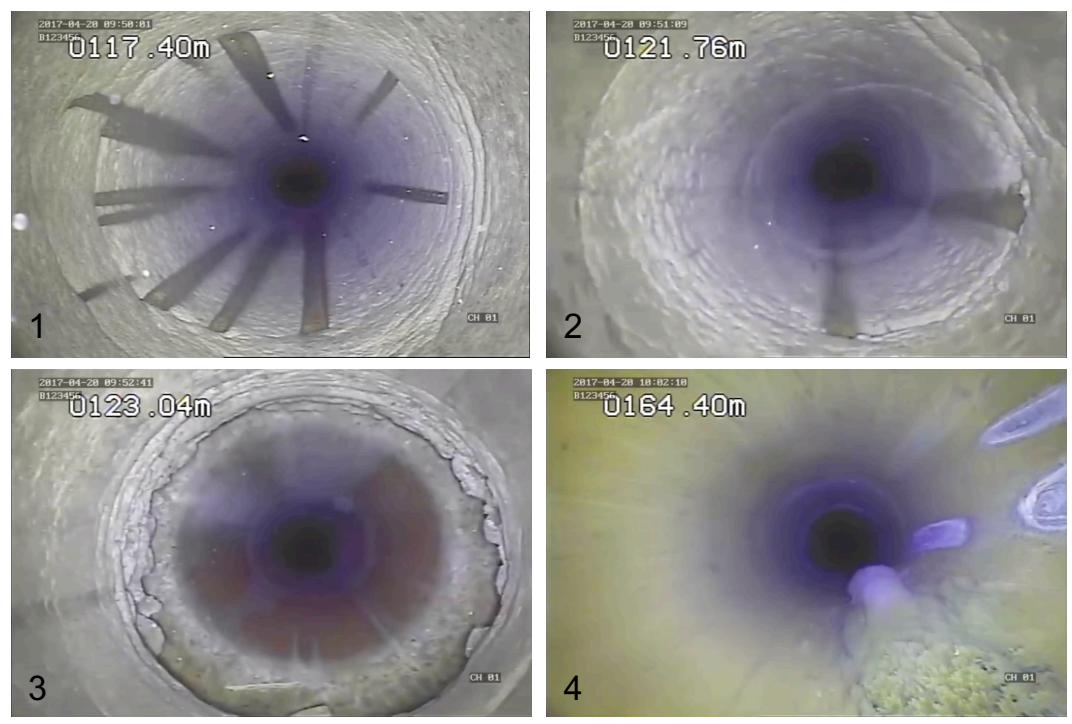

Figura 5.19. Imagens obtidas a partir da câmera para o poço 1204. (1 e 2) marcas de água escorrida na parede do furo; (3) oxidação da parede do furo, cor avermelhada, a partir dos 123,5 m; e (4) incrustação observada em 164 $\mathrm{m}$.

As sondas gama de ambas as marcas (RG e MSI) apresentaram resultados similares, não foi observada nenhuma resposta que pudesse indicar mudança litológica consistente.

O intervalo perfilado foi de 49 a $256 \mathrm{~m}$ com as sondas da RG (ótica e acústica), e da MSI (acústica e gama). Os dados obtidos com as duas sondas de imageamento (Figura 5.20) apresentaram boa correlação com as observações da câmera. O diâmetro médio da perfuração no trecho de rocha exposta variou de 145 a $210 \mathrm{~mm}$, praticamente o mesmo registrado pelo cáliper. Nos mais de $200 \mathrm{~m}$ de furo aberto perfilado foi registrado um desvio de cerca de $9 \mathrm{~m}$ para $\mathrm{N} 135^{\circ}$, inclinação média de $4,5 \%$. 


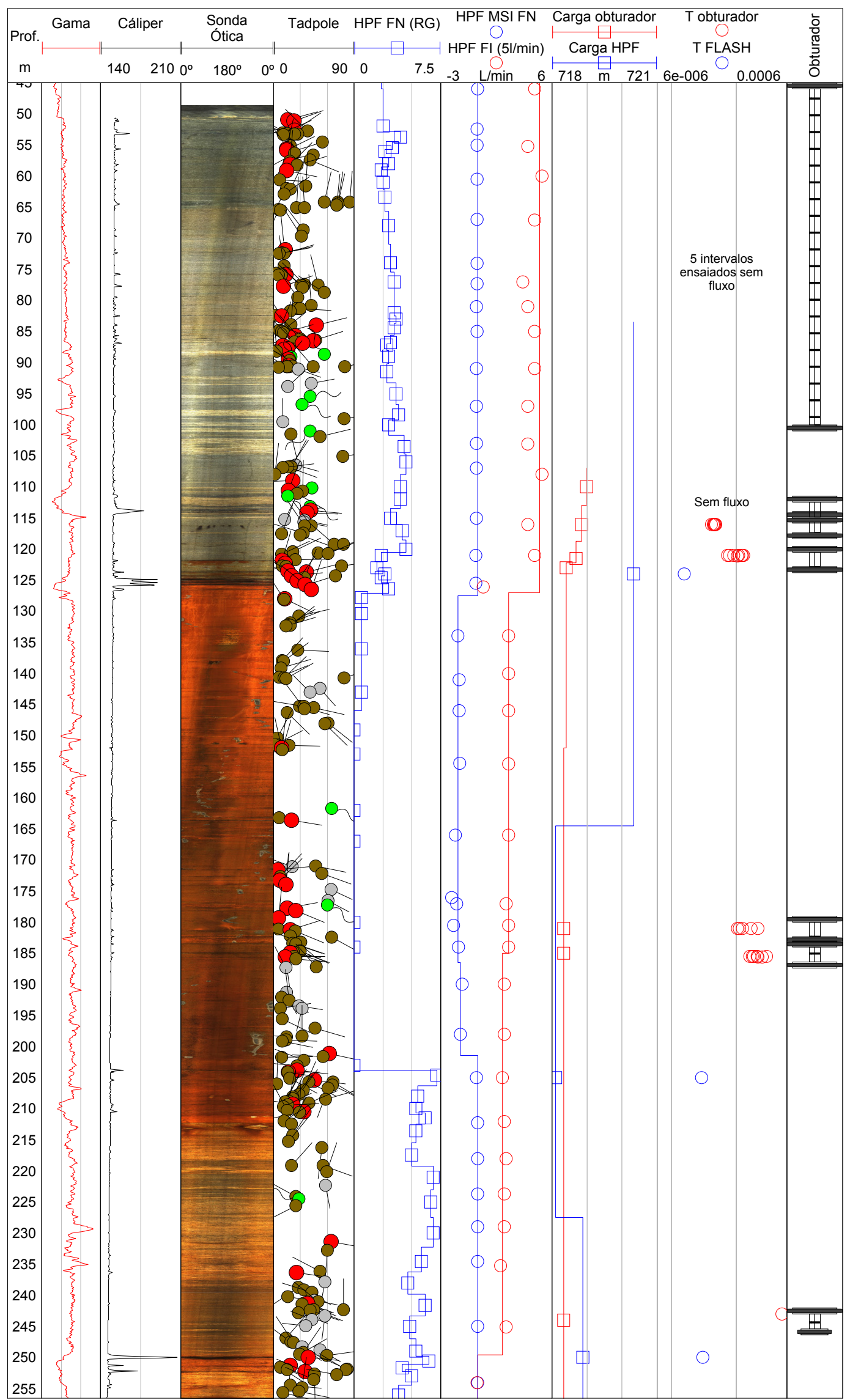

Figura 5.20. Perfil integrado do poço 1204 da Área S (ATV, gama, HPF, FLASH e obturador) 
A principal sonda utilizada para a identificação das estruturas foi a ótica, complementada pelos perfis acústicos. Apesar de identificados alguns trechos com incrustação na parede do furo com a câmera, as imagens da perfilagem ótica não foram prejudicadas e apresentaram boa resolução, identificando 266 fraturas. Dessas, 56 apresentaram abertura aparente superior a $10 \mathrm{~mm}$. As fraturas observadas são majoritariamente sub-horizontais (mergulho $<30^{\circ}$ ) e apresentam direções muito dispersas, com maior concentração dos mergulhos de NNE a ESE.

As medições de fluxo ambiente (NA estático em 5,12 m) com a sonda da RG foram muito diferentes daquelas medidas com a sonda da MSI. O fluxo da RG foi ascendente em todas as medições, exceto entre o trecho de 154 a198 m, em que o fluxo foi zero. A sonda da MSI apresentou fluxo descendente de forma consistente, embora apenas o intervalo de 115 a $198 \mathrm{~m}$ esteja dentro do limite de quantificação da sonda. A principal entrada de água estava em 125,5 m e a principal saída em 198 m. Embora a vazão de fluxo ambiente varie entre 1,4 e 2 1/min, adotou-se um valor médio de fluxo de $1,45 \mathrm{l} / \mathrm{min}$ para o trecho de 125 a $198 \mathrm{~m}$.

No ensaio com fluxo induzido (NA dinâmico em 6,17 m), foram observadas três zonas hidraulicamente ativas com respostas consistentes. A mais profunda a $250 \mathrm{~m}$ ( $2 \mathrm{l} / \mathrm{min})$, seguida por uma em $205 \mathrm{~m}$, em que o fluxo sobe para 2,5 1/min, e uma mais rasa em $124 \mathrm{~m}$, em que o fluxo se aproxima da vazão de bombeamento (5 1/min).

A avaliação conjunta dos dados do HPF da MSI para fluxo ambiente e induzido corrobora a hipótese da existência de ao menos três zonas hidraulicamente ativas. A zona mais profunda apresenta carga hidráulica próxima a carga média do poço e, portanto, não aparece no ensaio em fluxo ambiente.

O resultado do HPF foi simulado no FLASH-R, que apresentou resultados consistentes com a interpretação do fluxo $\left(\mathrm{EQM}\right.$ de $\left.1 \mathrm{E}^{-7}\right)$. Os resultados são apresentados na Tabela 5.8 e ilustrados na Figura 5.21.

Tabela 5.8. Resultados da modelagem de fluxo com o FLASH-R para o poço 1204

\begin{tabular}{|c|c|c|c|c|}
\hline Zona & $\begin{array}{c}\text { Carga } \\
\text { hidráulica }(\mathrm{m})\end{array}$ & $\begin{array}{c}\text { Transmissividade } \\
\left(\mathrm{m}^{2} / \mathrm{s}\right)\end{array}$ & Raio de influência & $\begin{array}{c}\text { Transmissividade } \\
\text { total do poço }\end{array}$ \\
\cline { 1 - 2 } $124 \mathrm{~m}$ & 720,33 & $1,6 \mathrm{E}^{-5}$ & \multirow{2}{*}{$30 \mathrm{~m}$} & \multirow{2}{*}{$7,5 \mathrm{E}^{-5} \mathrm{~m}^{2} / \mathrm{s}^{-5}$} \\
\cline { 1 - 2 } $205 \mathrm{~m}$ & 718,10 & $2,9 \mathrm{E}^{-5}$ & & \\
\hline
\end{tabular}


₹USGS FLASH - Flow Log Analysis of Single ₹USGS FLASH - Flow Log Analysis of Single Holes

\begin{tabular}{l|l|l} 
Introduction & Borehole and Test Data Flow Log Analysis
\end{tabular}

\section{Enter well and test data}

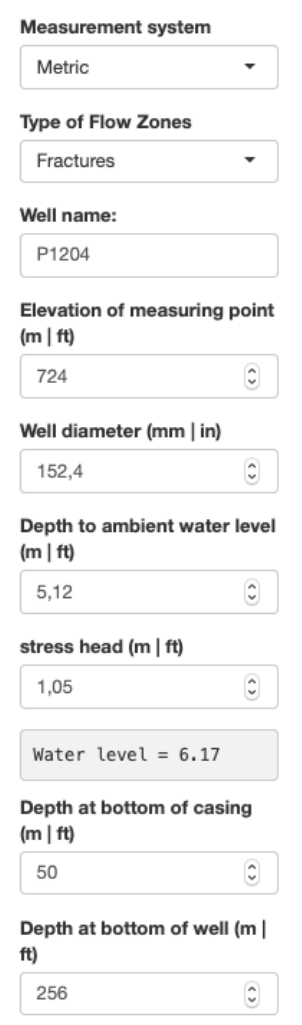
Separator
$\odot$ Comma Semicolon

Tab

0,1

$$
5
$$

$-0,1$

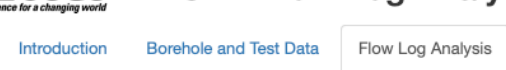

\section{Output my data}

Choose ambient flow txt File Browse... $\quad$ HPFM_1204_FN_PickTime Choose pumped flow txt File \begin{tabular}{|l|l|l|}
\hline Browse... Fl export.txt &
\end{tabular}

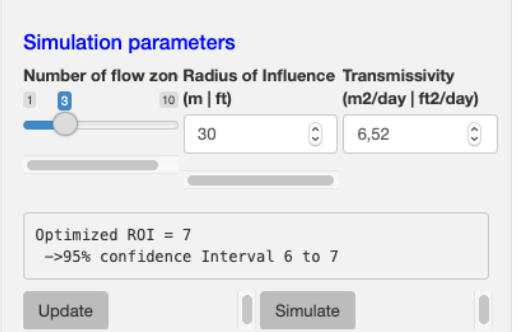
Interpreted Flow Zones Zone Depth Ambient flow Stressed flow Tfactor aH \begin{tabular}{|l|l|l|l|l|l}
3 & 124.00 & 0.00 & 5.00 & 0.21 & 1.45 \\
\hline 2 & 20500 & -1.45 & 250 & 0.09 & 0.79
\end{tabular} \begin{tabular}{r|r|r|r|r|r|}
\hline 2 & 205.00 & -1.45 & 2.50 & 0.39 & -0.78 \\
\hline 1 & 250.00 & 0.00 & 2.00 & 0.40 & 0.00 \\
\hline
\end{tabular} Optimization Results \begin{tabular}{|l|r|}
\hline Tractor & aH \\
\hline 0.21 & 1.45 \\
\hline
\end{tabular} \begin{tabular}{|l|r|}
\hline 0.21 & 1.45 \\
\hline 0.39 & -0.78 \\
\hline
\end{tabular} Upload complete

Simulation Parameters

Mean Square Error Sum Tfactor Estimated Ttotal Sum ah

Flowmeter Upward Min Quantification Limit L/min

Flowmeter Upward Max Quantification Limit (L/min

\section{Flowmeter Downward} Fowmeter Downward Min Gal/min)

Flowmeter Downward Max Qualmin)
Optimization parameters

\section{Estimate ROI -}

$\checkmark$ Solve with regularization

ABSmax T f factor minimum Regularization Weig

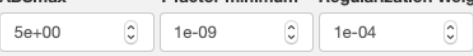

Optimization

Show 95\% confidence interval

\section{Simulated Flow Zones}

Zone Depth Farrield head Ambient Flow Stressed flow Ambient error Stressed error Zone T Ttotal \% \begin{tabular}{l|l|r|r|r|r|r|r|r|}
\hline 3 & 124 & 720.33 & 0.00 & 5.00 & 0.00 & 0.00 & 1.37 & 0.21 \\
\hline 2 & 205 & 718.10 & -1.45 & 2.50 & 0.00 & 0.00 & 2.54 & 0.39 \\
\hline
\end{tabular}

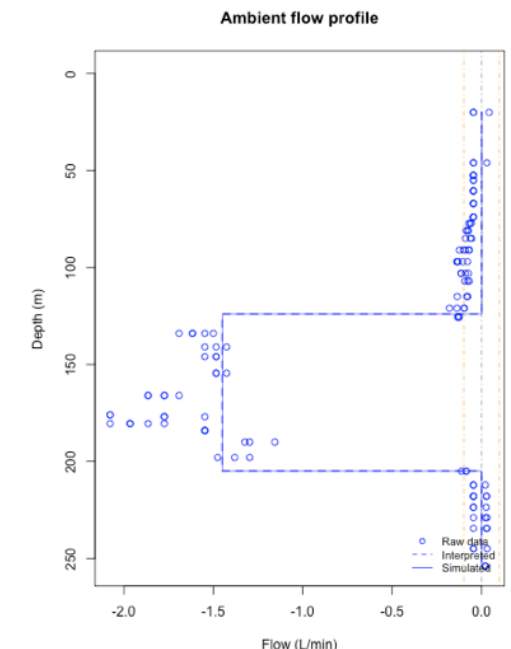

Stressed flow profile

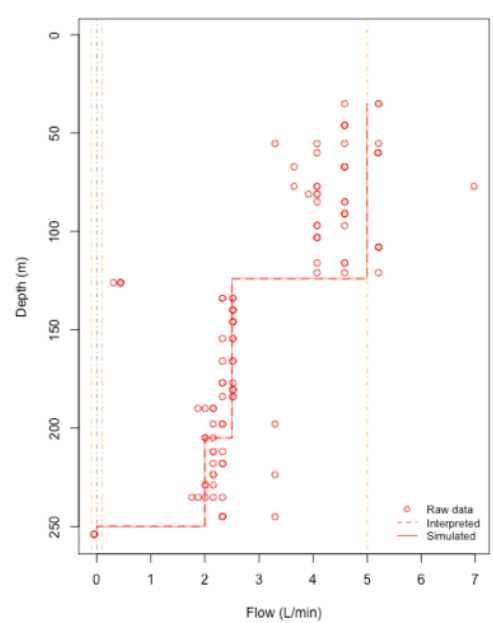

Figura 5.21. Resultado da modelagem de fluxo do HPF no programa FLASH-R para o poço 1204 
Com base no modelo hidráulico, e levando em consideração os objetivos específicos do estudo, foram realizados 12 ensaios hidráulicos e coletadas cinco amostras de água. Desses, cinco se mostraram transmissivos, e seus valores de carga hidráulica foram considerados para a interpretação do potencial de fluxo, além de um trecho superior em que a carga também foi considerada $(<110 \mathrm{~m})$. Um dos intervalos identificados pelo HPF ficou de fora dos ensaios com obturadores por falha no planejamento das atividades de campo (profundidade de $200 \mathrm{~m}$ ). Os resultados são apresentados na Tabela 5.9 e ilustrados na Figura 5.20. O perfil integrado dos dados em escala de detalhe é apresentado no Item 0 e exemplos de dados processados para ensaios de pulso com ar são apresentado no Item 0

Tabela 5.9. Resultados dos ensaios hidráulicos com obturadores no poço 1204

\begin{tabular}{|c|c|c|c|c|c|c|}
\hline $\begin{array}{l}\text { Intervalo } \\
\text { (m) }\end{array}$ & $\begin{array}{l}\text { Carga } \\
\text { hidráulica } \\
\text { (m) }\end{array}$ & $\begin{array}{l}\text { Transmissividade } \\
\qquad\left(\mathrm{m}^{2} / \mathrm{s}\right)\end{array}$ & $\begin{array}{l}\text { Abertura } \\
\text { fratura } \\
(\mathrm{mm})\end{array}$ & $\begin{array}{l}\text { Tipo de } \\
\text { ensaio }\end{array}$ & Amostragem & Comentários \\
\hline $\begin{array}{c}46,90 \mathrm{a} \\
49,24\end{array}$ & \multicolumn{6}{|c|}{ Ensaio de estanqueidade do sistema, não apresentou vazamento } \\
\hline $\begin{array}{c}50,65 \mathrm{a} \\
53,00\end{array}$ & \multirow{5}{*}{\multicolumn{6}{|c|}{ Sem fluxo }} \\
\hline $\begin{array}{c}59,03 \mathrm{a} \\
61,37\end{array}$ & & & & & & \\
\hline $\begin{array}{c}74,06 \mathrm{a} \\
76,41 \\
\end{array}$ & & & & & & \\
\hline $\begin{array}{l}99,00 \mathrm{a} \\
101,34\end{array}$ & & & & & & \\
\hline $\begin{array}{c}112,45 \mathrm{a} \\
114,8\end{array}$ & & & & & & \\
\hline$<110$ & 718,99 & \multicolumn{5}{|c|}{ Sem ensaio hidráulico, apenas monitoramento da carga } \\
\hline $\begin{array}{c}115 \mathrm{a} \\
117,35\end{array}$ & 718,84 & $4,5 \mathrm{E}^{-5}$ & 0,38 & Pulso & $\begin{array}{c}\text { Baixa vazão } \\
\text { com bomba } \\
\text { centrífuga }\end{array}$ & 7 ensaios \\
\hline $\begin{array}{l}120,5 \mathrm{a} \\
122,85\end{array}$ & 718,40 & $1 \mathrm{E}^{-4}$ & 0,50 & Pulso & $\begin{array}{c}\text { Baixa vazão } \\
\text { com bomba } \\
\text { centrífuga }\end{array}$ & 8 ensaios \\
\hline $\begin{array}{c}180 \mathrm{a} \\
182,35\end{array}$ & 718,34 & $1,4 \mathrm{E}^{-4}$ & 0,56 & Pulso & $\begin{array}{c}\text { Baixa vazão } \\
\text { com bomba } \\
\text { centrífuga }\end{array}$ & 6 ensaios \\
\hline $\begin{array}{c}184 \mathrm{a} \\
186,35\end{array}$ & 718,34 & $2,12 \mathrm{E}^{-4}$ & 0,64 & Pulso & $\begin{array}{c}\text { Baixa vazão } \\
\text { com bomba } \\
\text { centrífuga }\end{array}$ & 7 ensaios \\
\hline$>243 \mathrm{~m}$ & 718,33 & $5 \mathrm{E}^{-4}$ & 0,85 & $\begin{array}{c}\text { Carga } \\
\text { constante }\end{array}$ & $\begin{array}{c}\text { Baixa vazão } \\
\text { com bomba } \\
\text { centrífuga }\end{array}$ & $\begin{array}{l}3 \text { faixas de } \\
\text { vazão }\end{array}$ \\
\hline
\end{tabular}

A comparação entre os dados obtidos com o HPF e os obturadores não apresentaram boa correlação. As diferenças entre cargas hidráulicas e transmissividades são evidenciadas na 
Figura 5.20. Embora ambos os ensaios corroborem a existência de um fluxo descendente no poço 1204, a diferença de carga hidráulica de quase 2,3 m observada na simulação do FLASH$\mathrm{R}$ não corresponde ao valor medido com os obturadores, de $66 \mathrm{~cm}$.

Em relação à transmissividade, os ensaios com obturadores apresentaram valores uma ordem de grandeza maiores do que a modelagem no FLASH-R. Além disso, dentre os principais trechos transmissivos identificados com os obturadores, um deles não foi observado no HPF $(181 \mathrm{~m})$.

Das cinco amostras de água coletadas, apenas o intervalo de 120,65 a 123 m apresentou presença de contaminante (18 ug/1 de Cis-1,2-Dicloroeteno), em concentração inferior ao padrão ambiental da CETESB (50 ug/l). Também não foram observadas características hidroquímicas que pudessem caracterizar águas de diferentes idades ou origem.

Como esse foi o primeiro poço em que se aplicou as técnicas de investigação apresentadas, uma série de problemas operacionais ocorreram e influenciaram os resultados.

\subsection{2 Área M}

Localização: Indaiatuba, São Paulo

Empreendimento: área industrial em operação

Objetivo do trabalho: caracterização da dinâmica de fluxo de água no poço e coleta de amostras discretas para análise química. $\mathrm{O}$ trabalho fez parte do processo de gerenciamento ambiental da área.

Contexto geológico: a Área M está localizada na borda leste da Bacia Sedimentar do Paraná, onde sedimentos do Supergrupo Tubarão ou Grupo Itararé (Permiano Carbonífero) aparecem sobre o embasamento cristalino (pré-cambriano).

O Grupo Itararé (MILANI et al., 1994), também denominado Subgrupo Itararé (ROCHA-CAMPOS, 1967), constitui as camadas basais do Supergrupo Tubarão, importante aquífero superficial da região (NEVES, 2005; EZAKI et al., 2008). O Grupo Itararé teve sua deposição em camadas sob a ação de geleiras durante a glaciação permo-carbonífera e por ingressões marinhas (SOARES e LANDIM, 1973). São observados predominantemente na área, arenitos quartzosos, feldspáticos e arcoseanos mal selecionados, com intercalações de siltitos, folhelhos, argilitos, diamictitos e, raramente, níveis de carvão. Entre outras variações de litotipos sedimentares, ocorrem localmente arenitos com intercalações de argilitos, ritmitos e siltitos com seixos pingados (Neves, 2005), todos observados em poços. 
O embasamento cristalino corresponde a rochas de médio a alto grau metamórfico do Complexo Amparo (EBERT, 1968; HASUI et al., 1981; NEVES, 2005). Esse apresenta algumas variações regionais, mas na área de estudo e arredores é constituído por gnaisses com biotita, hornblenda e granada, com variados graus de migmatização. São observadas intercalações de quartzitos, xistos, anfibolitos, gonditos e metaultrabasitos (HASUI et al., 1981). Ocorrem também granitoides neoproterozóicos/paleozóicos (GALEMBECK et al., 2001) encaixados nos gnaisses e migmatitos, dentre os quais destaca-se Complexo Granitoide Itu (PASCHOLATI, 1990; GALEMBECK et al., 1997).

Estrutura disponível: quatro poços tubulares (P1, P2, P3 e P4) utilizados pela indústria para abastecimento. Os poços tiveram os equipamentos retirados e foi realizada a limpeza uma semana antes do início do trabalho. Como os quatro poços apresentaram resultados similares, apenas os dois (P2 e P4), mais relevantes para essa pesquisa, serão detalhados no estudo de caso. Um resumo das características desses poços é apresentado na Tabela 5.10.

Escopo: o trabalho foi realizado em quatro poços, e contemplou a execução de seis atividades de campo, divididas em duas etapas. A primeira de geofísica, e a segunda de ensaios hidráulicos e amostragem com obturadores. A etapa geofísica compreendeu as técnicas: filmagem com câmera; gama; ATV; e HPF. Na segunda etapa foram monitoradas as cargas hidráulicas, realizados ensaios hidráulicos do tipo pulso e carga constante, e coletadas amostras de água em intervalos discretos. 
Tabela 5.10. Resumo dos dados dos poços P2 e P4 da Área M obtidos no Sistema de Informação De Águas Subterrâneas (SIDAS) do Departamento de Águas e Energia Elétrica do Estado de são Paulo

\begin{tabular}{|c|c|c|c|}
\hline \multicolumn{2}{|c|}{ Características } & $\mathrm{P} 2$ & $\mathrm{P} 4$ \\
\hline \multirow{3}{*}{ Gerais } & Aquífero explorado & Sedimentar e Cristalino & Sedimentar e Cristalino \\
\hline & Data da construção & 1998 & 1999 \\
\hline & Cota & 611 & 615 \\
\hline \multirow{3}{*}{ Perfuração } & Método & $\begin{array}{c}\text { Rotativo direto até } 24,35 \\
\mathrm{~m} \text { e roto percussão até180 } \\
\mathrm{m}\end{array}$ & $\begin{array}{l}\text { Rotativo direto até } 20,45 \\
\mathrm{~m} \text { e roto percussão até267 } \\
\mathrm{m}\end{array}$ \\
\hline & Profundidade total & $180 \mathrm{~m}$ & $267 \mathrm{~m}$ \\
\hline & Diâmetro & $\begin{array}{l}-15 \mathrm{~m}: 311,15 \mathrm{~mm} \\
-24,35 \mathrm{~m}: 215,9 \mathrm{~mm} \\
-180 \mathrm{~m}: 152,4 \mathrm{~mm}\end{array}$ & $\begin{array}{l}-20,45 \mathrm{~m}: 215,9 \mathrm{~mm} \\
-267 \mathrm{~m}: 152,4 \mathrm{~mm}\end{array}$ \\
\hline \multirow{3}{*}{$\begin{array}{l}\text { Descrição } \\
\text { geológica }\end{array}$} & Solo de alteração & 0 a $15 \mathrm{~m}$ & 0 a $12 \mathrm{~m}$ \\
\hline & Formação Itararé & 15 a $122 \mathrm{~m}$ & 12 a $138 \mathrm{~m}$ \\
\hline & $\begin{array}{c}\text { Grupo Amparo } \\
\text { (Embasamento } \\
\text { Cristalino) }\end{array}$ & 122 a $180 \mathrm{~m}$ & 138 a $267 \mathrm{~m}$ \\
\hline \multirow{3}{*}{$\begin{array}{l}\text { Revestimento } \\
\text { (tubo liso) }\end{array}$} & Material & Aço preto & Aço preto \\
\hline & Extensão & $+0,5$ a $24,35 \mathrm{~m}$ & $+0,55$ a $20,45 \mathrm{~m}$ \\
\hline & Diâmetro & $152,4 \mathrm{~mm}$ & $152,4 \mathrm{~mm}$ \\
\hline \multirow{7}{*}{$\begin{array}{l}\text { Características } \\
\text { hidráulicas }\end{array}$} & Nível estático & $44,41 \mathrm{~m}$ & $34,20 \mathrm{~m}$ \\
\hline & $\begin{array}{l}\text { Vazão do ensaio de } \\
\text { bombeamento }\end{array}$ & $3,13 \mathrm{~m}^{3} / \mathrm{h}$ & $2,12 \mathrm{~m}^{3} / \mathrm{h}$ \\
\hline & Nível dinâmico & $163,87 \mathrm{~m}$ & $182,97 \mathrm{~m}$ \\
\hline & $\begin{array}{l}\text { Profundidade de } \\
\text { instalação da bomba }\end{array}$ & $174 \mathrm{~m}$ & $216 \mathrm{~m}$ \\
\hline & Vazão específica & $0,0262 \mathrm{~m}^{3} / \mathrm{h} / \mathrm{m}$ & $0,0143 \mathrm{~m}^{3} / \mathrm{h} / \mathrm{m}$ \\
\hline & $\begin{array}{c}\text { Rebaixamento } \\
\text { específico }\end{array}$ & $38,1661 \mathrm{~m} / \mathrm{m}^{3} / \mathrm{h}$ & $70,1745 \mathrm{~m} / \mathrm{m}^{3} / \mathrm{h}$ \\
\hline & Transmissividade & $0,4271 \mathrm{~m}^{2} / \mathrm{dia}$ & $0,1164 \mathrm{~m}^{2} / \mathrm{dia}$ \\
\hline
\end{tabular}

Método: as características específicas do método de trabalho foram:

1. ATV com gama (MSI-ABI-GR);

a. centralizador metálico duplo, não magnético, para furos de $152,4 \mathrm{~mm}$.

2. HPF (MSI); e

a. centralizador de plástico regulado em $160 \mathrm{~mm}$;

b. diverter de borracha para furos de $152,4 \mathrm{~mm}$;

c. ensaios: Fluxo Ambiente (FA) e Fluxo Induzido (FI), extração de água com bomba centrífuga (2,3 1/min no P2 e 3,5 1/min no P4); 
d. aferição de campo para fluxo zero e induzido; e

e. modelagem com FLASH-R. A transmissividade total do poço foi interpretada a partir do bombeamento para o ensaio com o HPF (FI).

3. MUST.

a. obturadores P5-9 com capa de borracha;

b. espaçamento entre obturadores de 3 e $4 \mathrm{~m}, \mathrm{P} 4$ e P2 respectivamente, determinado com base na avaliação integrada dos perfis gerados na etapa geofísica;

c. pressão diferencial de 7 bar para isolamento dos intervalos selecionados;

d. registro da profundidade com fita métrica reforçada;

e. monitoramento de cargas feito por meio de mangueiras de PE, conectadas aos intervalos intermediário e inferior, e mini-transdutores de pressão, inseridos nas mangueiras após o posicionamento da composição no intervalo de interesse. Transdutor superior inserido separadamente pelo tubo de boca do poço;

f. ensaio hidráulico de pulso com sistema pneumático de pressão e vácuo para o P4 e com injeção de água para o P2;

g. ensaio de carga constante por bombeamento com bomba centrífuga posicionada no intervalo e mangueira de PE. Antes de realizar o ensaio de pulso a mangueira da bomba centrifuga era vedado, evitando o efeito de armazenamento de água na mangueira de monitoramento de carga do intervalo; e

h. amostragem de água por baixa vazão com bomba centrífuga, mesmo sistema utilizado no ensaio de carga constante.

Resultados: Os resultados são apresentados de maneira sucinta para cada técnica na sua sequência de execução, destacando os aspectos mais relevantes para esta pesquisa.

Poço P2: A Tabela 5.11 apresenta um resumo dos resultados obtidos, que são detalhados na sequência. 
Algumas feições de fluxo foram observadas na parede do furo entre 40 e $50 \mathrm{~m}$ com a câmera. As imagens geradas (Figura 5.22) serviram para identificar a transição entre as rochas do Grupo Itararé e do Complexo Amparo $(107 \mathrm{~m})$. O contato entre tubo de revestimento e rocha se encontra em $24,70 \mathrm{~m}$ e a profundidade máxima observada $(182 \mathrm{~m})$ confirma o dado da perfuração.

Os dados obtidos com a sonda acústica apresentaram boa correlação com as observações da câmera. $\mathrm{Na}$ imagem acústica foi observado apenas um trecho em que a quebra na rocha resulta em perda do sinal acústico $(96,6 \mathrm{~m})$. O contato entre rocha sedimentar e a cristalina não ficou evidente na resposta da amplitude da sonda acústica, mas há indícios que isso ocorra em 106 m. A transição é marcada por uma redução consistente do cáliper (de 156 para $154 \mathrm{~mm}$ ), menor oscilação da amplitude do sinal acústico e a identificação de fraturas de alto ângulo na porção correspondente à rocha cristalina.

Tabela 5.11. Atividades realizadas e principais resultados do poço P2 da Área M

\begin{tabular}{|c|c|c|c|}
\hline Atividade & Dados coletados & Resultados & Comentários \\
\hline Câmera & 0 a $182 \mathrm{~m}$ & $\begin{array}{l}\text { - NA: } 41,3 \mathrm{~m} \\
\text { - Contato tubo/rocha: } 24,70 \\
\mathrm{~m}\end{array}$ & $\begin{array}{c}\text { Foi observado um } \\
\text { gotejamento acima do } \\
\text { nível d'água }\end{array}$ \\
\hline ATV MSI & 39,82 a $178 \mathrm{~m}$ & $\begin{array}{l}\text { - NA: } 34,9 \mathrm{~m} \\
\text { - Tubo/rocha: fora da água } \\
\text { - No fraturas: } 47 \\
\text { - Diâm.: } 151 \text { a } 182 \mathrm{~mm} \\
\text { - Desvio do poço: } 0,9 \mathrm{~m}\end{array}$ & $\begin{array}{l}\text { O contato entre rocha } \\
\text { sedimentar e cristalina } \\
\text { ocorre em } 107 \text { m pela } \\
\text { resposta da amplitude do } \\
\text { sinal acústico }\end{array}$ \\
\hline Gama MSI & \multicolumn{3}{|c|}{$\begin{array}{c}\text { Não foi utilizado embora fosse uma sonda importante na caracterização } \\
\text { estratigráfica }\end{array}$} \\
\hline HPF MSI & $\begin{array}{l}\text {-Fluxo ambiente } 10 \\
\text { pontos; } \\
\text {-Fluxo induzido } 10 \\
\text { pontos }\end{array}$ & $\begin{array}{l}\text { - Fluxo ambiente } \\
\text { descendente ( } 43,3 \text { a } 97 \mathrm{~m}) \\
\text { - Fluxo ascendente com } \\
\text { entrada a } 65 \mathrm{~m} \text { e fluxo } \\
\text { descendente de } 65 \text { a } 97 \mathrm{~m}\end{array}$ & $\begin{array}{l}\text { Durante o bombeamento o } \\
\text { fluxo se dividiu em } \\
\text { ascendente acima de } 65 \mathrm{~m} \\
\text { e descendente abaixo }\end{array}$ \\
\hline Ensaio hidráulico & 5 trechos & $\begin{array}{c}\text { - Transmissividade de } 3,2 \mathrm{E}^{-7} \\
\text { a } 4,5 \mathrm{E}^{-6} \mathrm{~m}^{2} / \mathrm{s} \\
\text { - Potencial de fluxo } \\
\text { descendente com variação de } \\
3,2 \mathrm{~m}\end{array}$ & \\
\hline Amostragem & 5 trechos & Amostragem por baixa vazão & $\begin{array}{l}\text { Foi observada } \\
\text { estratificação na } \\
\text { concentração dos } \\
\text { contaminantes }\end{array}$ \\
\hline
\end{tabular}

As fraturas desse poço foram interpretadas separadamente para as duas litologias observadas. A frequência de fraturas na porção sedimentar é maior ( 0,49 fratura/metro) do que na cristalina ( 0,23 fratura/metro). Não foram observadas tendências de concentração para as 
fraturas que caracterizassem diferentes grupos. A porção de rocha sedimentar apresenta fraturas com menor ângulo de mergulho, em sua maioria $<30^{\circ}$, e a porção cristalina apresenta fraturas com maior ângulo de mergulho, $>30^{\circ}$ para algumas fraturas.

As medições com o HPF em condição ambiente (NA estático em 40,53 m) apresentaram fluxo descendente com entrada de água em dois intervalos, de 41,53 (-0,32 1/min) e 68,44 m (0,92 1/min), sendo o mais profundo responsável por quase o dobro da vazão do primeiro. A saída de água ocorre nos dois intervalos entre $68,44(-0,21$ 1/min) e 100,08 $\mathrm{m}$, sendo a primeira a principal saída. No restante do poço o fluxo medido está abaixo do limite de detecção da sonda $(<0,11 / \mathrm{min})$, portanto foi considerado nulo.
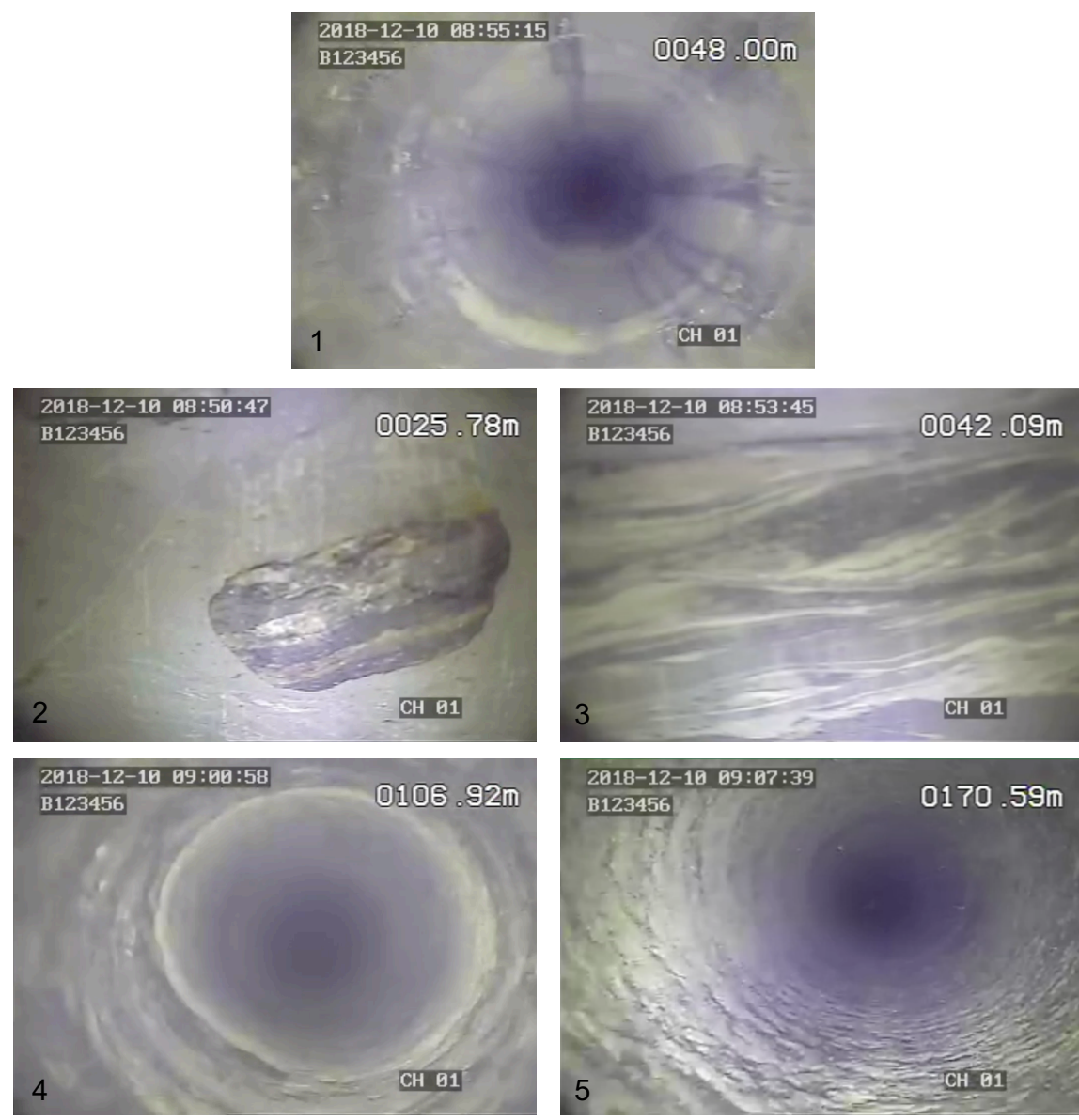

Figura 5.22. Imagens geradas com a câmera no poço P2 da área M. (1) indício de escorrimento de água na parede do furo; (2) imagem da rocha do Grupo Itararé, siltito com seixo pingado; (3) imagem da rocha do Grupo Itararé, intercalação arenito-argila; (4) contato entre a rocha do Grupo Itararé e do Complexo Amparo; (5) imagem da rocha do Complexo Amparo

No ensaio com bombeamento (NA dinâmico em 41,12 m), foi confirmada a principal zona produtora de água $(68,57$ a 50,96 m). O trecho de 55,02 a 68,57 m fornece água que é captada pela bomba e mantém um fluxo descendente no poço na mesma magnitude das 
medições em fluxo ambiente. No restante do poço, a partir dos 100 metros, o fluxo medido está abaixo do limite de detecção da sonda e foi considerado nulo.

As aferições de campo apresentaram bons resultados para o fluxo zero (revestimento e fundo do poço) e para a vazão de bombeamento (diferença de 0,1 1/min).

O resultado do HPF foi simulado no FLASH-R (Figura 5.23), que apresentou resultados consistentes com a interpretação do fluxo $\left(\mathrm{EQM}\right.$ de $\left.1 \mathrm{E}^{-5}\right)$. Os resultados são apresentados na Tabela 5.12 e ilustrados na Figura 5.24.

Tabela 5.12. Resultados da modelagem com o FLASH-R para o poço P2

\begin{tabular}{|c|c|c|c|c|}
\hline Zona & $\begin{array}{c}\text { Carga } \\
\text { hidráulica (m) }\end{array}$ & $\begin{array}{l}\text { Transmissividade } \\
\left(\mathrm{m}^{2} / \mathrm{s}\right)\end{array}$ & Raio de influência & $\begin{array}{l}\text { Transmissividade } \\
\text { total do poço }\end{array}$ \\
\hline $54,90 \mathrm{~m}$ & 570,78 & $2,69 \mathrm{E}-5$ & \multirow{4}{*}{$15 \mathrm{~m}$} & \multirow{4}{*}{$6,39 \mathrm{E}-5 \mathrm{~m} 2 / \mathrm{s}$} \\
\hline $61,40 \mathrm{~m}$ & 570,47 & $3,33 \mathrm{E}-5$ & & \\
\hline $68,44 \mathrm{~m}$ & 567,42 & $3,24 \mathrm{E}-6$ & & \\
\hline $96,40 \mathrm{~m}$ & 564,73 & $4,63 \mathrm{E}-7$ & & \\
\hline
\end{tabular}

Com base no modelo hidráulico, e levando em consideração os objetivos específicos do estudo, foram realizados cinco ensaios hidráulicos e amostragens de água. A relação de cargas hidráulicas medidas com os obturadores decresce conforme aumenta a profundidade, indicando a existência de fluxo ambiente descendente no poço. O gradiente varia mais de 13 metros entre a zona mais rasa e a mais profunda. Os valores de transmissividade variam três ordens de magnitude, sendo o intervalo de 51,7 a $55,7 \mathrm{~m}$ o mais transmissivo $\left(2,34 \mathrm{E}^{-3} \mathrm{~m}^{2} / \mathrm{s}\right)$, seguido do intervalo de 61,8 a $65,8 \mathrm{~m}\left(4,96 \mathrm{E}^{-4} \mathrm{~m}^{2} / \mathrm{s}\right)$. A Tabela 5.13 resume os dados obtidos nos ensaios e trechos amostrados. O perfil integrado dos dados em escala de detalhe é apresentado no Item 0 e exemplos de dados processados para ensaios de pulso com ar são apresentado no Item 0

Tabela 5.13. Resultados dos ensaios hidráulicos com obturadores no poço P2

\begin{tabular}{|c|c|c|c|c|c|}
\hline $\begin{array}{l}\text { Intervalo } \\
\text { (m) }\end{array}$ & $\begin{array}{c}\text { Carga } \\
\text { hidráulica (m) }\end{array}$ & $\begin{array}{c}\text { Transmissividade } \\
\left(\mathrm{m}^{2} / \mathrm{s}\right)\end{array}$ & $\begin{array}{c}\text { Abertura } \\
\text { fratura }(\mathrm{mm})\end{array}$ & Tipo de ensaio & Amostragem \\
\hline$<45$ & 574,36 & $2,34 \mathrm{E}^{-6}$ & 0,14 & $\begin{array}{c}\text { Carga } \\
\text { constante }\end{array}$ & Baixa vazão \\
\hline 46 a 50 & 573,76 & $1,02 \mathrm{E}^{-6}$ & 0,11 & $\begin{array}{c}\text { Carga } \\
\text { constante }\end{array}$ & Baixa vazão \\
\hline 51,7 a 55,7 & 573,13 & $2,30 \mathrm{E}^{-3}$ & 1,41 & $\begin{array}{c}\text { Carga } \\
\text { constante }\end{array}$ & Baixa vazão \\
\hline 61,8 a 65,8 & 571,20 & $4,96 \mathrm{E}^{-4}$ & 0,85 & $\begin{array}{c}\text { Carga } \\
\text { constante }\end{array}$ & Baixa vazão \\
\hline $\begin{array}{c}94,50 \mathrm{a} \\
98,50 \\
\end{array}$ & 571,16 & $1,04 \mathrm{E}^{-5}$ & 0,23 & $\begin{array}{l}\text { Pulso com } \\
\text { água }\end{array}$ & Baixa vazão \\
\hline$>98,50$ & $<561,00$ & $\begin{array}{l}\text { Trecho não ens } \\
\text { acima. Medidor }\end{array}$ & $\begin{array}{r}\text { o, medição } \\
\text { lível só che } \\
\text { abai }\end{array}$ & $\begin{array}{l}\text { arga durante en } \\
\text { até } 50 \text { metros } \\
\text { sso }\end{array}$ & $\begin{array}{l}\text { aio do trecho } \\
\text { o nível estava }\end{array}$ \\
\hline
\end{tabular}


ॠUSGS FLASH - Flow Log Analysis of Single ₹USGS FLASH - Flow Log Analysis of Single Holes

\begin{tabular}{|c|c|c|c|}
\hline Introduction & Borehole and Test Data & Flow Log Analy & \\
\hline \multicolumn{4}{|c|}{ Enter well and test data } \\
\hline \multicolumn{2}{|c|}{ Measurement system } & \multicolumn{2}{|c|}{ Choose ambient flow txt File } \\
\hline Metric & . & Browse... & P02_Ambient_DepthAdjus \\
\hline \multicolumn{2}{|c|}{ Type of Flow Zones } & \multirow{2}{*}{\multicolumn{2}{|c|}{$\begin{array}{l}\text { Upload completo } \\
\text { Choose pumped flow txt File }\end{array}$}} \\
\hline \multirow{2}{*}{\multicolumn{2}{|c|}{ Fractures }} & & \\
\hline Well name: & & Browse... & P02_Stress_DepthAdjuste \\
\hline \multicolumn{2}{|l|}{ P-02 } & \multicolumn{2}{|c|}{ Upload complete } \\
\hline \multirow{2}{*}{\multicolumn{2}{|c|}{$\begin{array}{l}\text { Elevation of measuring point } \\
(\mathrm{m} \mid \mathrm{ft})\end{array}$}} & \multirow{3}{*}{\multicolumn{2}{|c|}{$\begin{array}{l}\text { Separator } \\
\text { Comma } \\
\text { Semicolon } \\
\text { O Tab }\end{array}$}} \\
\hline & & & \\
\hline 611 & $\mathrm{~s}$ & & \\
\hline \multicolumn{4}{|c|}{ Well diameter $(\mathrm{mm} \mid \mathrm{in})$} \\
\hline 152,4 & $\therefore$ & \multirow{2}{*}{\multicolumn{2}{|c|}{$\begin{array}{l}\text { Flowmeter Upward Min } \\
\text { Quantification Limit (L/min | } \\
\text { Gal/min) }\end{array}$}} \\
\hline \multirow{2}{*}{\multicolumn{2}{|c|}{$\begin{array}{l}\text { Depth to ambient water level } \\
(\mathrm{m} \mid \mathrm{ft})\end{array}$}} & & \\
\hline & & \multirow{2}{*}{\multicolumn{2}{|c|}{$\begin{array}{|ll|}0,1 & \vdots \\
\end{array}$}} \\
\hline 40.53 & 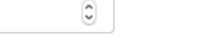 & & \\
\hline \multicolumn{2}{|c|}{ stress head $(m \mid f t)$} & \multirow{2}{*}{\multicolumn{2}{|c|}{$\begin{array}{l}\text { Flowmeter Upward Max } \\
\text { Quantification Limit (L/min | } \\
\text { Gal/min) }\end{array}$}} \\
\hline \multirow[t]{2}{*}{0.595} & \multirow[t]{2}{*}{$\hat{2}$} & & \\
\hline & & & $\hat{\theta}$ \\
\hline \multicolumn{2}{|c|}{ Water level $=41.125$} & \multirow{2}{*}{\multicolumn{2}{|c|}{$\begin{array}{l}\text { Flowmeter Downward Min } \\
\text { Quantification Limit (L/min | } \\
\text { Gal/min) }\end{array}$}} \\
\hline \multicolumn{2}{|c|}{$\begin{array}{l}\text { Depth at bottom of casing } \\
(\mathrm{m} \mid \mathrm{ft})\end{array}$} & & \\
\hline 24.7 & 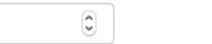 & \multicolumn{2}{|c|}{$-0,1$} \\
\hline \multicolumn{2}{|c|}{$\begin{array}{l}\text { Depth at bottom of well (m | } \\
\text { ft) }\end{array}$} & \multicolumn{2}{|c|}{$\begin{array}{l}\text { Flowmeter Downward Max } \\
\text { Quantification Limit (L/min | } \\
\text { Gal/min) }\end{array}$} \\
\hline 180 & 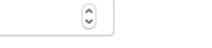 & -5 & $\hat{\theta}$ \\
\hline
\end{tabular}

\section{Output my data}
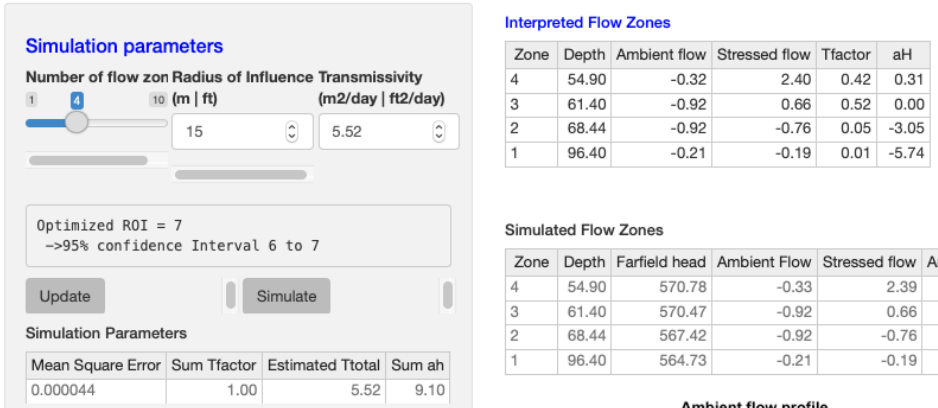

Optimization Results

$0.5222 \quad 0.000$

\begin{tabular}{|c|c|}
\hline 0.0222 & 0.00 \\
\hline 0.0081 & -.05 \\
\hline & -5.74 \\
\hline
\end{tabular}

Simulated Flow Zones

Zone Depth Farfield head Ambient Flow Stressed flow Ambient error Stressed error Zone T Ttotal \%

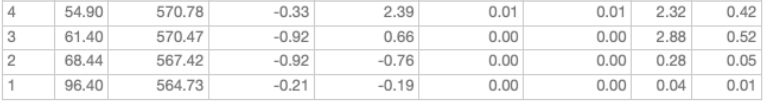

Mean Square Error Sum Thactor Estimated Ttotal Sum an
0.000044
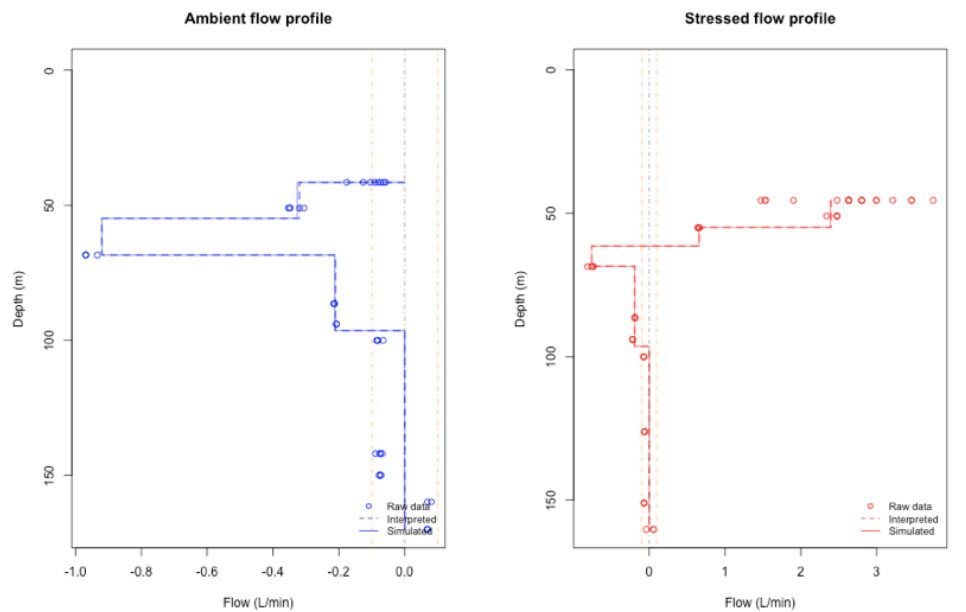

Optimization parameters

Estimate ROI $\quad-$

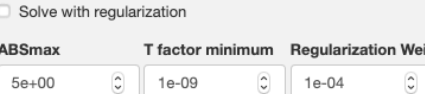

Optimization

Show 95\% confidence interval

Figura 5.23. Resultado da modelagem de fluxo do HPF no programa FLASH-R para o poço P2 


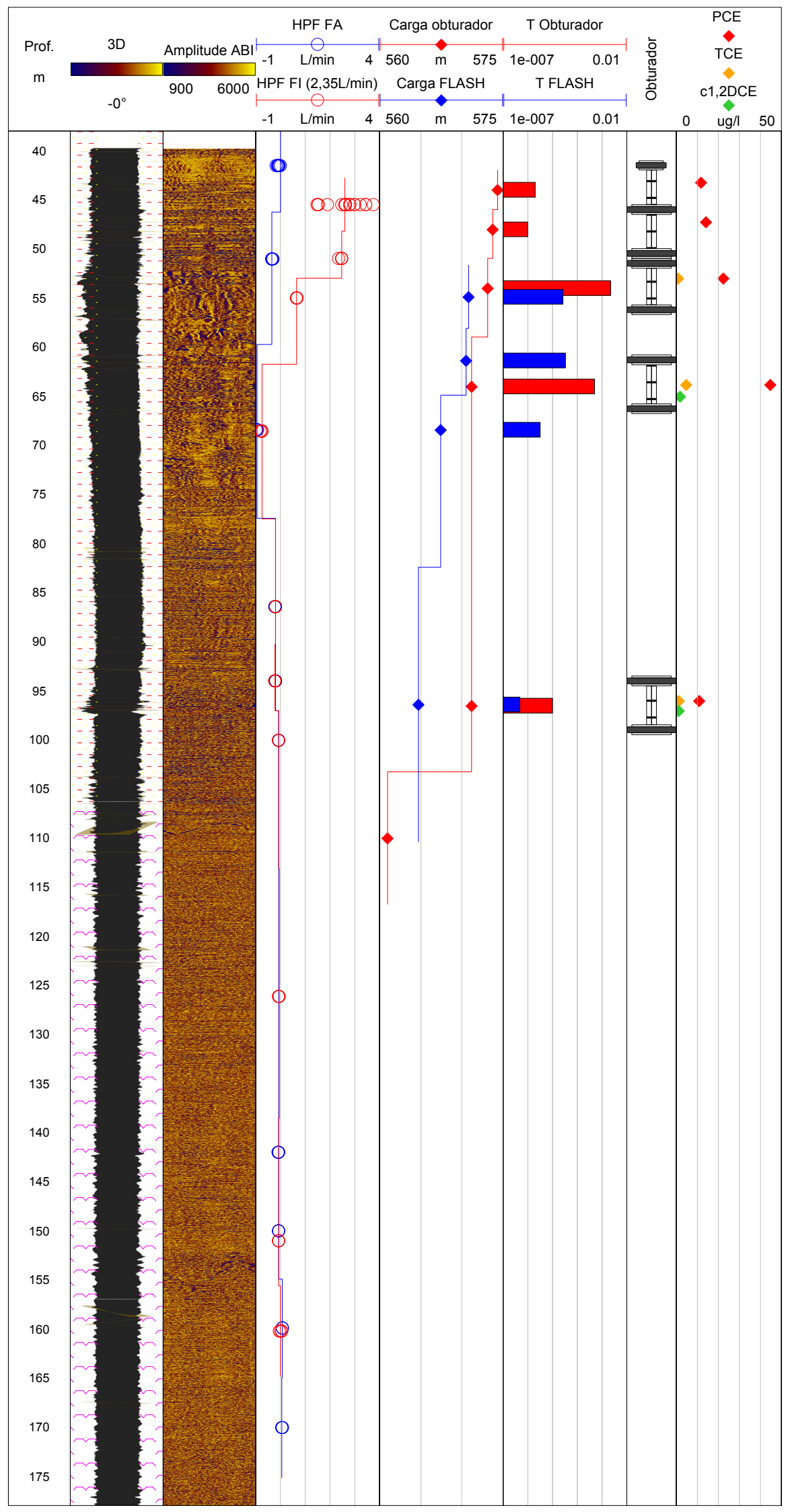

Figura 5.24. Perfil integrado do poço P2 da Área M (ATV, gama, HPF, FLASH e obturador) 
O ensaio mais profundo (94,50 a 98,50 m) foi o único feito com pulso de injeção de água, uma vez que a bomba utilizada para o ensaio de carga constante apresentou problema. Este método não gera um pulso instantâneo, uma vez que o processo de abertura e fechamento da válvula pneumática é gradual. Portanto, o valor da transmissividade obtido neste ensaio provavelmente foi superestimado.

A comparação entre os dados obtidos com o HPF e os ensaios com obturadores foram discrepantes em relação à variação de carga hidráulica e os valores de transmissividade. Embora as cargas hidráulicas confirmem o gradiente descendente observado com o HPF, a variação obtida na simulação do FLASH foi de apenas $4 \mathrm{~m}$ e não $13 \mathrm{~m}$. Com relação à transmissividade, os ensaios com obturadores apresentaram valores uma ordem de grandeza inferiores à modelagem no FLASH-R, o oposto tem sido observado nos outros estudos de caso.

Além disso, os trechos com maiores transmissividades também não foram os mesmos. As diferenças provavelmente estão associadas à precisão da técnica, processamento e a análise dos dados de ambos ensaios. Contudo, valores com até uma ordem de grandeza são considerados dentro de um limite aceitável quando comparados dados de ensaios discretos com furos abertos. Neste caso, o valor de transmissividade total do poço diferiu entre os dois ensaios, fazendo com que a modelagem no FLASH ficasse subestimada. O ideal seria fazer um novo ensaio de bombeamento com o furo aberto para recalibrar o modelo.

Todos os ensaios e amostragens foram feitos na porção de rocha sedimentar, havendo estratificação na presença e concentração de contaminantes (Figura 5.24). As duas zonas que são entradas de água no poço apresentaram as maiores concentrações de contaminantes e, portanto, são consideradas amostras representativas do aquífero sedimentar.

O perfil de concentração mostra um aumento consistente entre os 4 primeiros intervalos amostrados e uma redução significativa na amostra mais profunda (94,5 a 98,5 m), indicando que essa última é uma saída de água e pode ser uma amostra que sofre diluição da água de mistura do poço. Os três trechos mais profundos apresentam presença de TCE, dentre esses, os dois mais profundos apresentam também cis-1,2-DCE (ambos são produtos de degradação do PCE), ambos em baixas concentrações.

Os dados de concentração destes poluentes orgânicos dão indícios de que a contaminação está migrando pelo aquífero sedimentar e se aprofundando no aquífero cristalino por meio dos poços de abastecimento.

Poço P4: A Tabela 5.14 apresenta um resumo dos resultados obtidos, que são detalhados na sequência. 
Tabela 5.14. Atividades realizadas e principais resultados do poço P4 da Área M

\begin{tabular}{|c|c|c|c|}
\hline Atividade & Dados coletados & Resultados & Comentários \\
\hline Câmera & 0 a $267 \mathrm{~m}$ & $\begin{array}{l}\text { - NA: } 31,50 \mathrm{~m} \\
\text { - Contato tubo/rocha: } 20,50 \mathrm{~m}\end{array}$ & $\begin{array}{l}\text { Foi observada uma entrada de } \\
\text { água expressiva em } 29,4 \mathrm{~m}\end{array}$ \\
\hline ATV MSI & 28,90 a $262 \mathrm{~m}$ & $\begin{array}{l}\text { - NA: } 27,38 \mathrm{~m} \\
\text { - Tubo/rocha: fora da água } \\
\text { - No fraturas: } 107 \\
\text { - Diâm.: } 150 \text { a } 202 \mathrm{~mm} \\
\text { - Desvio do poço: } 2,13 \mathrm{~m} \\
\end{array}$ & $\begin{array}{l}\text { O contato entre rocha } \\
\text { sedimentar e cristalina ocorre } \\
\text { em } 118 \mathrm{~m} \text { pela resposta da } \\
\text { amplitude do sinal acústico }\end{array}$ \\
\hline Gama MSI & \multicolumn{3}{|c|}{ Não foi utilizado embora fosse uma sonda importante na caracterização estratigráfica } \\
\hline HPF MSI & $\begin{array}{l}\text {-Fluxo ambiente } \\
17 \text { pontos; } \\
\text {-Fluxo induzido } \\
17 \text { pontos } \\
\end{array}$ & \begin{tabular}{|l} 
- Fluxo ambiente descendente \\
$(27,38$ a $222 \mathrm{~m})$ \\
- Fluxo ascendente de 27,38 a 28 \\
e fluxo descendente de 28 a $222 \mathrm{~m}$ \\
\end{tabular} & $\begin{array}{c}\text { A vazão da fratura a } 29,4 \text { é } \\
\text { superior a } 51 / \text { min no ensaio } \\
\text { com fluxo ambiente e } \\
\text { induzido }\end{array}$ \\
\hline $\begin{array}{l}\text { Ensaio } \\
\text { hidráulico }\end{array}$ & 4 trechos & $\begin{array}{l}\text { - Transmissividade de } 1 \mathrm{E}^{-5} \text { a } 3 \mathrm{E}^{-5} \\
\mathrm{~m}^{2} / \mathrm{s} \\
\text { - Potencial de fluxo descendente } \\
\text { com variação de } 53 \mathrm{~m}\end{array}$ & $\begin{array}{c}\text { O potencial de fluxo } \\
\text { descendente é muito elevado. } \\
\text { Os valores foram } \\
\text { comprovados com medidor de } \\
\text { NA }\end{array}$ \\
\hline Amostragem & 4 trechos & Amostragem por baixa vazão & $\begin{array}{l}\text { Foi observada estratificação } \\
\text { na concentração dos } \\
\text { contaminantes }\end{array}$ \\
\hline
\end{tabular}

Durante a filmagem com a câmera foi observada uma fratura vertendo água para o poço em 29,44 m e a transição entre as rochas do Grupo Itararé e do Complexo Amparo em 137 m (Figura 5.25). O contato entre tubo de revestimento e rocha está em $24,70 \mathrm{~m}$ e a profundidade máxima observada (182 m) confirma o dado da perfuração.
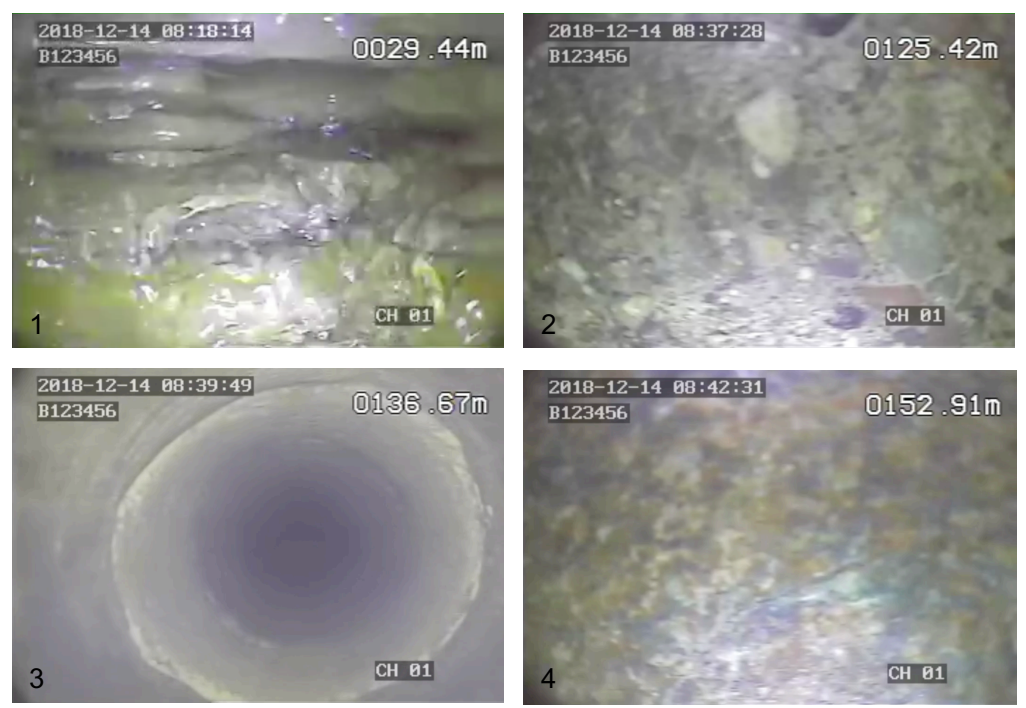

Figura 5.25. Imagens geradas com a câmera no poço P4 da área M. (1) fratura na rocha sedimentar vertendo água para o poço; (2) imagem da rocha do Grupo Itararé (diamictito); (3) contato entre a rocha do Grupo Itararé e do Complexo Amparo; (4) imagem da rocha do Complexo Amparo 
Os dados obtidos com a sonda acústica apresentaram boa correlação com as observações da câmera. A perfuração não apresentou grandes variações de diâmetro (150 a 202 mm), e foram obtidos resultados satisfatórios para a caracterização estrutural. A transição entre a rocha sedimentar e a cristalina é marcada por uma redução consistente do cáliper, menor oscilação da amplitude do sinal acústico e incidência de fraturas de alto ângulo na porção correspondente à rocha cristalina.

Assim como no P2, as fraturas foram interpretadas separadamente para as duas litologias observadas. A frequência de fraturas na porção sedimentar $(0,5$ fratura/metro) é semelhante a observada na cristalina ( 0,46 fratura/metro). Não foram observadas tendências de concentração para as fraturas que caracterizassem diferentes grupos. A porção de rocha sedimentar apresenta fraturas com menor ângulo de mergulho, em sua maioria $<30^{\circ}$, e a porção cristalina apresenta fraturas com maior ângulo de mergulho, no geral $>30^{\circ}$.

As medições com o HPF em condição ambiente (NA estático em 27,40m) apresentaram fluxo descendente no trecho do revestimento, acima de $5 \mathrm{l} / \mathrm{min}$. Foram identificadas duas entradas de água, a 29,4 e 31,8 m, com vazão em torno de 5 e 2 1/min respectivamente, e algumas fraturas que absorvem esse fluxo ao longo do poço até a profundidade de $188 \mathrm{~m}$. As medições realizadas entre 30 e $57 \mathrm{~m}$ apresentam valores acima do limite de quantificação da sonda e foi considerado que o fluxo nessa zona é superior a $5 \mathrm{l} / \mathrm{min}$. A principal saída observada neste ensaio foi entre 57 e $64 \mathrm{~m}$.

No ensaio com bombeamento (NA dinâmico em $28 \mathrm{~m}$ ) foram confirmadas as zonas hidraulicamente ativas em condições de fluxo ambiente. A diferença entre a vazão que é extraída do poço e a medida de fluxo descendente natural no intervalo de $31,5 \mathrm{~m}$ permitiu inferir que o fluxo da fratura em 29,4 m é de 5,2 1/min. Também foi possível observar outra entrada de água entre 31,50 e 33 m. A principal saída de água está entre 57 e 64 m.

As aferições de fluxo zero só foram realizadas no fundo do furo, uma vez que a zona de 29,4 m estava muito próxima do nível d'água e não foram obtidas leituras consistentes nessa porção superior.

O resultado do HPF foi simulado no FLASH-R (Figura 5.26), e a transmissividade total utilizada foi estimada pela função de otimização do programa $\left(1,74 \mathrm{E}^{-4} \mathrm{~m}^{2} / \mathrm{s}\right)$, para que a modelagem apresentasse boa correlação entre os dados interpretados e simulados (2 $\left.\mathrm{E}^{-2} \mathrm{EQM}\right)$. Os resultados são apresentados na Tabela 5.15 e ilustrados na Figura 5.27. 
Tabela 5.15. Resultados da modelagem de fluxo com o FLASH-R para o poço P4

\begin{tabular}{|c|c|c|c|c|}
\hline Zona & $\begin{array}{c}\text { Carga } \\
\text { hidráulica }(\mathrm{m})\end{array}$ & $\begin{array}{c}\text { Transmissividade } \\
\left(\mathrm{m}^{2} / \mathrm{s}\right)\end{array}$ & Raio de influência & $\begin{array}{c}\text { Transmissividade } \\
\text { total do poço }\end{array}$ \\
\hline $29 \mathrm{~m}$ & 587,67 & $1,17 \mathrm{E}^{-4}$ & \multirow{5}{*}{$3 \mathrm{~m}$} & \multirow{5}{*}{$1,74 \mathrm{E}^{-4} \mathrm{~m}^{2} / \mathrm{s}$} \\
\hline $60 \mathrm{~m}$ & 586,61 & $4,41 \mathrm{E}^{-5}$ & & \\
\hline $110 \mathrm{~m}$ & 585,65 & $5,09 \mathrm{E}^{-6}$ & & \\
\hline $160 \mathrm{~m}$ & 585,51 & $5,56 \mathrm{E}^{-6}$ & & \\
\hline $212 \mathrm{~m}$ & 584,33 & $2,31 \mathrm{E}^{-6}$ & & \\
\hline
\end{tabular}

Com base no modelo hidráulico, e levando em consideração os objetivos específicos do estudo, foram realizados quatro ensaios hidráulicos e cinco amostragens em trechos discretos do poço P4. Não foi possível ensaiar o intervalo mais raso porque o nível d'água ficou abaixo dos sensores utilizados para monitorar a variação de coluna de água. A relação de cargas hidráulicas medidas com os obturadores decresce conforme aumento da profundidade, indicando a existência de fluxo ambiente descendente no poço. O gradiente varia mais de $53 \mathrm{~m}$ entre a zona mais rasa e a mais profunda $(30,5 \mathrm{e}>115 \mathrm{~m})$. As medidas de carga foram confirmadas com um medidor de nível de fita. A Tabela 5.16 resume os dados obtidos nos ensaios e trechos amostrados. 
ॠUSGS FLASH - Flow Log Analysis of Single

\begin{tabular}{l} 
Introduction \\
Enter Well and test data \\
Measurement system and Test Data \\
\hline Metric
\end{tabular}
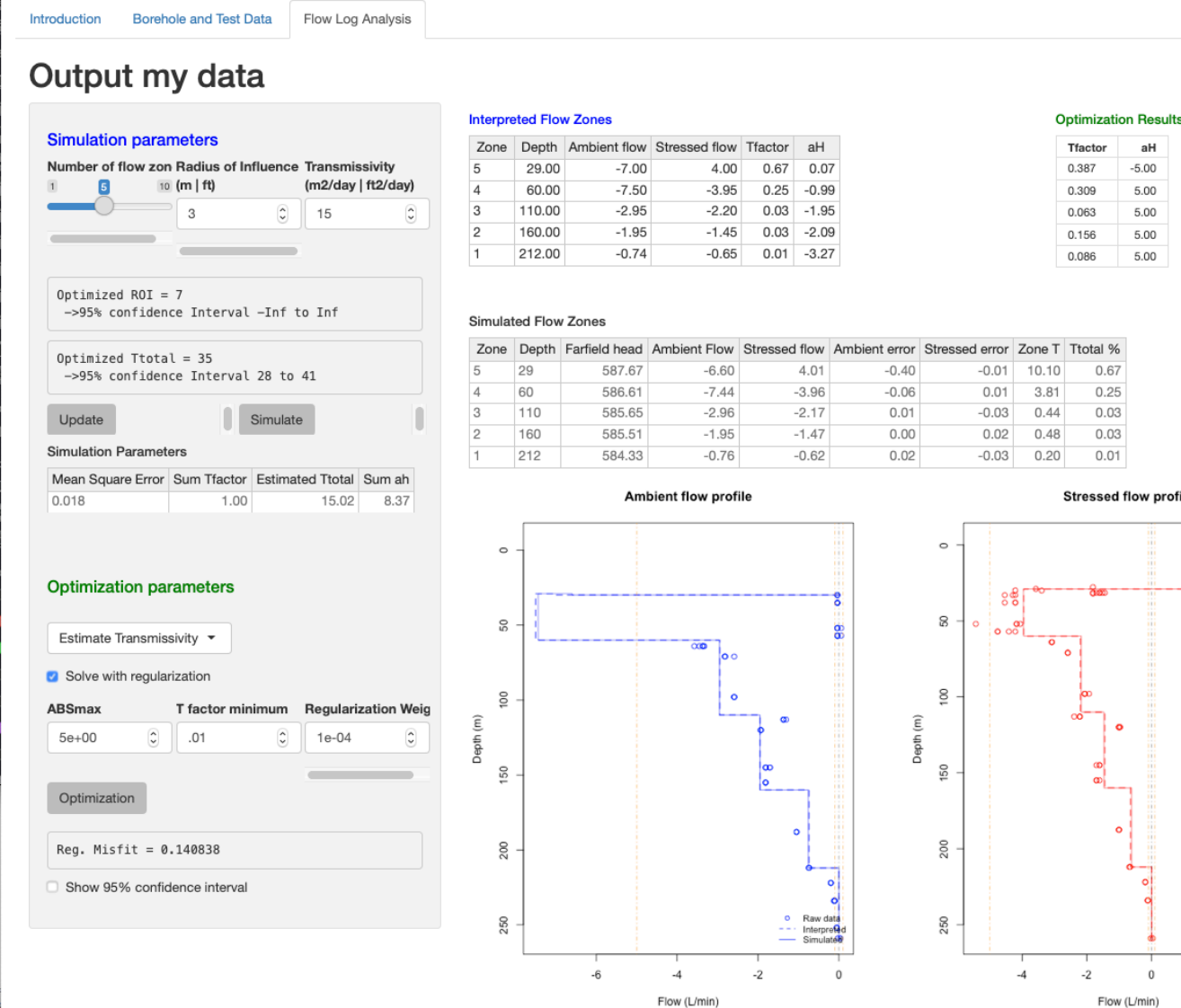

Figura 5.26. Resultado da modelagem de fluxo do HPF no programa FLASH-R para o poço P4 da Área M 


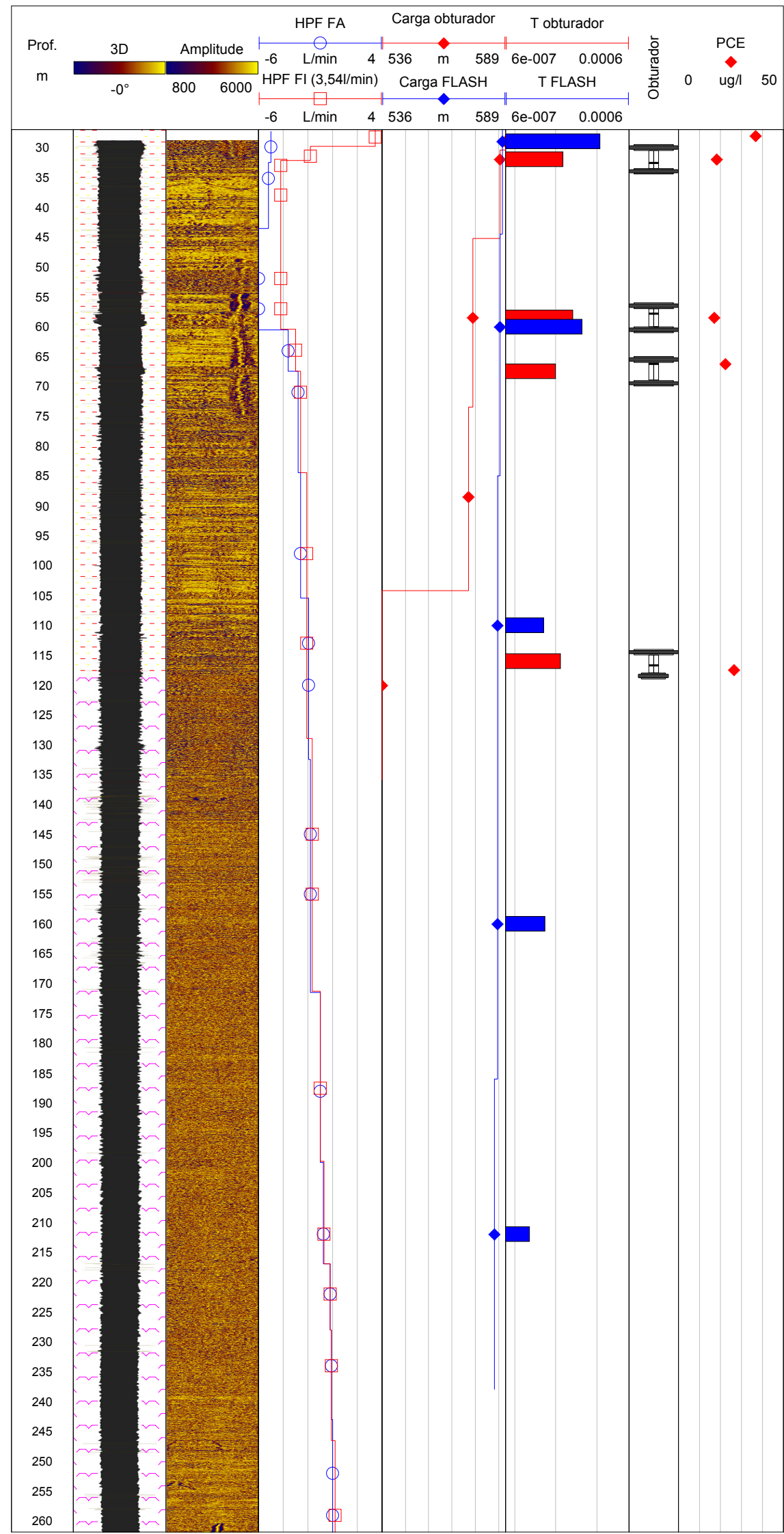

Figura 5.27. Perfil integrado do poço P4 da Área M (ATV, gama, HPF, FLASH e obturador) 
Tabela 5.16. Resultados dos ensaios hidráulicos com obturadores no poço P4

\begin{tabular}{|c|c|c|c|c|c|c|}
\hline $\begin{array}{l}\text { Intervalo } \\
\text { (m) }\end{array}$ & $\begin{array}{c}\text { Carga } \\
\text { hidráulica } \\
\text { (m) }\end{array}$ & $\begin{array}{c}\text { Transmissividade } \\
\left(\mathrm{m}^{2} / \mathrm{s}\right)\end{array}$ & $\begin{array}{c}\text { Abertura } \\
\text { fratura } \\
(\mathrm{mm})\end{array}$ & $\begin{array}{l}\text { Tipo de } \\
\text { ensaio }\end{array}$ & Amostragem & Comentários \\
\hline$<30,5$ & 588,97 & \multicolumn{3}{|c|}{ Não ensaiado } & $\begin{array}{l}\text { Amostrador } \\
\text { descartável }\end{array}$ & $\begin{array}{c}\text { nível d'água } \\
\text { ficou abaixo } \\
\text { do } \\
\text { transdutor de } \\
\text { pressão }\end{array}$ \\
\hline $\begin{array}{c}30,50 \mathrm{a} \\
33,50\end{array}$ & 586,60 & $2,34 \mathrm{E}^{-6}$ & 0,14 & pulso & $\begin{array}{l}\text { Baixa } \\
\text { vazão }\end{array}$ & $\begin{array}{l}\text { NA inferior } \\
\text { mais } \\
\text { profundo que } \\
\text { a } \\
\text { composição }\end{array}$ \\
\hline 57 a 60 & 574,85 & $1,02 \mathrm{E}^{-6}$ & 0,11 & pulso & $\begin{array}{l}\text { Baixa } \\
\text { vazão }\end{array}$ & \\
\hline 66 a 69 & 573,00 & $2,30 \mathrm{E}^{-3}$ & 1,41 & pulso & $\begin{array}{l}\text { Baixa } \\
\text { vazão }\end{array}$ & $\begin{array}{l}\text { NA inferior } \\
\text { mais } \\
\text { profundo que } \\
\text { a } \\
\text { composição }\end{array}$ \\
\hline$>115$ & 536 & $4,96 \mathrm{E}^{-4}$ & 0,85 & pulso & $\begin{array}{l}\text { Baixa } \\
\text { vazão }\end{array}$ & $\begin{array}{c}\text { Apenas } \\
\text { obturador } \\
\text { superior } \\
\text { inflado }\end{array}$ \\
\hline
\end{tabular}

Todas as amostras foram coletadas utilizando o método de baixa vazão, exceto a amostra mais rasa $(<30,5 \mathrm{~m})$ que foi coletada com amostrador descartável (bailer) em razão da coluna de água se encontrar abaixo da cota da bomba.

A comparação entre os dados obtidos com o HPF e os ensaios com obturadores são coerentes em relação ao sentido e magnitude de fluxo. Conforme pode ser observado na Figura 5.27. As duas principais zonas produtoras de água estão localizadas na porção sedimentar. A porção cristalina apresenta menor carga (53 m de diferença) e transmissividade acumulada (soma das transmissividade) menor que a porção sedimentar.

\subsection{3 Área U}

Localização: Storrs, Connecticut, Estados Unidos da América

Empreendimento: área de ensaios do USGS na Universidade de Connecticut

Objetivo do trabalho: testar equipamentos de geofísica e comparar técnicas de campo aplicadas a caracterização hidráulica de aquíferos fraturados

Contexto geológico: $\mathrm{O}$ embasamento na Área $\mathrm{U}$ é descrito como um gnaisse tipo Hebron, que aparece aflorante ou muito próximo à superfície, sobreposto por uma camada de 
depósitos glaciais estratificados e tilitos arenosos que chega a 5 metros de espessura (FAHEY e PEASE, 1977). A rocha metamórfica é uma combinação de rochas cálcio-silicáticas e rochas gnaisse-xistosas, estas últimas com camadas cinza escuras, granulação média a grossa, e que em sua composição contém andesito, quartzo, biotita e, de maneira concentrada, k-feldspato (RODGERS, 1985).

Estrutura disponível: três poços (B1, B2 e B3) perfurados na rocha com a finalidade de realizar ensaios e pesquisa aplicada. Os poços estão a menos de $22 \mathrm{~m}$ de distância um do outro. Um resumo das características mais relevantes dos poços é apresentado na Tabela 5.17.

Tabela 5.17. Resumo dos dados construtivos dos poços da Área U

\begin{tabular}{|c|c|c|c|}
\hline Características & B1 & B2 & B3 \\
\hline Método de perfuração & Rotativo & Rotativo & Rotativo \\
\hline Profundidade até a rocha $(\mathrm{m})$ & 5,49 & 4,57 & 3,66 \\
\hline Profundidade do furo $(\mathrm{m})$ & 73,93 & 135,42 & 76,86 \\
\hline $\begin{array}{c}\text { Comprimento do revestimento de PVC } \\
(\mathrm{m})\end{array}$ & 9,21 & 9,39 & 5,18 \\
\hline Diâmetro do poço (mm) & 152,4 & 152,4 & 152,4 \\
\hline Diâmetro do tubo de PVC $(\mathrm{mm})$ & 152,4 & 152,4 & 203,2 \\
\hline
\end{tabular}

Escopo: o trabalho foi realizado nos três poços, e contemplou a execução de sete atividades de campo, todas de geofísica. As técnicas empregadas foram: cáliper; resistividade (curta e longa); FTCR; gama; OTV e ATV; HPF; EMF; e SF.

Método: As características específicas do método de trabalho foram:

1. Cáliper e gama (MSI)

2. Resistividade (MSI)

3. ATV e gama (MSI-ABI-GR)

a. centralizador metálico duplo, não magnético, para furos de 152,4 mm

b. perfilagem sentido ascendente

\section{OTV (MSI-OBI)}

5. FTCR (MSI)

a. sem centralizador

b. perfilagem em fluxo ambiente e fluxo induzido em conjunto com o HPF

6. $\mathrm{HPF}(\mathrm{MSI})$ 
a. centralizador de plástico regulado em $160 \mathrm{~mm}$

b. diverter de borracha para furos de $152,4 \mathrm{~mm}$

c. ensaios: Fluxo Ambiente (FA) e Fluxo Induzido (FI), injeção de água (1,5 $1 / \min )$

d. aferição de campo para fluxo zero e induzido

e. modelagem com FLASH-R. A transmissividade total do poço foi interpretada a partir da vazão de injeção de água para o ensaio com o HPF (FI)

7. $\operatorname{EMF}(\mathrm{CG})$

a. centralizador de plástico regulado em $160 \mathrm{~mm}$

b. diverter de borracha para furos de $152,4 \mathrm{~mm}$

c. ensaios: Fluxo Ambiente (FA) e Fluxo Induzido (FI), injeção de água (6,36 $1 / \min )$

d. aferição de campo para fluxo zero e induzido

e. modelagem com FLASH-R. A transmissividade total do poço foi interpretada a partir da vazão de injeção de água para o ensaio com o EMF (FI)

\section{8. $\mathrm{SF}(\mathrm{MSI})$}

a. sem diverter

b. ensaios dinâmicos: Fluxo Ambiente (FA) e Fluxo Induzido (FI), injeção de água $(14,41 / \mathrm{min})$

Resultados: Os resultados são apresentados de maneira sucinta para cada técnica na sua sequência de execução, destacando os aspectos mais relevantes para esta pesquisa. Como os três poços apresentaram resultados similares, apenas o B3 será detalhado nesse estudo de caso. A Tabela 5.18 faz um resumo dos resultados obtidos.

A perfilagem com o cáliper não apresentou nenhuma obstrução ou problema construtivo no poço B3. A profundidade máxima foi $76,5 \mathrm{~m}$, bem próximo do registro da perfuração. $\mathrm{O}$ diâmetro medido variou de 160 a 195 mm, apresentando boa correlação com o diâmetro de perfuração $(152,4 \mathrm{~mm})$. 
Os dados de resistividade (curta e longa) e o gama não indicaram nenhuma mudança litológica ou alteração consistente na composição da rocha. Foram observados dois picos de resistividade nas profundidades de 22 e 54 m, mas sem correlação com aspectos visuais da rocha.

Tabela 5.18. Atividades realizadas e principais resultados do poço B3 da Área U

\begin{tabular}{|c|c|c|c|}
\hline Atividade & $\begin{array}{l}\text { Dados } \\
\text { coletados }\end{array}$ & Resultados & Comentários \\
\hline Cáliper MSI & 0 a $76 \mathrm{~m}$ & $\begin{array}{l}\text { - Diâmetro: } 160 \text { a } 195 \mathrm{~mm} \\
\text { - Tubo revestimento: } 0 \text { a } 5 \mathrm{~m}\end{array}$ & \\
\hline $\begin{array}{l}\text { Resistividade } \\
\text { MSI }\end{array}$ & 5 a $77 \mathrm{~m}$ & - Variação de 0 a 2500 Ohm-m & $\begin{array}{c}\text { Não indicou nenhuma } \\
\text { mudança litológica na porção } \\
\text { da rocha. Ocorreram picos de } \\
\text { resistividade nas profundidades } \\
22 \text { e } 54 \mathrm{~m}\end{array}$ \\
\hline Gama MSI & 5 a $77 \mathrm{~m}$ & - Variação de 0 a 400 CPS & $\begin{array}{l}\text { Não indicou nenhuma } \\
\text { mudança litológica de forma } \\
\text { consistente }\end{array}$ \\
\hline $\begin{array}{l}\text { OTV e ATV } \\
\text { MSI }\end{array}$ & 5 a $76 \mathrm{~m}$ & $\begin{array}{l}\text { - Tubo/rocha: } 7 \mathrm{~m} \\
\text { - No fraturas: } 25 \\
\text { - Diâm.: } 160 \text { a } 190 \mathrm{~mm} \\
\text { - Desvio do poço: } 7,6 \mathrm{~m}\end{array}$ & $\begin{array}{l}\text { O cáliper acústico não } \\
\text { apresentou resultados } \\
\text { consistentes quando } \\
\text { comparado com o cáliper } \\
\text { mecânico }\end{array}$ \\
\hline FTCR & $\begin{array}{c}3 \text { ensaios em } \\
\text { fluxo ambiente } \\
\text { e induzido junto } \\
\text { com os } \\
\text { flowmeters }\end{array}$ & $\begin{array}{c}\text { Fluxo descendente com entrada } \\
\text { entre } 7 \text { e } 32 \mathrm{~m}\end{array}$ & $\begin{array}{l}\text { A comparação entre fluxo } \\
\text { ambiente e induzido indica a } \\
\text { existência de entras de zonas } \\
\text { transmissivas na parte superior } \\
\text { do furo que apresenta fluxo } \\
\text { descendente }\end{array}$ \\
\hline HPF MSI & $\begin{array}{l}7 \text { intervalos em } \\
\text { fluxo ambiente } \\
\text { e induzido }\end{array}$ & \multirow{3}{*}{$\begin{array}{l}\text { - Fluxo ambiente abaixo do } \\
\text { limite de quantificação da sonda } \\
\text { - Fluxo induzido descendente } \\
\text { até } 30 \mathrm{~m}\end{array}$} & \multirow{3}{*}{$\begin{array}{l}\text { A principal fratura que absorve } \\
\text { o fluxo está muito próxima do } \\
\text { NA a } 6 \text { m. duas outras saídas } \\
\text { são identificadas com menor } \\
\text { vazão, a mais importante delas } \\
\text { a } 30 \text { m. Os resultados das } \\
\text { diferentes técnicas de } \\
\text { flowmeter são consistentes }\end{array}$} \\
\hline EMF CG & $\begin{array}{l}11 \text { intervalos } \\
\text { em fluxo } \\
\text { ambiente e } \\
\text { induzido }\end{array}$ & & \\
\hline SF MSI & $\begin{array}{l}\text { Perfilagem de } 5 \\
\text { a } 35 \mathrm{~m} \text { em } \\
\text { fluxo ambiente } \\
\text { e induzido }\end{array}$ & & \\
\hline
\end{tabular}

Os dados obtidos com as sondas de imageamento ótico e acústico (Figura 5.28) apresentaram boa correlação. A imagem acústica ficou prejudicada pela descentralização da sonda no furo e apresentou manchas escuras ao longo do perfil. Como consequência, o cáliper acústico não apresentou boa correlação com o mecânico. O diâmetro médio do furo aberto 
variou de 160 a $190 \mathrm{~mm}$ e foi registrado um desvio de 7,6 m (inclinação de $10^{\circ}$ ) na direção $\mathrm{N} 185^{\circ}$.

Foram identificadas 25 fraturas a partir da análise conjunta do OTV e ATV. O principal grupo de fraturas é sub-horizontal $\left(<30^{\circ}\right)$ e direção de mergulho NNE. O segundo grupo é composto por fraturas de médio ângulo (entre 30 e $60^{\circ}$ ) com direção de mergulho preferencialmente para $\mathrm{N} 120^{\circ}$.

As medições com os três tipos de flowmeter em condição ambiente (Figura 5.29; NA estático em 6,42 m) não apresentaram fluxo, todos os valores obtidos estavam abaixo do limite de quantificação. Os perfis de resistividade da água em condições ambiente não indicaram a presença de fluxo significativo, embora uma variação gradual seja observada nos primeiro 5 a 10 m, até a estabilização. A partir dos $70 \mathrm{~m}$ a resistividade diminui, em razão do fluxo nulo, ou devido ao acúmulo de sedimentos no fundo do poço.

Os três ensaios com fluxo induzido foram realizados com injeção de água em diferentes vazões para cada técnica.

No ensaio com o HPF (NA dinâmico em 6,82 m com injeção de 2,15 1/min), a principal zona produtora de água está em torno de 5,9 m. A vazão medida logo abaixo dessa zona foi de $-0,5 \mathrm{l} / \mathrm{min}$. Uma segunda saída foi observada entre 26,5 e 51,44 m. A partir dos 51,44 m todas as medidas foram de fluxo zero ou abaixo do limite de quantificação da sonda. A comparação entre a resistividade medida com fluxo induzido e com fluxo ambiente indica que há uma saída de água entre 11 e 27 m, contradizendo a interpretação do ensaio, que concluiu que a segunda zona hidraulicamente ativa se encontra entre 26,5 e $51,44 \mathrm{~m}$. No entanto, o tempo do ensaio pode não ter sido suficiente para a renovação da coluna de água no poço, embora o nível d'água já estivesse estável durante as medidas com o HPF.

No ensaio com o EMF (NA dinâmico em 3,69 m com injeção de 11,35 1/min), a principal zona produtora de água está em torno de 5,9 m. A vazão medida logo abaixo dessa zona foi -9 1/min. Uma segunda saída foi observada entre 10 e 12,6 m. A terceira saída foi observada entre 27 e $31 \mathrm{~m}$, com redução no fluxo de 5,5 para 1,4 1/min. Uma quarta saída também foi observada entre $31 \mathrm{~m}$ e o fundo do poço, absorvendo o restante do fluxo. A comparação entre as resistividades medidas com fluxo induzido e ambiente indica que a principal saída de água depois da zona mais rasa $(5,9 \mathrm{~m})$ é a fratura em $30 \mathrm{~m}$, a partir dessa profundidade a resistividade estabiliza até o fundo do poço. 


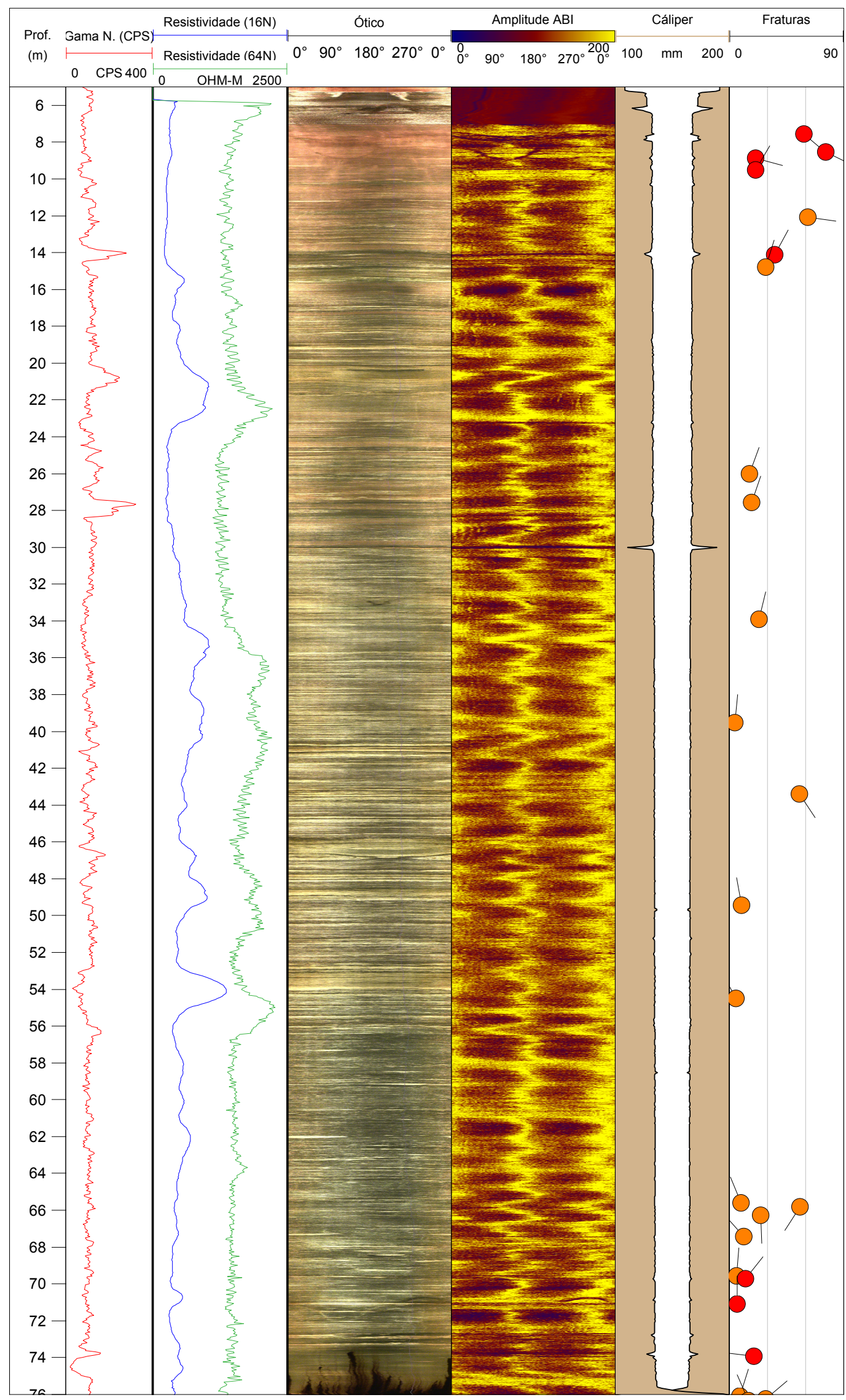

Figura 5.28. Perfil integrado do poço B3 da Área U 
O ensaio com o SF (NA dinâmico em 3,65 m com injeção de 14,38 1/min) confirmou as duas principais saídas de água observada com o EMF. A Fratura mais rasa não foi detectada por estar muito próxima do nível d'água, e pelo fato das medidas serem feitas com a sonda em movimento. Os perfis de resistividade não apresentaram resultados coerentes como nos outros dois ensaios, provavelmente em razão do distúrbio causado pela movimentação do SF na coluna de água.

A avaliação conjunta das três técnicas de flowmeter permitiu identificar quatro zonas de fluxo. O EMF foi o único a evidenciar todas as quatro zonas, sendo que o HPF e o SF identificaram apenas duas delas. Isso se deve às características dos equipamentos, sensibilidade e limite de quantificação de fluxo. Esperava-se que o HPF identificasse a fratura de 12,6 m, no entanto a variação de fluxo naquele intervalo ficou próximo ao limite de quantificação da sonda. Outra característica do poço B3 é que o nível d'água está muito próximo de fraturas transmissivas, e, com o aumento da vazão de injeção, o nível dinâmico sobe e outras fraturas mais rasas passam a absorver parte da água, influenciando na dinâmica de fluxo.

Os resultados do HPF e do EMF foram simulados no FLASH-R (Figura 5.30 e Figura 5.31), e apresentaram resultados consistentes com a interpretação do fluxo (EQM de $<1 \mathrm{E}^{-3}$ ). Os resultados são apresentados na Tabela 5.19 e ilustrados na Figura 5.29. Os resultados do SF não foram simulados pela falta de dados de fluxo na porção superior do poço, impossibilitando a normalização dos dados.

Tabela 5.19. Resultados da modelagem de fluxo com o FLASH-R para o poço B3

\begin{tabular}{|c|c|c|c|}
\hline \multirow{2}{*}{ Zona } & $\begin{array}{c}\text { Diferença de } \\
\text { carga }(\mathrm{m})\end{array}$ & \multicolumn{2}{|c|}{ Transmissividade $\left(\mathrm{m}^{2} / \mathrm{s}\right)$} \\
\cline { 3 - 4 } & 0 & $\mathrm{HPF}$ & $\mathrm{EMF}$ \\
\hline $5,9 \mathrm{~m}$ & 0 & $\begin{array}{c}\text { Não } \\
\text { detectada }\end{array}$ & $1,26 \mathrm{E}^{-4}$ \\
\hline $12,6 \mathrm{~m}$ & 0 & $\begin{array}{c}7,53 \mathrm{E}^{-5} \\
1,04 \mathrm{E}^{-4}\end{array}$ & $1,52 \mathrm{E}^{-4}$ \\
\hline $30 \mathrm{~m}$ & 0 & $\begin{array}{c}\text { Não } \\
\text { detectada }\end{array}$ & $5,20 \mathrm{E}^{-5}$ \\
\hline $50 \mathrm{~m}$ & $3,28 \mathrm{E}^{-4}$ & $4,32 \mathrm{E}^{-4}$ \\
\hline
\end{tabular}

As simulações de fluxo no FLASH-R para o HPF e o EMF, de maneira geral, apresentaram boa correlação, apesar da discrepância observada entre as zonas em 12,6 e 30m, uma vez que a primeira não foi identificada pelo HPF. O raio de influência utilizado para ambos os casos foi de $30 \mathrm{~m}$, e a diferença obtida no valor de transmissividade total para o poço pode ser explicada pelo aumento da vazão no ensaio com o EMF. 


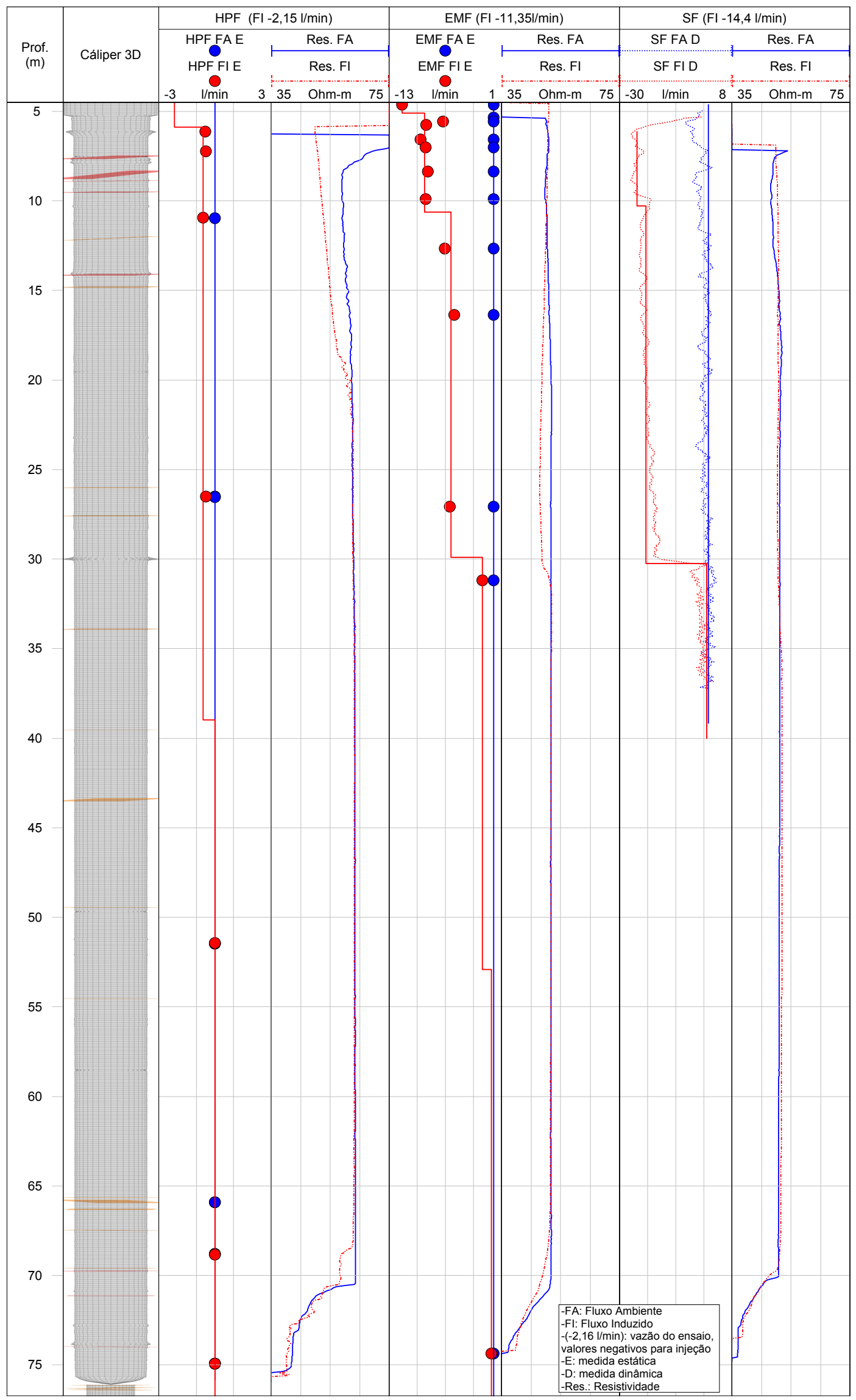

Figura 5.29. Resultado dos ensaios com flowmeters (HPF, EMF e SF) para o poço B3 


\section{ॠUSGS FLASH - Flow Log Analysis of SingleUSGS FLASH - Flow Log Analysis of Single Holes}

\begin{tabular}{l|l|l} 
Introduction Borehole and Test Data Flow Log Analysis &
\end{tabular}

\section{Enter well and test data}

\begin{tabular}{|c|c|}
\hline Measuren & \\
\hline Metric & r \\
\hline Type of Fl & \\
\hline Fracture & $r$ \\
\hline Well name & \\
\hline B3 & \\
\hline $\begin{array}{l}\text { Elevation } \\
(\mathrm{m} \mid \mathrm{ft})\end{array}$ & \\
\hline 152 & $\hat{c}$ \\
\hline Well diam & \\
\hline 152,4 & $\Leftrightarrow$ \\
\hline $\begin{array}{l}\text { Depth to a } \\
\text { (m|ftt }\end{array}$ & \\
\hline 6,82 & $\theta$ \\
\hline stress hea & \\
\hline$-0,125$ & $\Leftrightarrow$ \\
\hline Water 1 & \\
\hline $\begin{array}{l}\text { Depth at } \\
\text { ft) }\end{array}$ & \\
\hline 7 & $\hat{\sigma}$ \\
\hline Depth at & \\
\hline & $\approx$ \\
\hline
\end{tabular}

Separator

Tab

Qumin

\section{Output my data}

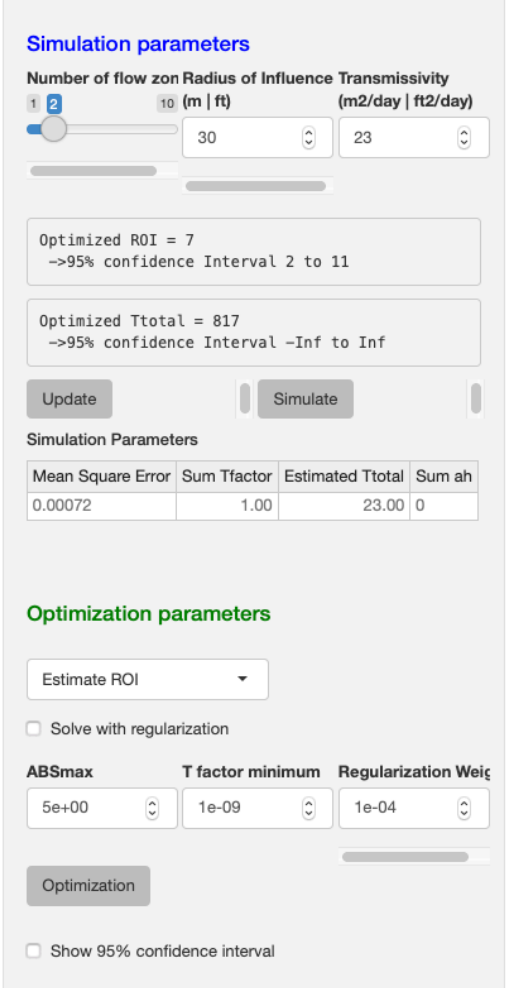

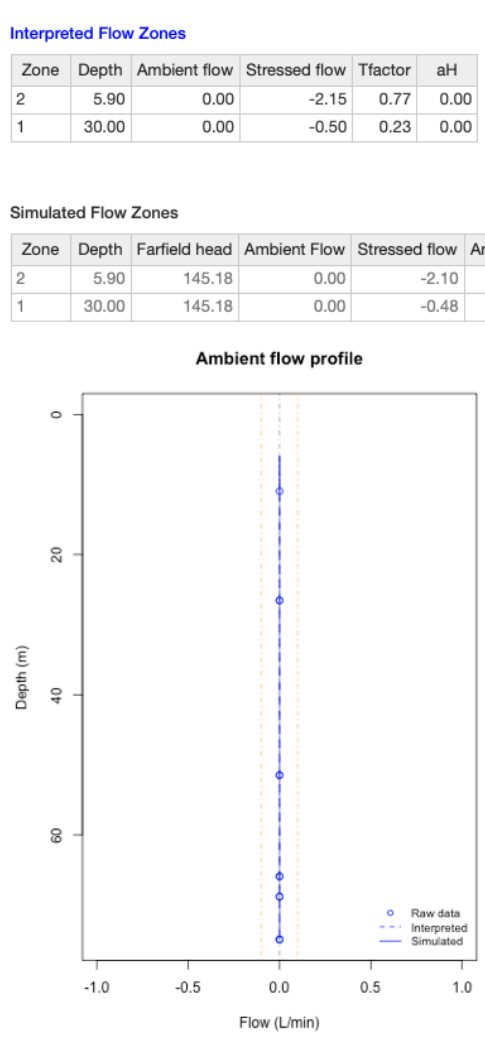

Optimization Results

Thactor aH

\begin{tabular}{l|l}
\hline 0.78 & 0.00 \\
\hline 0.22 & -0.00 \\
\hline
\end{tabular}

\section{Simulated Flow Zones}

Ambient error Stressed error Zone T Ttotal \%

Browse... $\quad$ HPF Fl.txt

\section{Flowmeter Upward Min}

Quantification Limit (L/min

Flowmeter Upward Max

Quantification Limit (L/min

Flowmeter Downward Min

Flowmeter Downward Max

$$
\text { i }
$$

Figura 5.30. Resultado da modelagem de fluxo do HPF no programa FLASH-R para o poço B3

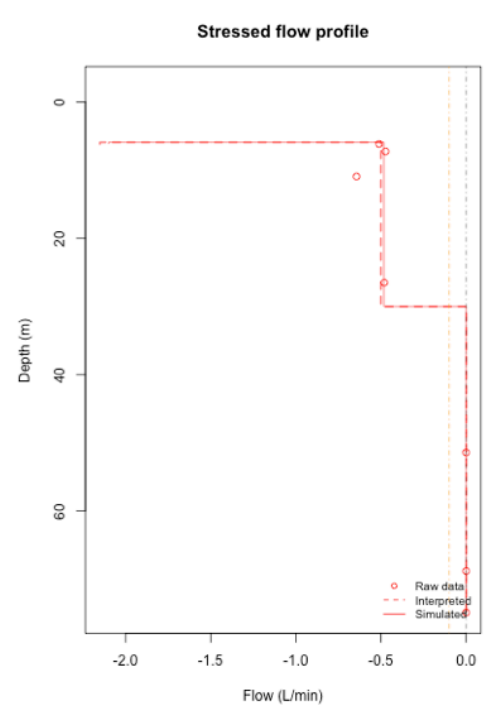




\section{₹USGS FLASH - Flow Log Analysis of Singl}

\begin{tabular}{|c|c|}
\hline Introduction & Borehole and Test \\
\hline \multicolumn{2}{|c|}{$\begin{array}{l}\text { Enter well and te } \\
\text { Measurement system }\end{array}$} \\
\hline Metric & v \\
\hline \multicolumn{2}{|c|}{ Type of Flow Zones } \\
\hline Fractures & v \\
\hline \multicolumn{2}{|l|}{ Well name: } \\
\hline B3 & \\
\hline \multicolumn{2}{|c|}{$\begin{array}{l}\text { Elevation of measuring point } \\
(\mathrm{m} \mid \mathrm{ft})\end{array}$} \\
\hline 152 & $\hat{\theta}$ \\
\hline \multicolumn{2}{|c|}{ Well diameter ( $\mathrm{mm}$ | in) } \\
\hline 152,4 & $\hat{\varepsilon}$ \\
\hline \multicolumn{2}{|c|}{$\begin{array}{l}\text { Depth to ambient water level } \\
(\mathrm{m} \mid \mathrm{ft})\end{array}$} \\
\hline 4,2 & $\hat{v}$ \\
\hline \multicolumn{2}{|c|}{ stress head $(m \mid f t)$} \\
\hline$-0,5$ & $\hat{\theta}$ \\
\hline \multicolumn{2}{|c|}{ Water level $=3.7$} \\
\hline \multicolumn{2}{|c|}{$\begin{array}{l}\text { Depth at bottom of casing }(\mathrm{m} \mid \\
\mathrm{ft} \text { ) }\end{array}$} \\
\hline 7 & $\hat{\theta}$ \\
\hline \multicolumn{2}{|c|}{ Depth at bottom of well $(m \mid f t)$} \\
\hline 77 & $\hat{v}$ \\
\hline
\end{tabular}

\author{
Flow Log Analysis
}

\section{ata}

Choose ambient flow txt File

\begin{tabular}{|l|l|}
\hline Browse... & EMF FA.txt
\end{tabular}

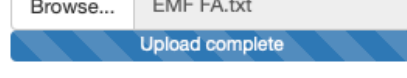

Choose pumped flow txt File

\begin{tabular}{|l|l|}
\hline Browse... EMF Fl.txt \\
\hline
\end{tabular}

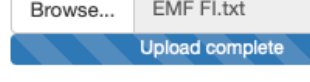

Separator

- Comma

Semicolon

Tab

Flowmeter Upward Min

Quantification Limit (L/min

Gal/min)

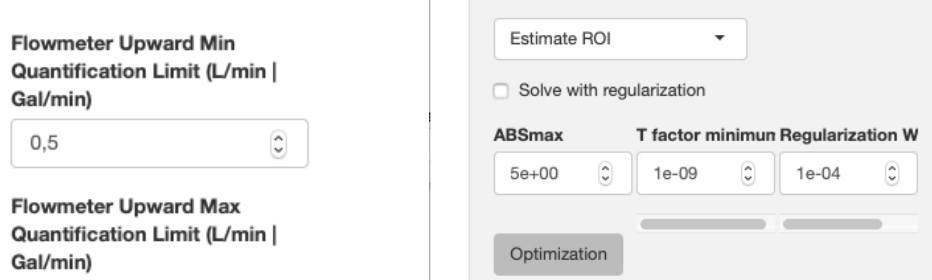

Quantification Limit (L/min

Gallming

30

Quantification Limit (L/min )

Gal/min)
Flowmeter Downward Max
Quantification Limit (Lmin
Gal/min)

$-30$

\section{Output my data}

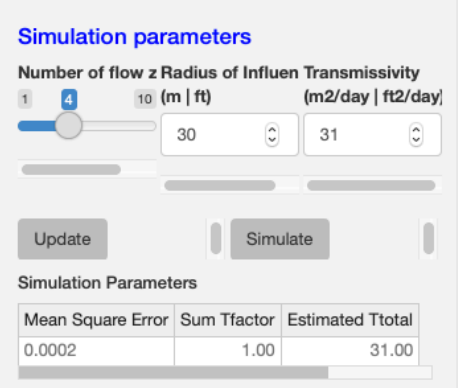

Optimization parameters

Show 95\% confidence interval

Interpreted Flow Zones
\begin{tabular}{|l|r|r|r|r|r|}
\hline Zone & Depth & Ambient flow & Stressed flow & Tfactor & aH \\
\hline 4 & 5.90 & 0.00 & -11.35 & 0.24 & 0.00 \\
\hline 3 & 12.60 & 0.00 & -8.60 & 0.29 & 0.00 \\
\hline 2 & 30.00 & 0.00 & -5.31 & 0.35 & 0.00 \\
\hline 1 & 50.00 & 0.00 & -1.38 & 0.12 & 0.00 \\
\hline
\end{tabular}

Simulated Flow Zones

Zone Depth Farfield head Ambient Flow Stressed flow Ambient error Stressed error Zone T Ttotal \%

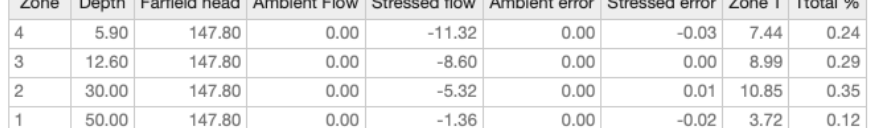

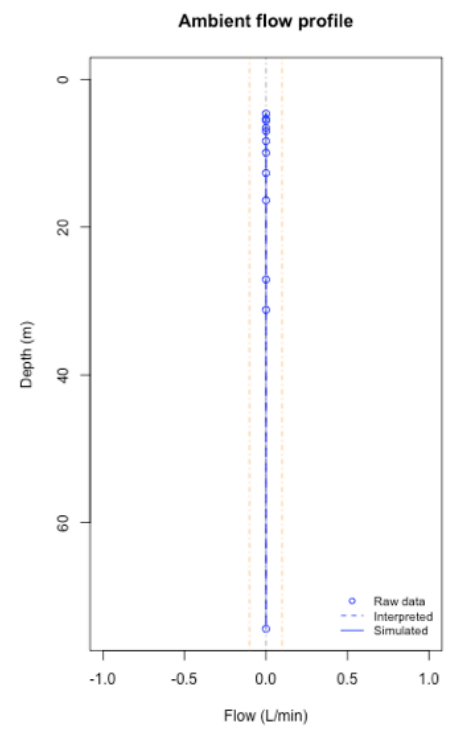

Optimization Results

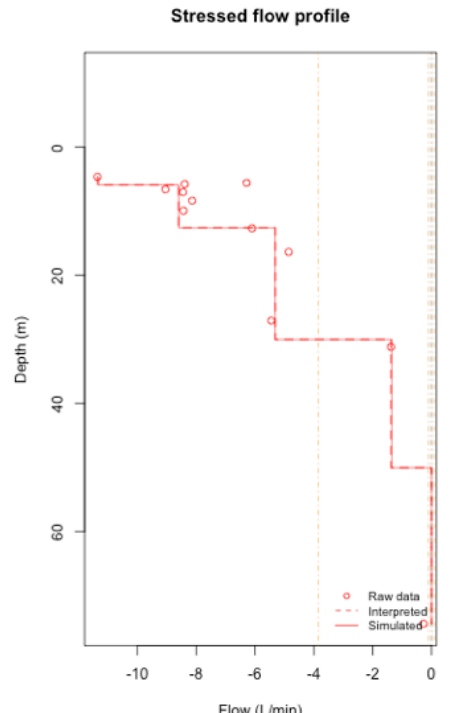

Figura 5.31. Resultado da modelagem de fluxo do EMF no programa FLASH-R para o poço B3 


\section{DISCUSSÃO}

O projeto e construção da MUST foi inspirado no trailer do grupo G360 (QUINN; CHERRY; PARKER, 2012) e no equipamento do USGS (SHAPIRO, 2001). A construção de uma unidade móvel deste tipo no Brasil impõe um serie de dificuldades com relação a disponibilidade de materiais, fornecedores e orçamento. Por se tratar de um projeto que compreende equipamentos e componentes específicos, em muitos casos a única opção foi a importação.

Para os materiais de consumo, buscou-se a substituição ou adaptação para fornecimento local, dada a necessidade de reposição constante, a instabilidade do dólar e a dificuldade de fazer o processo de importação. No caso dos obturadores, por exemplo, não foi encontrada uma alternativa local. A solução passa por um processo de desenvolvimento de equipamentos nacionais que substituam o importado. As principais diferenças entre os sistemas norte americanos e a MUST são apresentadas na Tabela 6.1.

O desenvolvimento da MUST demandou a integração de uma série de equipamentos e materiais. Ao longo dos trabalhos realizados, foram testados diferentes componentes e configurações a fim de aumentar a produtividade, melhorar a qualidade dos dados e o custo operacional. As principais considerações sobre os equipamentos, materiais e método de trabalho são descritas a seguir.

A montagem e movimentação da composição foi a atividade mais trabalhosa e de maior risco, tanto aos equipamentos quanto aos operadores. Os obturadores e componentes do sistema de movimentação (tripé, talha e corrente) são pesados, e no caso de uma operação manual de montagem na boca do poço, esta atividade se torna muito desgastante, demandando o uso de Equipamentos de Proteção Individual para a operação com segurança (bota com biqueira, capacete, luva óculos e protetor solar). Intervalos acima de um metro na composição tornam necessária a montagem em duas etapas, requerendo manobras adicionais para posicionar toda a composição dentro do furo. Nesses casos o ideal é ter um caminhão munck ou sistema de elevação com altura superior a seis metros. Isso também facilita a operação com tubos de aço ou PVC, possibilitando o uso de barras de seis metros de comprimento, reduzindo assim o número de manobras necessárias.

O maior risco aos equipamentos é a composição ficar travada ou cair no furo, sendo que a primeira pode causar a segunda. São dois os principais motivos de o equipamento ficar travado no poço por falhas operacionais. 
Tabela 6.1. Comparação entre os diferentes equipamentos para ensaio hidráulico e amostragem com obturadores, modelos norte americanos e a MUST

\begin{tabular}{|c|c|c|c|}
\hline Características & MUST & G360 & USGS \\
\hline $\begin{array}{l}\text { Movimentação } \\
\text { da composição } \\
\text { de obturadores }\end{array}$ & Guincho e corrente & $\begin{array}{l}\text { Guincho e cabo de aço } \\
\text { (sistema antigo) - } \\
\text { caminhão munck com } \\
\text { cabo de aço e tubulação } \\
\text { de metal (sistema atual) }\end{array}$ & $\begin{array}{l}\text { Caminhão munck com } \\
\text { cabo de aço e tubulação } \\
\text { de metal }\end{array}$ \\
\hline $\begin{array}{l}\text { monitoramento } \\
\text { da pressão nos } \\
\text { intervalos }\end{array}$ & $\begin{array}{c}\text { Transdutores } \\
\text { localizados nos } \\
\text { intervalos ou } \\
\text { mangueiras de acesso } \\
\text { ao intervalo e } \\
\text { transdutores } \\
\end{array}$ & $\begin{array}{l}\text { Transdutores } \\
\text { localizados nos } \\
\text { intervalos }\end{array}$ & \begin{tabular}{|c} 
Transdutores \\
localizados no topo da \\
composição com \\
sistema de válvulas para \\
comunicar com os \\
níveis superior e inferior \\
\end{tabular} \\
\hline $\begin{array}{l}\text { Componentes } \\
\text { utilizados nos } \\
\text { ensaios } \\
\text { hidráulicos }\end{array}$ & $\begin{array}{l}\text { Ensaio de pulso com ar } \\
\text { ou água; carga } \\
\text { constante com sistema } \\
\text { de tanque e bomba; e } \\
\text { injeção (sistema de } \\
\text { tanque e bomba) e } \\
\text { bombeamento (bomba } \\
\text { centrifuga) }\end{array}$ & $\begin{array}{l}\text { Ensaio de pulso com ar; } \\
\text { carga constante com } \\
\text { sistema de vaso de } \\
\text { pressão; e injeção } \\
\text { (sistema de vaso de } \\
\text { pressão) e bombeamento } \\
\text { (bomba centrifuga) }\end{array}$ & $\begin{array}{l}\text { Ensaio de pulso com } \\
\text { água; carga constante } \\
\text { com sistema de vaso de } \\
\text { pressão; e injeção } \\
\text { (sistema de vaso de } \\
\text { pressão) e bombeamento } \\
\text { (bomba centrifuga) }\end{array}$ \\
\hline Mobilidade & Trailer & $\begin{array}{c}\text { Trailer e caminhão } \\
\text { munck }\end{array}$ & $\begin{array}{c}\text { Componentes } \\
\text { organizados em caixas } \\
\text { para serem despachados } \\
\text { e montados em qualquer } \\
\text { lugar. Geralmente } \\
\text { alugam um trailer ou } \\
\text { montam tendas }\end{array}$ \\
\hline Amostragem & $\begin{array}{l}\text { Bomba centrífuga ou } \\
\text { sistema de ar } \\
\text { comprimido para baixa } \\
\text { vazão }\end{array}$ & $\begin{array}{c}\text { Bomba centrífuga ou de } \\
\text { bexiga }\end{array}$ & $\begin{array}{c}\text { Bomba centrífuga ou de } \\
\text { bexiga }\end{array}$ \\
\hline
\end{tabular}

O menos comum, mas de consequência grave, é a movimentação da composição para cima sem manter a tensão nos cabos e mangueira que descem junto. Caso essas sejam prensadas entre o obturador e a parede, há grandes chances de a composição travar e não subir ou descer até que se consiga empurrar o sistema para baixo e retirar os tubos e cabos. Uma forma de prevenir isso é manter a tração nos cabos e tubos durante a subida e amarralos na corrente num intervalo de $2 \mathrm{~m}$, nos primeiro $20 \mathrm{~m}$, e depois a cada $5 \mathrm{~m}$.

O mais comum é a composição ficar travada devido à expansão ou esmagamento da borracha dos obturadores (Figura 6.1), decorrente da variação da pressão diferencial interna e externa (coluna de água do poço). Quando isso ocorre, a borracha é danificada pelo atrito com a rocha. No caso do esmagamento, o lado que fica em contato com a rocha é sempre o mesmo, e vai se formando um sulco longitudinal na borracha, diminuindo a eficiência de isolamento dos obturadores. Para evitar este tipo de problema é necessário 
um controle rigoroso da pressão interna dos obturadores durante a movimentação. Para isso, também é necessário um controle da posição da composição no furo e do nível d'água.
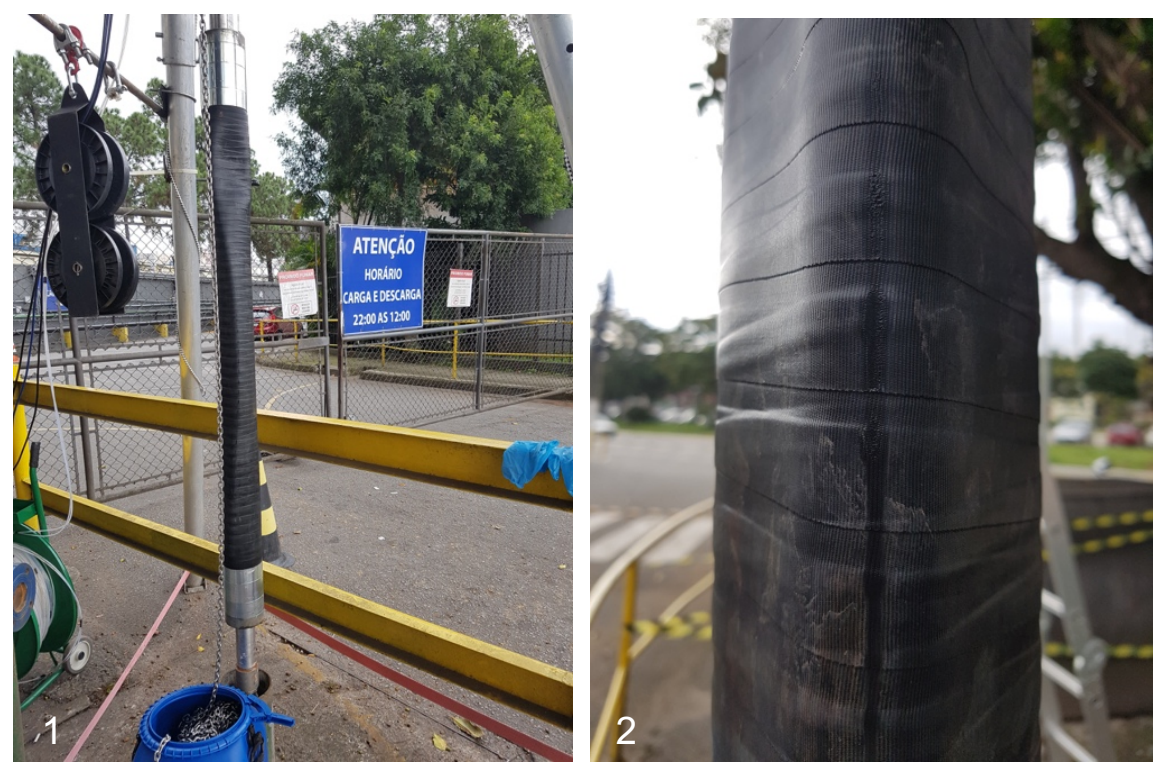

Figura 6.1. (1) obturador com a borracha esmagada pela pressão da coluna de água sendo retirado do poço 1204; (2) detalhe da borracha esmagada e o início da formação de um sulco longitudinal, que pode afetar o isolamento de intervalos durante a realização de ensaios

Uma solução que foi adotada para evitar o desgaste das borrachas importadas foi o uso de uma capa de borracha, presa ao obturador por uma abraçadeira metálica. Essa solução resolveu o problema, mas dificultou a movimentação do obturador no furo, em razão da redução do espaço livre entre a composição e o furo. Em poços de $150 \mathrm{~mm}$ de diâmetro, a folga passou de $40 \mathrm{~mm}$ para $20 \mathrm{~mm}$, o que na prática requer maior controle da pressão diferencial na borracha e aumenta a chance do equipamento travar devido à expansão e colapso da borracha. Quando isso acontece, existe o risco de a abraçadeira romper e a capa sair do obturador, o que pode causar um travamento pior que no caso da mangueira (Figura 6.2). Colocando em risco toda a composição, que pode ficar presa dentro do poço.

Casos extremos em que a composição fica travada dentro do poço não são comuns, mas podem ocorrer. Ao planejar o trabalho é importante que se saiba dos riscos, que pode resultar na perda do equipamento e até mesmo do poço. Sabendo dos riscos inerentes a atividade de ensaio e amostragem com obturadores, uma medida mitigatória das perdas em casos de acidentes é ter o menor número possível de equipamentos dentro do furo. 

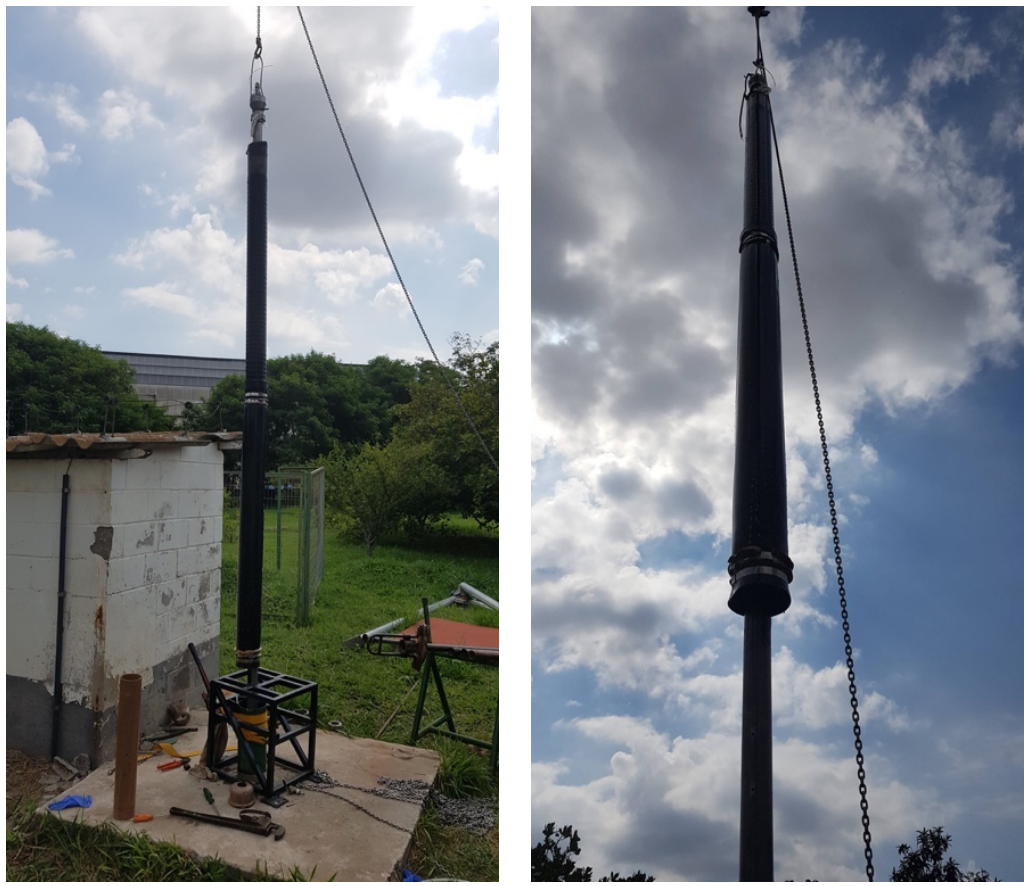

Figura 6.2. Trabalho em que o obturador ficou travado no poço e foi necessário o uso de caminhão munck para retira-lo do poço

As configurações de operação da MUST foram implementadas visando a redução de custo operacional e tempo de trabalho, sem prejuízo à qualidade dos dados produzidos. Embora não tenham sido realizados ensaios com as duas configurações em um mesmo poço, para uma comparação ideal, ambas foram testadas e documentadas em condições parecidas (características dos poços e contexto hidrogeológico). Os aspectos que se buscou avaliar foram: comparação entre as configurações dos ensaios (carga hidráulica, ensaio de pulos, de carga constante e bombeamento); operação e produtividade.

\section{Comparação entre as configurações}

O primeiro ensaio é o de estanqueidade, pelo qual se determina se o intervalo está isolado ou se existe vazamento pelos obturadores ou pela rede de fraturas. Geralmente, este é realizado pelo ensaio de pulso com ar ou água. A qualidade desse ensaio é determinada por dois fatores, a resolução do sistema de monitoramento de variação da pressão nos intervalos, e a magnitude do distúrbio aplicado. A configuração A tem uma resolução inferior ao B, por outro lado, o ensaio de pulso com ar tem maior volume de atuação. Portanto, ambas configurações são equivalentes desde que aplicado um distúrbio de volume adequado. Para o B, o pulso deve ser de pelo menos 5 metros.

Para o ensaio de pulso, a configuração A é mais adequada por ter um volume de propagação maior do ensaio com ar, com um mesmo deslocamento da coluna de água, sem sair do regime de fluxo laminar. Na configuração B o ensaio de pulso com água, que 
seria uma opção ao ensaio com ar, não foi bem sucedido por não causar um distúrbio instantâneo em razão do processo de abertura e fechamento da válvula pneumática.

O ensaio de carga constante com injeção apresentou resultado similar para as duas configurações em condições de nível d'água raso (inferior a 10 m). Em condições de nível d'água profundo, a configuração A teve melhores resultados, por possibilitar maior controle da pressão de injeção com uma válvula de retenção regulável acoplada ao miniobturador. No caso de ensaio com extração de água, a configuração A é a única que possibilita o isolamento do intervalo de teste e também produz resultados melhores. Para o ensaio de bombeamento ambas configurações obtiveram resultados parecidos.

Com relação a qualidade da amostragem, este trabalho não obteve dados suficientes para comparar as diferentes configurações. A principal diferença entre elas é a possibilidade de realizar a troca ou descontaminação dos materiais utilizados entre cada intervalo amostrado. O que se pode afirmar é que, com base nos trabalhos realizados, foi observada estratificação nas concentrações de compostos de interesse nas amostragens coletadas com a configuração $\mathrm{B}$, em que não é realizada troca de mangueiras $\mathrm{e}$ descontaminação entre amostras de um mesmo furo.

Outro aspecto com relação à qualidade do processo de amostragem com obturadores é o risco de contaminação cruzada decorrente da absorção que pode ocorrer nos materiais utilizados não são descartáveis (e.g. borracha dos obturadores, tubos de PVC, tubos de aço e bomba de amostragem). Em dois dos estudos de caso foram coletadas amostras de branco de equipamentos (INMETRO, 2019), em ambos casos não foram detectadas nenhuma das substâncias de interesse analisadas. O procedimento de coleta dessas amostras consistiu em enxaguar as borrachas, tubos e bomba com água destilada e envio para o laboratório (Figura 6.3).
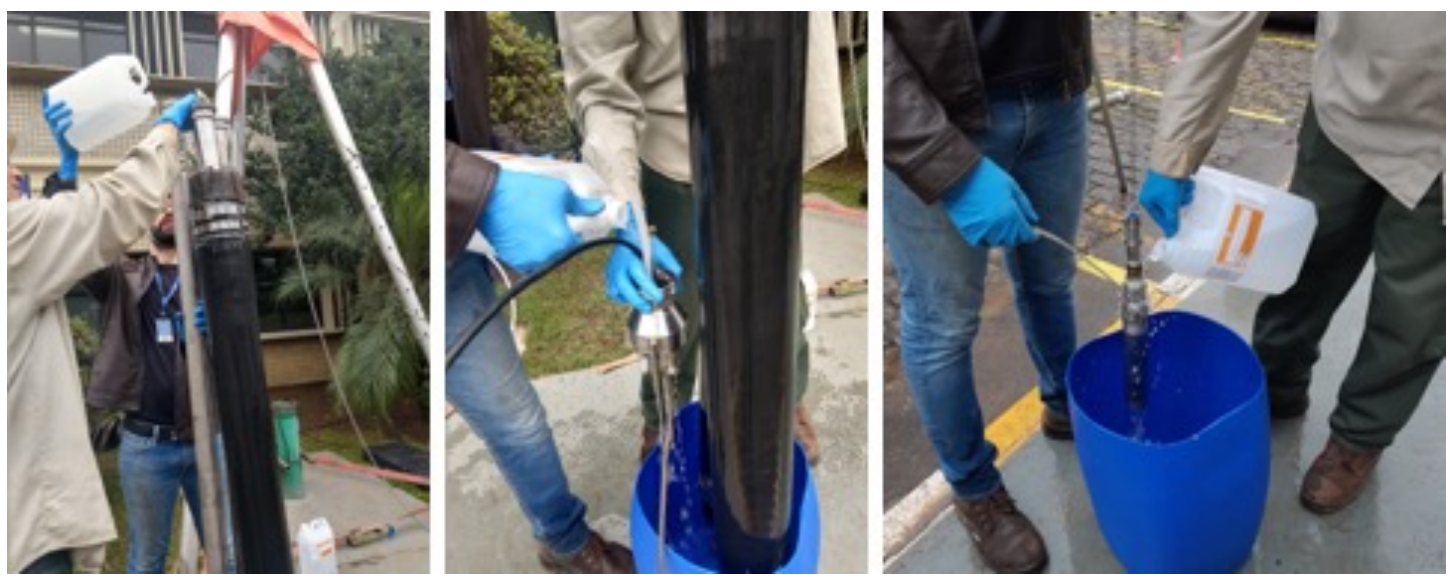

Figura 6.3. Coleta de amostra de branco de equipamento para controle de qualidade da amostragem e avaliação de contaminação cruzada pelos equipamentos 


\section{Operação e produtividade}

A comparação entre as configurações com relação à operação e produtividade depende dos tipos de ensaios realizados em cada estudo de caso específico. Por a configuração B não utilizar os tubos de PVC, sua operação é mais rápida. As mangueiras utilizadas nela são emendadas a cada $50 \mathrm{~m}$ com conexões de engate rápido e após o trabalho são descartadas. A configuração A demanda o acoplamento de tubos a cada $2 \mathrm{~m}$ e sua limpeza ao término do trabalho.

Fazendo um comparativo de horas, a configuração B leva metade do tempo da configuração A no processo de movimentação da composição, e cerca de $30 \%$ do tempo para a preparação do ensaio de bombeamento ou amostragem. Contudo, a maior parte do tempo utilizado na realização da amostragem é devido ao processo de purga e coleta, e não à montagem (que pode variar de 15 min para a configuração B para até 1 hora para a configuração A).

Por outro lado, a configuração A tem menos chance de acidentes envolvendo o travamento do equipamento no furo. Os tubos de PVC possibilitam empurrar a composição para baixo em casos de aumento na tensão da corrente ou travamento, e impedem que os tubos e cabos, quando bem amarrados, sejam prensados entre o obturador e a parede do furo.

Para que a produtividade da configuração A seja igual a B, é necessário o uso de um sistema de movimentação com um munck. O custo de mobilização e operação do sistema com um equipamento deste tipo não é elevado quando a etapa de coleta dos dados é eficiente e não ocorrem problemas operacionais ou acidentes.

Após quatro anos de pesquisa e desenvolvimento da MUST, conclui-se que não existe uma configuração ideal. Os objetivos e as especificidades de cada caso tornam necessária uma avaliação individual para adequar a unidade a cada projeto, conforme discutido no capítulo anterior. Portanto, é mais importante ter um sistema versátil, facilmente adaptável, do que uma configuração rígida pré-estabelecida.

\section{Método de caracterização}

As técnicas de caracterização de aquíferos fraturados foram empregadas em mais de trinta poços, que apresentavam características construtivas e hidrogeológicas distintas. A experiência prática adquirida possibilitou a organização de um método de trabalho para a aquisição e processamento de dados em campo. São compreendidos aspectos construtivos e físicos do poço; características da rocha; feições estruturais; e propriedades hidráulicas do poço e do aquífero. 
O método apresentado contempla o uso de 11 técnicas distintas, a maior parte delas geofísicas. Cada uma com sua especificidade e contribuição ao proposito geral de caracterizar as propriedades do poço da rocha e do aquífero. No entanto, não são raras situações em que é necessário priorizar técnicas e limitar o escopo de trabalho. Nestes casos, as sondas que garantem um escopo mínimo no maior número de cenários são, a câmera, a sonda acústica, o flowmeter (HPF ou EMF) e os obturadores. Com esta combinação é possível garantir a segurança do trabalho, identificar aspectos visuais do furo, registrar a variação de diâmetro ao longo do perfil, caracterizar feições estruturais, entender a dinâmica de fluxo dentro do poço, e obter parâmetros hidráulicos e hidroquímicos do aquífero.

A limitação de se trabalhar com um escopo reduzido é que situações adversas podem comprometer o trabalho e gerar incertezas quanto aos dados produzidos. As condições reais de trabalho são conhecidas conforme se avança com cada uma das técnicas e, portanto, as alternativas precisam estar disponíveis ou serem planejadas com antecedência.

O poço 255 ilustra essa situação, onde a perfilagem acústica não obteve bons resultados (Figura 6.4). Se a sonda ótica e o cáliper não estivessem disponíveis, a caracterização dos aspectos construtivos e estruturais de mais de $70 \%$ do furo não teria sido possível. Sem essa primeira parte os resultados da hidráulica teriam sido ainda mais comprometidos, tanto da etapa do HPF como dos obturadores.

Algumas técnicas não apresentam uma contribuição significativa para a caracterização hidrogeológica, especialmente se tratando de aquíferos em rochas cristalinas. São estas o gama, a resistividade, a FTCR e o SF. As duas primeiras são importantes para a caracterização estratigráfica de depósitos sedimentares, além de, no caso da resistividade curta, indicar problemas construtivos relacionado à infiltração de lama de perfuração na matriz da rocha, que pode resultar em diminuição da transmissividade. A sonda FTCR, embora auxilie na interpretação do fluxo, não é essencial para a caracterização hidráulica e tem resultados muito limitados. O SF dentre as três técnicas de flowmeter, é a que tem pior desempenho, que além de apresentar muito ruído nos dados, só consegue identificar alterações de fluxo muito elevadas.

Das técnicas de fluxo as que apresentaram melhor resultado foram o HPF, o EMF e os obturadores. As duas primeiras têm exatamente a mesma função embora algumas características tornem ambas complementares. O HPF tem resolução e limite de detecção de fluxo ideal para baixas vazões $(0,1$ a 5 l/min), o que é mais comumente observado nas 
condições de fluxo ambiente. O EMF tem ampla faixa de detecção $(0,5$ a 40 1/min), pode ser utilizado para medidas dinâmicas e estáticas e possui os sensores de temperatura e resistividade integrados.

Ensaios bem executados com flowmeters e interpretados com o programa FLASH permitem a obtenção, de maneira prática e rápida, as propriedades hidráulicas das principais zonas transmissivas que interceptam o poço. Dependendo dos objetivos do trabalho, esse tipo de ensaio pode ser suficiente para uma caracterização hidráulica eficiente. Caso um detalhamento hidráulico e hidroquímico seja necessário, o uso de obturadores pode complementar os dados hidráulicos obtidos por essas técnicas.

O uso de obturadores é a técnica mais robusta e confiável para a caracterização hidráulica em poços tubulares, com uma faixa de detecção de 6 ordens de magnitude para a transmissividade contra 2 do HPF. Além disso, as medidas de carga hidráulica são medidas diretas, por sensores ou medidores de nível, e não resultado de uma solução analítica, o que faz com que o dado seja confiável se coletado de maneira adequada. Obturadores também possibilitam a obtenção de um mesmo parâmetro hidráulico por diferentes ensaios, se adequando a condições variadas de campo e escala de trabalho. Cabe ressaltar que existem outros ensaios e técnicas que fazem uso de obturadores não abordados nesse trabalho (e.g. ensaios com traçadores)

A integração dos dados produzidos com o uso de obturadores e técnicas geofísicas é importante, especialmente quando se dispõe de grande quantidade de dados. Sem a avaliação conjunta dos dados perde-se eficiência e qualidade na caracterização do furo e sua interação com o aquífero. O gerenciamento dos dados, a visualização, a comparação e a interpretação conjunta são otimizadas com o uso de uma ferramenta como o WellCad. 


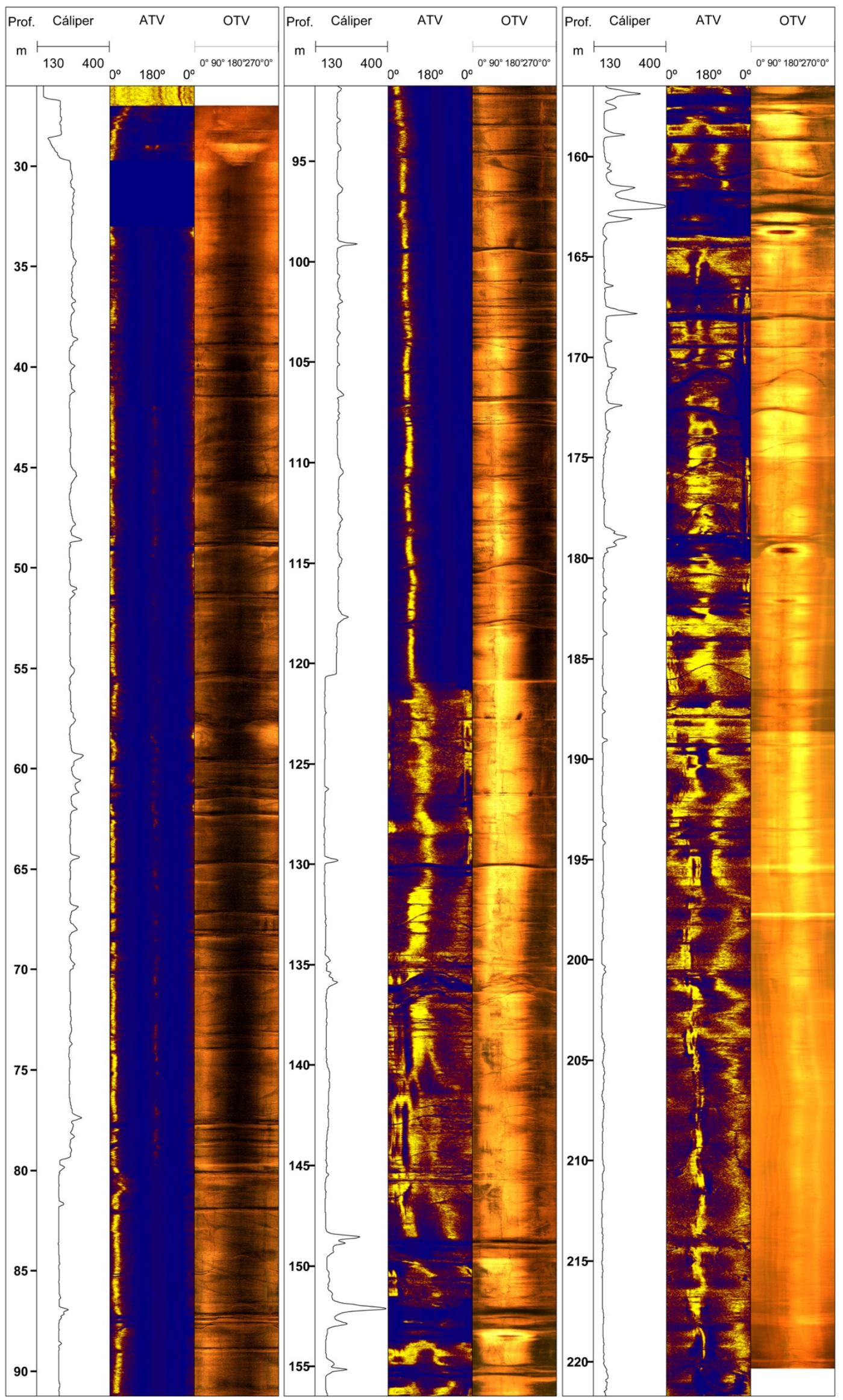

Figura 6.4. Resultados das perfilagens cáliper, ATV e OTV para o poço 255. As manchas azuis escuras no perfil do ATV são resultado da descentralização da sonda no furo 
A partir da análise integrada dos dados conclui-se que, em geral, há uma boa correlação entre os dados obtidos pelos flowmeters (HPF e EMF) e os obturadores, confirmando o observado em outros estudos (BORGNE et al., 2007; LO et al., 2014; MIYAKAWA et al., 2000; PAILLET, 2004). O uso de flowmeters é muito importante para uma avaliação geral do fluxo (dados semi quantitativos), direcionando a etapa com obturadores. Esta combinação de técnicas reduz custo e tempo de execução, e melhora a qualidade do trabalho.

Os resultados obtidos nos mais de 20 poços ensaiados com o HPF e obturadores confirmam o observado por Long e Billaux (1987), de que em um furo são poucas as fraturas (cerca de 1\%) que contribuem para o fluxo em larga escala. Por isso, é ideal que se utilize os ensaios com flowmeters e FTCR para mapear as zonas hidraulicamente ativas, e definir os trechos de interesse para aprofundar as atividades de caracterização com obturadores, que requerem mais tempo e tem maior custo.

No caso da caracterização hidroquímica, amostras discretas em furos abertos só podem ser obtidas com o uso de obturadores, ainda assim, sujeitas a vazamentos em trechos irregulares do furo. Amostras de intervalos cujo potencial hidráulico é superior à carga hidráulica média do poço, são representativas de um compartimento do aquífero, já que em condições normais vertem água para o poço. Por outro lado, as amostras com potencial hidráulico inferior, recebem água de mistura do poço. Isto gera uma incerteza com relação à representatividade da amostra coletada nestes intervalos. Em ambos os casos, é importante que seja realizada a purga da água de mistura do poço e monitorados os parâmetros físico químicos. No caso de zonas que recebem água do poço, quanto maior o tempo de isolamento e o volume de purga, mais representativa tende a ser a água daquele compartimento hidráulico.

A partir da experiência adquirida da aplicação prática das técnicas mencionadas, foi elaborada uma tabela comparativa das técnicas utilizadas (Tabela 6.2) para auxiliar na escolha das ferramentas mais adequadas para projetos de caracterização de aquíferos fraturados utilizando poços tubulares. Além dos aspectos técnicos, foram levados em consideração o tempo de execução, o custo e a complexidade de coleta e processamento dos dados. 
Tabela 6.2. Análise comparativa das técnicas utilizadas no método de caracterização de aquíferos fraturados por meio de poços tubulares

\begin{tabular}{|c|c|c|c|c|c|c|c|c|c|c|c|c|}
\hline \multicolumn{2}{|r|}{$\begin{array}{l}\text { Característica } \\
\text { avaliada }\end{array}$} & Câmera & Cáliper & Gama & OTV & ATV & Resistividade & FTCR & $\mathrm{HPF}$ & EMF & SFM & $\begin{array}{l}\text { Obturadores } \\
\text { pneumáticos }\end{array}$ \\
\hline \multicolumn{13}{|c|}{ Custo de execução } \\
\hline \multicolumn{2}{|c|}{ Tempo de execução } & & & & & & & & $\begin{array}{c}\text { Além dos } \\
\text { ensaios } \\
\text { tempo de } \\
\text { estabilização } \\
\text { do NA } \\
\end{array}$ & $\begin{array}{c}\text { Além dos } \\
\text { ensaios } \\
\text { tempo de } \\
\text { estabilização } \\
\text { do NA } \\
\end{array}$ & & \\
\hline \multicolumn{2}{|r|}{$\begin{array}{l}\text { Complexidade na } \\
\text { coleta de dados }\end{array}$} & & & & & & & & & & & \\
\hline \multicolumn{2}{|c|}{$\begin{array}{l}\text { Complexidade no } \\
\text { processamento e } \\
\text { interpretação dos } \\
\text { dados }\end{array}$} & & & & & & & & & & & \\
\hline & $\begin{array}{l}\text { Precisão } \\
\text { da medida }\end{array}$ & $\begin{array}{l}\text { Qualidade } \\
\text { da imagem } \\
\text { ruim }\end{array}$ & $\begin{array}{c}\text { Diâmetro } \\
\text { médio, } \\
\text { não } \\
\text { identifica } \\
\text { estruturas } \\
\text { menores }\end{array}$ & & & & & & & & & \\
\hline \multirow{7}{*}{\begin{tabular}{l}
0 \\
0 \\
0 \\
0 \\
0 \\
0 \\
.0 \\
\hdashline \\
0 \\
0 \\
0
\end{tabular}} & $\begin{array}{c}\text { Rocha } \\
\text { sedimentar }\end{array}$ & & & & & & & & & & & \\
\hline & Rocha cristalina & & & & & & & & & & & \\
\hline & Turbidez da água & & & & & & & $\begin{array}{c}\text { Desde que } \\
\text { não impeça } \\
\text { a leitura }\end{array}$ & $\begin{array}{l}\text { Desde que } \\
\text { não impeça } \\
\text { a leitura }\end{array}$ & $\begin{array}{c}\text { Desde que } \\
\text { não impeça } \\
\text { a leitura }\end{array}$ & $\begin{array}{c}\text { Desde que } \\
\text { não impeça } \\
\text { a leitura }\end{array}$ & \\
\hline & $\begin{array}{l}\text { Incrustação nas } \\
\text { paredes do furo }\end{array}$ & & & & & & & $\begin{array}{c}\text { Desde que } \\
\text { não impeça } \\
\text { a leitura }\end{array}$ & $\begin{array}{c}\text { Desde que } \\
\text { não impeça } \\
\text { a leitura } \\
\end{array}$ & $\begin{array}{c}\text { Desde que } \\
\text { não impeça } \\
\text { a leitura } \\
\end{array}$ & $\begin{array}{c}\text { Desde que } \\
\text { não impeça } \\
\text { a leitura } \\
\end{array}$ & \\
\hline & Furos irregulares & & & & & & & & $\begin{array}{c}\text { Difícil } \\
\text { interpretação }\end{array}$ & $\begin{array}{l}\text { Medidas } \\
\text { estáticas e } \\
\text { dinâmicas }\end{array}$ & $\begin{array}{l}\text { Medidas } \\
\text { estáticas e } \\
\text { dinâmicas }\end{array}$ & $\begin{array}{l}\text { Dificuldade } \\
\text { de isolar } \\
\text { intervalos }\end{array}$ \\
\hline & Poços revestidos & & & & & & & & & & & \\
\hline & $\begin{array}{l}\text { Volume/raio de } \\
\text { investigação }\end{array}$ & & & & & & & & & & & $\begin{array}{l}\text { Varia de } \\
\text { acordo com } \\
\text { o ensaio }\end{array}$ \\
\hline \multirow{4}{*}{ 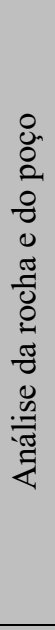 } & Diâmetro do furo & qualitativo & $\begin{array}{l}\text { Diâmetro } \\
\text { médio }\end{array}$ & & & $\begin{array}{c}\text { Diâmetro } \\
360^{\circ}\end{array}$ & & & & & & \\
\hline & $\begin{array}{l}\text { Irregularidade do } \\
\text { furo }\end{array}$ & & & & & $\begin{array}{c}\text { Perda do } \\
\text { sinal em } \\
\text { paredes } \\
\text { muito } \\
\text { irregulares } \\
\end{array}$ & & & & & & \\
\hline & $\begin{array}{c}\text { Caracterização } \\
\text { litológica e } \\
\text { aspectos da rocha }\end{array}$ & $\begin{array}{l}\text { Imagens } \\
\text { da rocha }\end{array}$ & & $\begin{array}{l}\text { Resposta } \\
\text { qualitativa }\end{array}$ & $\begin{array}{l}\text { Imagem de } \\
\text { alta } \\
\text { resolução }\end{array}$ & $\begin{array}{c}\text { Contraste } \\
\text { na } \\
\text { amplitude } \\
\text { do sinal } \\
\end{array}$ & $\begin{array}{l}\text { Resposta } \\
\text { qualitativa }\end{array}$ & & & & & \\
\hline & $\begin{array}{l}\text { Estruturas da } \\
\text { rocha (fraturas) }\end{array}$ & qualitativo & & & $\begin{array}{l}\text { Fraturas; } \\
\text { estruturas } \\
\text { dúcteis; } \\
\text { bandamento }\end{array}$ & $\begin{array}{l}\text { Fraturas; } \\
\text { breakouts }\end{array}$ & & & & & & \\
\hline \multirow{6}{*}{ 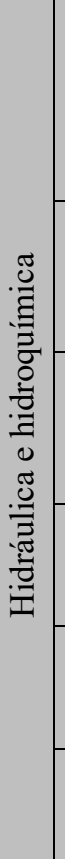 } & $\begin{array}{l}\text { Identificação de } \\
\text { atividade } \\
\text { hidráulica }\end{array}$ & $\begin{array}{l}\text { Apenas } \\
\text { fora } \\
\text { d'água ou } \\
\text { feições de } \\
\text { fluxo }\end{array}$ & $\begin{array}{l}\text { Apenas } \\
\text { abertura } \\
\text { aparente }\end{array}$ & & $\begin{array}{l}\text { Apenas fora } \\
\text { d'água ou } \\
\text { feições de } \\
\text { fluxo }\end{array}$ & $\begin{array}{l}\text { Apenas } \\
\text { abertura } \\
\text { aparente }\end{array}$ & & $\begin{array}{l}\text { Principais } \\
\text { zonas }\end{array}$ & $\begin{array}{l}\text { Principais } \\
\text { zonas }\end{array}$ & $\begin{array}{l}\text { Principais } \\
\text { zonas }\end{array}$ & $\begin{array}{c}\text { Principais } \\
\text { zonas }\end{array}$ & \\
\hline & $\begin{array}{c}\text { Determinação de } \\
\text { cargas } \\
\text { hidráulicas }\end{array}$ & & & & & & & & $\begin{array}{c}\text { Modelagem } \\
\text { dos dados }\end{array}$ & $\begin{array}{c}\text { Modelagem } \\
\text { dos dados }\end{array}$ & $\begin{array}{c}\text { Modelagem } \\
\text { dos dados }\end{array}$ & \\
\hline & $\begin{array}{l}\text { Determinação de } \\
\text { transmissividades }\end{array}$ & & & & & & & & $\begin{array}{c}\text { Modelagem } \\
\text { dos dados }\end{array}$ & $\begin{array}{c}\text { Modelagem } \\
\text { dos dados }\end{array}$ & $\begin{array}{c}\text { Modelagem } \\
\text { dos dados }\end{array}$ & \\
\hline & Fluxo elevado & & & & & & & $\begin{array}{c}\text { Pouca } \\
\text { interferência }\end{array}$ & $\begin{array}{c}\leq 81 / \min \\
\text { sem diverter }\end{array}$ & $\begin{array}{c}\leq 40 \mathrm{l} / \mathrm{min} \\
\text { com diverter }\end{array}$ & $\leq 7501 / \min$ & \\
\hline & Fluxos baixos & & & & & & & $\begin{array}{l}\text { Perfilar } \\
\text { devagar }\end{array}$ & $\geq 0,11 / \mathrm{min}$ & $\begin{array}{l}\geq 0,5 \\
1 / \mathrm{min}\end{array}$ & $\geq 10 \mathrm{l} / \mathrm{min}$ & \\
\hline & Hidroquímica & & & & & & & $\begin{array}{l}\text { Cunha } \\
\text { salina }\end{array}$ & & & & \\
\hline & Legenda & \multicolumn{3}{|c|}{ Não aplicável } & \multicolumn{3}{|c|}{ Contribui mas não é a finalidade } & Atende $\mathrm{p}$ & cialmente & \multicolumn{3}{|c|}{ Atende integralmente } \\
\hline
\end{tabular}

*NA não aplicável 
Com relação ao uso de poços tubulares para estudos de aquíferos fraturados, em situações reais, o uso dos poços é importante para a maior parte das estratégias que se tenha conhecimento. Além dos poços tubulares serem encontrados com frequência em áreas onde o aquífero fraturado está acessível para abastecimento, eles possibilitam o seu acesso de maneira rápida e com baixo custo.

O principal aspecto que influencia a qualidade dos dados obtidos de poços tubulares é o método de perfuração. Os poços de abastecimento são perfurados pelo método de percussão, roto percussão ou rotativo, este último com menor frequência por ter um custo maior. Os dois primeiros são mais destrutivos; geram irregularidades nas paredes do poço com maior frequência e intensidade; resultam em desvio direcional maior; criam bolsões em locais de menor resistência da rocha (e.g. zona de fraturas ou fraqueza da rocha); e apresentam maior risco de caimento das paredes. Portanto, este é um critério importante para seleção de poços, priorizando aqueles perfurados pelo método rotativo.

O segundo aspecto que mais influencia a qualidade dos dados é a condição em que o poço se encontra, que está relacionada à sua construção, idade, manutenção, características da rocha e composição química da água.

As características construtivas são: diâmetro de perfuração, em alguns casos isso pode variar ao longo do furo; proteção sanitária, que evita a percolação de água superficial, sedimentos e contaminantes para dentro do poço; o selo e o revestimento da porção porosa ou de menor estabilidade da rocha, consequentemente com maior propensão a caimentos; e a captação de água da porção porosa, por meio da instalação de tubo filtro.

A idade do poço comumente está relacionada ao seu estado de preservação. Poços antigos sem manutenção preventiva tem maior chance de apresentar desgaste, rompimento do revestimento, acúmulo de incrustação e sujeira. As características da rocha e da água são responsáveis pelo acúmulo de material em suspensão; incrustação nas paredes do poço; colmatação de fraturas; e corrosão de revestimentos metálicos.

A câmera tem como principal função identificar a atual situação do poço, que pode estar impróprio para o trabalho, sendo necessária a limpeza prévia, ou ser inapto para o trabalho, por colocar em risco os equipamentos ou por não apresentar as características adequadas ao estudo (e.g. poço inteiro revestido).

A atividade de limpeza é muito comum no mercado de perfuração de poços. A escolha do método mais adequado deve levar em consideração o objetivo do trabalho, as características construtivas e hidráulicas do poço, e os equipamentos e insumos disponíveis pelos prestadores 
de serviço locais. O mais comum é o tratamento químico com substâncias desincrustantes, seguido do bombeamento da água pelo método de airlift (injeção de ar com pressão), e desinfecção com cloro.

A escovação das paredes do poço é importante para garantir a qualidade da filmagem e da perfilagem ótica. Especialmente quando há muita incrustação nas paredes.

A forma como é realizado o bombeamento por airlift tem impacto na eficiência da remoção do material em suspensão e incrustado. O mais indicado, é que se faça o bombeamento em diferentes profundidades, do fundo para o topo, com a saída de água pela boca do tubo de revestimento. Isso faz com que toda a coluna de água seja retirada, carregando todo o material indesejado. No entanto, em situações de nível d’água profundo, é comum o uso de um tubo auxiliar, de menor diâmetro, para extração da água. 


\section{CONCLUSÕES}

Este trabalho apresenta uma avaliação de técnicas para a caracterização de aquíferos fraturados por meio de poços tubulares e propõe um método de trabalho otimizando os recursos disponíveis. A robustez do método reside na obtenção dos parâmetros mais sensíveis ou mais importantes por diferentes técnicas, o que permite uma análise de sensibilidade e confiabilidade dos dados para tomadas de decisão no âmbito do projeto em execução. A aplicação do método de trabalho em poços tubulares em aquíferos fraturados configura uma condição de trabalho desafiadora e complexa quando comparado às demais condições de trabalho. Portanto, sua aplicação em sondagens e aquíferos sedimentares pode ser feita sem grandes alterações. Contudo, nos casos de aquíferos sedimentares outras técnicas podem ser incorporadas como potencial espontâneo, gama espectral, onda ultrassônica (full wave sonic).

Este trabalho contemplou o aprimoramento da técnica de modelagem de fluxo em furos abertos, para ensaios com flowmeter, que resultou em uma nova versão do programa FLASH. Esta versão melhorou a compatibilidade do programa com outros idiomas (inglês e português), unidades de medidas (SI e imperial) e sistemas operacionais (todas as plataformas e por navegador da internet). Além disso, por se tratar de programa desenvolvido em plataforma livre, com código fonte aberto, o programa possibilita sua atualização e melhoria continua pelos usuários finais.

A unidade móvel desenvolvida para ensaios hidráulicos e amostragem com obturadores em intervalos discretos do poço/furo se mostrou um equipamento eficiente e versátil para a caracterização hidráulica e hidroquímica. Nos estudos de caso foi demonstrado o método de trabalho para a obtenção dos parâmetros carga hidráulica, transmissividade e para a coleta de amostras de água representativas de estruturas que interceptam o poço. A configuração utilizada permite a quantificação da transmissividade na faixa de $\mathrm{E}^{-3} \mathrm{a} \mathrm{E}^{-8} \mathrm{~m}^{2} / \mathrm{s}$ para ensaios tipo pulso e carga constante, e até $\mathrm{E}^{-2} \mathrm{~m}^{2} / \mathrm{s}$ para ensaios de bombeamento. Outros tipos de ensaios hidráulicos podem ser realizados com a unidade móvel e que não fizeram parte deste trabalho (e.g. ensaios de perda d'água, fluxo dipolo, traçadores).

O maior desafio para a construção e operação da unidade móvel foi a falta de componentes nacionais. O processo de importação dificulta o acesso a materiais de consumo que tem custo elevado (e.g. borrachas dos obturadores) além de estar sujeito à variação do dólar. Para evitar este tipo de dificuldade seria necessário o desenvolvimento de fornecedores locais. 
O método de trabalho foi desenvolvido a partir da aplicação das técnicas de caracterização em 29 poços tubulares e foi constatado que a sequência de trabalho apresentada em três etapas (preliminar, geofísica e ensaios hidráulicos e amostragem com obturadores) é a mais adequada para evitar complicações na coleta de dados e obter bons resultados.

Foram utilizadas dez técnicas geofísicas e testadas duas configurações de trabalho com obturadores. Cada uma destas com características próprias, e que contribuem de maneira distinta para a caracterização das propriedades do poço, da rocha e do aquífero. No entanto, nos casos em que não se dispõe de recurso ou tempo, as sondas que garantem um escopo mínimo no maior número de cenários possíveis são, a câmera, a sonda acústica, o flowmeter (HPF ou EMF) e os obturadores. Esta combinação, em geral, permite uma caracterização adequada e com segurança das características do poço, da rocha e do aquífero.

A comparação entre as técnicas geofísicas resultou numa tabela que auxilia a tomada de decisão sobre quais os métodos mais adequados para cada projeto específico (TABLEA). Apesar de algumas sondas serem mais versáteis que outras, a combinação de todas as técnicas utilizadas garante maior robustez ao método e contribuem para um resultado representativo. Dentre as técnicas de imageamento, a sonda ótica apresentou a melhor resolução e qualidade de imagem. Por outro lado, a sonda acústica é a que cobre o maior número de cenários e que serve tanta para a caracterização estrutural quanto para medir variação de diâmetro tridimensional.

Com relação aos flowmeters, o magnético (EMF) apresentou o melhor resultado por permitir maior faixa de medição, e registro de fluxo estático (pontual) e dinâmico (com movimentação da sonda). O flowmeter de pulso de calor (HPF) também apresentou bons resultados, mas tem como limitação a faixa de vazão que este tipo de sonda mede (de 0,1 a 4 L/min). Já o Spinner flowmeter (SF) apresentou resultados menos precisos e com bastante ruído, dificultando sua utilização em condições de fluxo natural e, portanto, em modelagens no FLASH-R.

O uso de obturadores para ensaio hidráulico e amostragem é a atividade que demanda mais tempo e recursos. Portanto, antes do seu uso é importante realizar o ensaio com o flowmeter, em condições ambiente e de fluxo induzido, para conhecer a dinâmica de fluxo do poço e principais zonas hidraulicamente ativas. Com isso, é possível reduzir o número de manobras da composição de obturadores e focar nos intervalos de interesse, aumentando a eficiência em campo. 
Com relação às configurações de trabalho com obturadores, a configuração B demanda menos tempo de execução. A movimentação com a talha elétrica e o munck se mostraram a maneira mais segura de fazer a movimentação da composição, sendo que a segunda tem um custo maior que a primeira ( $\mathrm{R} \$ 600,00$ a $\mathrm{R} \$ 1.500,00$ por dia de trabalho). O uso fita métrica reforçada foi a melhor solução encontrada para o controle da profundidade da composição. Diante dos riscos que envolvem a descida de equipamentos em furos irregulares, ter o menor número de equipamentos acoplados à composição é uma medida que mitiga perdas e danos aos equipamentos.

A amostragem de água pela configuração A permite a descontaminação do conjunto de equipamentos utilizados para amostragem e troca da mangueira, o que torna essa a mais adequada para evitar a contaminação cruzada entre diferentes intervalos. Com relação aos equipamentos da composição, que não são descontaminados durante a operação em um poço não realizado nenhum estudo mais aprofundado que comprove não haver contaminação cruzada entre intervalos. Por outro lado, a coleta de brancos de equipamento antes do início de um novo trabalho, após sua descontaminação em trabalhos anteriores, não apresentaram a presença de contaminantes, indicando que o processo de limpeza e descontaminação com água pressurizada e sabão neutro foram eficientes.

O uso de poços tubulares existentes constituem uma etapa importante que compõe uma estratégia de caracterização de aquíferos fraturados, levando em consideração a complexidade desses aquíferos e a dificuldade de acesso. Um aspecto importante a ser levado em consideração e discutido com as partes envolvidas antes de realizar qualquer trabalho em poços tubulares é o risco de acidentes. Não são raros os casos em que os equipamentos inseridos no poço ficam presos, podendo resultar até mesmo na perda do poço, ou parte dele. A partir da experiência adquirida por meio dos estudos de caso conclui-se que os principais aspectos que influenciam a qualidade dos trabalhos em poços tubulares são:

1. método utilizado na perfuração do poço;

2. condição em que o poço se encontra;

3. preparação adequada da etapa de campo

4. sequência de execução das técnicas de caracterização;

5. procedimentos de coleta de dados; e

6. procedimentos de processamento e análise dos dados. 
Existem técnicas que não fizeram parte deste projeto, mas são adequadas à caracterização de aquíferos fraturados e podem ser acrescentadas em trabalhos futuros, como ensaios entre poços. Estes ensaios possibilitam obter informações da rede de fraturas em furos abertos (PAILLET, 1993; WILLIAMS; LACOMBE; JOHNSON, 2007; WILLIAMS; PAILLET, 2002). São três as dificuldades de se realizar este tipo de ensaio: (1) são necessários dois poços próximos, um para monitoramento e outro para ensaio com oflowmeter; (2) os poços precisam estar hidraulicamente conectados por uma fratura ou pela rede de fraturas; e (3) ocorrência de interferências (bombeamento ou injeção) de outros poços próximos em uso durante o ensaio, podem comprometer os resultados.

Em suma, este trabalho visa contribuir com o desenvolvimento desta área do conhecimento, bem como atualizar e incorporar técnicas amplamente utilizadas no exterior. Os aquíferos fraturados estão presentes em grande parte do território brasileiro, e são um recurso essencial ao desenvolvimento social e econômico do país pelos serviços ambientais que prestam. 


\section{REFERÊNCIAS BIBLIOGRÁFICAS}

ALMEIDA, F. D., HASUI, Y., BRITO NEVES, B. B., FUCK, R. A. Províncias estruturais brasileiras. In: SIMPÓSIO DE GEOLOGIA DO NORDESTE, 8, 1977. p363-391.

BARBOSA, M.B., TERRY, N., DAY-LEWIS, F.D., BERTOLO, R. AND LANE, J.W., JR. A New R Program for Flow-Log Analysis of Single Holes (FLASH-R). Groundwater, 2020. doi:10.1111/gwat.12994

BARBOSA, M. B. Sistema de informações geográficas aplicado ao gerenciamento da contaminação da antiga ZUPI 131, Jurubatuba, São Paulo. 2015. Dissertação (Mestrado) Instituto de Geociências, 2015.

BEAR, J. Dynamics of fluids in porous media, AM. Elsevier, New York, 1972.

BECKER, K.; FISHER, A. T. Borehole packer tests at multiple depths resolve distinct hydrologic intervals in 3.5-Ma upper oceanic crust on the eastern flank of Juan de Fuca Ridge. Journal of Geophysical Research: Solid Earth, v. 113, n. 7, p. 1-12, 2008.

BERKOWITZ, B. Characterizing flow and transport in fractured geological media: A review. Advances in Water Resources, v. 25, n. 8-12, p. 861-884, 2002.

BORGNE, T. LE et al. Comparison of alternative methodologies for identifying and characterizing preferential flow paths in heterogeneous aquifers. p. 134-148, 2007.

BREDEHOEFT, J. Models and model analysis. Ground Water, v. 48, n. 3, p. 328, 2010.

BUSSE, J. et al. Field performance of the heat pulse flow meter: Experiences and recommendations. Journal of Applied Geophysics, v. 126, p. 158-171, 2016.

CAMPBELL SCIENTIFIC, disponível em: $<$ https://www.campbellsci.com.br/>. Acesso em: 07set. 2019.

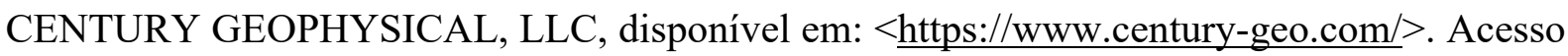
em: 07set. 2019.

CHERRY, J. A.; PARKER, B. L.; KELLER, C. A new depth-discrete multilevel monitoring approach for fractured rock. Ground Water Monitoring and Remediation, v. 27, n. 2, p. 5770, 2007.

CLAUSER, C. Permeability of crystalline rocks. Eos, Transactions American Geophysical Union, v. 73, n. 21, p. 233-233, 26, 1992.

COLLIER, H. A. Borehole Geophysical Techniques for Determining the Water Quality and Reservoir Parameters of Fresh and Saline Water Aquifers in Texas, 1993.

COOK, Peter G. A guide to regional groundwater flow in fractured rock aquifers. Henley Beach, South Australia: Seaview Press, 2003.

COUTINHO, J. M. V. carta geológica da região metropolitana da grande São Paulo, São Paulo: EMPLASA, 1980. Escala 1:100.00.

DAY-LEWIS, F. D., JOHNSON, C. D., PAILlET, F. L., \& HALFORD, K. J. A Computer Program for Flow-Log Analysis of Single Holes (FLASH). Ground Water, v. 49, n. 6, p. 926-931, 2011.

DOMENICO, P. A.; SCHWARTZ, F. W. Physical and Chemical Hydrogeology. 2 ed. New York: John Wiley and Sons, 1990. 
EBERT, H. Ocorrências de fácies granulíticas no sul de Minas Gerais e em áreas adjacentes em dependência da estrutura orogênica: hipóteses sobre sua origem. Anais da Academia Brasileira de Ciências, 40, 215-229, 1968.

ELSWORTH, D.; DOE, T. W. Application of Non-linear Flow Laws in Determining Rock Fissure Geometry From Single Borehole Pumping Tests. International Journal of Rock Mechanics and Mining Sciences \& Geomechanics Abstracts, v. 23, n. 3, p. 245-254, 1986.

EZAKI, S., HYPOLITO, R., PÉREZ-AGUILAR, A., Gamito, D., Moura, C. L., Pugas, M. S., ... \& Nascimento, S. C. Hidroquímica dos Aquíferos Tubarão, Cristalino e do Manto de Intemperismo da Região de Salto-Indaiatuba (SP). Águas Subterrâneas, 2008.

FAHEY, R. J., \& PEASE, M. H. Preliminary bedrock geologic map of the South Coventry quadrangle, Tolland County, Connecticut (No. 77-584). USGS, 1977.

FANTI, A. et al. Application of Geophysical Logging and Straddle Packers for the Investigation of a Fractured Aquifer in a Contaminated Area by Chlorinated Solvents in Sao Paulo State, Brazil. Journal of Water Resource and Protection, v. 09, n. 10, p. 1145-1168, 2017.

FERNANDES, A. J. et al. Modelo geométrico de fraturas e análise da tectônica rúptil aplicados ao estudo do fluxo do aquífero cristalino, São Paulo (SP). Revista do Instituto de Geociências, v. 16, n. 3, p. 71-88, 2016.

FETTER, C. W. Applied Hydrogeology. 4. ed. New Jersey: Prentice Hall, 2001.

FIACCO, R. J.; DALY, M. H.; DROBINSKI, J. C. Application of the Fractured Bedrock Toolbox at Multiple Sites in New England. U.S. EPA/NGWA Fractured Rock Conference: State of the Science and Measuring Success in Remediation. Anais...Portland: U.S.EPA/NGWA, 2004.

FREEZE, A. R.; CHERRY, J. A. Groundwater. Upper Saddle River: Prentice Hall, 1979.

FUSP (Fundação de Apoio à Universidade de São Paulo). Plano de Bacia Hidrográfica do Alto Tietê. In: Caderno Técnico Institucional, São Paulo, 2002.

GALE, J. E. Assessing the Permeability Characteristics of Fractured Rock. Geological Society of America Special Papers, v. 189, p. 163-182, 1982.

GALE, J. E., \& Witherspoon, P. A. An approach to the fracture hydrology at Stripa, preliminary results: Berkeley, Lawrence Berkeley Laboratory, LBL-7079, 1979.

GALEMBECK, T. M. B., WERNICK, E., \& HÖRMANN, P. K. Chemistry of Biotites and Whole Rocks from the Rapakivi Itu Complex (Late Precambrian), State of São Paulo, SE Brazil. Anais da Academia Brasileira de Ciências, 414-429, 1997.

GALEMBECK, T., WERNICK, E., \& GODOY, A. M. Tipologia de Granitos I e A (Rapakivi) coexistentes no Complexo Granitóide Itu, SP. São Paulo, UNESP. Geociências, 20(1), 2536, 2001.

GOLDER, -GOLDER ASSOCIATES LTD. Fractured Bedrock Field Methods and Analytical Tools Volume I: Main report Scandinavian Journal of Clinical and Laboratory Investigation. Burnaby, British Columbia: [s.n.]. Disponível em: $<$ http://www.tandfonline.com/doi/full/10.1080/00365510410006036>.

GRUNDFOS, disponível em: < https://www.grundfos.com/>. Acesso em: 09set. 2019.

HAIMSON, B. C.; DOE, T. W. State of stress, permeability, and fractures in the Precambrian granite of northern Illinois. Journal of Geophysical Research, v. 88, p. 7355-7371, 1983. 
HASUI, Y., DANTAS, A. S. L., CARNEIRO, C. D. R., \& BISTRICHI, C. A. O embasamento Pré-Cambriano e Eo-Paleozóico em São Paulo. Instituto de Pesquisas Tecnológicas do Estado de São Paulo, Mapa Geológico do Estado de São Paulo, 1981. Escala 1:500.000, 1245

HESS, A. E. Identifying hydraulically conductive fractures with a slow-velocity borehole flowmeter. Canadian Geotechnical Journal, v. 23, n. 1, p. 69-78, 1986.

HOLLOWAY, O. G.; WADDELL, J. P. Design and Operation of a Borehole Straddle Packer for Ground-Water Sampling and Hydraulic Testing of Discrete Intervals at U.S. Air Force Plant 6, Marietta, Georgia. 2008. Georgia: [s.n.]. Disponível em: $<$ http://pubs.usgs.gov/of/2008/1349/>.

HUBBERT, M. King et al. Darcy's law and the field equations of the flow of underground fluids. 1956.

HVORSLEV, M. J. Time Lag and Soil Permeability in Ground-Water Observations. Bulletin n. 36, n. 36, p. $53,1951$.

INSTITUTO NACIONAL DE METROLOGIA, QUALIDADE E TECNOLOGIA (INMETRO). Critérios para acreditação da amostragem de águas e Matrizes Ambientais. NIT-DICLA-057. Rio de Janeiro: INMETRO. 2019. Disponível em $<$ http://www.inmetro.gov.br> Acesso em: 12 dez. 2019.

JOHNSON, C. D. et al. Characterization of Fractures and Flow Zones in a Contaminated Crystalline-Rock Aquifer in the Tylerville Section of Haddam, Connecticut. U.S. Geological Survey Data Series 1020, p. 40, 2016.

KEYS, W. S. Borehole geophysics applied to ground-water investigations. In: INTERIOR, U. S. D. OF THE (Ed.). Borehole geophysics applied to ground-water investigations. [s.1.] U.S. Geological Survey, 1990. p. 150.

KONZUK, J. S.; KUEPER, B. H. Evaluation of cubic law based models describing singlephase flow through a rough-walled fracture. Water Resources Research, v. 40, n. 2, p. 1-17, 2004.

L'APICCIRELLA, E. S. P. CONTAMINAÇÃO E ÁREAS DE RESTRIÇÃO DE USO DE ÁGUA SUBTERRÂNEA NO ENTORNO DO CANAL JURUBATUBA EM SÃO PAULO - SP. [s.1.] Universidade de São Paulo, 2009.

LANE, John W. An integrated geophysical and hydraulic investigation to characterize a fractured-rock aquifer, Norwalk, Connecticut. US Department of the Interior, US Geological Survey, 2002.

LAPCEVIC, P. A.; NOVAKOWSKI, K. S.; SUDICKY, E. A. The interpretation of a tracer experiment conducted in a single fracture under conditions of natural groundwater flow. Water Resources Research, v. 35, n. 8, p. 2301-2312, 1999.

LAVAL UNDERGROUND SURVEY, R-CAM 1300 XLT TECH, SPECS CAMERA FOR

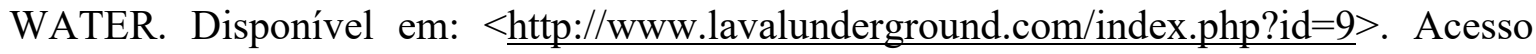
em: 09set. 2019.

LIMA, D. D. A. Atlas Nacional do Brasil. Maps II-1 1. Instituto Brasileiro de Geografia e Estatística (IBGE), Conselho Nacional de Geografia, Rio de Janeiro, Brasil, 1966.

$\mathrm{LO}, \mathrm{H}$. et al. The combined use of heat-pulse flowmeter logging and packer testing for transmissive fracture recognition. Journal of Applied Geophysics, v. 105, p. 248-258, 2014. 
LONG, J. C. S. et al. Porous media equivalents for network of discontinuous fractures. Water Resources Research, v. 18, n. 3, p. 645-658, 1982.

LONG, J. C. S.; BILLAUX, D. M. From field data to fracture network modeling: An example incorporating spatial structure. Water Resources Research, v. 23, n. 7, p. 1201-1216, 1987.

LOUIS, C., AND PERNOT, M. Three Dimensional Investigation Of Flow Conditions Of Grand Maison Damsite, In: PROCEEDINGS, SYMPOSIUM ON PERCOLATION THROUGH FISSURED ROCK: INTERNATIONAL SOCIETY OF ROCK MECHANICS, T4-F:1-16, 1972.

MALIVA, R. G. Aquifer characterization techniques. Berlin: Springer, 2016.

MILANI, E. J.; FRANÇA, A. B.; SCHNEIDER, R. L. Bacia do Paraná: Bulletin Geociencias do Petrobrás, v. 8. 1994.

MIYAKAWA, K. et al. Detection of hydraulic pathways in fractured rock masses and estimation of conductivity by a newly developed TV equipped flowmeter. v. 56, p. 19-27, 2000.

MOUNT SOPRIS INSTRUMENTS, Disponível em: $<$ https://mountsopris.com/>. Acesso em: 09set. 2019.

MULDOON, Maureen; BRADBURY, Ken R. Site characterization in densely fractured dolomite: comparison of methods. Groundwater, v. 43, n. 6, p. 863-876, 2005.

NEVES, Mirna Aparecida. Análise integrada aplicada à exploração de água subterrânea na bacia do rio Jundiaí (SP). 2005.

NEWHOUSE, M. W.; IZBICKI, J. A.; SMITH, G. A. Comparison of velocity-log data collected using impeller and electromagnetic flowmeters. Groundwater, v. 43, n. 3, p. 434438, 2005.

NICHOLL, M. J. et al. Saturated flow in a single fracture: Evaluation of the Reynolds equation in measured aperture fields. Water Resources Research, v. 35, n. 11, p. 3361-3373, 1999.

NOVAKOWSKI, K. et al. Measurements of groundwater velocity in discrete rock fractures. Journal of Contaminant Hydrology, v. 82, p. 44-60, 2006.

NRC, N. R. C. Rock Fractures and Fluid Flow: Contemporary Understanding and Applications. Washington, DC: The National Academies Press, 1996.

PAILLET, F. Borehole flowmeter applications in irregular and large-diameter boreholes. Journal of Applied Geophysics, v. 55, n. 1-2, p. 39-59, 2004.

PAILLET, F. L. Flow modeling and permeability estimation using borehole flow logs in heterogeneous fractured formations. Water Resources Research, v. 34, n. 5, p. 997, 1998.

PAILLET, F. L. Hydraulic head applications of flow logs in the study of heterogeneous aquifers. Groundwater, 2001.

PAILLET, F. L. Using borehole geophysics and cross-borehole flow testing to define hydraulic connections between fracture zones in bedrock aquifers. Journal of Applied Geophysics, v. 30, p. 261-279, 1993.

PAILLET, F. L.; CROWDER, R. E. Generalized Approach for the Interpretation of Geophysical Well Logs in Ground-Water Studies-Theory and Application. Groundwater, v. 34, n. 5, p. 883-898, 1996. 
PAILLET, Frederick L.; OLLILA, Paul. Identification, characterization, and analysis of hydraulically conductive fractures in granitic basement rocks, Millville, Massachusetts. Water-Resources Investigations, Report, p. 94-4185, 1994.

PAILLET, Frederick L.; REESE, Ronald S. Integrating borehole logs and aquifer tests in aquifer characterization. Groundwater, v. 38, n. 5, p. 713-725, 2000.

PARKER, B. L.; CHAPMAN, S. W.; CHERRY, J. A. Plume Persistence in Fractured Sedimentary Rock After Source Zone Removal. Ground Water, v. 48, n. 6, p. 799-808, 2010.

PARKER, B. L.; CHERRY, J. A.; CHAPMAN, S. W. Discrete Fracture Network Approach for Studying Contamination in Fractured Rock. Aquamundi, n. dez., p. 101-116, 2012.

PASCHOLATI, Elisabete Maria; FUJIMORI, Kenkichi. Caracterização geofísica da suíte intrusiva de Itu. 1990.

PEHME, P. E. et al. Enhanced detection of hydraulically active fractures by temperature profiling in lined heated bedrock boreholes. Journal of Hydrology, v. 484, p. 1-15, 2013.

PEHME, P. E. et al. Improved resolution of ambient flow through fractured rock with temperature logs. Groundwater, v. 48, n. 2, p. 191-205, 2010.

PEHME, P. et al. Detailed measurement of the magnitude and orientation of thermal gradients in lined boreholes for characterizing groundwater flow in fractured rock. Journal of Hydrology, v. 513, p. 101-114, 2014.

PULS, R. W., \& BARCELONA, M. J. Low-flow (minimal drawdown) ground-water sampling procedures. US Environmental Protection Agency, Office of Research and Development, Office of Solid Waste and Emergency Response, 1996.

QUINN, P. M.; CHERRY, J. A.; PARKER, B. L. Depth-discrete specific storage in fractured sedimentary rock using steady-state and transient single-hole hydraulic tests. Journal of Hydrology, v. 542, p. 756-771, 2016.

QUINN, P. M.; CHERRY, J. A.; PARKER, B. L. Quantification of non-Darcian flow observed during packer testing in fractured sedimentary rock. Water Resources Research, v. 47, n. 9, p. 15, set. 2011.

QUINN, P. M.; PARKER, B. L.; CHERRY, J. A. Using constant head step tests to determine hydraulic apertures in fractured rock. Journal of Contaminant Hydrology, v. 126, n. 1-2, p. 85-99, 2011.

QUINN, P. M.; PARKER, B. L.; CHERRY, J. A. Validation of non-Darcian flow effects in slug tests conducted in fractured rock boreholes. Journal of Hydrology, v. 486, p. 505-518, 2013 .

QUINN, P.; CHERRY, J. A.; PARKER, B. L. Hydraulic testing using a versatile straddle packer system for improved transmissivity estimation in fractured rock boreholes. 2012.

QUINN, P.; PARKER, B. L.; CHERRY, J. A. Blended head analyses to reduce uncertainty in packer testing in fractured-rock boreholes. Hydrogeology Journal, v. 24, n. 1, p. 59-77, 14 fev. 2016.

UNITED STATES. BUREAU OF RECLAMATION. Engineering geology field manual. US Department of the Interior, Bureau of Reclamation, 1991.

RENSHAW, C. E. On the relationship between mechanical and hydraulic apertures in roughwalled fractures. Journal of Geophysical Research, v. 100, n. B12, p. 24629-24636, 1995. 
ROBERTSON GEO, disponível em: <https://www.robertson-geo.com/>. Acesso em: 09set. 2019.

ROBINSON, J. et al. Imaging Pathways in Fractured Rock Using Three-Dimensional Electrical Resistivity Tomography. Groundwater, v. 54, n. 2, p. 186-201, 2016.

ROCHA-CAMPOS, A. C. The Tubarao Group in the Brazilian portion of the Parana basin. Problems in Brazilian Gondwana Geology, p. 27-102, 1967.

RODGERS, J. Bedrock geological map of Connecticut: Connecticut Geological and Natural History Survey. Natural Resources Atlas Series Map, v. 2, 1985.

SAUTER, M. Assessment of hydraulic conductivity in a karst aquifer at local and regional scale. Proceedings of Third Conference on Hydrogeology, Ecology, Monitoring and Management of Ground Water in Karst Terranes. Anais...Nashville, USA: 1991

SHAPIRO, A. M. Cautions and Suggestions for Geochemical Sampling in Fractured Rock. Groundwater Monitoring \& Remediation, 2002.

SHAPIRO, A. M. Characterizing Ground-Water Chemistry and Hydraulic Properties of Fractured-Rock Aquifers Using the Multifunction Bedrock-Aquifer Transportable Testing Tool (BAT 3). U.S. Geological Survey Fact sheet, n. August, p. 2-5, 2001.

SHAPIRO, Allen M. Characterizing Hydraulic Properties and Ground-Water Chemistry in Fractured-Rock Aquifers: A User's Manual for the Multifunction Bedrock-Aquifer Transportable Testing Tool (BAT3). Geological Survey (US), 2007.

SHAPIRO, A. M.; HSIEH, P. A. How good are estimates of transmissivity from slug tests in fractured rock? Ground Water, v. 36, n. 1, p. 37-48, 1998.

SHAPIRO, A. M.; LADDERUD, J. A.; YAGER, R. M. Interpretation of hydraulic conductivity in a fractured-rock aquifer over increasingly larger length dimensions. Hydrogeology Journal, v. 23, n. 7, p. 1319-1339, 2015.

SILVA, J. A. F. Estimativa de recarga e caracterização hidroquímica e isotópica das águas subterrâneas dos aquíferos da região do canal do Jurubatuba. 2018. Tese de Doutorado. Universidade de São Paulo.

SINGHAL, B. B. S.; GUPTA, R. P. Applied Hydrogeology of Fractured Rocks. 2. ed. [s.1.] Springer Science \& Business Media, 2010.

SNOW, D. T. A Parallel Plate Model of Fractured Permeable Media. p. 344, 1965.

SNOW, D. T. Anisotropie Permeability of Fractured Media. Water Resources Research, v. 5, n. 6, p. 1273-1289, 1969.

SOARES, P. C., \& LANDIM, P. M. B. (1973). Aspectos regionais da estratigrafia da Bacia do Paraná no seu flanco nordeste. In: CONGRESSO BRASILEIRO DE GEOLOGIA. Vol. 27, No. 1973, p. 243-256.

SOKOL, D. Position and Fluctuations of Water Level in Wells Perforated in More Than One Aquifer. Journal of Geophysical Research, v. 68, n. 4, p. 1079-1080, 1963.

STERRETT, R. Groundwater and Wells. 3. ed. New Brigton, MN: Johnson Screens, 2007.

SUDICKY, E. A.; MCLAREN, R. G. The Laplace Transform Galerkin Technique for largescale simulation of mass transport in discretely fractured porous formations. Water Resources Research, v. 28, n. 2, p. 499-514, 1992. 
Swagelok, disponível em: <https://www.swagelok.com/en/>. Acesso em: 09set. 2019.

THERRIEN, R.; SUDICKY, E. A. Three-dimensional analysis of variably-saturated flow and solute transport in discretely-fractured porous media. Journal of Contaminant Hydrology, $\mathrm{v}$. 23, n. 1-2, p. 1-44, 1996.

TRESSOLDI, M. Uma contribuição à caracterização de maciços rochosos fraturados visando a proposição de modelos para fins hidrogeológicos e hidrogeotécnicos. [s.1.] Universidade de São Paulo, 1991.

VAN DER KAMP, G. Methods for determining the in situ hydraulic conductivity of shallow aquitards - An overview. Hydrogeology Journal, v. 9, n. 1, p. 5-16, 2001.

VAN GOLF-RACHT, T. D. Fundamentals of Fractured Reservoir Engineering. [s.1.] Elsevier, 1982. v. 12

WAHNFRIED, I. Modelo conceitual de fluxo do aquitarde Serra Geral e do sistema Aquífero Guarani na região de Ribeirão Preto, SP. [s.1.] Universidade de São Paulo, 2010.

WILLIAMS, J. H.; JOHNSON, C. D. Acoustic and optical borehole-wall imaging for fracturedrock aquifer studies. v. 55, p. 151-159, 2004.

WILLIAMS, John H. et al. Cross-borehole flow tests and insights into hydraulic connections in fractured mudstone and sandstone. In: Symposium on the Application of Geophysics to Engineering and Environmental Problems 2007. Society of Exploration Geophysicists, 2007. p. 1140-1152.

WILLIAMS, J. H.; PAILLET, F. L. Using flowmeter pulse tests to define hydraulic connections in the subsurface: A fractured shale example. Journal of Hydrology, v. 265, n. 1-4, p. 100$117,2002$.

WILSON, B. J. T. et al. An Evaluation of Borehole Flowmeters Used to Measure Horizontal Ground-Water Flow in Limestones of Indiana, Kentucky, and Tennessee, 1999. 2001.

WITHERSPONN, P. A. et al. Validity of Cubic Law for Fluid Flow in a Deformable Rock Fracture. Water Resources Research, v. 16, n. 6, p. 1016-1024, 1980.

YOUNG, Steven C.; PEARSON, Hubert S. The electromagnetic borehole flowmeter: Description and application. Groundwater Monitoring \& Remediation, v. 15, n. 4, p. 138147, 1995.

ZIMMERMAN, R. W. et al. Non-linear regimes of fluid flow in rock fractures. International Journal of Rock Mechanics and Mining Sciences, v. 41, n. 3, p. 163-169, 2004.

ZIMMERMAN, R. W.; BODVARSSON, G. S. Hydraulic conductivity of rock fractures. Transport in porous media, v. 23, n. 1, p. 1-30, 1996. 
Barbosa, M. B. (2020).

9 APÊNDICES 
Apêndice I: uma nova versão do programa flash em $\mathbf{r}$ para a análise de ensaios em um único furo (artigo) 


\title{
Groundwater
}

\author{
Methods Note/
}

\section{A New R Program for Flow-Log Analysis of Single Holes (FLASH-R)}

\author{
by Marcos B. Barbosa ${ }^{1}$, Neil Terry², Frederick D. Day-Lewis², Reginaldo Bertolo ${ }^{3}$, and John W. Lane Jr²
}

\begin{abstract}
A new version of the computer program FLASH (Flow-Log Analysis of Single Holes) is presented for the analysis of borehole vertical flow logs to estimate fracture (or layer) transmissivities and far-field hydraulic heads. The program is written in R, an open-source environment. All previous features have been retained and new features incorporated including more rigorous parameter estimation, uncertainty analysis, and improved data import. The program has a dynamic user interface compatible with most operating systems.
\end{abstract}

\section{Introduction}

Borehole flow logging is a well-regarded technique that allows the assessment of important hydraulic features of boreholes and aquifers. The use of high-resolution tools (Hess 1986; Molz et al. 1994) increases the confidence in field data (Busse et al. 2016) to estimate hydraulic parameters in an inexpensive and fast manner. Transmissivity, ambient flow direction, and hydraulic heads associated with fractures are commonly obtained from the analysis of single-hole tests using ambient and stressed flow profiles to calibrate a simple analytical solution, either transient run to quasi-steady state (Paillet 1998) or fully steadystate (Day-Lewis et al. 2011). Here, we follow the latter approach, which is based on the Thiem equation (Thiem 1906). The solution for both flow equations, ambient or "static" flow (Equation 1) and steady pumping/injection (Equation 2), are used to solve for two sets of unknowns:

${ }^{1}$ Corresponding author: Institute of Geoscience, University of Sao Paulo, 562 Lago Street, Sao Paulo 05508 080, Brazil; 55 (11) 993361965; marbbar@usp.br

${ }^{2}$ Office of Groundwater, Branch of Geophysics, U.S. Geological Survey, 11 Sherman Place, Unit 5015, Storrs, CT, 06269.

${ }^{3}$ Institute of Geoscience, University of Sao Paulo, 562 Lago Street, Sao Paulo 05508 080, Brazil.

Article impact statement: We present a new version of FLASH, written in the R language, for analysis of borehole flow logs and estimation of aquifer properties.

Received August 2019, accepted February 2020.

Published 2020. This article is a U.S. Government work and is in the public domain in the USA.

doi: $10.1111 /$ gwat. 12994 the transmissivity values and static hydraulic-head differences associated with the flow regime. The static water level is then used to convert the analytical solutionderived hydraulic-head differences between zones to absolute depth to water level.

$$
Q_{i}=-\frac{2 \pi T_{i}\left(h_{W}-h_{i}\right)}{\ln \left(r_{0} / r_{W}\right)},
$$

where $Q_{i}$ is the volumetric flow into the well from flow zone $i$ [L3T -1$] ; h_{w}$ and $h_{i}$ are, respectively, the hydraulic head $[L]$ at the radius of the well $r_{w}$, and at radial distance $r_{0}$, commonly taken as the radius of influence, where heads do not change as a result of pumping, in which case $h_{i}$ is the connected far-field head for zone $i$; and $T_{i}$ is the transmissivity of flow zone $i$ [L2T - 1].

$$
\begin{aligned}
Q_{i}^{a} & =\frac{2 \pi T_{i}^{\mathrm{factor}} T^{\mathrm{total}}\left(h_{W}^{a}-h_{i}^{0}\right)}{\ln \left(r_{0} / r_{W}\right)}, \\
Q_{i}^{s} & =\frac{2 \pi T_{i}^{\mathrm{factor}} T^{\mathrm{total}}\left(h_{W}^{s}-h_{i}^{0}\right)}{\ln \left(r_{0} / r_{W}\right)},
\end{aligned}
$$

where $T_{i}^{\text {factor }}$ is the fraction of the borehole's transmissivity contributed by flow zone $i[-] ; T^{\text {total }}$ is the total transmissivity of the flow zones intersected by the borehole [L2T - 1]; $h_{W}^{a}, h_{W}^{s}$ are the ambient and stressed water levels in the well, respectively $[\mathrm{L}] ; h_{i}^{0}$ is the far-field head in flow zone $i[\mathrm{~L}]$. 
Modeling and analysis tools have broadened the use of flowmeters for hydraulic characterization of aquifers. Day-Lewis et al. (2011) developed a spreadsheet-based program for Flow-Log Analysis of Single Holes (FLASH) based on Equations 2 and 3. The spreadsheet was developed for Microsoft Excel and uses Visual Basic for Applications routines for parameter estimation. The use of FLASH allows for estimation of the transmissivity or radius of influence of the well as well as the transmissivities and far-field hydraulic heads of each flow zone. Other features available with the spreadsheet are plotting options for porous or fractured aquifers, and manual or automated calibration; the latter is implemented using the Excel Solver which uses an optimization tool based on a Generalized Reduced Gradient algorithm (Lasdon and Smith 1992). Optional regularization constraints are supported with user-defined weights. Regularization is useful to identify the simplest analytical solution that matches data, where the match is only as good as warranted by the measurements given their associated measurement errors.

Because FLASH runs in Microsoft Excel, the user is generally restricted to this software when processing the data. Cross-platform problems have been observed by some users, as have issues with regional settings and macro security settings, thus limiting the use of FLASH. The spreadsheet format itself, while appealing to many users, may also impede community development of the code.

The advent of broadband internet and high-level programming languages like $\mathrm{R}$ are reshaping the way data are stored and processed. Open source coding allows universal access to cutting-edge technology and transparency in science. Therefore, there is great value in developing and honing existing tools to fit this new trend in science. This paper presents the R version of FLASH (FLASH-R) and (1) has expanded program functionality, (2) is platform independent, (3) is open source code and easily modified and extended by advanced users; and (4) uses a graphical user-interface.

\section{Software Implementation}

The analysis of single hole flowmeter data used in FLASH-R is based on the Thiem equation (Thiem 1906) for confined radial flow. Considering Thiem-based analytical solutions for two flow conditions (i.e., ambient and stressed) allows for the estimation of hydraulic heads and transmissivity for each flow zone and the borehole's total transmissivity or radius of influence. Additional information regarding this approach is available DayLewis et al. (2011). The assumptions made for the analysis are confined radial flow from each flow zone, a single radius of influence for all flow zones, and that ambient and stressed test data are collected under quasisteady state flow.

FLASH-R is written in $\mathrm{R}$ ( $\mathrm{R}$ Core Team 2018) and aims to improve the previous version developed in Excel (Day-Lewis et al. 2011). The graphical user interface (GUI) runs with the shiny package (Chang et al.
2019). Other packages that are used in the GUI include shinyjs for javascript operations (Attali 2017), shinysky for interactive table plotting (Dai 2019), scales for graph components formatting, and constrOptim for the nonlinear constrained automated optimization (R Core Team 2018). All previous features were retained and others were incorporated as well, such as: deployment as an R App, upload of raw (or preprocessed) data, unit conversion, evaluation of estimation uncertainty, and report export capabilities.

The FLASH-R App is structured across three sections/tabs of the user interface: "Introduction," "Borehole and Test Data" and "Flow Log Analysis". "Introduction" describes the operation of the App, details the parameters to be entered and explains how to proceed with the flow log analysis. The "Borehole and Test Data" tab (Figure 1) is used to enter basic information of the well (well construction, name, water level, etc.), the probe quantification limits and test data (see Paillet 2004 for details on data correction), which can be imported straight to the App through the browse function by selecting .txt format file. The "Flow Log Analysis" tab is used for entering the calibration parameters and flow interpretation and is also where the simulated flow profiles are displayed. Flow interpretation is made by the user for both ambient and stressed conditions. By convention, positive values are used for upward flow and negative values for downward flow. The flow profiles display four components: uploaded data as points, interpreted profile as dashed lines, simulated profile as solid lines, and the flowmeter quantification limits as orange dashed lines (the zero reference line is also plotted in gray; Figure 2).

In the "Borehole and Test Data" tab, the user must select the measurement system to be used. The units must be consistent, following parameter units above each field for metric and imperial systems such that the internal calculations are coherent. A second parameter to be used is the type of flow zones (porous or fractured systems) that will determine the aspect of the flow profile plotting, with linear increases/decreases over layers in porous media and abrupt step increases/decreases for fractures.

Importing field data is very straightforward, but for the import and read table functions used by $\mathrm{R}$ to work properly it is necessary to be consistent with the default data layout. The first row contains the title, the second the units and the remaining row contains the data. The column order is depth, acquisition time, pick time, and flow. The importing wizard allows the user to select three types of column separators: comma, semicolon, or tab.

All the information that is used to calibrate the analytical solution is gathered in the "Flow Log Analysis" tab. These are the numbers of flow zones, the radius of influence, total transmissivity, and interpreted flow zone parameters. Each interpreted flow zone has an associated zone identifier, bottom depth of the zone, ambient flow, stressed flow, transmissivity factor, and head difference. This tab also includes all the outputs that are generated in the App, such as the simulated flow zones, simulation parameters and flow log profiles, automated calibration 
\begin{tabular}{l|l|l} 
Introduction & Borehole and Test Data Flow Log Analysis
\end{tabular}

\section{Enter well and test data}

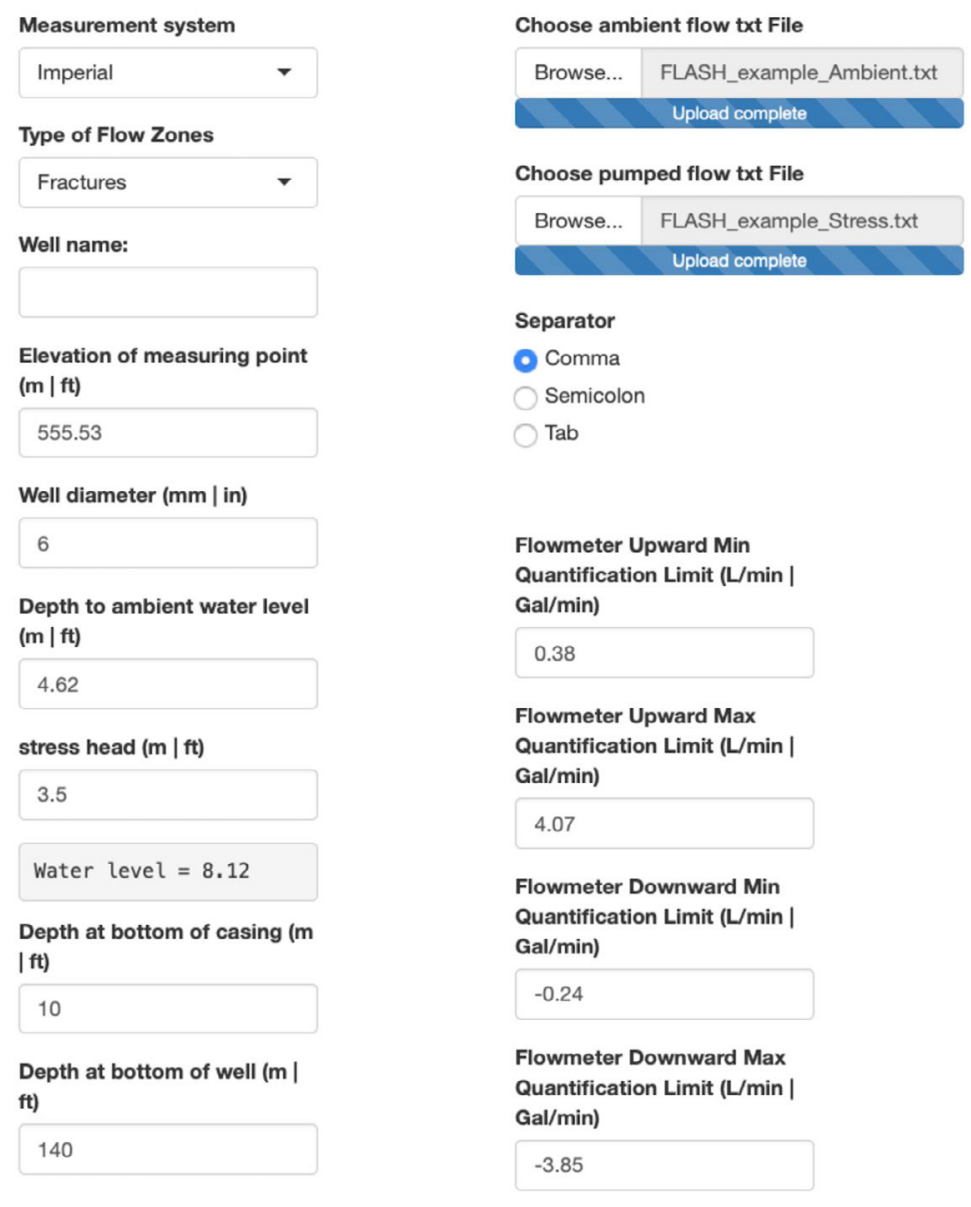

\begin{tabular}{rrrr} 
Ambient flow raw data & & \\
Depth_ft & $\begin{array}{r}\text { Acq. } \\
\text { Time_ }\end{array}$ & $\begin{array}{r}\text { Pick } \\
\text { Time_s }\end{array}$ & Flow_Gal./min. \\
\hline 21.00 & 0 & 0 & 0.00 \\
\hline 33.50 & 0 & 0 & 0.00 \\
\hline 37.00 & 0 & 0 & 0.02 \\
\hline 39.10 & 0 & 0 & 0.02 \\
\hline 50.00 & 0 & 0 & 0.02 \\
\hline 63.00 & 0 & 0 & 0.02 \\
\hline 69.50 & 0 & 0 & 0.00 \\
\hline 89.10 & 0 & 0 & 0.00 \\
100.00 & 0 & 0 & 0.00 \\
\hline 109.00 & 0 & 0 & 0.00 \\
\hline & & & \\
\hline
\end{tabular}

\begin{tabular}{rrrr} 
Pump flow raw data & & \\
Depth_ft & $\begin{array}{r}\text { Acq. } \\
\text { Time_ }\end{array}$ & $\begin{array}{r}\text { Pick } \\
\text { Time_s }\end{array}$ & Flow_Gal./min. \\
\hline 21.30 & 0 & 0 & 0.33 \\
35.50 & 0 & 0 & 0.50 \\
\hline 37.00 & 0 & 0 & 0.49 \\
\hline 50.00 & 0 & 0 & 0.25 \\
\hline 64.00 & 0 & 0 & 0.23 \\
\hline 66.00 & 0 & 0 & 0.00 \\
82.00 & 0 & 0 & 0.00 \\
\hline 100.00 & 0 & 0 & 0.00 \\
\hline 125.00 & 0 & 0 & 0.00 \\
\hline
\end{tabular}

Figure 1. Flash-R App "Borehole and Test Data" tab view.

parameters and controls. The automated calibration can be used to find the best fit for the transmissivity factor, head difference and total transmissivity or radius of influence, which can be determined by the user based on the data available. Automated calibration constraints can be applied to the solution using regularization parameters such as the maximum absolute head difference, the minimum transmissivity factor and the regularization weight. Although rarely needed by FLASH users, regularization is helpful for problems involving a large number of flow zones and noisy or erroneous data. In these cases, it will help to avoid matching the noise in data and producing unrealistic estimates such as head differences on the order of 10 's of meters, or more.

Manual calibration of the analytical flow solution is performed by entering the transmissivity and radius of influence (this can be based on field data or literature) and adjusting the values of transmissivity factors and head differences, which are, respectively, the percentage of the total transmissivity attributed to each zone $i$ (Tfactor $i$ ), and the difference in head between each flow zone and the borehole static water level. Every time the parameters are adjusted, the user must press the simulate button to update the simulated table and flow profile graph. Once the simulated profile is in agreement with the interpreted profile it means that the calibration has converged to a best fit. Another parameter that shows this convergence is the mean squared error (MSE) presented on the simulation parameters table which can be activated through the check box under the update and simulate buttons.

Automated calibration uses the constrOptim function from the R stats package (R Core Team 2018), which performs a constrained optimization based on NelderMead, quasi-Newton and conjugate-gradient algorithms. When running the automated calibration, the user must specify if the optimization will estimate the transmissivity or the radius of influence as the solution can only account for the ratio of total transmissivity divided by $\ln \left(r_{0} / r_{w}\right)$ as described in detail in Day-Lewis et al. (2011). Because total transmissivity can be obtained in a more reliable and 


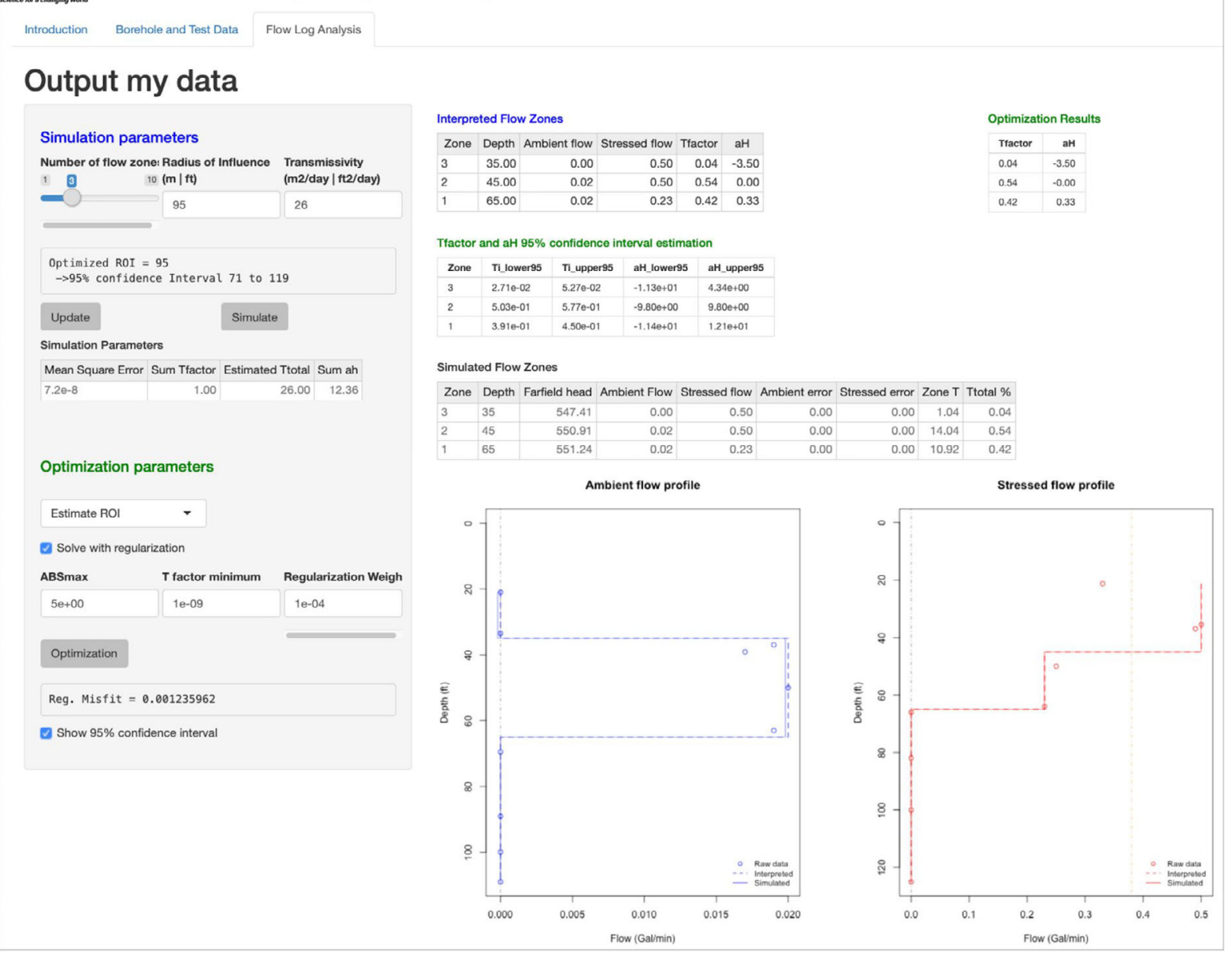

Figure 2. Flash-R App "Flow Log Analysis" tab view. This tab is used to input interpreted flow parameters and variables to perform the flow analysis and determine the hydraulic parameters such as far-field head, transmissivity and the well radius of influence or transmissivity.

direct way (slug or pumping test), generally it is preferred to estimate the radius of influence instead. However, in cases where the transmissivity is unreliable, it is possible to estimate this parameter by setting the radius of influence based on literature values. It is important to mention that both FLASH versions assume that all flow zones have the same radius of influence, when in fact this parameter could vary between flow zones. Because the radius of influence is comprised in a logarithmic term of flow equation, transmissivity estimation is not very sensitive to this parameter. Automated calibration can be performed with regularization constraints defined by the user.

Parameter uncertainty in the form of confidence intervals are calculated from a final call to the $\mathrm{R}$ optim function, which outputs a Hessian matrix. For the optimization problem considered in FLASH-R, the Hessian matrix can be considered the inverse of the parameter covariance matrix (Dovì et al. 1991); therefore, the square root of the diagonal elements of the inverse of this Hessian matrix gives an estimate of the standard errors (SE) in the optimization. The $95 \%$ confidence intervals are computed as the optimized values $\pm 1.96 *$ SE.

\section{Example}

For the purpose of comparison of both versions of FLASH, the example application presented here (Figure 3) draws on the dataset used in Day-Lewis et al. (2011) from a fractured-rock aquifer previously published by Johnson et al. (2005). This program also has been tested with additional datasets with varying flow conditions to ensure its reliability. The automated flow simulations were run with multiple starting conditions to help ensure the results do not correspond to local minima in the optimization.

Under ambient conditions, the dataset presents an upward flow with an inflow zone at a depth of 65 feet and output at 35 feet. When the well is stressed by pump, two inflow zones are observed, one at 65 feet and another at 45 feet. This means that the far-field head of the intermediate zone is practically the same as the ambient water level and its transmissivity is very similar to the deeper flow zone with almost half of the pumped flow coming from it. The fact that the shallow flow zone is not evident during pumping indicates relatively low transmissivity or a far-field head similar to the head at the borehole under stressed conditions, or both conditions. 
(a) Flowmeter log Vertical Flow

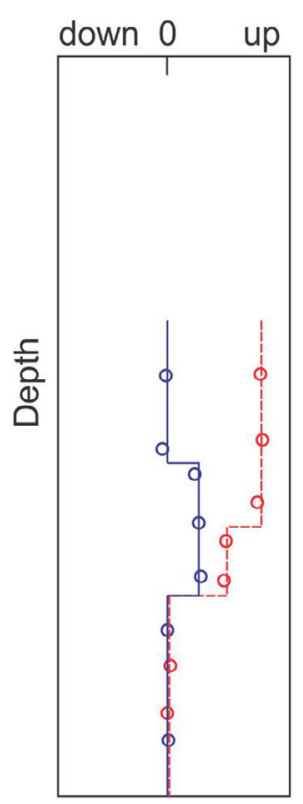

(b) Open hole flow dynamic under ambient and stressed (pumping) condition

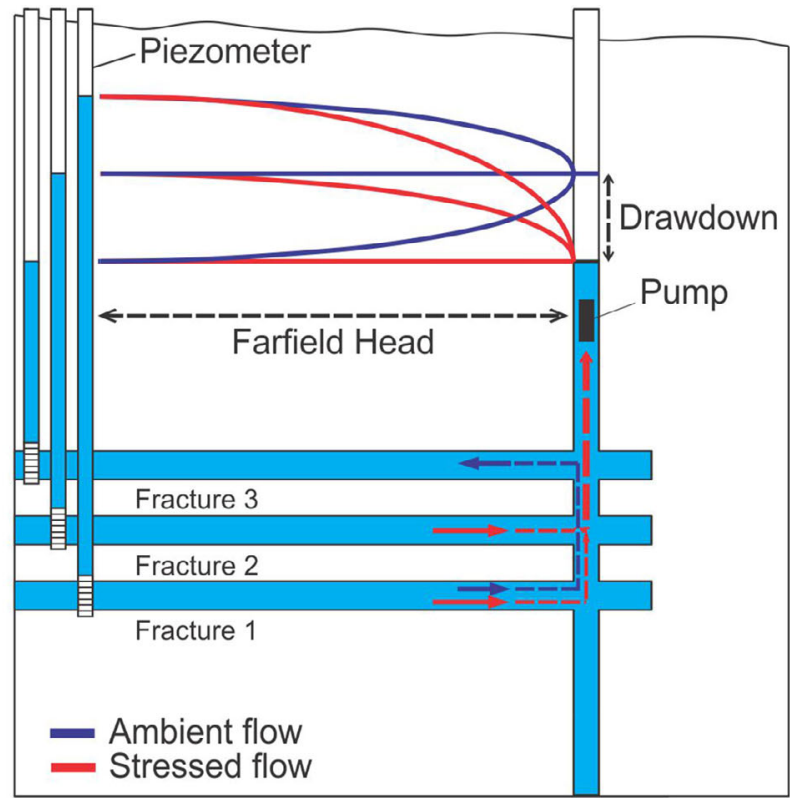

Figure 3. Schematic of flowmeter experiment in a fractured-rock aquifer, with (a) flow-log profiles for ambient (blue) and stressed (dashed red) conditions; and (b) conceptual cross sections of flow system for ambient and stressed condition.

The results obtained with FLASH-R (Figure 2) using the automated calibration presented MSE on the order of $10^{-8}$ and showed a good fit to the interpreted flow. The calibration was performed attributing 1 to the radius of influence and 0 to all transmissivity factor and head difference; thus, no previous manual calibration was performed before running the automated calibration. Within the first trial the solution was very close to the interpreted data and within the third trial a good fit was reached for both ambient and stressed flow profiles (Figure 2).

Manual and automated calibrations were performed to compare the processing and results for both FLASH versions. The varying parameters were radius of influence, transmissivity factor and head for each zone. Minor differences in values of MSE for the manual calibration were observed between both versions, probably due to decimal approximation or differences in the optimization approach. Consistent results were obtained in both versions and automated calibration proved to be not sensitive to the analytical solution starting parameters.

\section{Conclusions}

A new version of FLASH is presented aiming to improve the capabilities of this tool and the user experience. The program is written in $\mathrm{R}$, an open source environment, with a dynamic user interface that is compatible with any operating system and digital platform. This version overcomes problems and limitations experienced by users with the first version of FLASH, including (1) the need to purchase proprietary spreadsheet software, (2) macro security issues, and (3) the need for users to access and modify advanced settings that often require administrative privileges. As an open source code, the tool can be customized and improved by users and updates can easily be incorporated. Additional features were added to enhance data processing including (1) advanced optimization tools, (2) analysis of parameter uncertainty, (3) functions for importing data; and (4) means to document experimental setup within the App. Future releases of FLASH could include functionality for preprocessing data and cross-hole flow logging (Roubinet et al. 2015).

\section{Acknowledgments}

The authors are grateful for the Coordenação de Aperfeiçoamento de Pessoal de Nível Superior-Brazil (CAPES) and FAPESP - Brazil (process 10311-3) for partially financing this study, the U.S. Geological Survey Water Availability and Use Science Program, and the U.S. Geological Survey Toxic Substances Hydrology Program. We also thank Cian Dawson, Alisa Mast, John Williams, and two anonymous reviewers for their help in reviewing and improving this manuscript and associated software. Any use of trade, firm, or product names is for descriptive purposes only and does not imply endorsement by the U.S. Government.

\section{Authors' Note}

The authors do not have any conflicts of interest or financial disclosures to report. The software described in this paper is available from Barbosa et al 2020. 


\section{References}

Attali, D. 2017. shinyjs: Easily improve the user experience of your Shiny Apps in seconds. R package version 0.9.1. https://CRAN.R-project.org/package=shinyjs (accessed December 1, 2018).

Barbosa, M.B., N. Terry, F.D. Day-Lewis, R. Bertolo, and J.W. Lane Jr. 2020. FLASH-R v1.0: U.S. Geological Survey software release, January 20, 2020, https://doi.org/10.5066/ P9U9V9YU.

Busse, J., F.L. Paillet, A. Hossack, D. Bringemeier, A. Scheuermann, and L. Li. 2016. Field performance of the heat pulse flow meter: Experiences and recommendations. Journal of Applied Geophysics 126: 158-171.

Chang, W., J. Cheng, J.J. Allaire, Y. Xie, and J. McPherson. 2019. shiny: Web application framework for R. R package version 1.3.2. https://CRAN.R-project.org/package=shiny (accessed March 2, 2020).

Dai, Z.J. 2019. shinysky: A set of shiny components and widgets. $\mathrm{R}$ package version 0.1.3. https://github.com/AnalytixWare/ ShinySky (accessed March 2, 2020).

Day-Lewis, F.D., C.D. Johnson, F.L. Paillet, and K.J. Halford. 2011. A computer program for flow-log analysis of single holes (FLASH). Groundwater 49, no. 6: 926-931.

Dovì, V.G., O. Paladino, and A.P. Reverberi. 1991. Some remarks on the use of the inverse hessian matrix of the likelihood function in the estimation of statistical properties of parameters. Applied Mathematical Letters 4: 87.

Hess, A.E. 1986. Identifying hydraulically conductive fractures with a slow-velocity borehole flowmeter. Canadian Geotechnical Journal 23, no. 1: 69-78.
Johnson, C.D., C.K. Kochiss, and C.B. Dawson. 2005. Use of discrete-zone monitoring systems for hydraulic characterization of a fractured-rock aquifer at the University of Connecticut landfill, Storrs, Connecticut, 1999 to 2002. Water-Resources Investigations Report 03-4338, 105. Reston, Virginia: USGS.

Lasdon, L.S., and S. Smith. 1992. Solving large sparse nonlinear programs using GRG. ORSA Journal on Computing 4, no. 1: $2-15$.

Molz, F.J., et al. 1994. Borehole flowmeters: Field application and data analysis. Journal of Hydrology 163, no. 3-4: 347-371.

Paillet, F.L. 2004. Borehole flowmeter applications in irregular and large-diameter boreholes. Journal of Applied Geophysics 55, no. 1-2: 39-59.

Paillet, F.L. 1998. Flow modeling and permeability estimation using borehole flow logs in heterogeneous fractured formations. Water Resources Research 34, no. 5: 997.

R Core Team. 2018. R: A Language and Environment for Statistical Computing. Vienna, Austria: R Foundation for Statistical Computing. https://www.R-project.org/ (accessed December 15, 2019).

Roubinet, D., J. Irving, and F.D. Day-Lewis. 2015. Development of a new semi-analytical model for cross-borehole flow experiments in fractured media. Advances in Water Resources 76: 97-108.

Thiem, G. 1906. Hydologische methoden, 56. Leipzig: J.M. Gebhardt.

Winston C., J. Cheng, J.J. Allaire, Y. Xie, and J. McPherson. 2018. shiny: Web Application Framework for $R$. $R$ package version 1.1.0. https://CRAN.R-project.org/package=shiny 
Apêndice II: perfil geofísico em detalhe do poço 1204 


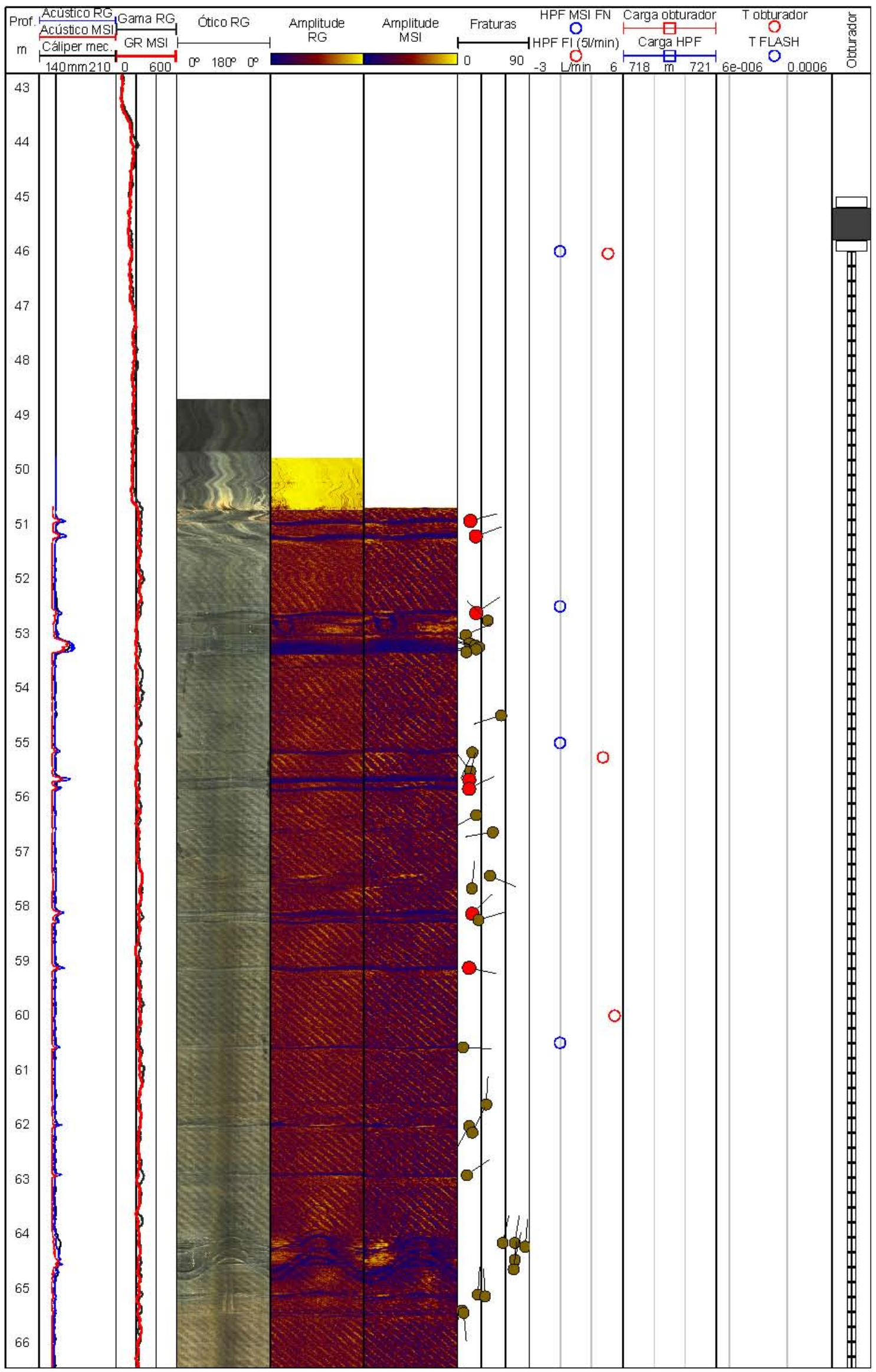




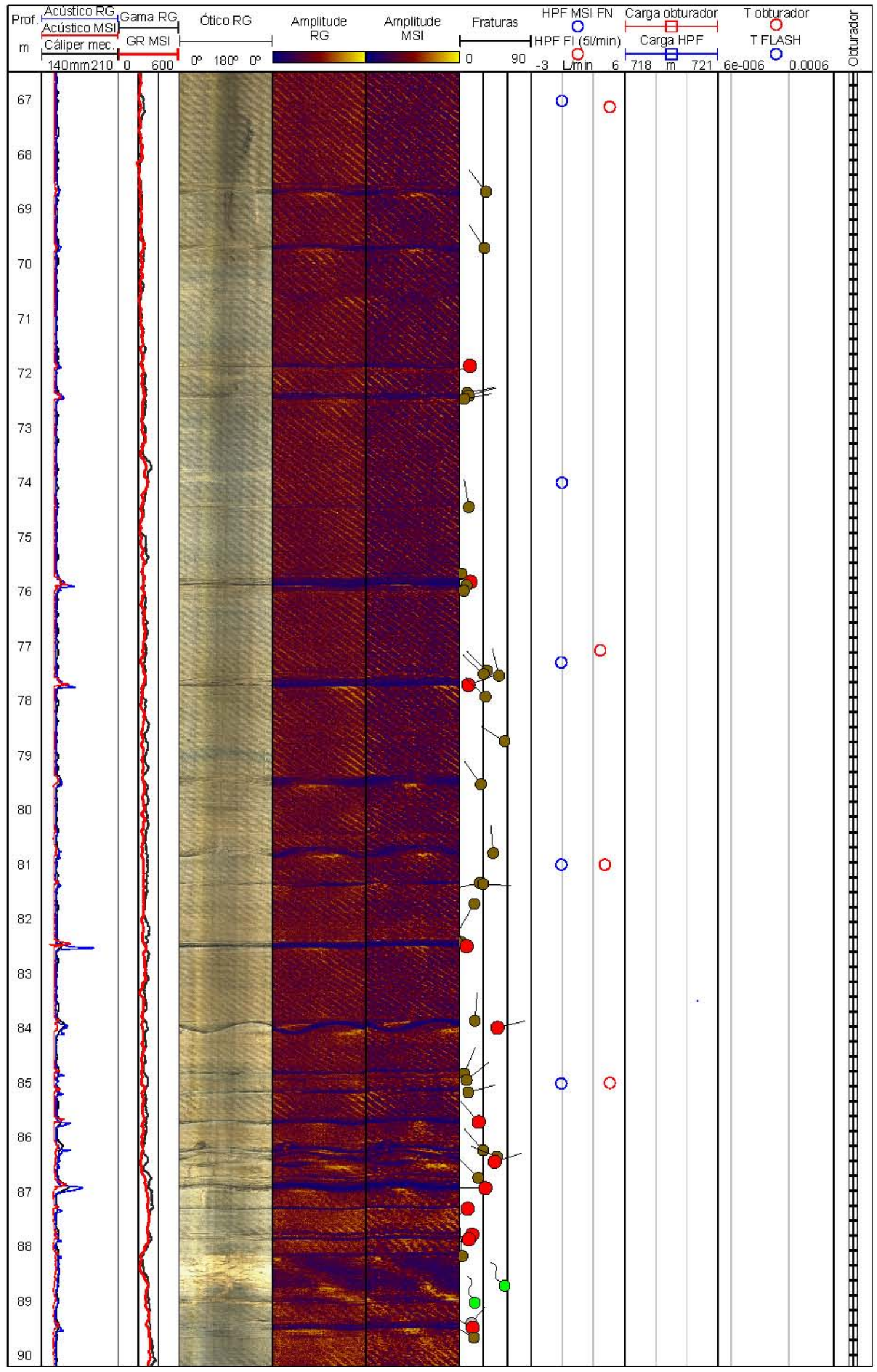




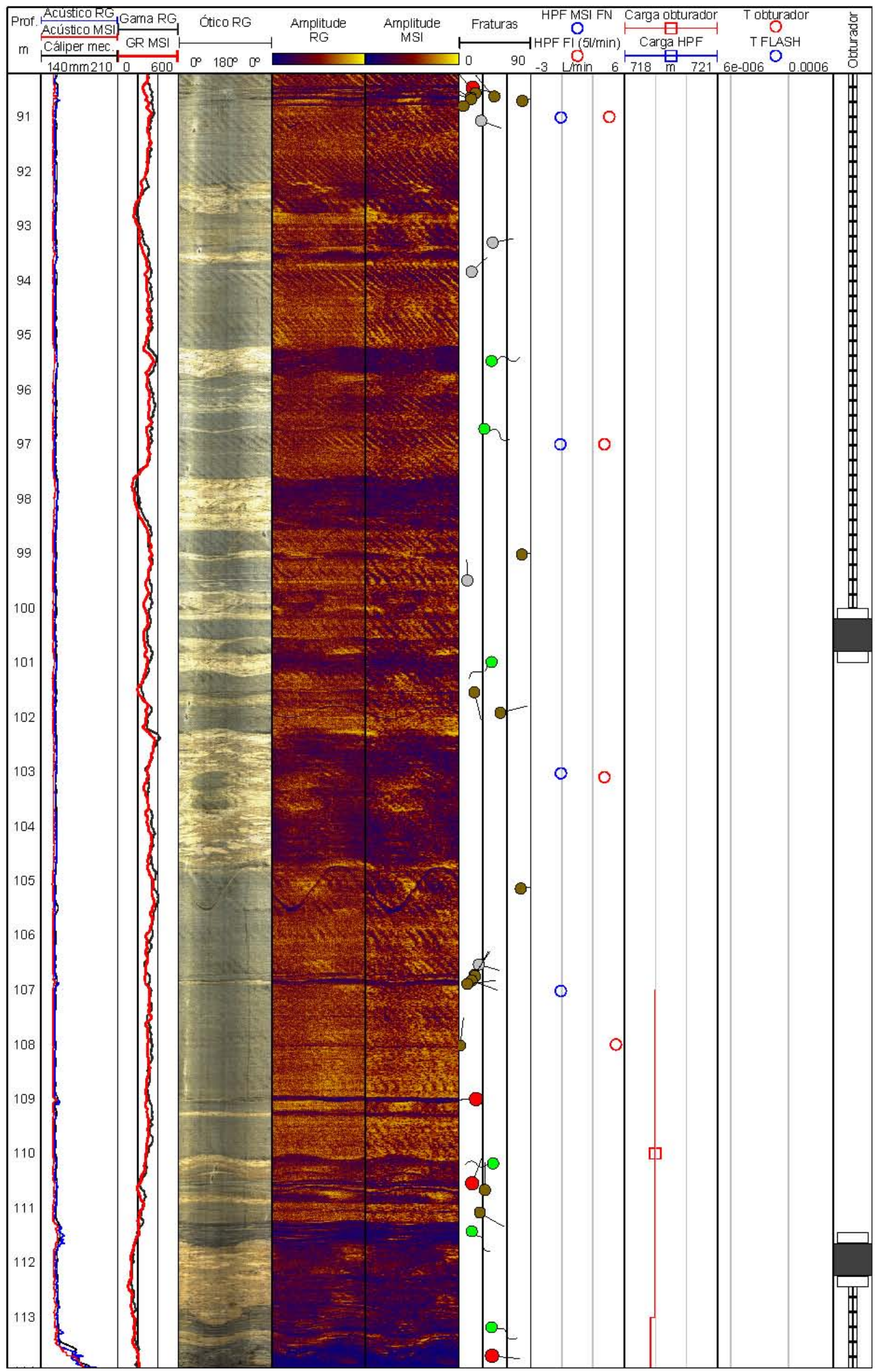




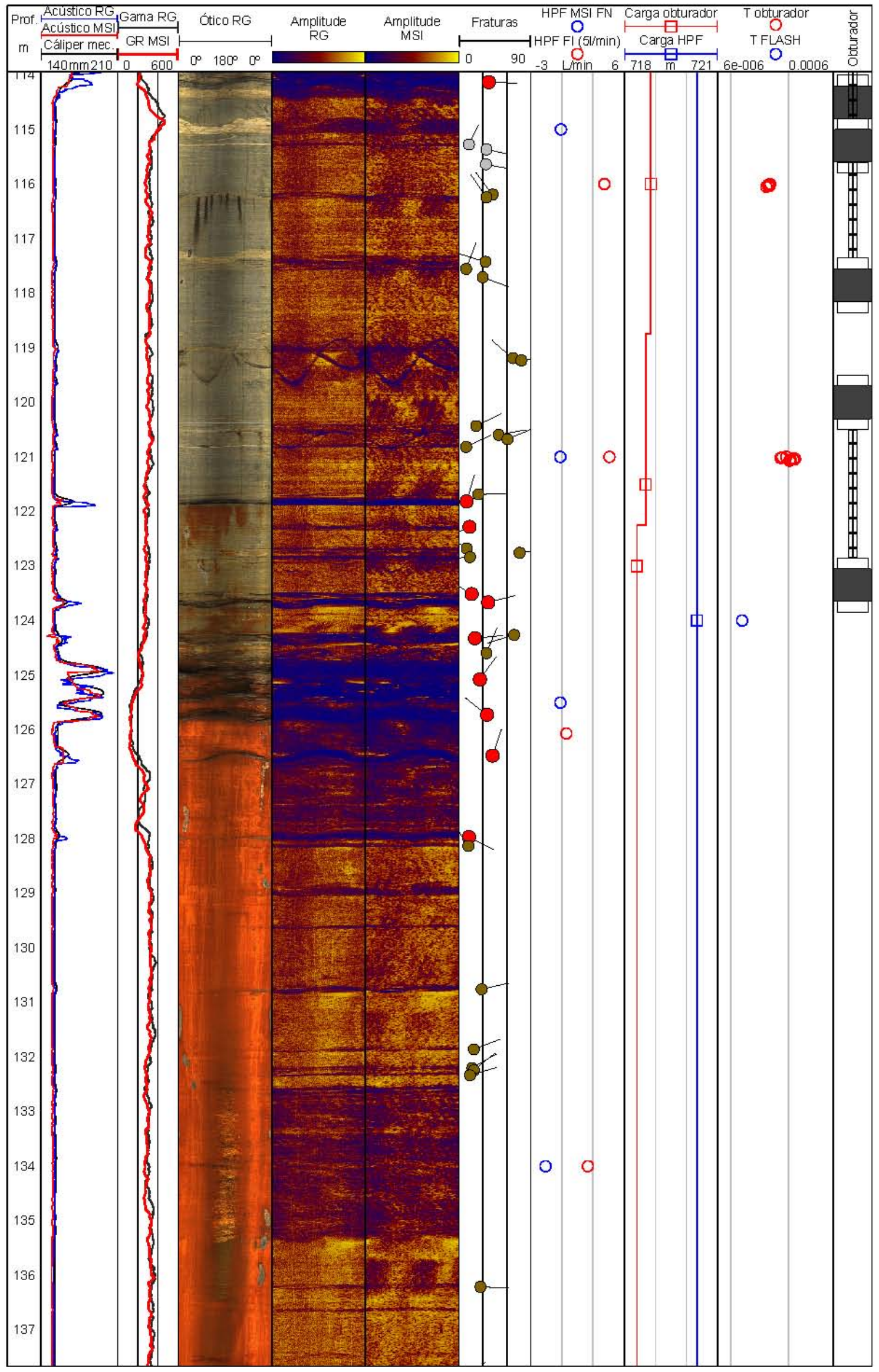




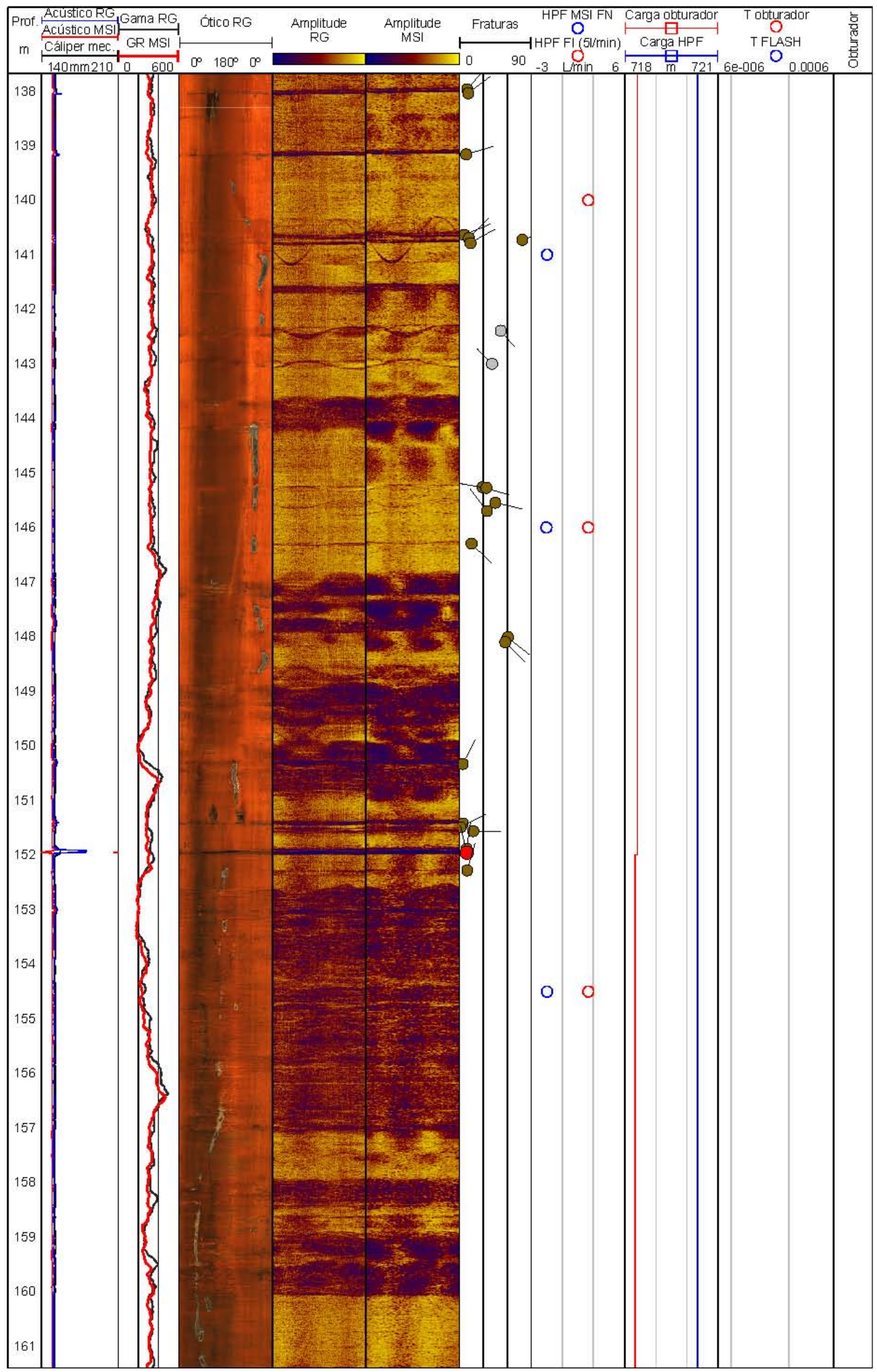




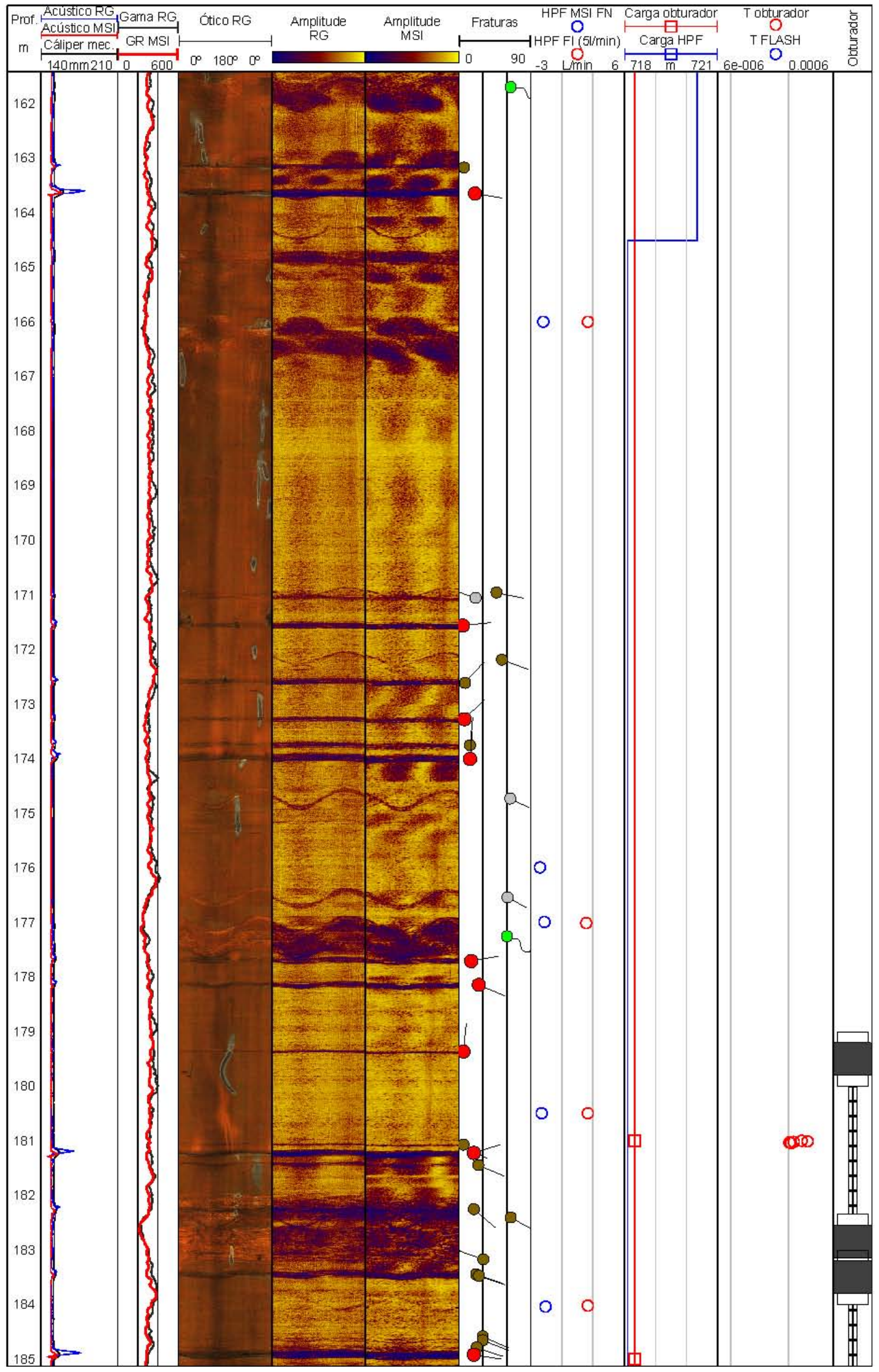




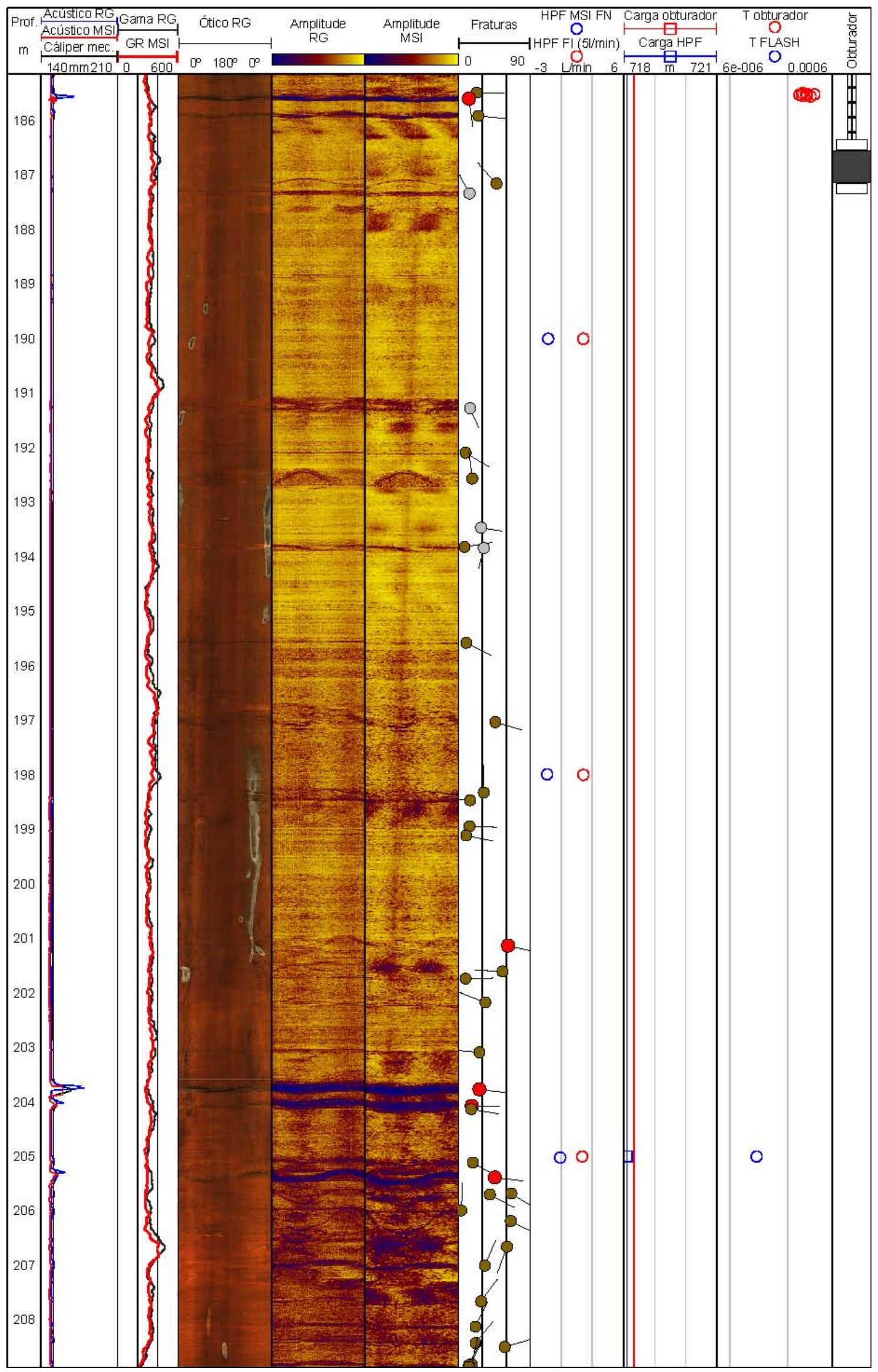




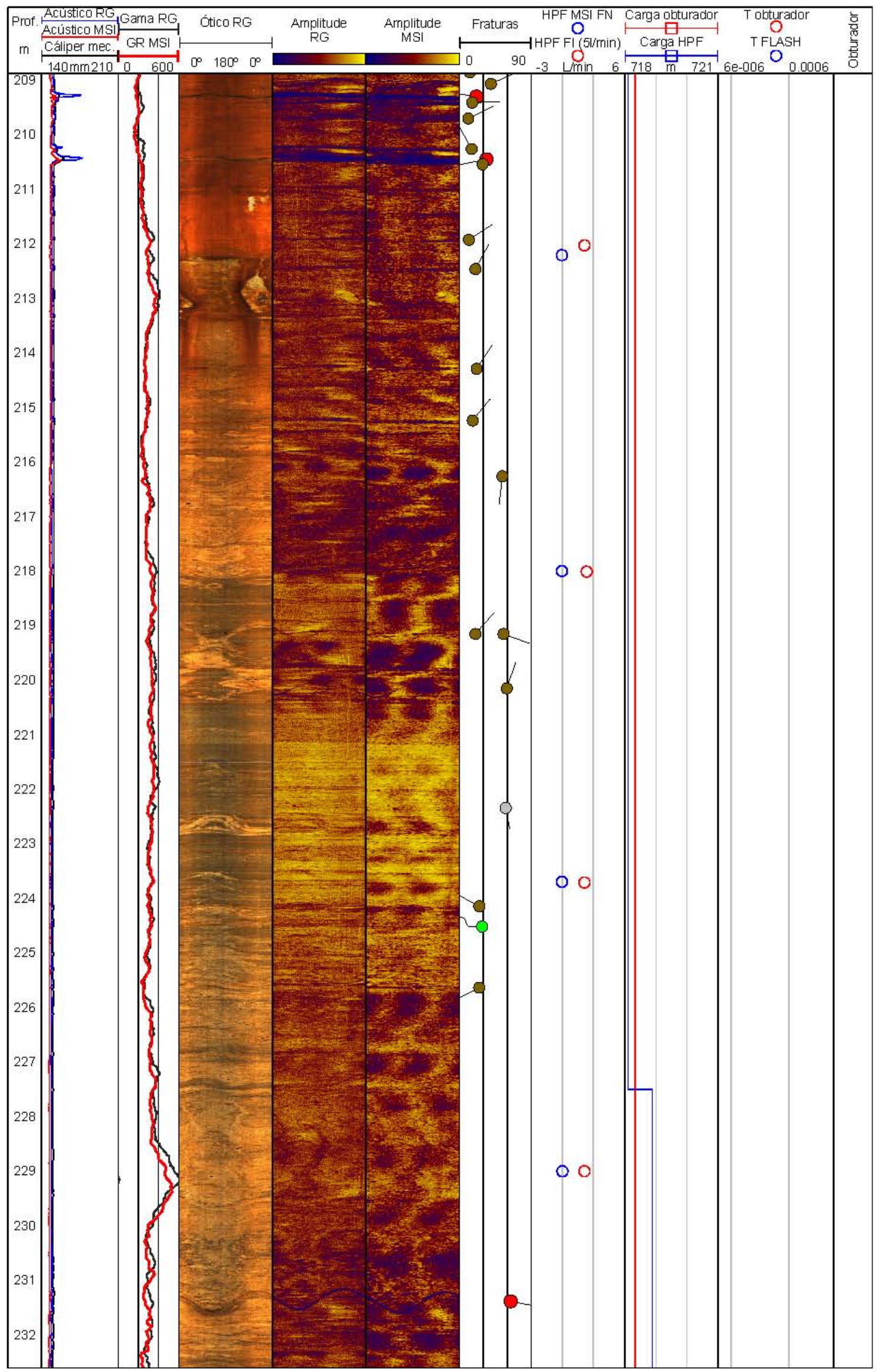




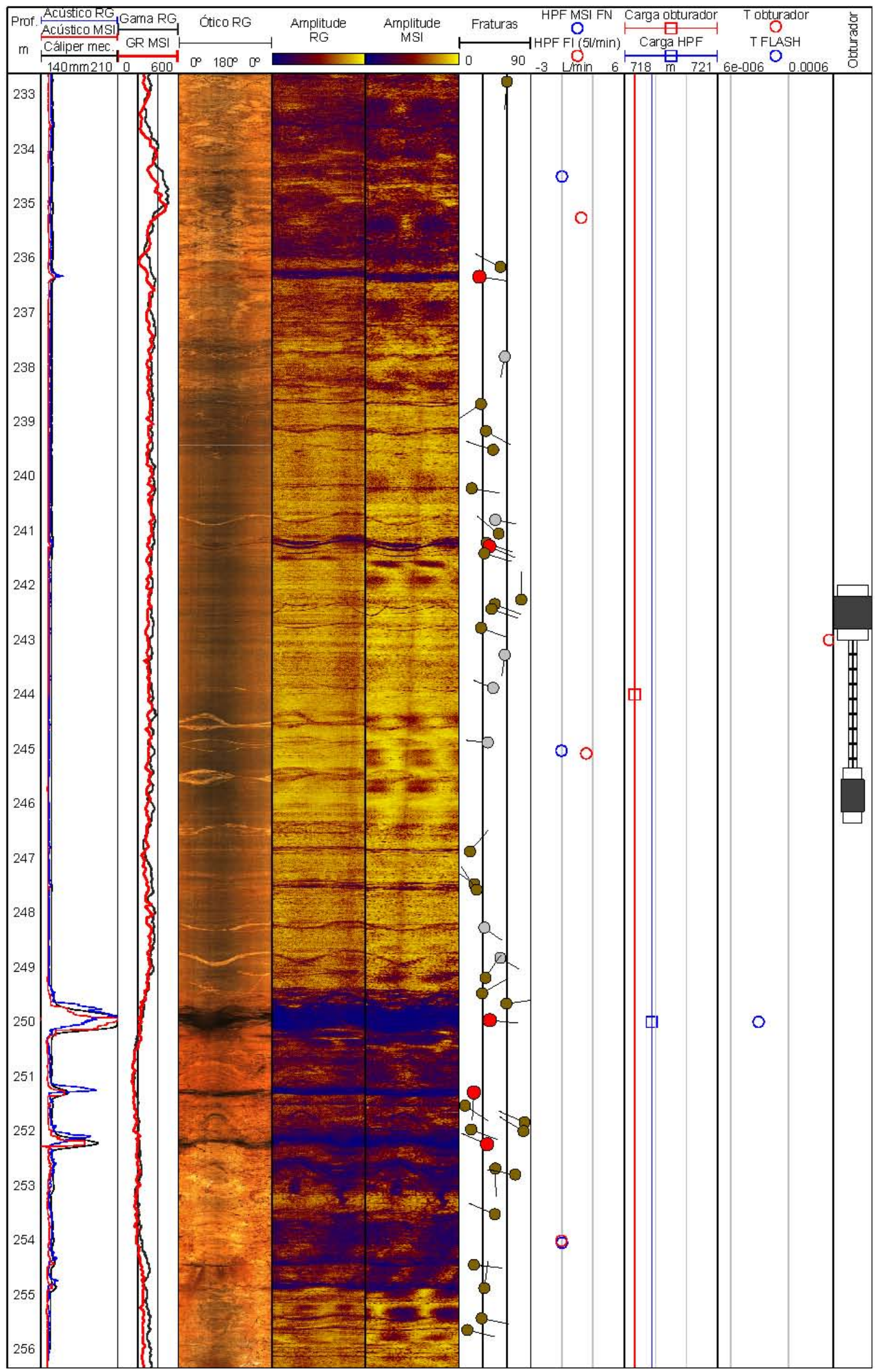




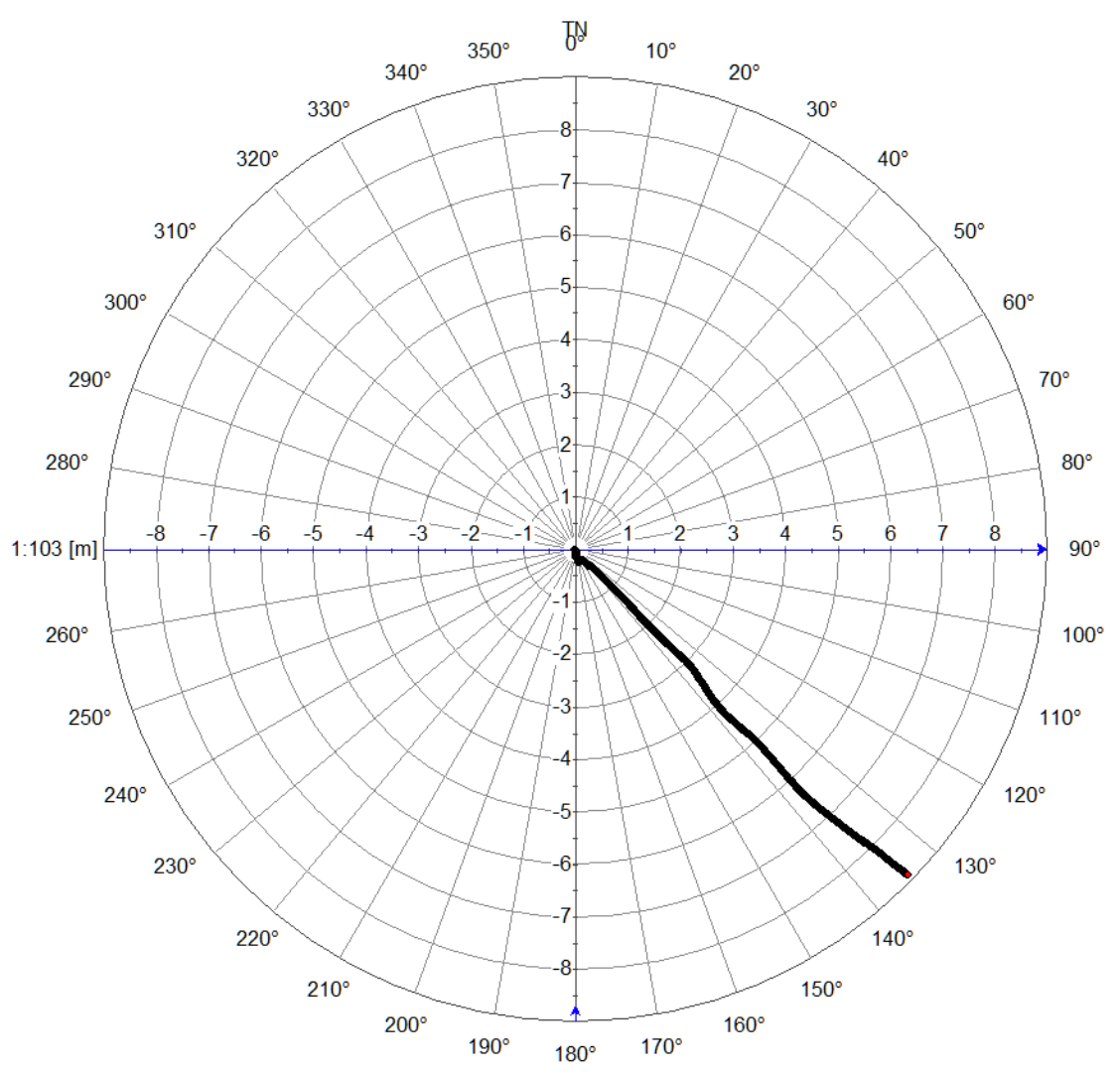

Perfil de desvio do poço Bulls-eye

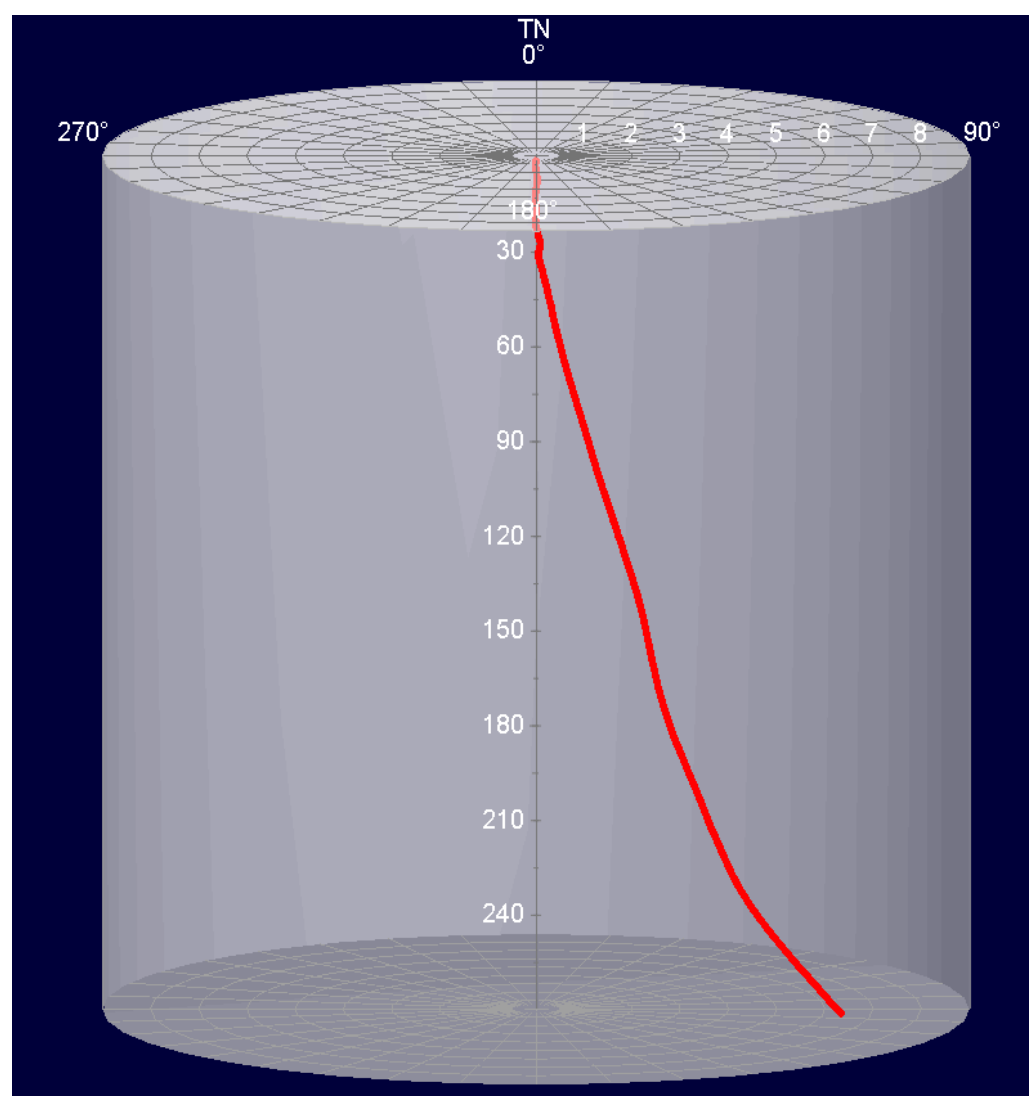

Perfil de desvio do poço vertical 


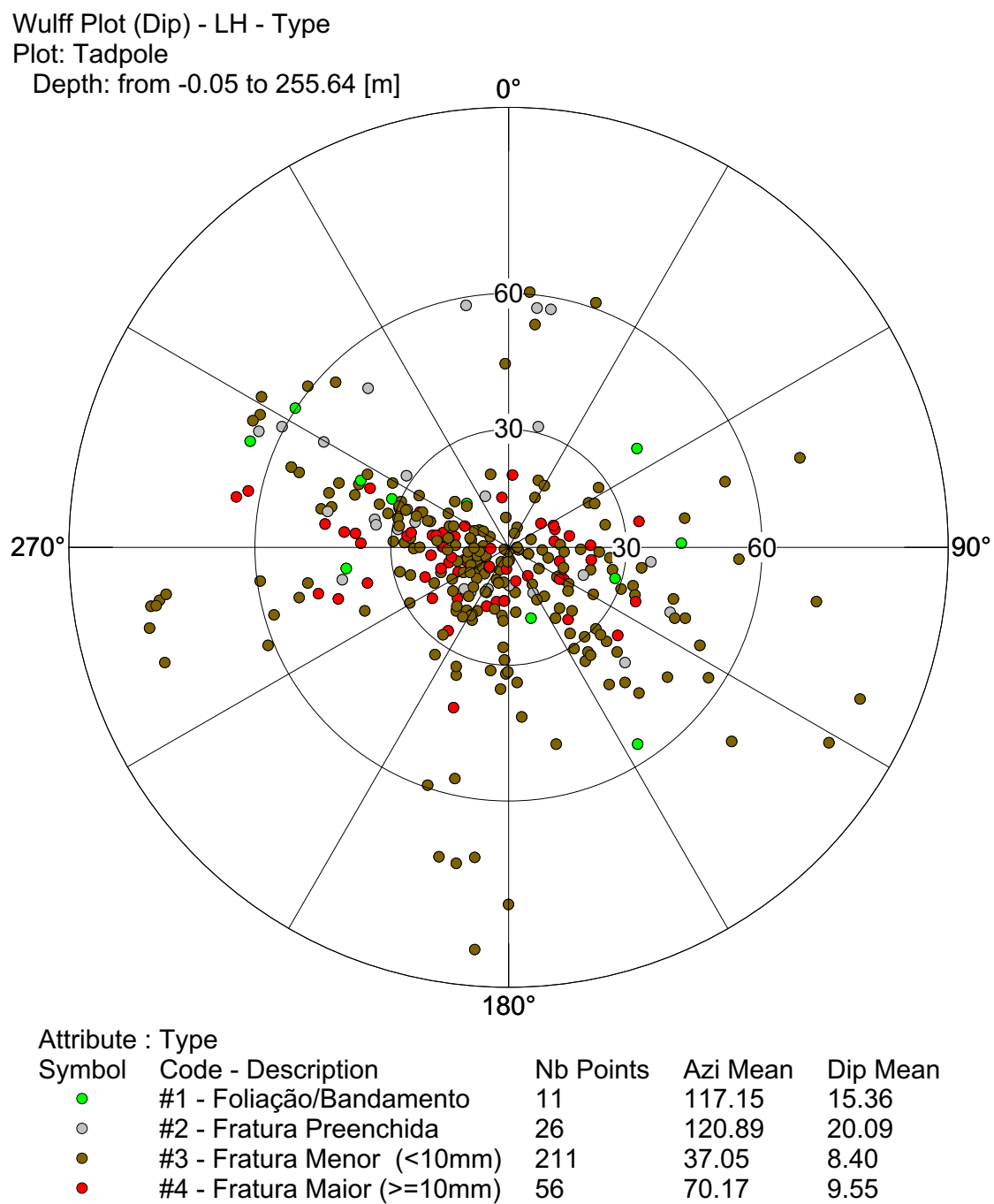

Estereograma das feições observadas no poço 1204 
Apêndice III: exemplo de dados brutos e processados dos ensaios com obturadores 
Barbosa, M. B. (2020).

Tese de Doutorado - IGc/USP

Exemplo de sequência de ensaios tipo pulso para o poço 1204

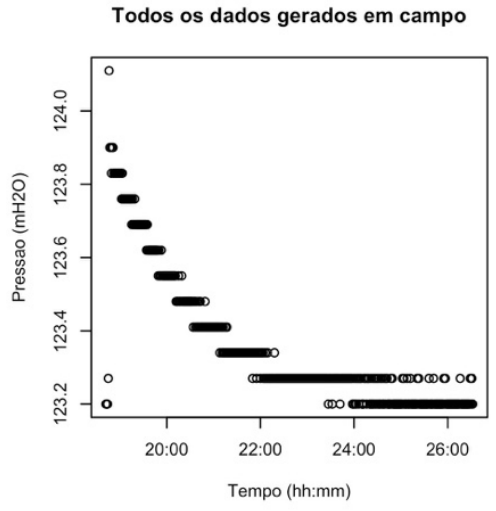

Dados para calculo da transmissividade
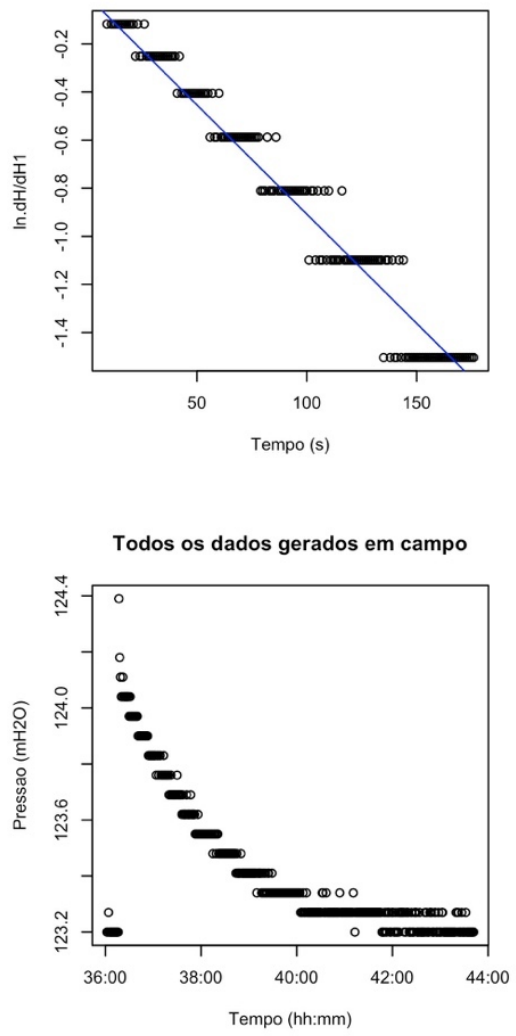

Dados para calculo da transmissividade

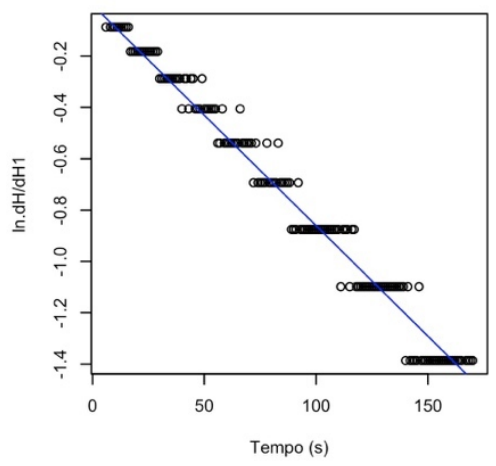

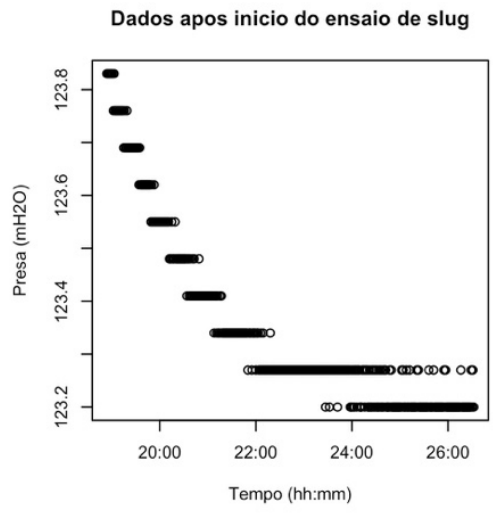
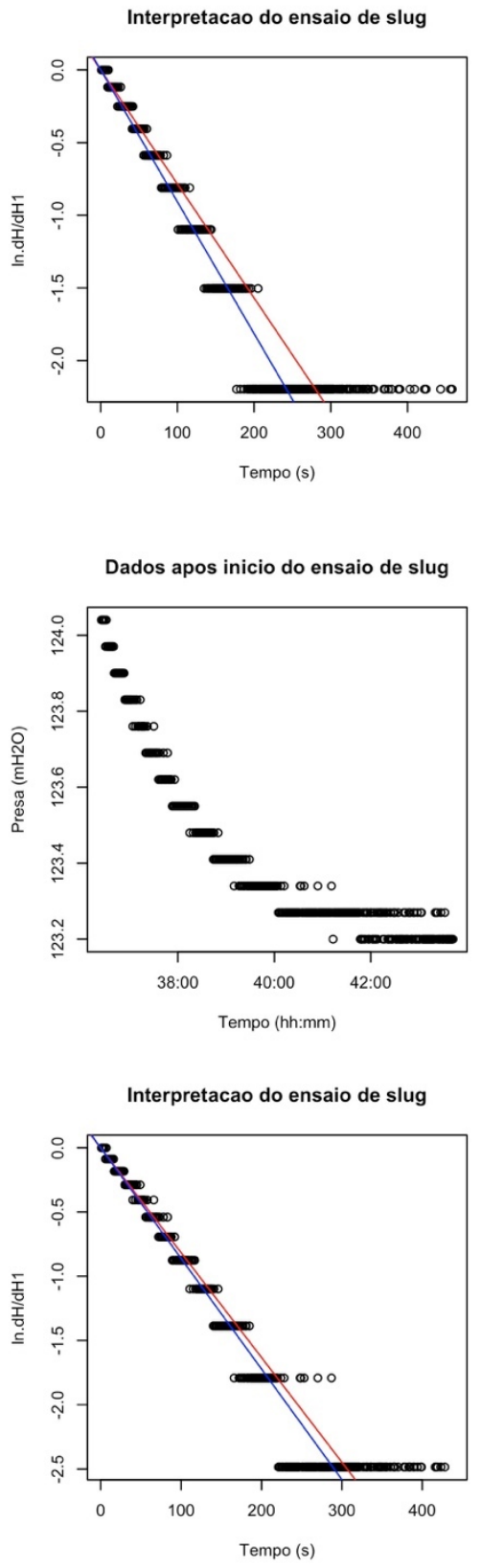

Dados do ensaio apos normalizacao

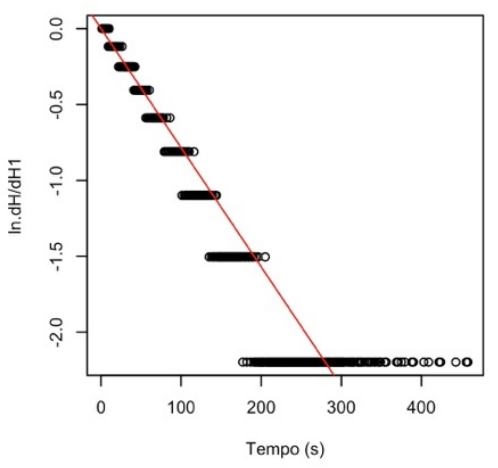

Ensaio de pulso descendente Intervalo de 119 a 122 m

Dados do ensaio apos normalizacao

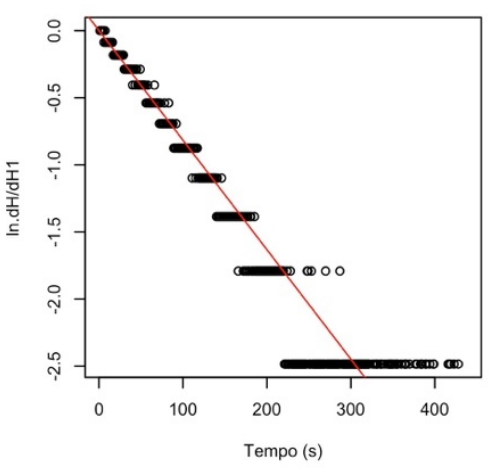

Ensaio de pulso descendente Intervalo de 119 a $122 \mathrm{~m}$ 
Barbosa, M. B. (2020).

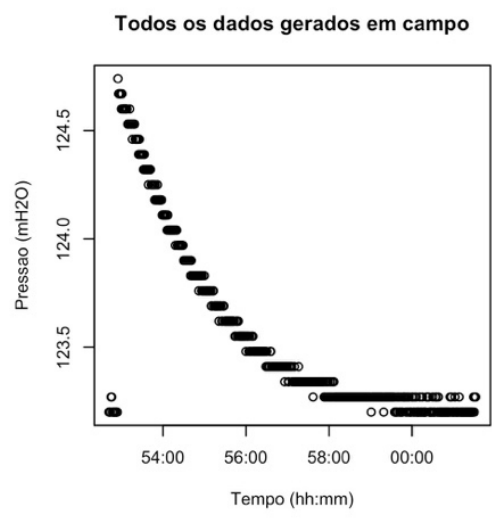

Dados para calculo da transmissividade
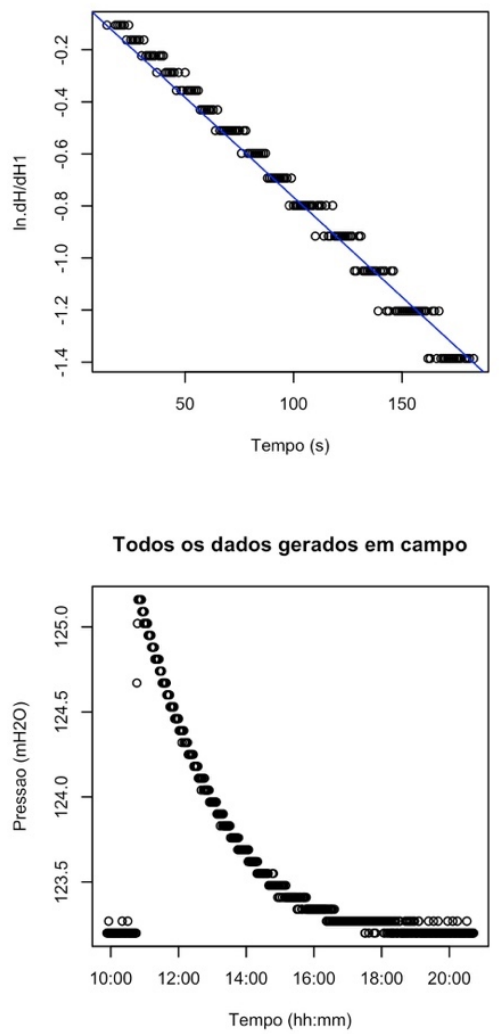

Dados para calculo da transmissividade

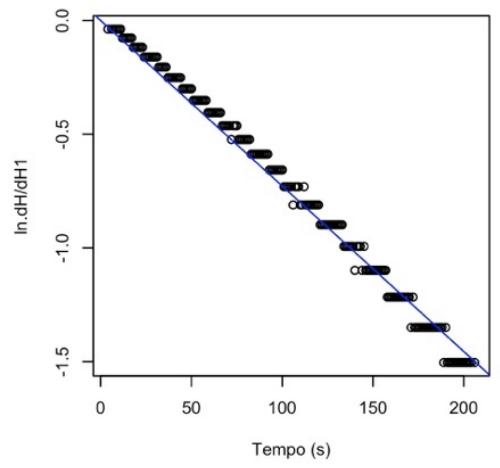

Dados apos inicio do ensaio de slug

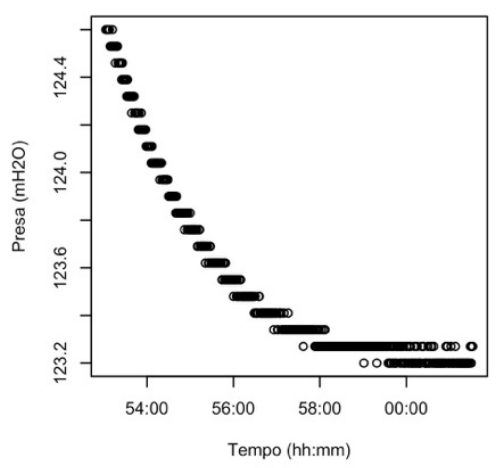

Interpretacao do ensaio de slug

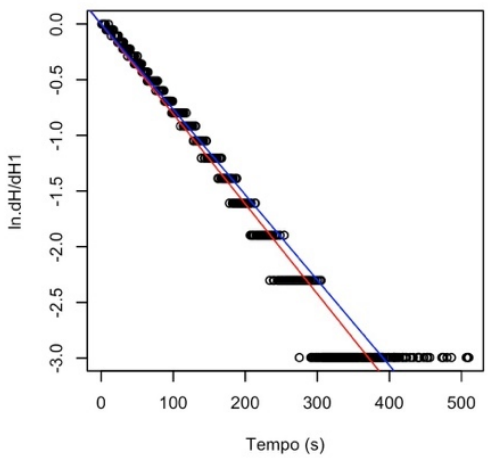

Dados apos inicio do ensaio de slug

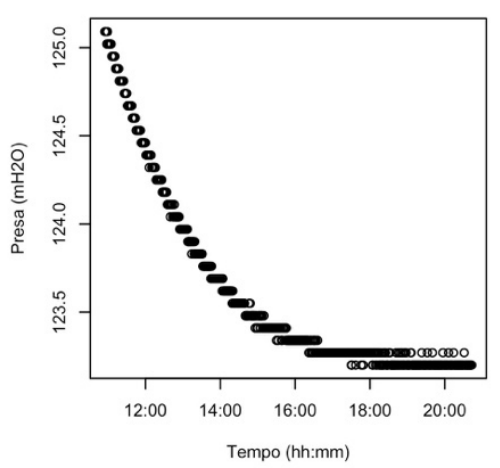

Interpretacao do ensaio de slug

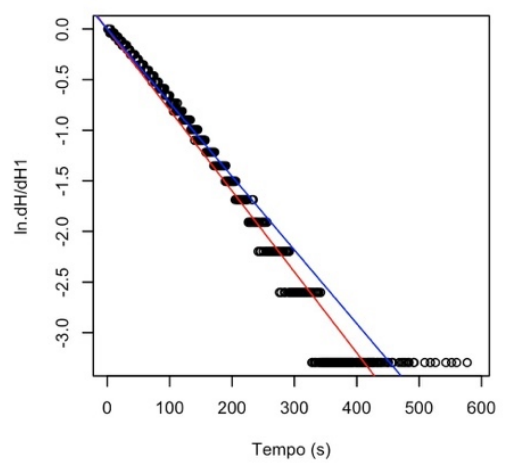

Tese de Doutorado - IGc/USP
Dados do ensaio apos normalizacao

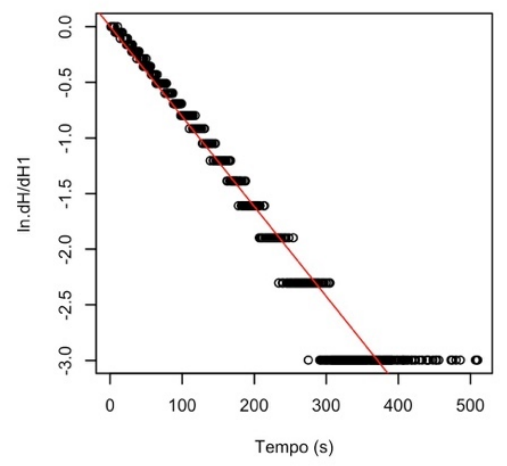

Ensaio de pulso descendente Intervalo de 119 a $122 \mathrm{~m}$

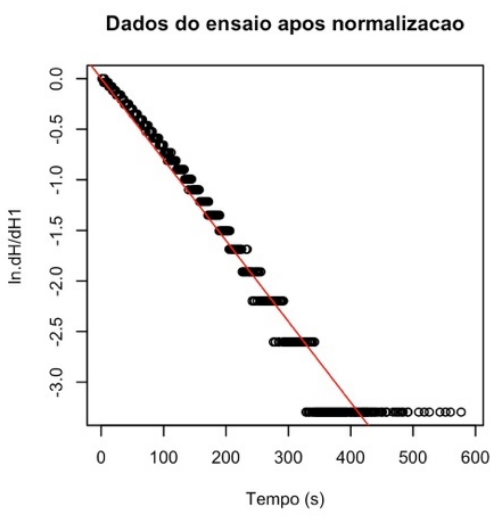

Ensaio de pulso descendente Intervalo de 119 a 122 m 
Exemplo de sequência de ensaios tipo pulso para o poço P3 da Área M
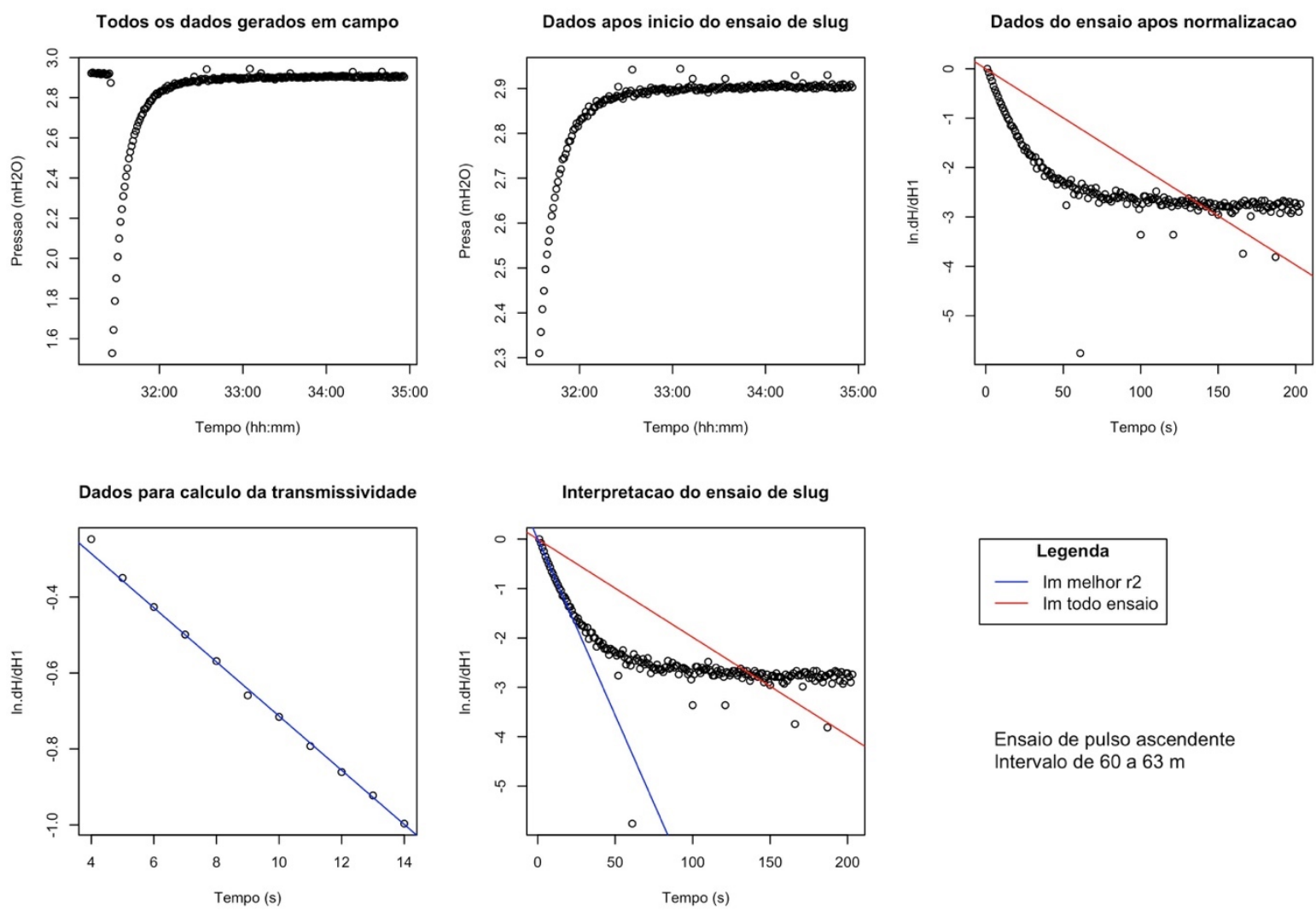

Ensaio de pulso ascendente
Intervalo de 60 a $63 \mathrm{~m}$

Todos os dados gerados em campo

Dados apos inicio do ensaio de slug
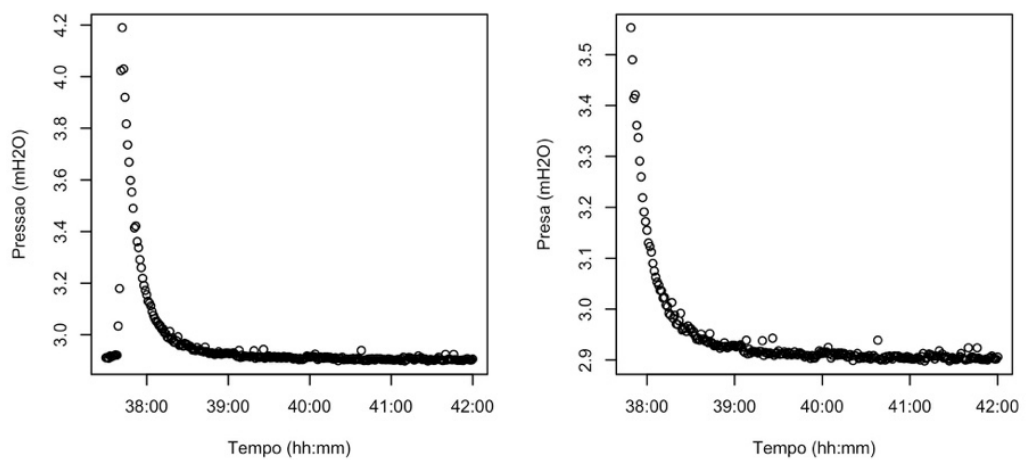

Dados do ensaio apos normalizacao

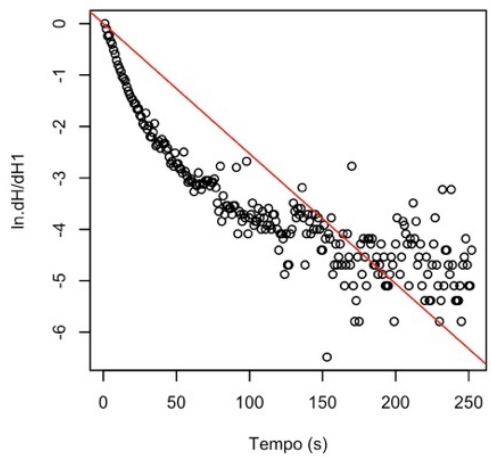

Dados para calculo da transmissividade
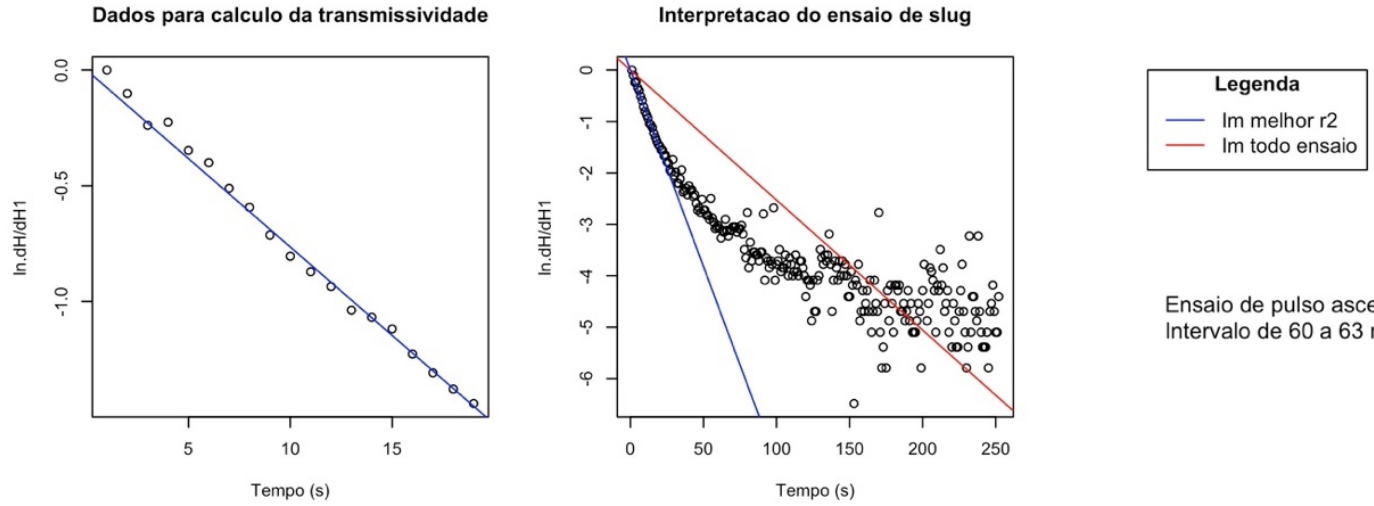

Ensaio de pulso ascendente Intervalo de 60 a $63 \mathrm{~m}$ 

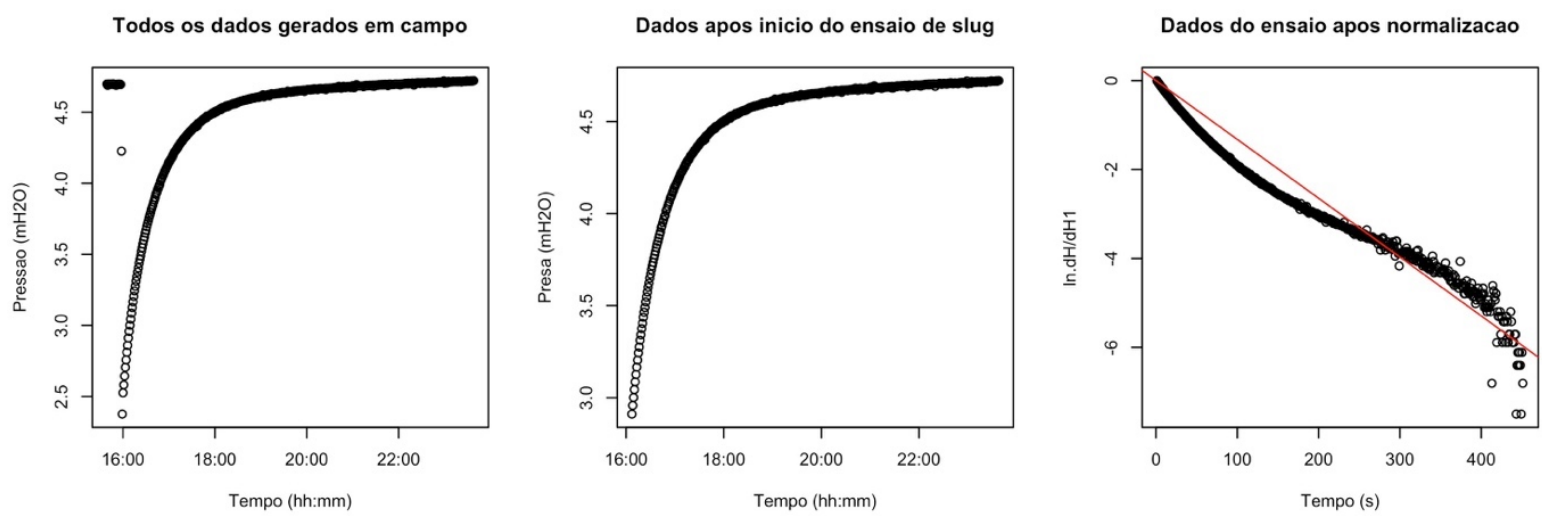

Dados para calculo da transmissividade
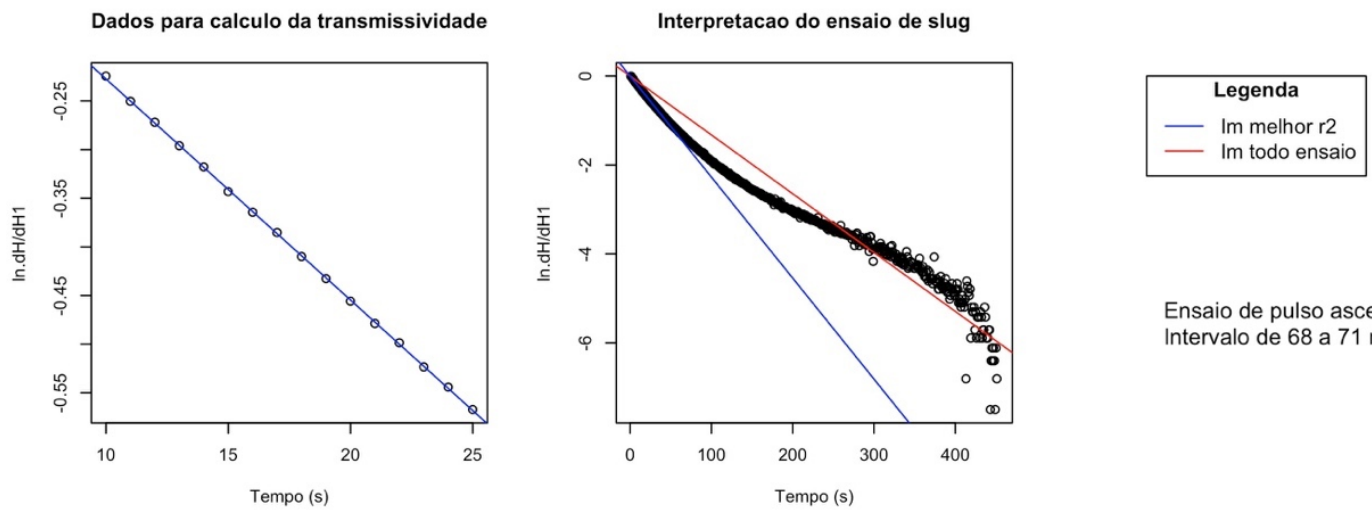

Ensaio de pulso ascendente Intervalo de 68 a $71 \mathrm{~m}$

Todos os dados gerados em campo

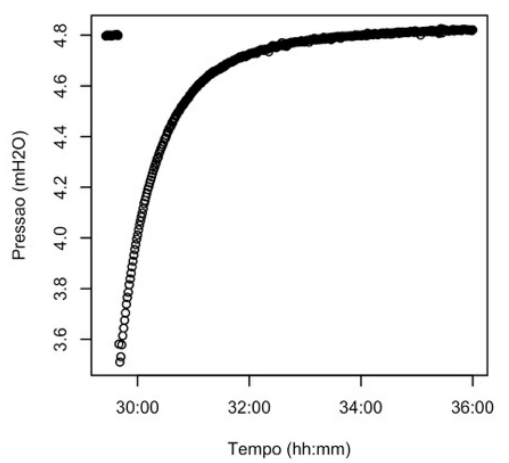

Dados para calculo da transmissividade

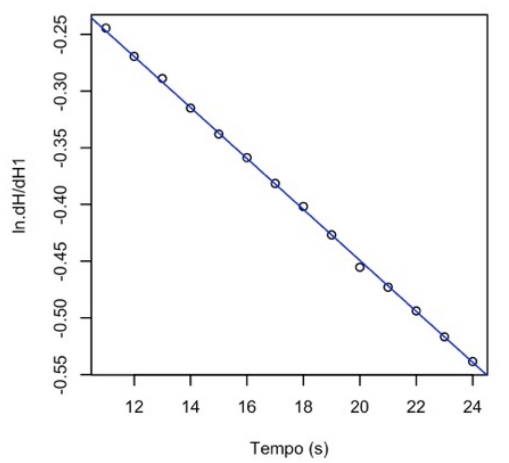

Dados apos inicio do ensaio de slug
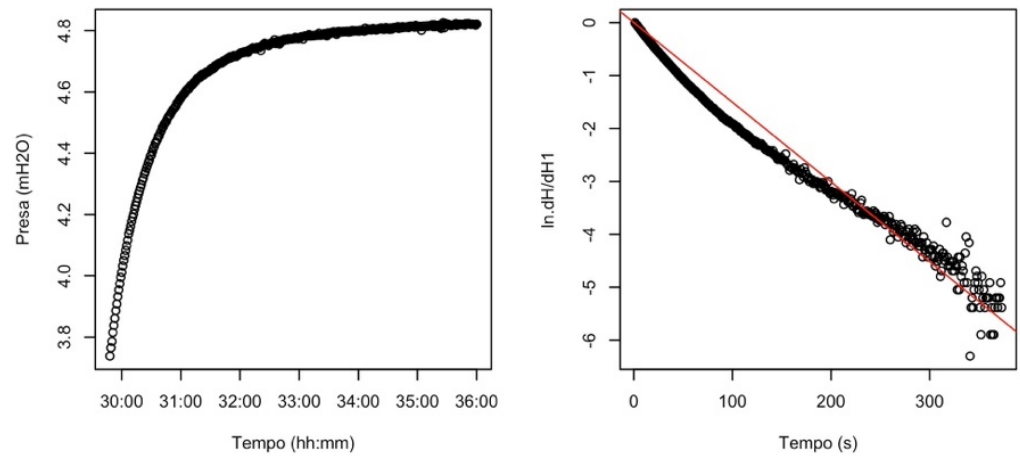

Interpretacao do ensaio de slug

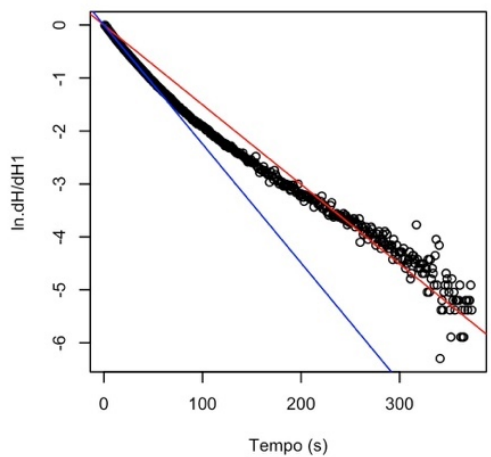

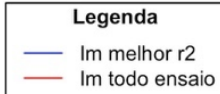

Ensaio de pulso ascendente Intervalo de 68 a $71 \mathrm{~m}$ 

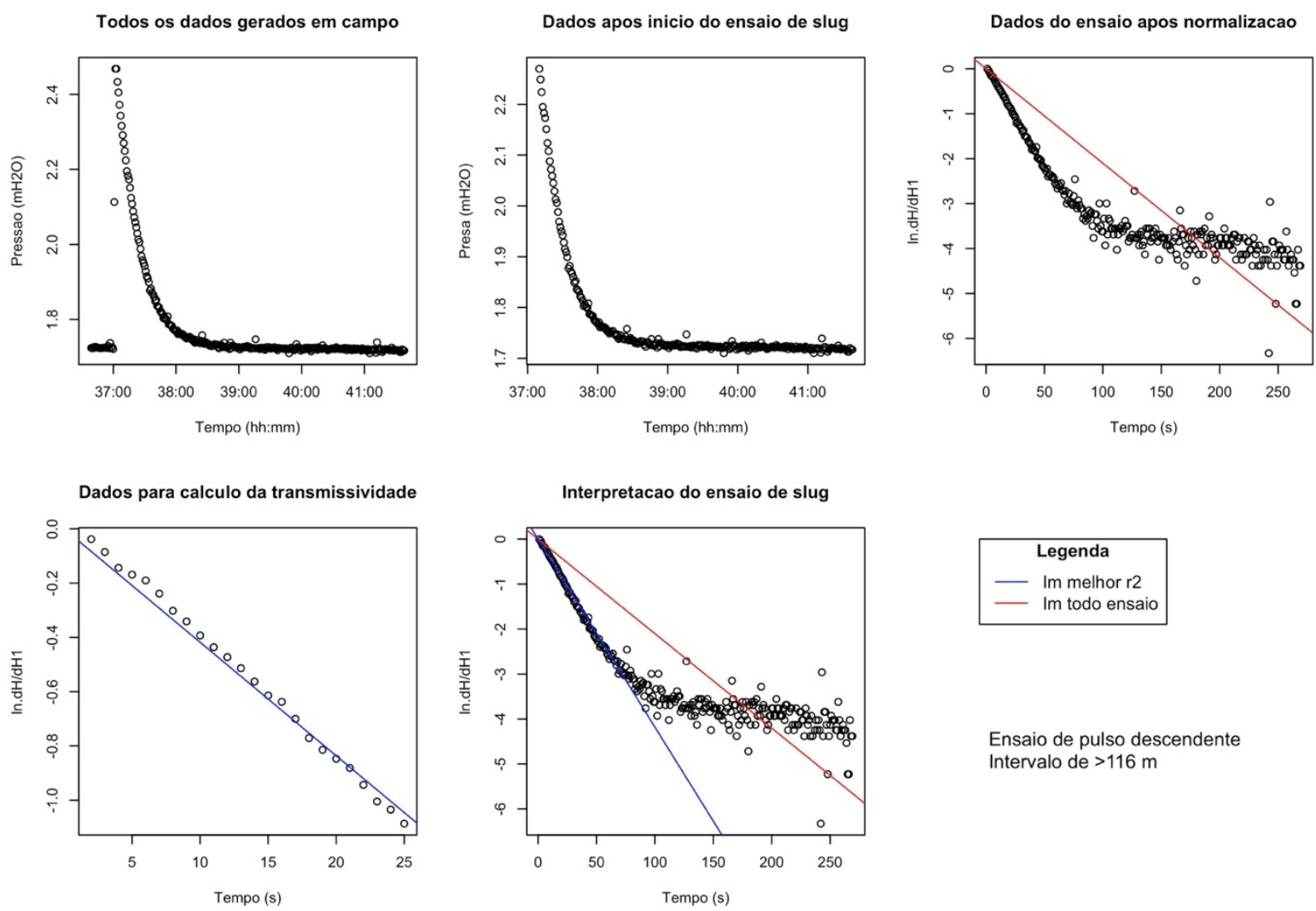

Ensaio de pulso descendente Intervalo de $>116 \mathrm{~m}$
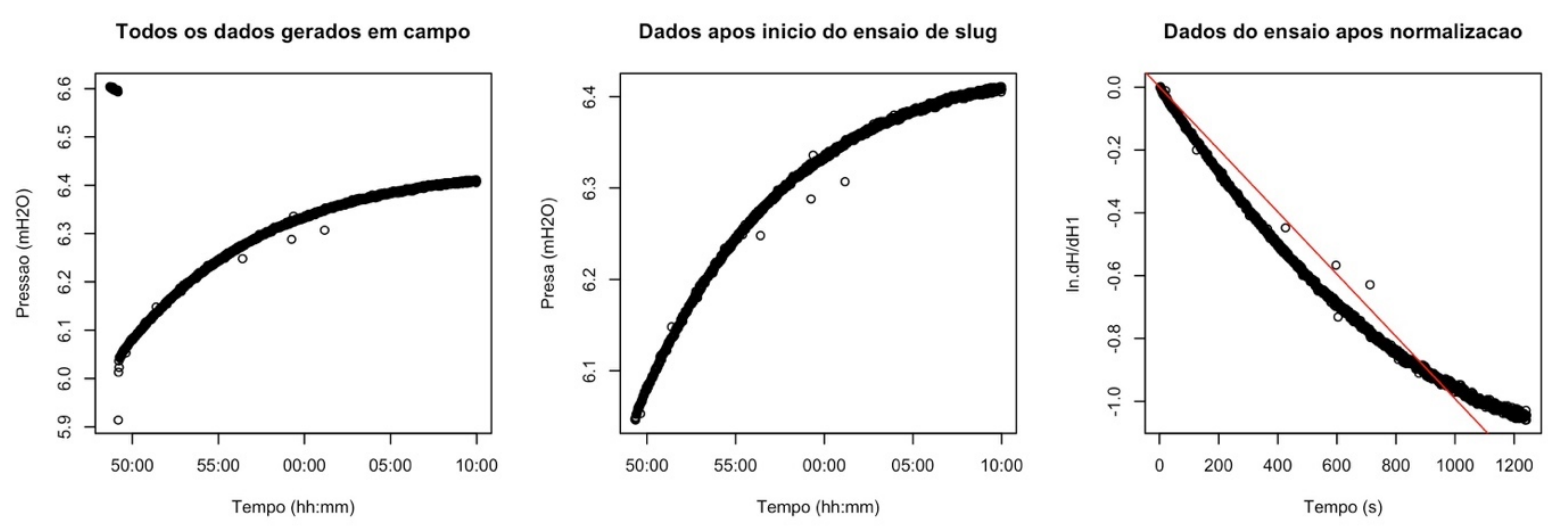

Dados para calculo da transmissividade
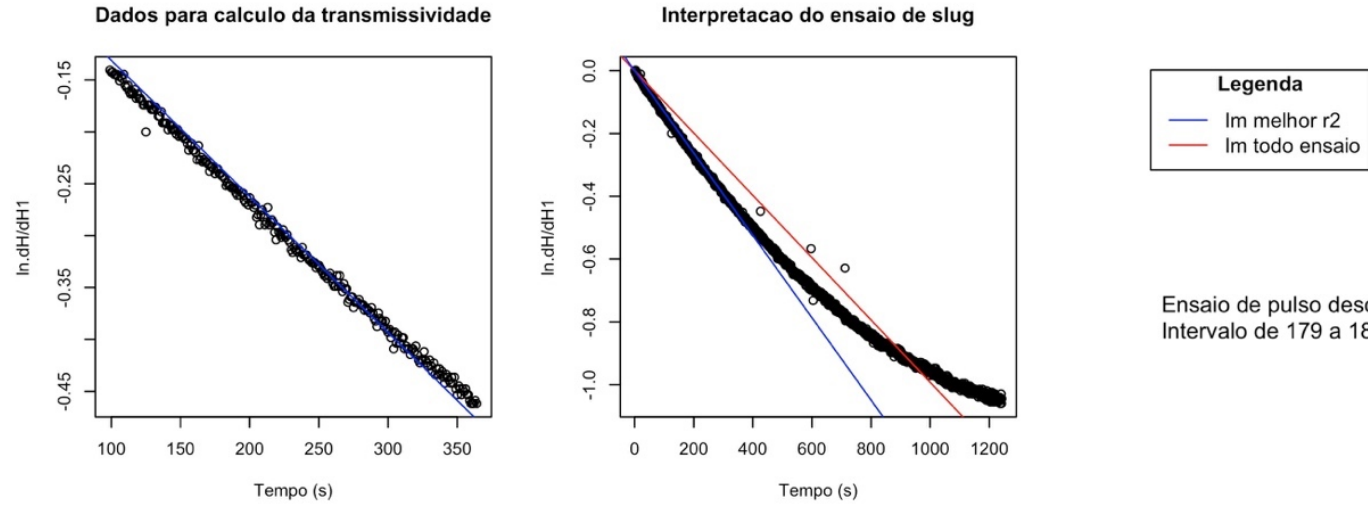

Ensaio de pulso descendente Intervalo de 179 a 183 m 

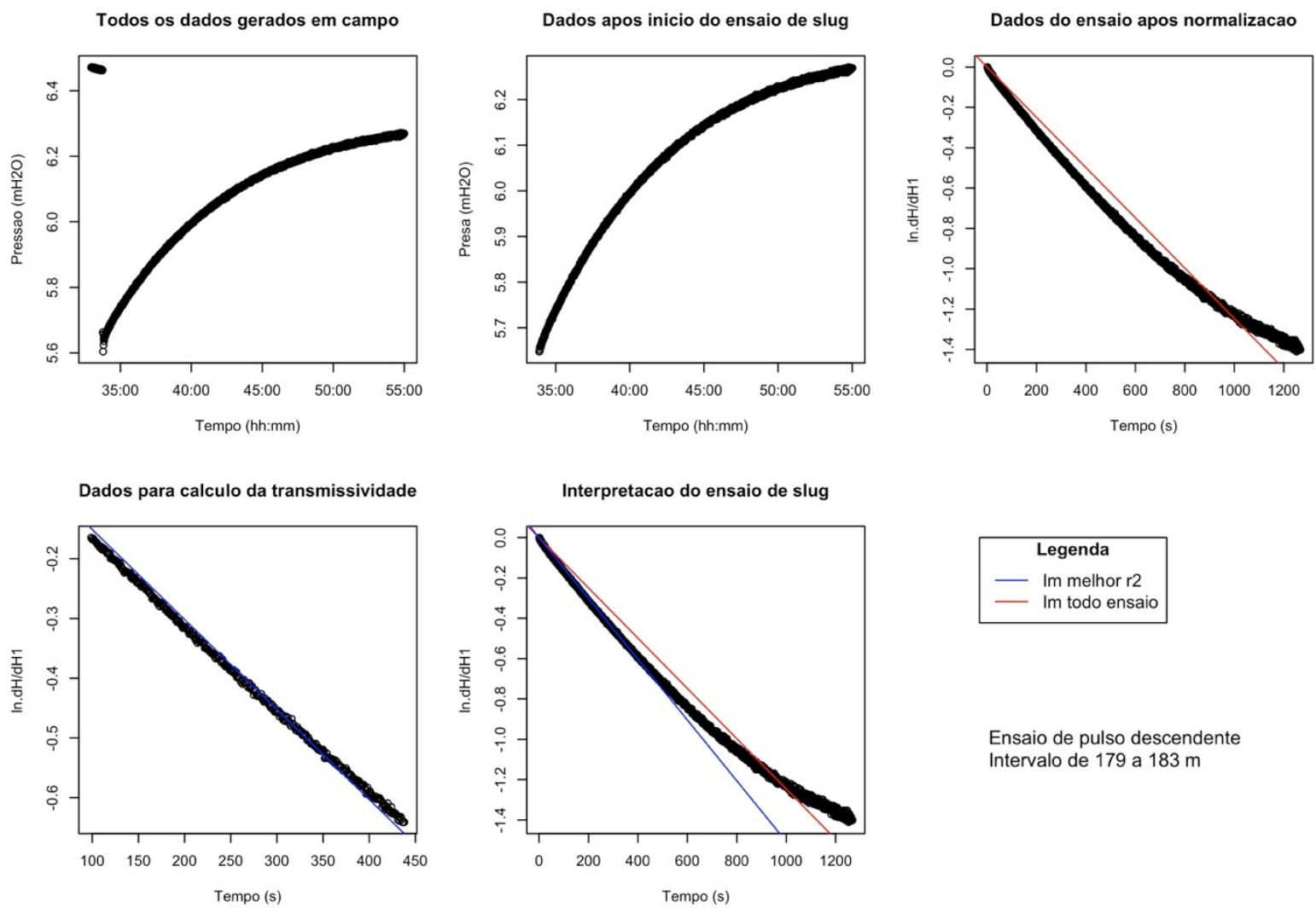

Ensaio de pulso descendente Intervalo de 179 a 183 m
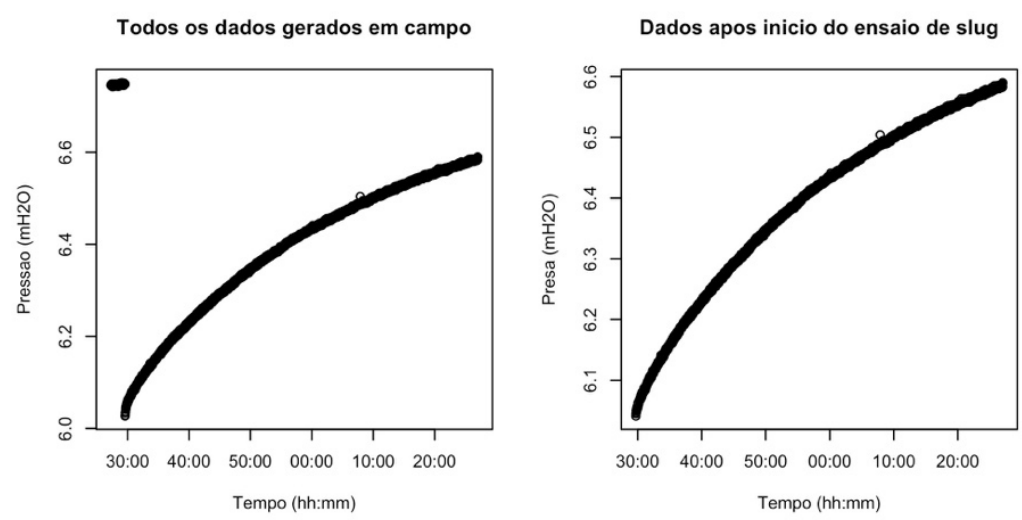

Dados do ensaio apos normalizacao

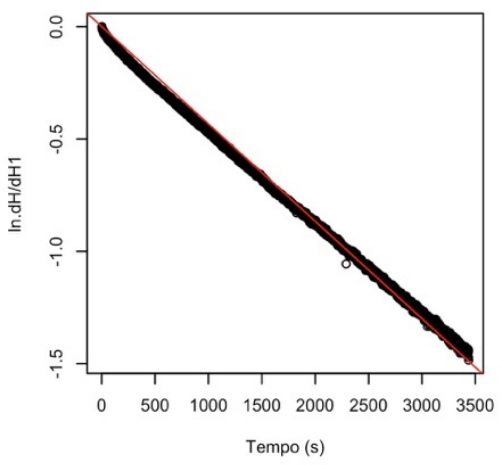

Dados para calculo da transmissividade

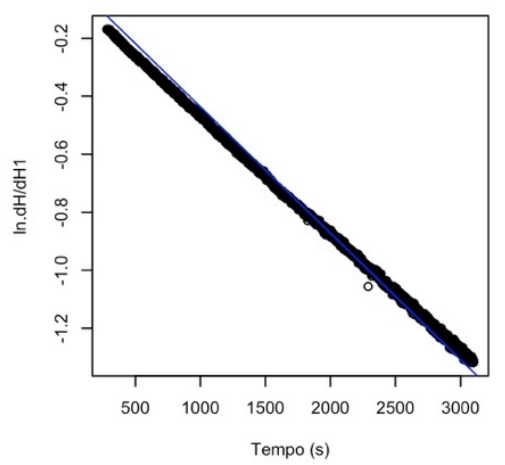

Interpretacao do ensaio de slug

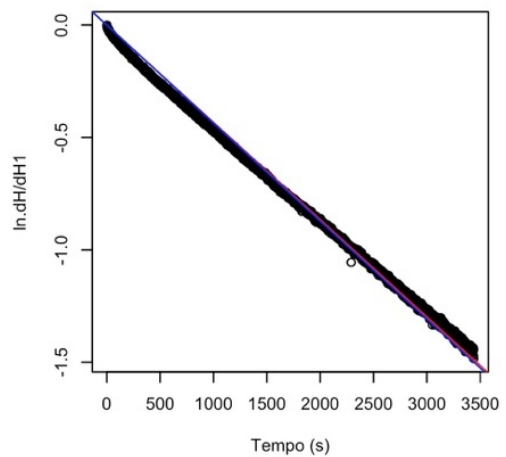

Ensaio de pulso descendente Intervalo de 186 a 190 m 